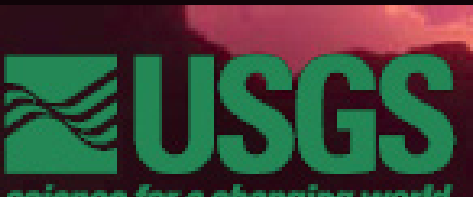

science for a changing world

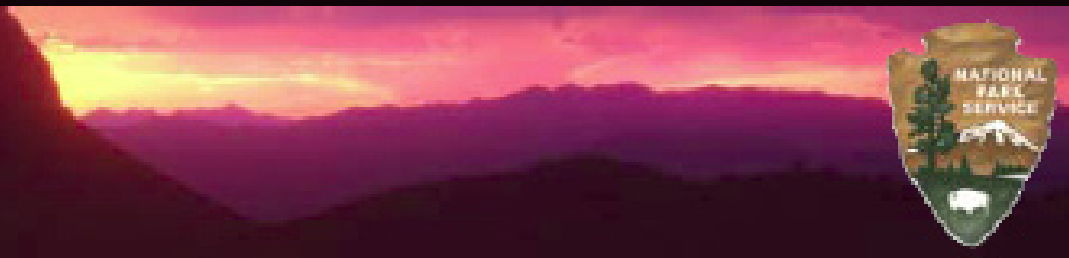

In Cooperation with the University of Arizona, School of Natural Resources

\title{
Vascular Plant and Vertebrate Inventory of Saguaro National Park, Tucson Mountain District
}

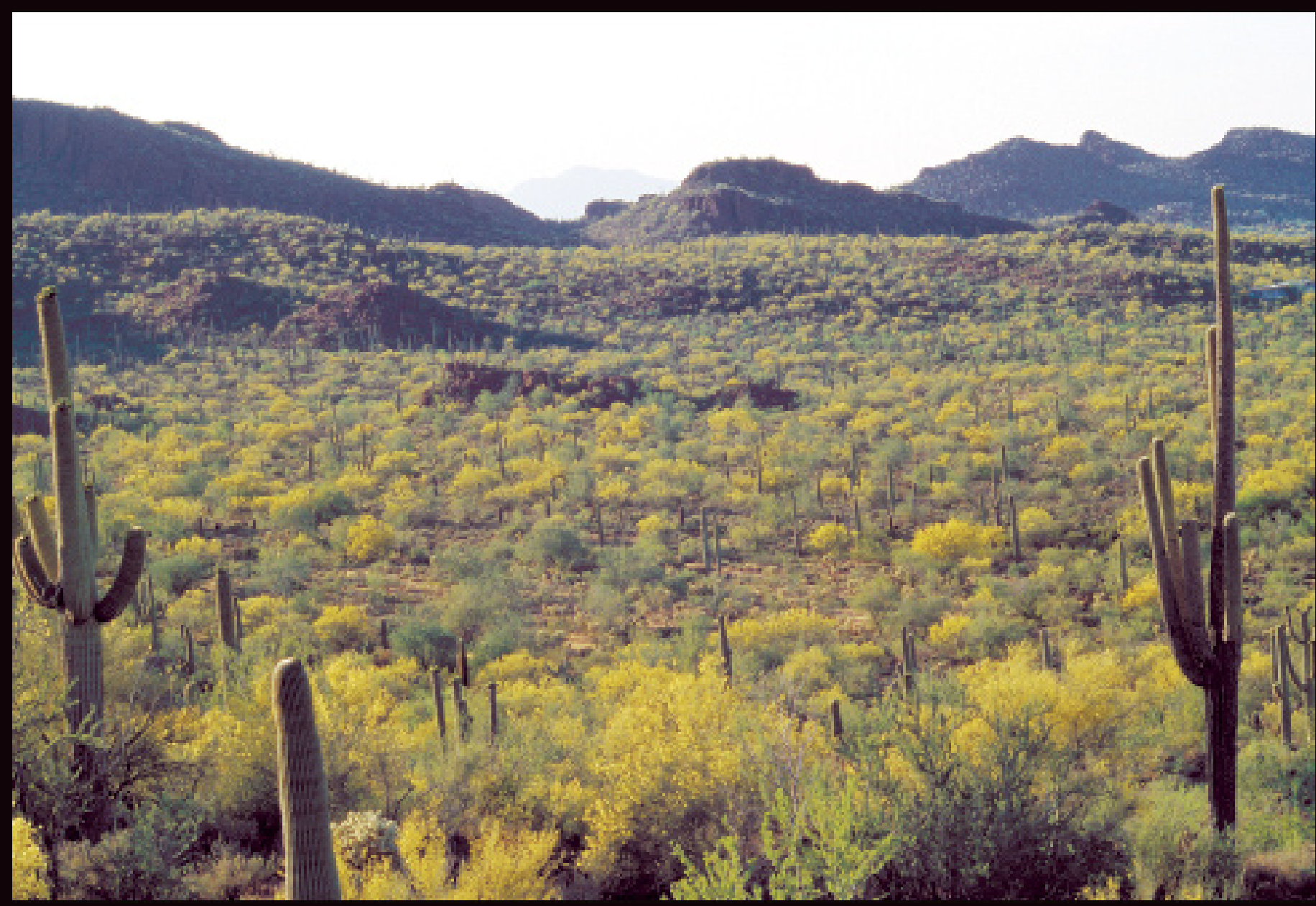

Open-File Report 2007-1296

U.S. Department of the Interior

U.S. Geological Survey

National Park Service

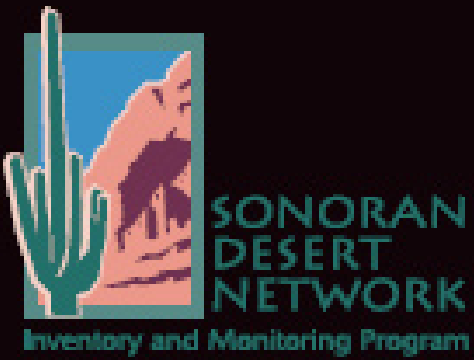


This page left intentionally blank. 


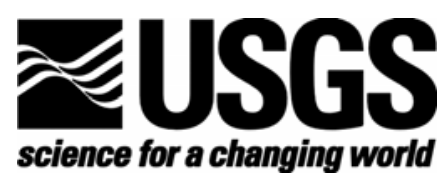

In cooperation with the University of Arizona, School of Natural Resources

\section{Vascular Plant and Vertebrate Inventory of Saguaro National Park, Tucson Mountain District}

Edited by Brian F. Powell, William L. Halvorson, and Cecilia A. Schmidt

Open-File Report 2007-1296

U.S. Department of the Interior

U.S. Geological Survey

National Park Service

U.S. Geological Survey

Southwest Biological Science Center

Sonoran Desert Research Station University of Arizona School of Natural Resources 125 Biological Sciences East

Tucson, Arizona 85721 


\section{U.S. Department of the Interior \\ DIRK KEMPTHORNE, Secretary}

\section{U.S. Geological Survey \\ Mark Myers, Director}

U.S. Geological Survey, Reston, Virginia: 2007

For product and ordering information:

World Wide Web: http://www.usgs.gov/pubprod

Telephone: 1-888-ASK-USGS

For more information on the USGS-the Federal source for science about the Earth, its natural and living resources, natural hazards, and the environment:

World Wide Web:http://www.usgs.gov

Telephone: 1-888-ASK-USGS

\section{Suggested Citation}

Powell, B.F, Halvorson, W.L., and Schmidt, C.A., eds., 2007, Vascular plant and vertebrate inventory of Saguaro National Park, Tucson Mountain District: U.S. Geological Survey Open-File Report 2007-1296, 92 p.

[http://pubs.usgs.gov/of/2007/1296/].

Cover photo: Saguaro National Park, Tucson Mountain District. Photograph by Don Swann.

Any use of trade, product, or firm names is for descriptive purposes only and does not imply endorsement by the U.S. Government. 


\section{Editors and Authors}

Brian F. Powell and Cecilia A. Schmidt

School of Natural Resources

125 Biological Sciences East, Building 43

The University of Arizona

Tucson, AZ 85721

William L. Halvorson

USGS SBSC Sonoran Desert Research Station

125 Biological Sciences East, Building 43

The University of Arizona

Tucson, AZ 85721
Aaron D. Flesch

School of Natural Resources

325 Biological Sciences East, Building 43

The University of Arizona

Tucson, AZ 85721

Don E. Swann

Saguaro National Park

3693 South Old Spanish Trail

Tucson, AZ 85730

\section{U.S. Geological SBSC Survey Sonoran Desert Research Station Personnel}

Charles van Riper III, Station Leader

William L. Halvorson, Research Ecologist

Cecil R. Schwalbe, Ecologist

Michael R. Kunzmann, Ecologist (Emeritus)

Kathryn Thomas, Ecologist

Pamela Nagler, Physical Scientist

Phil Rosen, Ecologist

Program and Expertise Areas of USGS and UA Personnel

$\begin{array}{ll}\text { Administration \& Outreach } & \text { Fire Management } \\ \text { Laura Opalka } & \text { Dennis Suhre } \\ \text { Wendy Parrish } & \text { Cori Dolan } \\ \text { Emily Sherbrooke } & \text { James Feldmann } \\ \text { Charles van Riper III } & \text { Bill Halvorson } \\ & \\ \text { Avian Ecology } & \text { Invasive Species Research } \\ \text { Claire Crow } & \text { Patricia Guertin } \\ \text { Glenn Johnson } & \text { Jim Malusa } \\ \text { Chris O'Brien } & \text { Phil Rosen } \\ \text { Brian Powell } & \text { Cecil Schwalbe } \\ \text { Charles van Riper III } & \text { Brent Sigafus } \\ & \text { Dennis Suhre } \\ \text { Data Management } & \text { Kathryn Thomas } \\ \text { Brent Sigafus } & \\ & \text { Inventory \& Monitoring } \\ \text { Ecology of Amphibians \& Reptiles } & \text { Patricia Guertin } \\ \text { Kevin Baker } & \text { Bill Halvorson } \\ \text { Cristina Jones } & \text { Pamela Nagler } \\ \text { Dave Prival } & \text { Brian Powell } \\ \text { Phil Rosen } & \text { Cecilia Schmidt } \\ \text { Cecil Schwalbe } & \\ \text { Brent Sigafus } & \text { Vegetation Mapping \& Ecology } \\ & \text { Patricia Guertin } \\ & \text { Bill Halvorson } \\ & \text { Jim Malusa } \\ & \text { Kathryn Thomas }\end{array}$

USGS Southwest Biological Science Center http://sbsc.wr.usgs.gov

USGS Southwest Biological Science Center, Sonoran Desert Research Station http://sbsc.wr.usgs.gov/sdrs 


\section{Table of Contents}

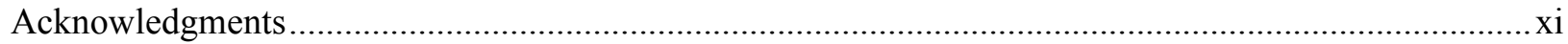

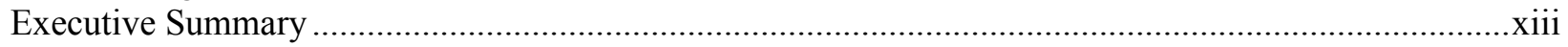

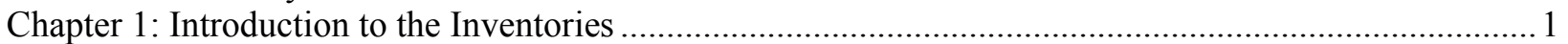

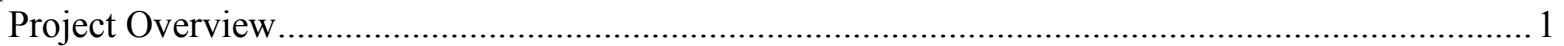

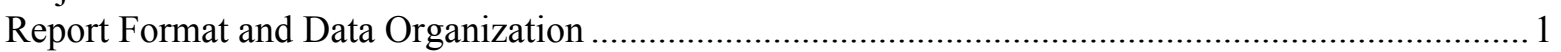

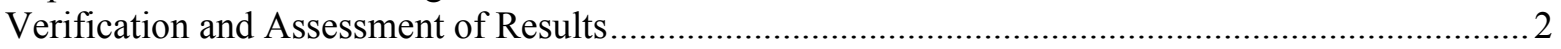

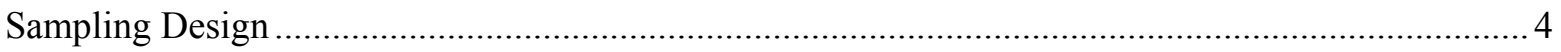

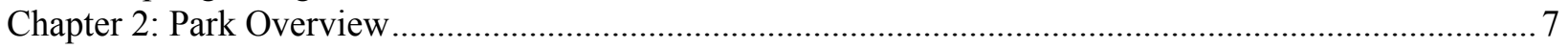

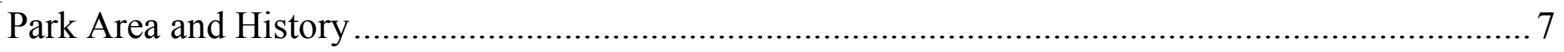

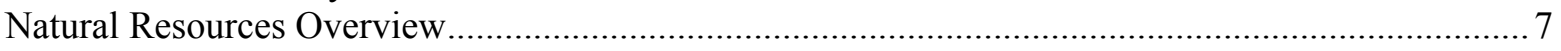

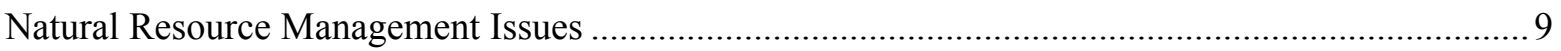

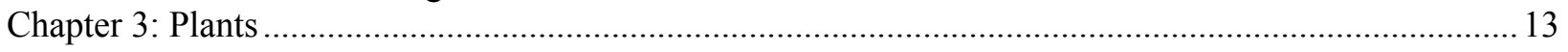

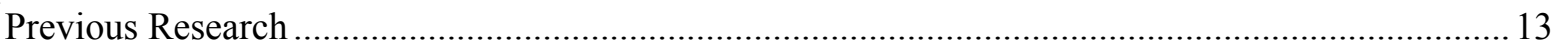

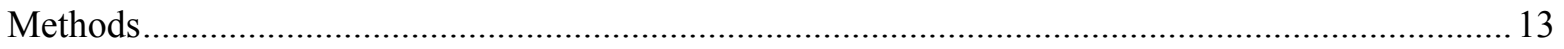

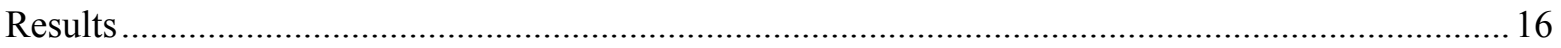

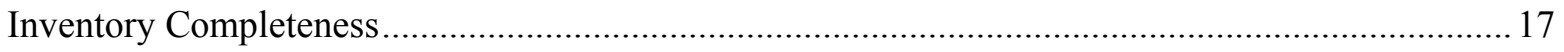

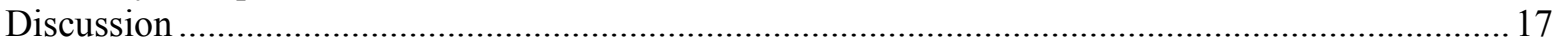

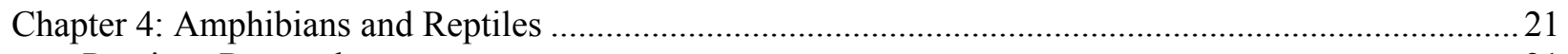

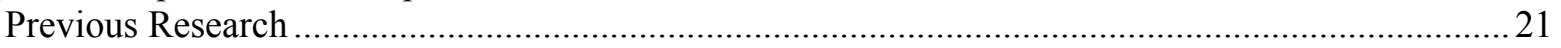

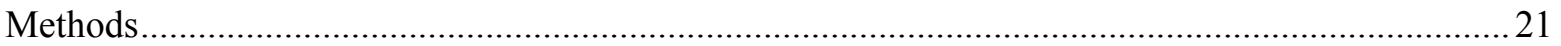

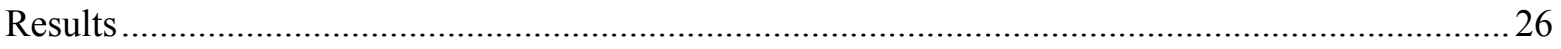

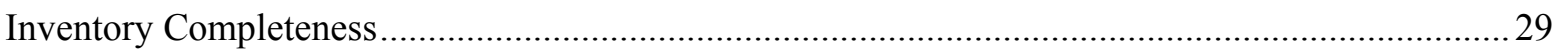

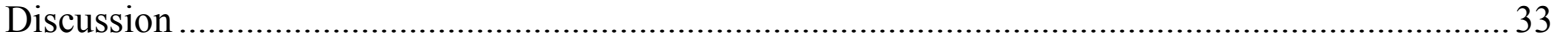

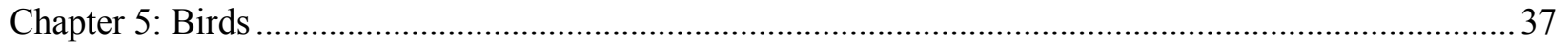

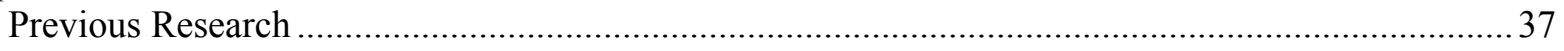

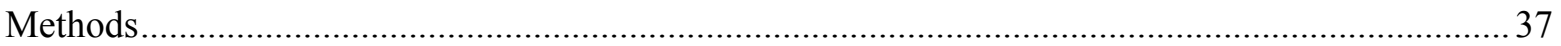

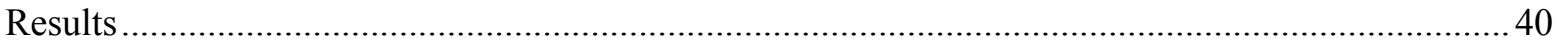

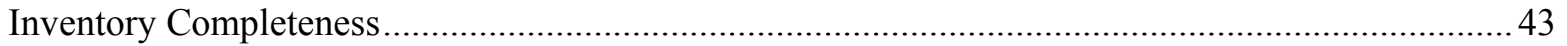

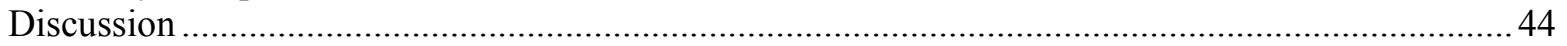

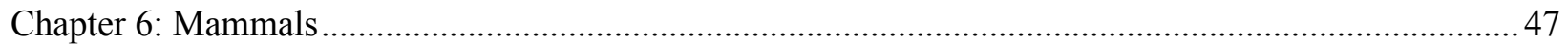

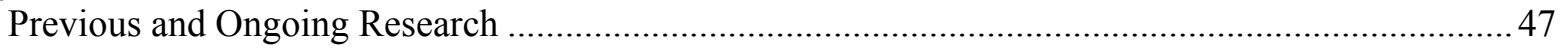

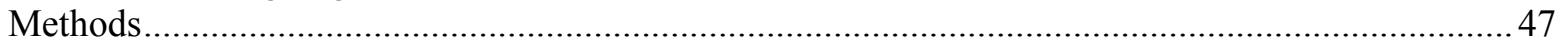

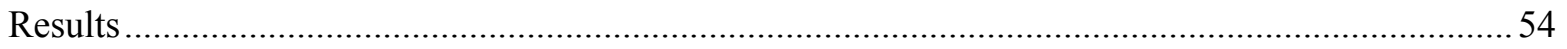

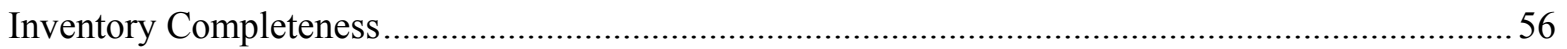

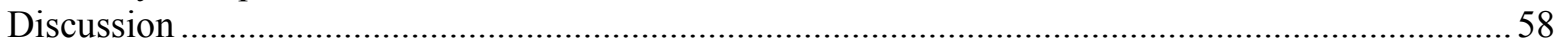

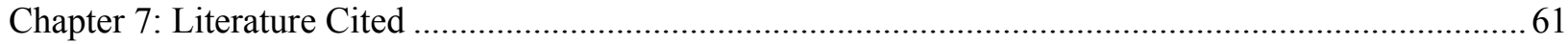




\section{List of Tables}

Table 1. Summary of vascular plant and vertebrate inventories at Saguaro National Park, Tucson Mountain District, 1999-2005.. xiii

Table 1.1. Museums that were queried in 1998 for vertebrate specimen vouchers with "Arizona" and "Saguaro National Park" and "Saguaro National Monument" in the collection location. 3

Table 2.1. Average monthly climate data for the University of Arizona (low elevation; the closest climate monitoring station to the district), 1894-2004.

Table 4.1. Characteristics of three major active survey methods used during surveys for herpetofauna, Saguaro NP, Tucson Mountain District, 2001 and 2002.

Table 4.2. Herpetofauna survey effort by method and year, Saguaro NP, Tucson Mountain District, 2001 and 2002.

Table 4.3. Number of animals and species detected per hour by method and year, Saguaro NP, Tucson Mountain District, 2001 and 2002.

Table 4.4. Relative abundance (mean and SE; no./ha/hr) of herpetofauna detected during intensive surveys along random focal-point transects $(n=5)$ in spring (11-17 April) and summer (16-24 July) 2001, Saguaro NP, Tucson Mountain District.

Table 4.5. Relative abundance (mean $+\mathrm{SE}$; no./10 hrs) of amphibians and reptiles detected during extensive surveys $(n=55)$, by topographic formation, Saguaro NP, Tucson Mountain District, 2001 and 2002. 28

Table 4.6. Relative abundance (no./hr) of amphibians and reptiles detected during road surveys in Saguaro NP, Tucson Mountain District, 2001 and 2002.

Table 4.7. Relative abundance (no./100 hrs) of animals trapped in pitfall trap array $(n=1)$ in Saguaro NP, Tucson Mountain District, 2001 and 2002.

Table 5.1. Summary of bird survey effort by UA inventory personnel, Saguaro NP, Tucson Mountain District, 2001 and 2002.

Table 5.2. Total number of observations (sum) and relative abundance (mean $+\mathrm{SE}$ ), by transect, of birds recorded during repeat-visit VCP surveys, Saguaro NP, Tucson Mountain District, 2001 and 2002.

Table 5.3. Mean relative abundance of birds from reconnaissance VCP surveys, Saguaro NP, Tucson Mountain District, 2002.

Table 5.4. Mean relative abundance of birds, by transect, from nocturnal surveys, Saguaro NP, Tucson Mountain District, 2001 and 2002.

Table 5.5. Number of observations for each breeding behavior for birds, Saguaro NP, Tucson Mountain District, 2001 and 2002.

Table 6.1. Summary of small mammal trapping effort, Saguaro NP, Tucson Mountain District, 2001 and 2002.

Table 6.2. Summary of infrared-triggered camera effort, Saguaro NP, Tucson Mountain District, 20022005.

Table 6.3. Relative abundance of small mammals trapped at Saguaro NP, Tucson Mountain District, 2001 and 2002 at random (R) and non-random (NR) trapping grids. 
Table 6.4. Results of roost site detections and netting for bats, Saguaro NP, Tucson Mountain District, 2001 and 2002.

Table 6.5. Number of photographs of mammal species, from infrared-triggered photography, Saguaro NP, East, 1999-2005. .56

Table 6.6. List of possible bat and rodent species for Saguaro NP, Tucson Mountain District. 58 


\section{List of Figures}

Figure 1.1. Layout of 1-km focal-point transects showing layout of amphibian and reptile plots (C), small-mammal trapping grids (D), and bird survey stations (E), Saguaro NP, Tucson Mountain District..

Figure 2.1. Location of the two districts of Saguaro National Park in southern Arizona. 8

Figure 2.2. Composite aerial photograph showing major features of Saguaro NP, Tucson Mountain District.

Figure 2.3. Comparison of monthly weather data during the time of the majority of the inventory effort (2001-2003) compared to the mean (1894-2004 for University of Arizona; thick solid line in all figures), Tucson Mountain District, Saguaro National Park. 10

Figure 3.1. Layout of a modified-Whittaker plot, Saguaro NP, Tucson Mountain District, 2001. 14

Figure 3.2. Locations of modified-Whittaker plots and point-intercept transects (line transect), Saguaro NP, Tucson Mountain District, 2001.

Figure 3.3. Typical layout of point-intercept transects, Saguaro NP, Tucson Mountain District, 2001.... 16

Figure 3.4. Number of plant species at the five random sites that were found by each of the two field methods used at focal points (point-intercept transect and modified-Whitaker plot), Saguaro

NP, Tucson Mountain District, 2001.

Figure 3.5. Vertical vegetation structure (A) and ground cover type (B), by transect, and from pointintercept transects, Saguaro NP, Tucson Mountain District, 2001.

Figure 4.1. Typical plot layout of herpetofauna subplots along a 1-km focal-point transect $(n=5)$, Saguaro NP, Tucson Mountain District.

Figure 4.2. Study site locations for herpetofauna, Saguaro NP, Tucson Mountain District, 2001 and 2002.

Figure 4.3. Species accumulation curve for herpetofauna surveys, all methods combined, Saguaro NP, Tucson Mountain District, 2001 and 2002..

Figure 4.4. Species accumulation curve for herpetofauna surveys, by survey type, Saguaro NP, Tucson Mountain District, 2001 and 2002.

Figure 5.1. Location of VCP and nocturnal survey stations for birds, Saguaro NP, Tucson Mountain District, 2001 and 2002.

Figure 5.2. Species accumulation curve for birds, all survey methods, Saguaro NP, Tucson Mountain District, 2001 and $2002 .$. 44

Figure 6.1. Location of random and non-random small-mammal trapping sites, bat trapping stations, and Trailmaster cameras (infrared-triggered cameras), Saguaro NP, Tucson Mountain District, 2001. .48

Figure 6.2. Location of infrared-triggered camera units, Saguaro NP, 2002-2005. 49

Figure 6.3. Layout of small-mammal trapping grids along focal-point transects, Saguaro NP, Tucson Mountain District, 2001..

Figure 6.4. Detailed layout of small-mammal trapping grids at Saguaro NP, Tucson Mountain District, 2001 and 2002. 
Figure 6.5. Typical configuration for an active infrared-triggered camera system.

Figure 6.6. Species accumulation curve for small-mammal trapping, Saguaro NP, Tucson Mountain District, 2001.

Figure 6.7. Species accumulation curve for infrared-triggered photography, Saguaro NP, Tucson Mountain District, 2002-2005. 


\section{List of Appendices}

Appendix A. List of plant species that were observed (O) or collected (X) at Saguaro NP, Tucson Mountain District.

Appendix B. List of reptiles and amphibians by University of Arizona Inventory personnel and field method(s) used to detect them, Saguaro NP, Tucson Mountain District,

2001 and 2002. 78

Appendix C. List of bird species observed at Saguaro NP, Tucson Mountain District by UA inventory personnel (2001 and 2002) or by other survey efforts or lists: Monson and Smith (M\&S; 1986), Yensen (YE; 1976), Short (SH; 1996), and

Kline (KL; 1998).

Appendix D. List of mammals observed at Saguaro NP, Tucson Mountain District by University of Arizona (UA) and Saguaro National Park (SNP) Inventory personnel (by survey type, 2001-2005 and other efforts.

Appendix E. Vertebrate specimen and photograph vouchers collected by University of Arizona or park personnel, Saguaro National Park,Tucson Mountain District, 1997-2002.

Appendix F. List of existing specimen vouchers collected prior to our inventory effort. .86

Appendix G. Percent composition (Comp.) and cover from point-intercept transects, by height category, Saguaro NP, Tucson Mountain District, 2001.

Appendix H. Presence of plant species at modified-Whitaker vegetation plots, by vegetation community and plot number, Saguaro NP, Tucson Mountain District, 2001

Appendix I. Detail of small mammal trapping effort at Saguaro NP, Tucson Mountain District, 2001 and 2002.

Appendix J. Summary of field research for bats, Saguaro NP, Tucson Mountain District, 2001 and 2002. 


\section{Acknowledgments}

Thanks to Saguaro National Park Superintendent Sarah Craighead, Chief of Science and Resource Management Meg Weesner, and biologists Natasha Kline and Don Swann for providing leadership and administrative support for this project. Other park staff who assisted our project included Matt Daniels, Mark Holden, and Robert Stinson. This project was funded by the National Park Service (NPS) Inventory and Monitoring program (I\&M) and was made possible by the collaboration of many people at the University of Arizona (UA), NPS, and U.S. Geological Survey (USGS). Administration of the project was facilitated by the Desert Southwest and Colorado Plateau Cooperative Ecosystem Studies Units (CESUs). The Southern Arizona Office of the NPS assisted with the development of the original study plan that led directly to initiation of this project. Additional support (monetary and in-kind) for infraredtriggered photography was provided by the Western National Parks Association, Friends of Saguaro National Park, T\&E Inc., and the UA Undergraduate Biology Internship Program.

Andy Hubbard at the Sonoran Desert Network I\&M program has been a great advocate of our program. He also provided funds for Don Swann to work on this report. Kathy Davis, Superintendent of Tuzigoot and Montezuma Castle national monuments played an instrumental role in this project by providing important early initiative. Larry Norris at the Desert Southwest CESU has provided strong support for our program and spent considerable time and effort providing clear and timely administrative assistance. Matt Goode, Don Swann, and Dale Turner provided much of the early planning for this project; we are indebted to their vision and work. Eric Albrecht was an outstanding spokesperson and leader of the program; he was an invaluable member of the team and his contributions are sorely missed.

We thank a core group of dedicated field biologists who collected a wealth of data at Saguaro National Park: Greta Anderson, Theresa DeKoker, Meg Quinn, Dale Turner, and Emily Willard (plants); Dan Bell, Kevin Bonine, James Borgmeyer, Philip Brown, Matt Goode, Dave Prival, and Mike Wall (amphibians and reptiles); Eric Albrecht, Gavin Beiber, Chris Kirkpatrick, and Gabe Martinez (birds); Eric Albrecht, Melanie Bucci, Matt Caron, Matt Colvin, Tony Dee, Mark Holden, Neil Perry, Jason Schmidt, Ronnie Sidner, Patty Stern, Sandy Wolf, and Erin Zylstra (mammals). We are appreciative of the following people, many of whom never ventured into the field, but whose work in the office made the field effort successful: Debbie Angell, Jennifer Brodsky, Chuck Conrad, Louise Conrad, Brian Cornelius, Taylor Edwards, Carianne Funicelli, Marina Hernandez, Colleen McClain, Heather McClaren, Lindsay Norpel, Ryan Reese, Jill Rubio, Brent Sigafus, Taffy Sterpka, Jenny Treiber, Zuleika Valdez, Alesha Williams, and Erin Zylstra. Pam Anning, Kristen Beaupré, and Matthew Daniels assisted with database design. Pam Anning also provided the maps for this report. Additional administrative support was provided by Valery Catt, Jenny Ferry, Andy Honaman, Terri Rice, and especially Cecily Westphal of the School of Natural Resources at the UA. Special thanks to Lisa Carder and Kathleen Docherty for their years of hard work on all aspects of the project.

Technical support was graciously provided by the following experts: Dan Austin, Michael Chamberland, Phil Jenkins, and Charlotte and John Reeder at the UA Herbarium; Tom Huels of the UA ornithology collection; George Bradley of the UA herpetology collection; and Yar Petryszyn and Melanie Bucci of the UA mammal collection. Thanks to Sharon Megdal and Peter Wierenga, the current and former directors, respectively, of the UA Water Resources Research Center, and all their staff. Thanks to Mau-Crimmins et al. (2005) and Sprouse et al. (2002) for use of their background information on the district and Aaron Flesch (Flesch 2001) for use of some of his discussion in the mammal chapter. We received many excellent comments on the amphibian and reptile chapter from Phil Rosen and Cecil Schwalbe. Larry Norris, Don Swann, and Meg Quinn reviewed an earlier version of this report. 


\section{Executive Summary}

This report summarizes the results of the first comprehensive inventory of plants and vertebrates at the Tucson Mountain District (TMD) of Saguaro National Park, Arizona. From 2001 to 2003 we surveyed for vascular plants and vertebrates (amphibians, reptiles, birds, and mammals) at the district to document the presence of species within its boundaries. Park staff also carried out extensive infraredtriggered camera work for medium and large mammals from 2002-2005 and results from that effort are reported here. Our spatial sampling design for all taxa employed a combination of random and nonrandom survey sites. Survey effort was greatest for medium and large mammals and herpetofauna. Because we used repeatable study designs and standardized field methods, these inventories can serve as the first step in a biological monitoring program for the district. We also provide an overview of previous survey efforts in the district. We use data from our inventory and other surveys to compile species lists and to assess inventory completeness.

The survey effort for herpetofauna, birds, and medium and large mammals was the most comprehensive ever undertaken in the district. We recorded a total of 320 plant and vertebrate species, including 21 species not previously found in the district (Table 1). Based on a review of our inventory and past research at the district, there have been a total of 723 species of plants and vertebrates found there. We believe inventories for most taxonomic groups are nearly complete.

Based on our surveys, we believe the native plant and vertebrate community compositions of the district are relatively intact, though some species loss has occurred and threats are increasing, particularly to herpetofauna and larger mammals. Of particular note is the relatively small number of non-native species and their low abundance in the district, which is in contrast to many nearby natural areas. Rapidly expanding development on the west, north, and east sides of the district is cause for concern that the park continue its commitment to environmental restoration, which is largely responsible for reducing the threats posed by non-native plants. With continued maintenance of natural processes and the ecological structure of the park's biodiversity, the park will become an increasingly important place to both the general public and the scientific community.

This report supersedes results reported in Powell et al. $(2002,2003)$.

Table 1. Summary of vascular plant and vertebrate inventories at Saguaro National Park, Tucson Mountain District, 1999-2005.

\begin{tabular}{|c|c|c|c|c|}
\hline \multirow[b]{2}{*}{ Taxonomic group } & \multicolumn{2}{|c|}{ UA inventory } & \multirow[b]{2}{*}{$\begin{array}{c}\text { Number of } \\
\text { non-native species }\end{array}$} & \multirow[b]{2}{*}{$\begin{array}{c}\text { Total number of species } \\
\text { on district list }\end{array}$} \\
\hline & $\begin{array}{c}\text { Number of } \\
\text { species recorded }\end{array}$ & $\begin{array}{l}\text { Number of new species } \\
\text { added to district list }\end{array}$ & & \\
\hline Plants & 180 & 8 & 47 & 512 \\
\hline Amphibians and Reptiles & 34 & 0 & 0 & 37 \\
\hline Birds & 73 & 4 & 2 & 134 \\
\hline Mammals & 33 & 9 & 2 & 40 \\
\hline Totals & 320 & 21 & 50 & 723 \\
\hline
\end{tabular}




\title{
Chapter 1: Introduction to the Inventories
}

\author{
Brian F. Powell, Cecilia A. Schmidt, and William L. Halvorson
}

\section{Project Overview}

Inventory: A point-in-time effort to document the resources present in an area.

In the early 1990 s, responding to criticism that it lacked basic knowledge of natural resources within parks, the National Park Service (NPS) initiated the Inventory and Monitoring Program (I\&M) to detect long-term changes in biological resources (NPS 1992a). At the time of the program's inception, basic information, including lists of plants and animals, was absent or incomplete for most park units (Stohlgren et al. 1995b).

Species inventories have both direct and indirect value for management of the park and are an important first step in long-term monitoring. Species lists are not only useful in resource interpretation and facilitating visitor appreciation of natural resources, but are also critical for making management decisions. Knowledge of which species are present, particularly sensitive species, and where they occur provides for informed planning and decision-making (e.g., locating new facilities). Thorough biological inventories provide a basis for choosing parameters to monitor and can provide baseline data for monitoring ecological populations and communities. Inventories can also test sampling designs, field methods, and data collection protocols, and provide estimates of variation that are essential in prospective power analysis.

\section{Goals}

The purpose of this study was to complete basic inventories for vascular plants and vertebrates at the Tucson Mountain District (TMD) of Saguaro National Park. This effort was part of a larger biological inventory of eight NPS units in southern Arizona and southwestern New Mexico (Davis and Halvorson 2000; e.g., Powell et al. 2006a, 2005). Our goals were to:

Conduct field surveys to document at least $90 \%$ of all species of vascular plants and vertebrates expected to occur at the district.
(2)

Use repeatable sampling designs and survey methods that allow estimation of parameters of interest (e.g., relative abundance).

Compile historic occurrence data for all species of vascular plants and vertebrates from three sources: museum records (voucher specimens), previous studies, and park records.

Create resources useful to park managers, including detailed species lists, maps of study sites, and high-quality digital images for use in resource interpretation and education.

The bulk of our effort addressed the first two goals. To maximize efficiency (i.e., the number of species recorded by effort) we used field methods designed to detect multiple species. We did not undertake single-species surveys for threatened or endangered species.

\section{Report Format and Data Organization}

Like the report for the Rincon Mountain District (Powell et al. 2006b), each taxon-specific chapter in this report has separate authorship. As such there are some differences in the organization and content of each chapter. Appendices related to each chapter are attributed to the respective author(s). We organized a single literature cited chapter at the end of the report.

In the text, we report both common and scientific names for plants, and for vertebrates we report only common names (listed in phylogenetic sequence) unless we reference a species that is not listed later in an appendix; in this case, we present both common and scientific names. For each taxonomic group we include an appendix of all species that we recorded in the district (Appendices A-D). In the amphibian and reptile and mammal chapters we review species that were likely or confirmed to have been present historically or that we suspect are currently present and may be recorded with additional survey effort. Scientific and common names used throughout this document are current according 
to accepted authorities for each taxonomic group: Integrated Taxonomic Information System (ITIS 2005) and the PLANTS database (USDA 2005) for plants; Stebbins (2003) for amphibians and reptiles; American Ornithologists' Union (AOU 1998, 2003) for birds; and Baker et al. (2003) for mammals. We recognize that the designation of a plant as "non-native" using the aforementioned lists may lead to the misclassification of some species, because these lists indicate only species status in North America as a whole, not regions within the continent. Therefore, our flora underestimates the number of non-native species, but because no authoritative list of non-native species exists for the region, we believe that use of these lists is justified.

\section{Spatial Data}

Most spatial data are geographically referenced to facilitate mapping of study plots and locations of plants or animals. Coordinates were stored in the Universal Transverse Mercator (UTM) projection (Zone 12), using the North American Datum of 1983 (NAD 83). We recorded UTM coordinates using hand-held Garmin E-Map ${ }^{\circledR}$ Global Positioning System (GPS) units (Garmin International Incorporated, Olathe, KS; horizontal accuracy approximately $10-30 \mathrm{~m}$ ). We obtained some plot or station locations by using more accurate Trimble Pathfinder ${ }^{\circledR}$ GPS units (Trimble Navigation Limited, Sunnyvale, CA; horizontal accuracy about $1 \mathrm{~m}$ ). Although we mapped the locations of study plots, stations, or transects on Digital Orthophoto Quarter Quads (DOQQ; produced by the USGS), the locations of study areas will remain with the park and NPS Sonoran Desert Network I\&M office in Tucson. We also produced distribution maps for all vertebrate species from this and other recent survey efforts (including wildlife observation cards at the park). Those maps will be archived in the same locations as the GPS coordinates.

\section{Species Conservation Designations}

We indicate species conservation designations by the following agencies: U.S. Fish and Wildlife Service (responsible for administering the Endangered Species Act), USDA Forest Service, Arizona Game and Fish Department, and Partners in Flight (a partnership of dozens of federal, state and local governments, non-governmental organizations, and private industry).

\section{Databases and Data Archiving}

We entered field data into taxon-specific databases (Microsoft Access version 97) and checked all data for transcription errors. From these databases, we reproduced copies of the original field datasheets using the "Report" function in Access. The output looks similar to the original datasheets but data are easier to read. The databases, printouts of field data, and other data such as digital photographs have been distributed to park staff and will be archived at Special Collections at the University of Arizona. Original copies of all datasheets currently reside at the I\&M office in Tucson and may be archived at another location. Along with the archived data, we will include copies of the original datasheets and a guide to filling them out. This information, in conjunction with the text of this report, should enable future researchers to repeat our work.

\section{Verification and Assessment of Results}

\section{Photograph Vouchers}

Whenever possible, we documented vertebrate species with analog color photographs. Many of these photographs show coloration or other characteristics of visual appearance in detail, and they may serve as educational tools for the park staff and visitors. We obtained a close-up photograph of each animal "in hand" and, if possible, another photograph of the animal in natural surroundings. Photographs are archived with other data as described above.

\section{Voucher Specimens}

Voucher specimens are an indisputable form of evidence of a species occurrence. For plants, we searched the University of Arizona Herbarium for specimens from the district (see Appendix A for results), and we collected herbarium specimens whenever flowers or fruit were present on plants. All specimens that we collected were accessioned into the University of Arizona Herbarium. To prioritize vertebrate species for voucher collection, we first searched the park's 
specimen collection and that of other universities and collections (Table 1.1; see Appendix F for results). When we did collect specimens, most were found dead. When necessary, we euthanized animals according to procedures of the University of Arizona's Institutional Animal Care and Use Committee, prepared the specimens using UA methods, and deposited them in the appropriate collection at the University of Arizona.

\section{Assessing Inventory Completeness}

We assessed inventory completeness by (1) examining the rate at which new species were recorded in successive surveys (i.e., species accumulation curves; Hayek and Buzas 1997) and (2) comparing the list of species we recorded with a list of species likely to be present based on previous research and/or expert opinion. We created species accumulation curves for all taxonomic groups except plants. For all accumulation curves (unless indicated otherwise), we randomized the order of the sampling periods to break up clusters of new detections that resulted from temporal conditions (e.g., monsoon initiation) independent of cumulative effort. We used the computer program Species Richness and Diversity III (Pisces Conservation Ltd., IRC House, Pennington, Lymington, UK) to calculate species accumulation curves where the order of samples was shuffled the maximum number of times and the average was plotted, thereby smoothing the curve.

\section{Estimating Abundance}

Estimating population size is a common goal of biologists who are motivated by the desire to reduce (pest species), increase (endangered species), maintain (game species), or monitor (indicator species) population size. Our surveys at the district were generally focused on detecting species rather than estimating population size. In many cases, however, we present estimates of "relative abundance" by species to provide information on areas in which species might be more or less common. Relative abundance is an index to population size; we calculate it as the number of individuals of a species recorded, scaled by survey effort. If we completed multiple surveys in comparable areas, we included a measure of precision (usually standard error) with the mean of those survey results.

Indices of abundance are presumed to correlate with true population size, but ecologists do not typically attempt to account for variation in detectability among different species or groups of species under different circumstances. Metrics (rather than indices) of abundance do consider variation in detection probability, and these include density (number of individuals per unit area; e.g., one western diamondback rattlesnake per $\mathrm{km}^{2}$ ) and absolute abundance (population size; e.g., 150 western diamondback rattlesnakes). These estimates are beyond the scope of our research. While it is true that indices to abundance have often been criticized (and with good reason, c.f. Anderson 2001), the

Table 1.1. Museums that were queried in 1998 for vertebrate specimen vouchers with "Arizona" and "Saguaro National Park" and "Saguaro National Monument" in the collection location.

\begin{tabular}{ll}
\hline Collection & Collection cont. \\
\hline Brigham Young University & Oklahoma Museum of Natural History, Norman \\
Chicago Academy of Sciences & Peabody Museum, Yale University \\
Cincinnati Museum of Natural History \& Science & Saguaro National Park (collection now at the Western \\
Cornell Vertebrate Collections, Cornell University & Archaeological and Conservation Center, Tucson) \\
George Mason University (Fairfax, VA) & Strecker Museum, Baylor University, Waco \\
Illinois Natural History Survey & Texas Cooperative Wildlife Collection \\
Marjorie Barrick Museum, University of Nevada-Las Vegas & Tulane Museum of Natural History \\
Michigan State University Museum (East Lansing) & University of Arizona \\
Milwaukee Public Museum & University of Texas, Arlington \\
Museum of Natural History, University of Kansas & University of Illinois, Champaign-Urbana \\
Museum of Texas Tech University & University of Colorado Museum \\
Museum of Vertebrate Zoology, University of California, Berkeley & United States National Museum \\
Museum of Life Sciences, Louisiana State University, Shreveport & Walnut Canyon National Monument \\
Natural History Museum of Los Angeles County & Western Archaeological and Conservation Center, Tucson \\
North Carolina State Museum of Natural Sciences & Wupatki National Monument \\
\hline
\end{tabular}


abundance information that we present in this report is used to characterize the commonness of different species rather than to quantify changes in abundance over long periods of time (e.g., monitoring). As such, relative abundance estimates are more useful than detectabilityadjusted estimates of density or abundance for only a few species or raw count data for all species without scaling counts by survey effort.

\section{Sampling Design}

\section{Overview}

Sampling design is the process of selecting sample units from a population or area of interest. Unbiased random samples allow inference to the larger population from which those samples were drawn and enable one to estimate the true value of a parameter. The precision of these estimates, based on sample variance, increases with the number of samples taken; theoretically, random samples can be taken until all possible samples have been selected and precision is exact - a census has been taken and the true value is known. Non-random samples are less likely to be representative of the entire population, because the sample may (intentionally or not) be biased toward a particular characteristic, perhaps one of interest or convenience.

In our surveys we employed both random and non-random spatial sampling designs for all taxa. For random sites, we co-located all taxonomic studies at the same sites (focal points and focal-point transects; see below for more information) because some characteristics, especially vegetation, could be used to explain differences in species richness or relative abundance among transects. We also used vegetation floristics and structure to group transects into community types that allowed more accurate data summaries. The location of nonrandom study sites was entirely at the discretion of each field crew (i.e., plants, birds, etc.) and we made no effort to co-locate them.

\section{Focal Points and Focal-point Transects: Random Sampling}

We chose a simple random design to assign the location of our focal points. This was in contrast to the stratified random design that we used at the Rincon Mountain District, which had numerous environmental communities that corresponded to elevational gradients (Powell et al. 2006b). At the Tucson Mountain District we used the following process to assign the location of random study areas. First, we created 50 random (hereafter referred to as "focal") points using the Animal Movement extension for ArcView (developed by the USGS Alaska Science Center - Biological Science Office), using uniform distribution, allowing zero meters to the district boundary, and zero meters between points. For each focal point, we generated a random bearing (the numbers ranged from 0 to 359). We then used the Bearing and Distance extension for ArcView (developed by Ying Ming Zhou, March 29, 2000; downloaded from ESRI ArcScripts website) to create points based on the distance and bearing from the original points. This gave us start points and end points for all 50 focal points. We then used the "from" and "to" coordinates to draw the transect line using an Avenue script ("Draw line by coordinates," developed by Rodrigo Nobrega, August 13, 1998; downloaded from ESRI ArcScripts website). The result was randomly placed, 1000-m line transects (hereafter referred to as "focal-point transects" or "transects"). Focal-point transects were not allowed to overlap. If this occurred, an entire new selection was conducted until a scenario of no overlapping transects was achieved.

Many focal-point transects were not used because either some part of them lay outside of the district boundary or they were in areas where the terrain was too steep to work safely (i.e., crossed areas with slopes exceeding 35 degrees). These "danger" areas were derived from 30$m$ Digital Elevation Models using the Spatial Analyst extension for ArcView. The final design produced four bird-survey stations spaced 250$\mathrm{m}$ apart; 10, $100 \times 100-\mathrm{m}$ amphibian and reptile plots; and 20, $50 \times$ x 5-m mammal plots along the focal-point transect line (Fig. 1.1). We sampled vegetation by point intercept along six, $50-\mathrm{m}$ transects (see Chapter 3 for more information).

To map the location of plots, we designed a footprint of the sampling grids using an Avenue Script ("View.CreateTransectLines," by 
Neal Banerjee, October 5, 2000; downloaded from ESRI ArcScripts website) to create grid lines every $100 \mathrm{~m}$ that were perpendicular (90 degrees) to a "dummy" transect (Fig. 1.1A). These grid lines were converted from graphics to shapes using the XTools extension for ArcView (developed by the Oregon Department of Forestry). We then generated points where each grid line intersected the transect using the Themes Intersections to Points extension for ArcView (developed by Arun Saraf, November 11, 1999; downloaded from ESRI ArcScripts website) (Fig. 1.1B).

We created $100 \times 100-m$ squares centered on each intersection point to generate the amphibian and reptile plots using the Square Buffer Wizard extension for ArcView (developed by Robert J. Scheitlin, May 12, 2000; downloaded from ESRI ArcScripts website). These squares were numbered 1 to 10 in the direction of the transect bearing (Fig. 1.1C). The same process was repeated to create the mammal plots (Fig. 1.1D). Four bird survey stations were created by selecting the center of mammal plots $3,8,13$, and 18 and buffering each of these points with a radius of $125 \mathrm{~m}$ (Fig. 1.1E). These circles were numbered 1 to 4 in the direction of the transect bearing.

\section{Non-random Selection of Study Sites}

Many areas of the district contain unique areas requiring special surveys for all taxa. Cliffs, rocky outcrops, and ephemeral pools were likely to be missed if we located our study sites only in random areas. These areas are diversity "hotspots" and are therefore crucial to visit in order to complete the species inventories. We selected these study areas based on our knowledge of the district.

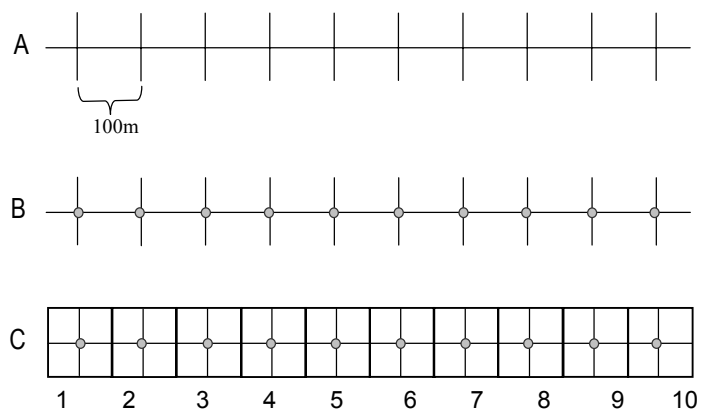

D
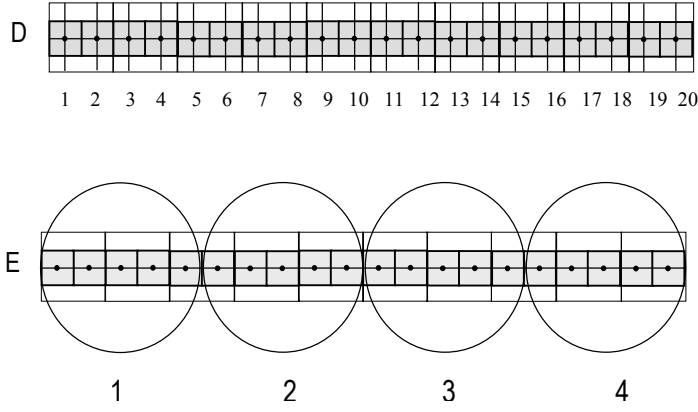

Figure 1.1. Layout of 1-km focal-point transects showing layout of amphibian and reptile plots (C), smallmammal trapping grids (D), and bird survey stations (E), Saguaro NP, Tucson Mountain District. Figures A and B represent the building blocks of the other transects. 


\section{Chapter 2: Park Overview}

\section{Brian F. Powell, Cecilia A. Schmidt, and William L. Halvorson}

\section{Park Area and History}

Saguaro National Park is located in eastern Pima County adjacent to Tucson, Arizona (Fig. 2.1). Originally designated as a national monument, the park was created in 1933 to preserve the "exceptional growth" of the saguaro cactus (NPS 1992b). In 1961, the park was expanded to include over 9,000 ha of the Tucson Mountains (known as the Tucson Mountain District) and was expanded again by legislation in 1976 and 1994. The Tucson Mountain District is the subject of this report (see Powell et al. 2006b for the Rincon Mountain District report). The Tucson Mountain District consists of 9,727 ha and is bounded by private and state land to the north, east, and west and by Pima County's Tucson Mountain Park and private land to the south. Although created to preserve natural resources, the park is also home to Native American campsites and petroglyphs and contains remnants of early ranching and mining (NPS 1992b). Annual visitation to both districts of the park averages approximately 700,000 (NPS 2005).

\section{Physiography, Geology, and Soils}

Saguaro National Park is located within the Basin and Range Physiographic Province. The district encompasses much of the Tucson Mountains. These mountains were created through uplifted, tilted and faulted intrusives, volcanics and sediments. Topography at Tucson Mountain District ranges from desert flats to rocky outcroppings. Elevation at Tucson Mountain District ranges from $670 \mathrm{~m}$ on the west side of the district to $1429 \mathrm{~m}$ at Wasson Peak. There are many rock types found in Tucson Mountain District including limestone, rhyolite, sandstone, and granite. The Tucson Mountains are predominated by rhyolite, laid down during a period of volcanism about 70 million years ago (Scarborough 2000).

The Tucson Mountain District is characterized by a rugged, boulder-strewn terrain that is cut from many steep-channeled washes that run only ephemerally. Below the foothills, these washes fan out into larger multi-channeled bodies. The district contains no natural sources of perennial water; however there are several drainages, such as King Canyon and Javelina and Panther Peak washes that often flow during periods of heavy rainfall.

\section{Natural Resources Overview}

\section{Climate}

Saguaro National Park experiences an annual bimodal pattern of precipitation that is characterized by heavy summer (monsoon) storms brought about by moisture coming from the Gulf of Mexico, and less intense frontal systems coming from the Pacific Ocean in the winter. On average, approximately one-half of the annual precipitation falls from July through September (Table 2.1; WRCC 2005). The area's hot season occurs from April through October; daily maximum temperatures exceed $40^{\circ} \mathrm{C}$. Winter temperatures can dip below freezing and snow occurs, but is uncommon, on Wasson Peak.

From 2001 to 2003, during the time of most of our inventory effort, average annual precipitation totals ranged from slightly to substantially below the long-term mean of 28.6 $\mathrm{cm}(21.7 \mathrm{~cm}$ in 2001, $19.0 \mathrm{~cm}$ in 2002 and 26.5 $\mathrm{cm}$ in 2003; Fig. 2.3; WRCC 2005). Average annual temperatures from 2001 to 2003 were above the long-term mean of $21.3^{\circ} \mathrm{C}\left(21.5^{\circ} \mathrm{C}\right.$ in $2001,21.6^{\circ} \mathrm{C}$ in 2002 and $22.0^{\circ} \mathrm{C}$ in 2003; Fig 2.3; WRCC 2005).

\section{Vegetation}

Sonoran desertscrub is the dominant vegetation community in the district and is found throughout the district except at the highest points near Wasson Peak, where there is representation of semi-desert grasslands. According to Rondeau et al. (1996), the district has seven plant associations based on Brown and Lowe (1980) classification: Creosote Bush Association, Creosote BushBursage Association, Palo Verde-SaguaroIronwood Association, Palo Verde-Saguaro Association, Jojoba Mixed-Scrub Association, Desert Grassland and Desert Riparian Scrub. 


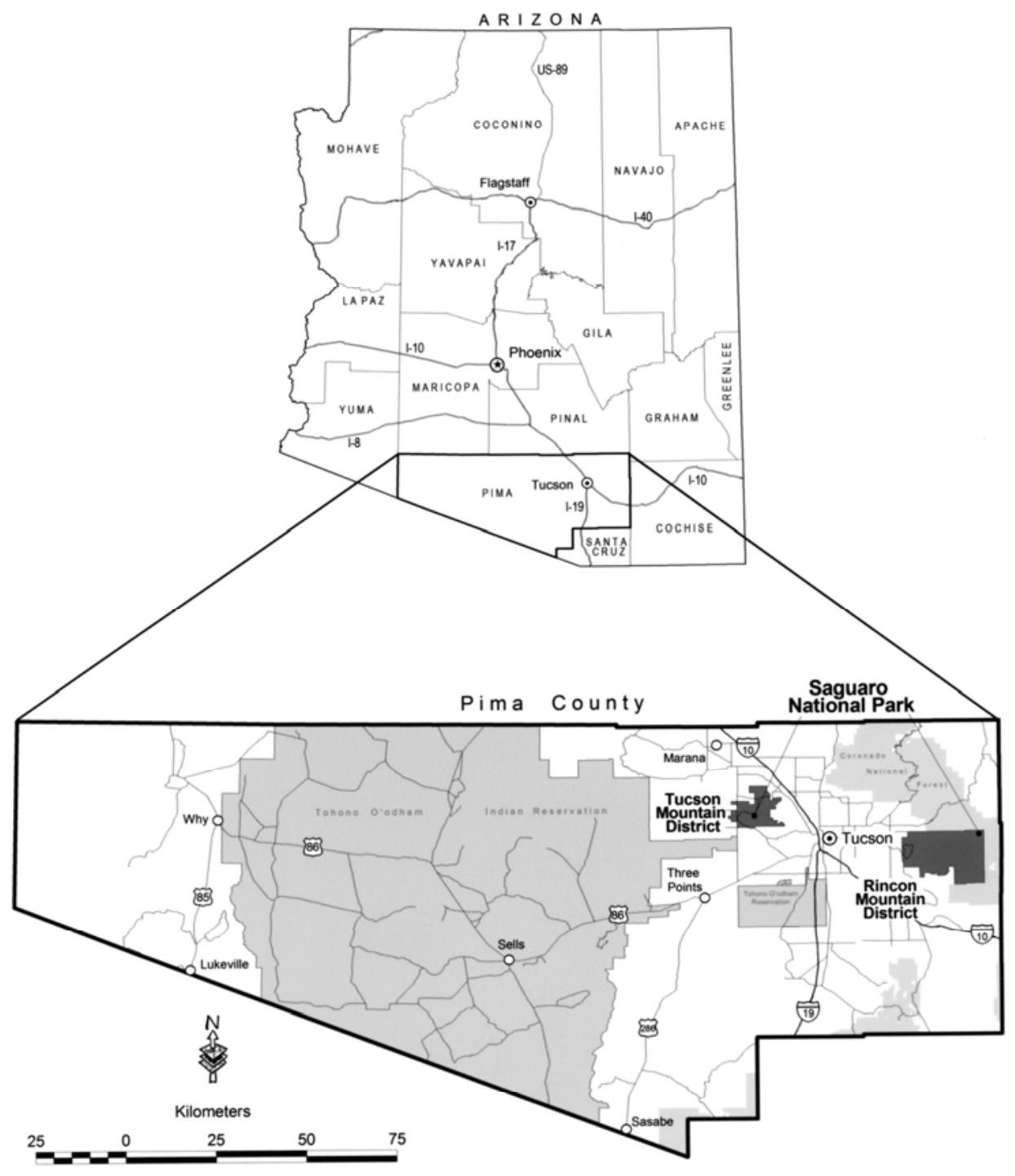

Figure 2.1. Location of the two districts of Saguaro National Park in southern Arizona.

Table 2.1. Average monthly climate data for the University of Arizona (low elevation; the closest climate monitoring station to the district), 1894-2004. Data from WRCC (2005).

\begin{tabular}{lccccccccccccc}
\hline & \multicolumn{11}{c}{ Month } \\
\cline { 2 - 13 } Characteristic & Jan & Feb & Mar & Apr & May & Jun & Jul & Aug & Sep & Oct & Nov & Dec & Annual \\
\hline Maximum temperature $\left({ }^{\circ} \mathrm{C}\right)$ & 18.6 & 20.5 & 23.5 & 27.8 & 32.6 & 37.7 & 37.8 & 36.7 & 35.1 & 29.9 & 23.5 & 19.0 & 28.6 \\
Minimum temperature $\left({ }^{\circ} \mathrm{C}\right)$ & 3.1 & 4.5 & 6.7 & 9.9 & 14.2 & 19.3 & 23.3 & 22.4 & 19.3 & 12.7 & 6.6 & 3.4 & 12.1 \\
Precipitation $(\mathrm{cm})$ & 2.3 & 2.2 & 1.9 & 1.0 & 0.4 & 0.7 & 5.2 & 5.4 & 3.0 & 1.9 & 2.0 & 2.5 & 2.3 \\
\hline
\end{tabular}




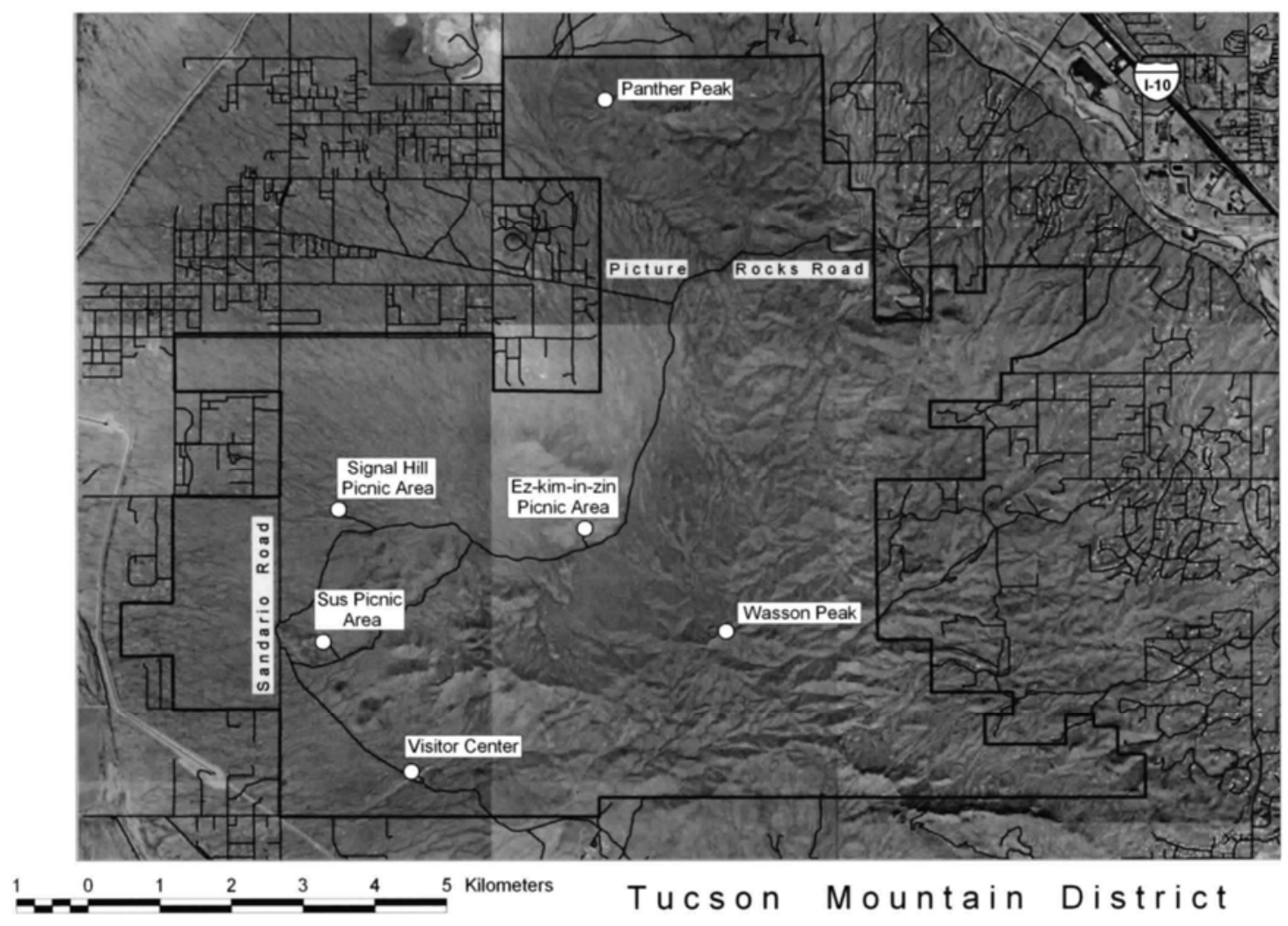

Figure 2.2. Composite aerial photograph showing major features of Saguaro NP, Tucson Mountain District.

The dominant trees and shrubs in the district are triangle-leaf bursage (Ambrosia deltoidea), palo verde (Cercidium spp.), Ironwood (Olneya tesota), acacia (Acacia spp.), and creosote bush (Larrea tridentata). Succulents are ubiquitous and include: saguaro (Carnegia gigantea), agave (Agave spp.), yucca (Yucca spp.), barrel cactus (Ferocactus), pincushion cactus (Mammillaria spp.), and prickly pear and cholla (Opuntia spp.). Warm- and cool-season annuals, both native (e.g., woolly plantain; Plantago patagonica) and introduced (e.g., red brome; Bromus rubens) are common following rainfall.

\section{Natural Resource Management Issues}

\section{Adjacent Land Development}

Increasing housing development along the east and west boundaries of the district has become the most pressing natural resource issue. Located between both districts of the park, the greater
Tucson metropolitan area is one of the fastest growing in the United States (PAG 2005). The area currently has an estimated population of 800,000 , a $44 \%$ increase over the last two decades. The increase in human residents brings with it a variety of natural-resource-related problems including harassment and predation of native species by feral animals, increased traffic leading to altered animal movement patterns and mortality, the spread of non-native species, illegal collections of animals, vandalism, increased water demands, air pollution from vehicle emissions, and visual intrusions to the natural landscape (Briggs et al. 1996). Throughout this document we highlight some of these impacts as they pertain to each taxonomic group.

\section{Non-native Species and Changes to Vegetation}

The spread of non-native species within the district is an important natural resource issue. 

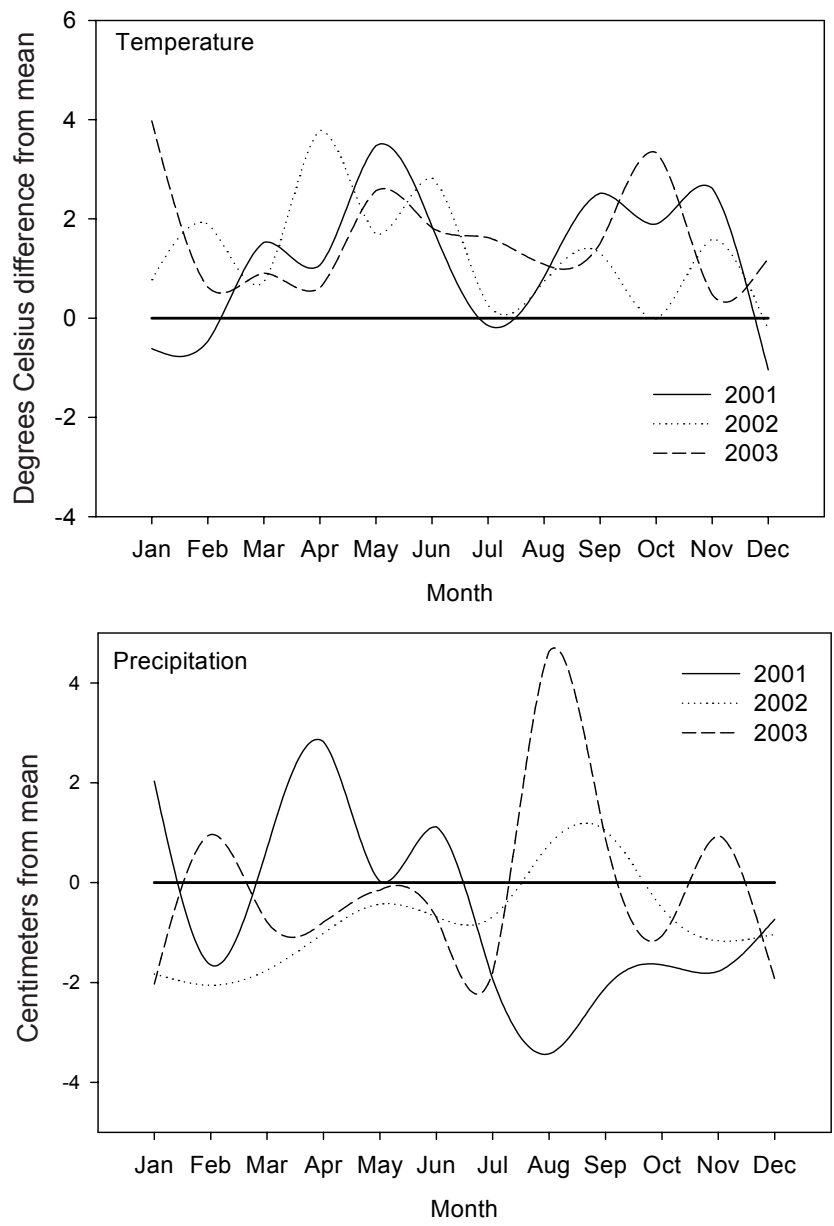

Figure 2.3. Comparison of monthly weather data during the time of the majority of the inventory effort (2001-2003) compared to the mean (1894-2004 for University of Arizona; thick solid line in all figures), Tucson Mountain District, Saguaro National Park. Data from WRCC (2005).

In particular buffelgrass, Lehmann lovegrass, red brome, and other non-native grasses have increased in the last ten years (Funicelli et al. 2001). The spread of some non-native plants used for landscaping, such as crimson fountaingrass from development bordering the district is also a concern, especially along washes. The invasion of non-native grasses has led to structural changes in vegetation, from areas that supported mostly sparse bunchgrasses to areas of fairly uniform grass cover. This change in species composition and structure can alter the fire regime of the area by supporting higher fire frequencies, thereby leading to other changes in vegetation composition and structure (Burgess et al. 1991, Anable et al. 1992). Nowhere are these effects more evident than in the Sonoran desertscrub vegetation community, which rarely burned historically (Steenbergh and Lowe 1977). Many native plant species, especially succulents, are not adapted to short duration but highintensity fires and therefore die (Schwalbe et al. 1999, Dimmitt 2000). Fires such as the Mother's Day Fire (Rincon Mountain District), fueled largely by non-native grasses, have caused a high mortality of saguaro cactus (Schwalbe et al. 1999; see Chapter 3 for additional information). 


\section{Abandoned Mines}

The Tucson Mountain District has numerous seeps and pools located inside mines, which can be a source for water contamination. In particular, soil samples from the Old Yuma Mine identified high contaminant levels for arsenic, copper, zinc, and lead. These contaminants could easily enter local water supplies as a result of heavy rainfall and subsequent runoff (Mott 1997). Other mines in the district, such as Gould Mine and Mile Wide Mine, have tailings which could leach contaminants into residential water sources. Not all abandoned mines pose an environmental hazard and risk to public health. Old Yuma and Gould mines are important roosting sites for bats (see Chapter 6). 


\section{Chapter 3: Plants}

\section{Brian F. Powell and Cecilia A. Schmidt}

\section{Previous Research}

Among the earliest botanical information for the district is a list of 430 species, compiled by Ranger-Naturalist Richard Wadleigh, known or suspected to occur in the district (1969). The list was a good start for compiling information on the flora of the district, but was not based on collections. The best flora for the district was by Van Devender (1992) and Rondeau et al. (1996), who produced a comprehensive inventory of the district and other areas of the Tucson Mountains. They included extensive information on the distribution, abundance, elevation range, and flowering phenology of the species that they found during field research from 1987 to 1993. This remains the most comprehensive synthesis of information on the plants of the district and we refer the reader to their work for an annotated species list and discussions of biogeography. They also provide an excellent overview of previous research and collecting from the range and comparisons to other floras of the region. Our work was intended to revise their species list for the district and to provide supporting data for the vertebrate inventories.

In 1990 the park established 20 plots to document injury to saguaro cactus and to map the distribution of other plants. Park personnel used these plots to establish 20 long-term vegetation transects in low-elevation areas of the district and used the point-intercept method in multiple years and seasons from 1998 to 2005 (Holden 2005). To our knowledge, no comprehensive species list was produced from that effort. In 2002, park personnel established an additional four transects on recently acquired lands. Funicelli et al. (2001) resurveyed the original 20 plots, which were also used by Turner and Funicelli (2000) to resurvey the condition and population structure of saguaro cacti. The saguaro cactus, the park's namesake, has been one of the most investigated non-agricultural plants in the world. McAuliffe (1993) provides an excellent overview of saguaro research at the park. Halvorson and Guertin (2003) mapped locations of 5 species of nonnative plants, and Bertelsen (1998) completed inventories of two pieces of land that had been added to the district in 1994. May (1970) produced the first vegetation-type map for the district, and there are plans to update the map (Andy Hubbard, pers. comm.).

We located specimens representing 362 species at the University of Arizona Herbarium, many of which were collected by Rondeau et al. (1996). Because of its close proximity to Tucson, and the 1904 establishment of the Carnegie Desert Botanical Laboratory on Tumamoc Hill, there has been considerable collecting in the Tucson Mountains. See Rondeau et al. (1996) for an excellent summary of collecting in the range.

\section{Methods}

We used three methods to survey for plants: (1) general botanizing surveys that involved opportunistically collecting species that we thought might be new to the district list or that we could not identify in the field, (2) modified Whittaker plots, and (3) line transects at all focal-point transects (FPT) to make quantitative comparisons among areas, provide data for longterm monitoring, and provide supporting data for the vertebrate inventories.

\section{General Botanizing}

\section{Methods}

Whenever possible we collected at least one representative specimen (with reproductive structures) for each plant species that we encountered. We also maintained a list of species observed but not collected. When we collected a specimen, we assigned it a collection number and recorded the flower color, associated dominant vegetation, date, collector name(s), and UTM coordinates. We pressed and processed the specimens on site. Specimens remained pressed for two to three weeks and were later frozen for 48 hours or more to prevent infestation by insects and pathogens. Mounted specimens were accessioned into the University of Arizona Herbarium. 
Effort

We collected specimens during 10 days of fieldwork from 12 April to 10 October 2001.

\section{Analysis}

We present a variety of summary statistics: total number of species found and number and percent of native and non-native species.

\section{Modified-Whittaker Plots}

\section{Methods}

We used modified-Whittaker plots to characterize the plant community at a single area associated with focal points. Each plot was 20 x $50 \mathrm{~m}$ (1000 $\mathrm{m}^{2}$ ) and contained 13 subplots of three different sizes (see Stohlgren et al. 1995a): 0.5 x 2 m (10 subplots), 2 × $5 \mathrm{~m}$ (2 subplots), and 5 × $20 \mathrm{~m}$ (1 subplot) (Fig. 3.1; Shmida 1984). We estimated the cover $\left(\mathrm{m}^{2}\right)$ of each plant species for the entire $1000 \mathrm{~m}^{2}$ plot. For all subplots we simply noted the presence of each species. For a more detailed explanation of the data collection method, see Shmida (1984). For safety reasons, we deviated from the methods outlined in Shmida (1984) by not surveying against the contours in steep areas.
Effort

We used modified-Whittaker plots at 5 focal points (Fig. 3.2). We used a single observer (Patty West) to estimate percent cover in the 20 x $50 \mathrm{~m}$ plot, but other observers occasionally assisted with noting presence of plants in subplots.

\section{Analysis}

In this report we indicate the presence of each species over the entire plot. We also note patterns of species richness among plots. We do not give as complete a summary of the data as for pointintercept transects because the latter method is more repeatable and less subjective. However, we have provided more complete summary data for modified-Whitaker plots to the park and the raw data will be available through the park and network.

\section{Point-intercept Transects}

\section{Methods}

We used the point-intercept method (Bonham 1989) to sample vegetation along 50-m transects located along each focal-point transect (Fig.

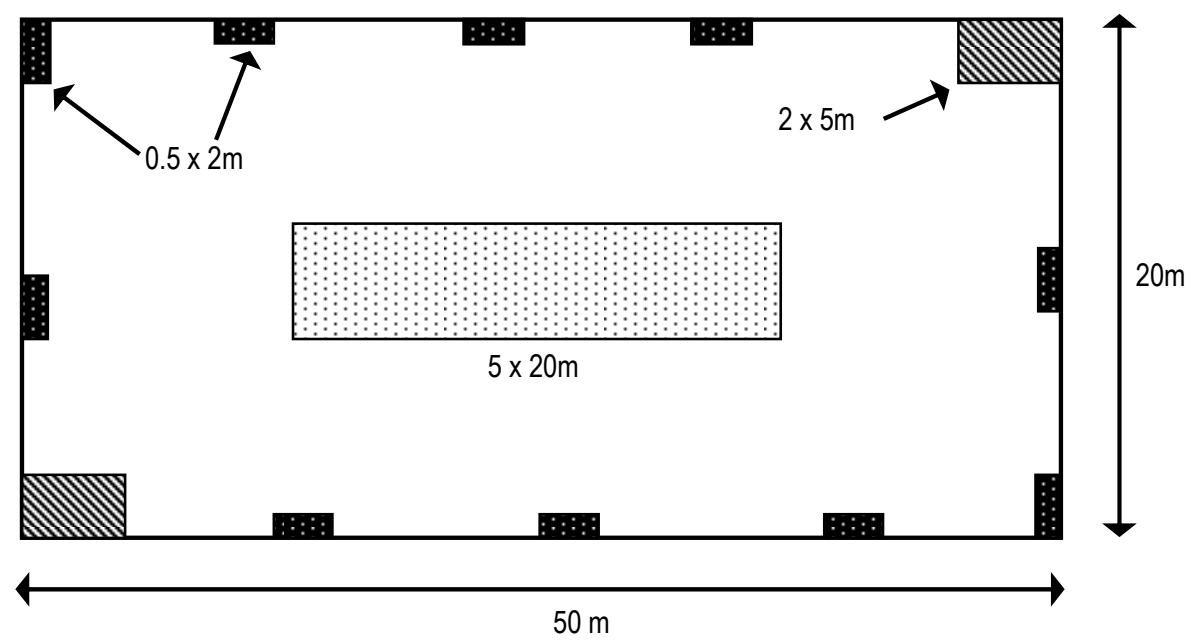

Figure 3.1. Layout of a modified-Whittaker plot, Saguaro NP, Tucson Mountain District, 2001. 

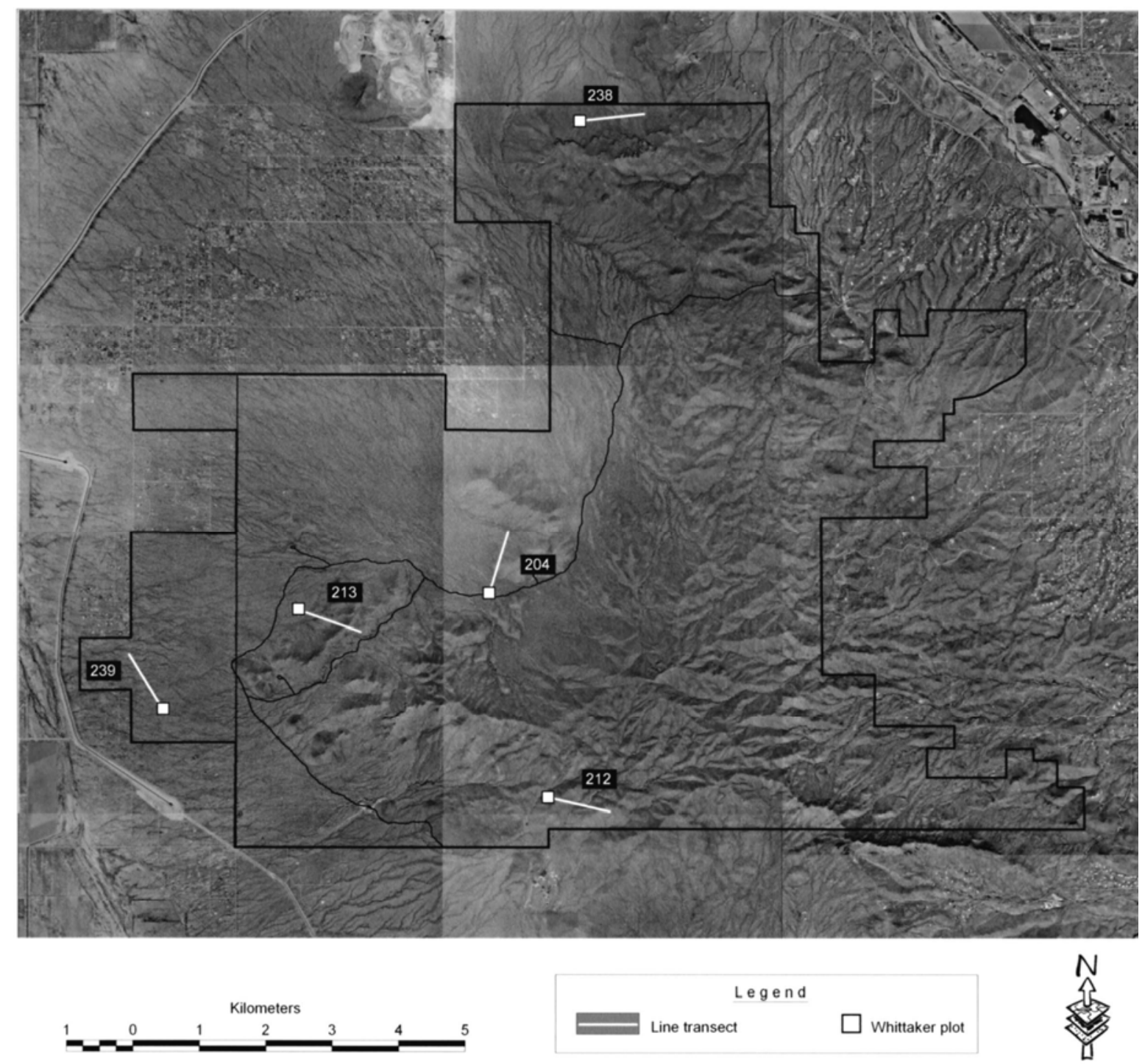

Figure 3.2. Locations of modified-Whittaker plots and point-intercept transects (line transect), Saguaro NP, Tucson Mountain District, 2001.

3.3). Point-intercept transects began at 25,125 , $425,525,825$ and $925 \mathrm{~m}$ from the beginning of the transect (i.e., focal point). For example, the first transect started at $25 \mathrm{~m}$ from the focal point and went to the $75-\mathrm{m}$ mark. We placed a $50-\mathrm{m}$ transect tape along the length of each transect section. In each of four height categories $(<0.5$ $\mathrm{m}, 0.5-2 \mathrm{~m}, 2-4 \mathrm{~m}$, and $>4 \mathrm{~m}$ ) we recorded the species of the first plant intercepted by a vertical line every $1 \mathrm{~m}$ along the transect line $(n=300$ points for most transects). We created the vertical line using a graduated pole and extrapolated contacts in a fourth height category $(>4 \mathrm{~m})$, which was rarely used. We classified groundcover as rock, bare ground, annual forb, grass, or woody debris.

\section{Effort}

We surveyed along each of the five random transects in the spring of 2001. We typically worked in groups of two or three field personnel, but sometimes had as many as five field 
personnel. We surveyed a total of 300 points along most transects, but we surveyed 1000 points along transect number 204 to test the feasibility of completing that many points.

\section{Analysis}

We calculated percent cover and percent composition for each species in each height category. Percent cover is the number of times a species was encountered along the entire length of the transect divided by effort (in most cases a maximum of 300 intercepts per height category) and multiplied by 100 . We calculated percent composition of each species in each height category as the number of times a species was encountered divided by the number of times all other species were encountered. If there was at least a single species encountered along a transect (in a height category), the total percent composition equaled 100 percent.

\section{Results}

We found 180 species during our inventory effort (Appendix A). Of these, we observed or collected at least 8 but as many as 28 new species for the district, including 7 non-native species. (In all we confirmed eight new species for the district, with 20 new species possible but unsubstantiated because of a lack of a specimen.) Many of the new species for the district $(n=$ 22) were from our point-intercept transects and modified-Whitaker plots, though most of these new species were observations and not based on voucher specimens. Based on a review of current and past research efforts, there have been a total of 512 species documented for the district, of which $9.1 \%(n=47)$ are non-native.

\section{General Botanizing and Specimen Collection}

We collected 89 specimens representing 74 species during general botanizing surveys (Appendix A). We collected specimens from 33 sites. We found two new species of plants for the district while conducting general botanizing surveys.

\section{Focal Points-General Patterns}

We found 176 species on point-intercept transects and modified-Whitaker plots. The mean number of species per site was $80( \pm 10.1$ [SD]). The range was 61 species (Point 213) to 116 species (Point 204). Of the 176 total species, we found 14 species at all five sites and 95 species at only a single site (Appendices G, H).

\section{Point-intercept Transects}

We found 83 species along all five point-intercept transects (Appendix G). The mean number of species at each transect was $31( \pm 7.5)$ and ranged from 14 to 57 (Fig. 3.4). Based on the presence of vegetation in each of the four height categories, there were some differences in vegetation structure among transects (Fig. 3.5). However, all transects exhibited the same pattern and were approximately what we expected: more vegetation close to the ground and progressively less vegetation in successive height categories. Percent ground cover by type was variable among transects (Fig. 3.5).

\section{Modified-Whitaker Plots}

We recorded 151 species on modified-Whitaker plots. The mean number of species per plot

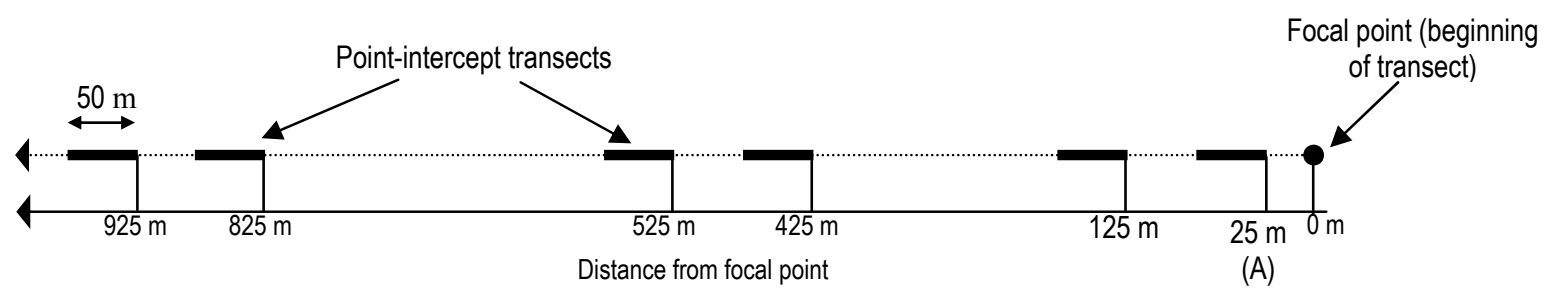

Figure 3.3. Typical layout of point-intercept transects, Saguaro NP, Tucson Mountain District, 2001. 


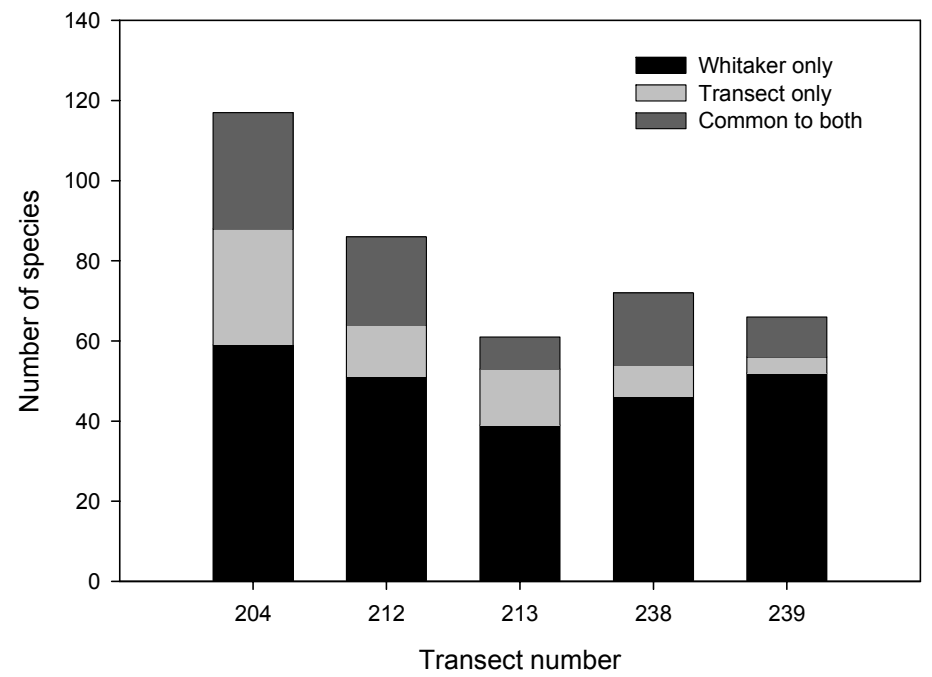

Figure 3.4. Number of plant species at the five random sites that were found by each of the two field methods used at focal points (point-intercept transect and modified-Whitaker plot), Saguaro NP, Tucson Mountain District, 2001.

was $65 \pm 7.3$ with the range from 45 to 89 . We observed 73 species on a single plot and 10 species on all five plots (Appendix G). Yellow palo verde (Parkinsonia microphylla) was found on all plots and was among the most common species.

\section{Modified-Whitaker vs. Point-intercept Transects}

Comparing both Modified-Whitaker plots and point-intercept transects, we found a mean of $43 \%( \pm 8.1)$ more species on Modified-Whitaker plots (Fig. 3.4). The percentage of the total number of species observed on both plots and transects for each site was only $18( \pm 3.1)$.

\section{Inventory Completeness}

The Tucson Mountains have a long tradition of botanical studies and collecting, starting with the establishment of the Carnegie Desert Botanical Laboratory (now called the Desert Laboratory) on the east edge of the Tucson Mountains in the beginning of the $20^{\text {th }}$ century. Though not a part of the park, the Desert Laboratory is one of the longest-running ecological research sites in the world and, as a result, has produced important research that has applicability to the district (e.g. Goldberg and Turner 1986). As a result of these and other research and collecting efforts, both outside and inside the district's boundaries, the Tucson Mountains have one of the best regional floras in the southwest. Yet we found evidence that the flora for the district is not complete. In particular, we found at least eight new species of plants (and as many as 28) for the district with minimal survey effort. We found most of these species away from trails (the typical location for collections) and associated with focal points. Therefore, it is difficult to determine if ours and other surveys have reached the goal of documenting $90 \%$.

\section{Discussion}

The Tucson Mountain District has a representative flora of the Tucson Mountains with some special elements. This dry mountain range contains very few sources of perennial water, but still maintains a surprisingly high plant species richness when compared to other areas with similar features (Rondeau et al. 1996). This richness is due to geographic location, elevation range, climate, and differences in soil types.

The Tucson Mountains have mild winters and infrequent frost, allowing many frostsensitive species to thrive (Rondeau et al. 1996). 

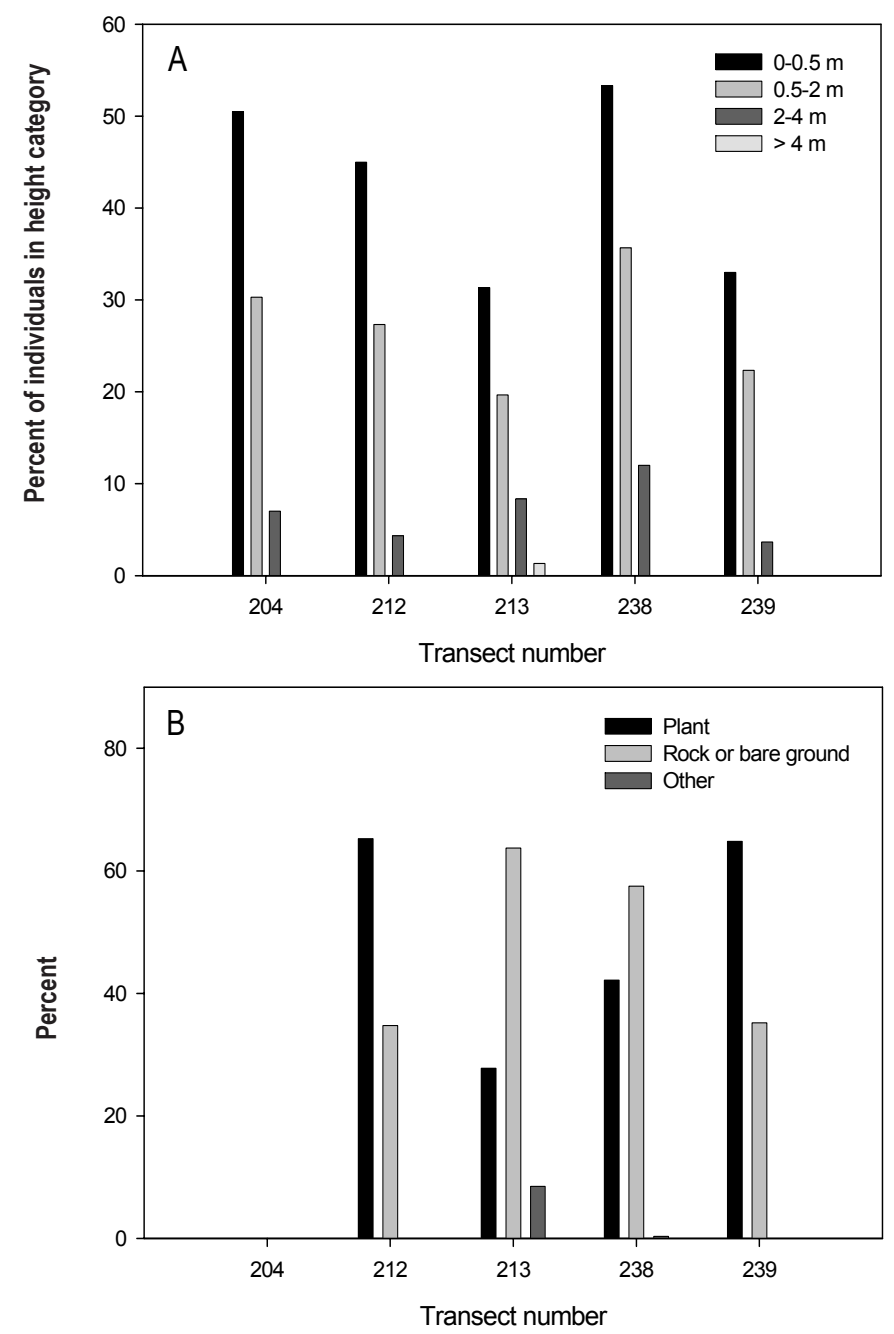

Figure 3.5. Vertical vegetation structure (A) and ground cover type (B), by transect, and from pointintercept transects, Saguaro NP, Tucson Mountain District, 2001. Zero values for ground cover for transect 204 are because we did not record ground cover at that transect.

These species, such as desert ironwood (Olneya tesota), are absent from the cooler Rincon Mountain District. The Tucson Mountains are also noted for being at a transition zone among a number of phytogeographic provinces, with floristic influences from the Mojave, Chihuahuan, and Great Basin deserts (McLaughlin and Bowers 1999).

The area on and around Wasson Peak is a notable site within the Tucson Mountains in general, and the district in particular. In this highest-elevation site of the range is a remnant patch of semi-desert grassland, which is responsible for many plants with distributions that are largely restricted to that community including black, hairy, and sideoats grama (Bouteloua spp.), plains lovegrass (Eragrostis intermedia), curly mesquite grass (Hilaria belangeri), and shin dagger (Agave schottii). Also on Wasson Peak are relicts of the chaparral community, species such as Arizona rosewood (Vauquelinia californica) and banana yucca (Yucca baccata). This area is very much at an ecotone and will likely be subsumed, in the coming decades, by the lower-elevation desert scrub vegetation community as a result of global 
climate change (Allen and Breshears 1998). Therefore, we anticipate a declining trend in the richness and abundance of grassland-associated species on and around Wasson Peak. Evidence of an increase in woody plant cover throughout the district (Funicelli et al. 2001) is further proof that encroachment of woody plants into the semidesert grasslands may be happening at a rapid pace.

The current distribution and abundance of non-native plant species appear to occur in $>2 \%$ of the land area of the district (Holden 2005; Funicelli et al. 2001), yet the number of nonnative species is increasing. The percentage of non-native species on long-term monitoring transects in the district increased from $2.5 \%$ in 2001 to $10.5 \%$ in 2005 (Holden 2005), though it is unclear if this increase is biologically significant or an artifact of sampling error or seasonal conditions. Despite the lack of clear evidence for recent trends in the distribution of non-native species, the general trend is for non-native species to remain at low abundance, then increase rapidly in the span of a few years because conditions are favorable. For example, the distribution and abundance of buffelgrass (Pennisetum ciliare) at the Desert Laboratory was restricted to a few isolated populations in the early 1990s but has since spread to large and contiguous patches throughout the area (Desert Laboratory, unpublished data).

Non-native plants are an important management concern because they alter ecosystem function and processes (Naeem et al. 1996, D'Antonio and Vitousek 1992), reduce abundance of native species, and cause potentially permanent changes in diversity and species composition (Bock et al. 1986, D'Antonio and Vitousek 1992). However, some species have stronger impacts on the ecological community than others. In assessing the potential threat posed by non-native species, it is important to consider the spatial extent of species, particularly those species that have been identified as "invasive" or of management concern. The most widespread and potentially disruptive non-native species in the district are the perennials buffelgrass and crimson fountain grass (Pennisetum setaceum) and the annuals red brome (Bromus rubens), redstem fillaree (Erodium cicutarium), barley (Hordeum murinum), and London rocket (Sisymbrium irio). The park has had a successful eradication program for targeted buffelgrass and fountain grass, in particular. This control program has been extremely successful at preventing widespread establishment of the many problem species. Given this success continued non-native plant control seems warranted. Another species that has not yet been recorded at the district is Sahara mustard (Brassica tournefortii). This species will likely become established on the west side of the monument in sandy substrates. In years of substantial winter rains it may dominate some sites.

\section{Additional Research and Monitoring Needed}

We suggest that additional surveys are needed to complete the species list for the district and that surveys should take place throughout the district, particularly off trails, especially to relocate and collect vouchers for the 20 species that were only observed in 2001. However, because of the increased number and distribution of non-native and invasive species in the region and concern for their impacts on natural areas, we suggest that surveys adjacent to development and along roads are most likely to ensure early detection of potentially invasive species. We also suggest that surveys should take place after good monsoon and winter rains to ensure collection of annuals.

Vegetation monitoring will be an important component of the I\&M program at Saguaro National Park and other park units in the Sonoran Desert Network (Mau-Crimmins et al. 2005), yet field methods and communities for vegetation monitoring have not yet been established. Our use of the modified-Whittaker plots and pointintercept transects provides data to inform that program. If the goal of the I\&M program is to monitor species richness or species composition, the modified-Whittaker plots may be more appropriate than the point-intercept method because of the higher species richness observed on the modified-Whittaker plots. However, observer bias in estimating species cover is the most important limitation of the modifiedWhittaker and similar methods for monitoring 
that parameter. In fact, variation in estimates of cover can be so great as to obscure trend detection for all but the most extreme changes (Kennedy and Addison 1987). Bias can be minimized by reducing the size of the quadrat (Elzinga et al. 2001). With regards to observer bias, the point-intercept (or similar line-intercept) transects produced less biased estimates of species cover because there was less opportunity for interpretation. Elzinga et al. (2001) provide an excellent overview of the major survey methods for monitoring plants, including a good discussion of observer bias issues.

If the goal of the monitoring program is to monitor changes in vegetation structure and gross vegetation characteristics (i.e., dominant plant species), then the point-intercept method is likely the more appropriate of the two methods. Because transects are spaced over a 1-km transect, estimates of cover are likely to be more representative of the study area than a single $20 \mathrm{~m}$ x $50 \mathrm{~m}$ plot. Further, accuracy of cover estimates from point-intercept transects and quantification of the vegetation heterogeneity can be assessed by using estimates from each 50-m transect section. Estimates of accuracy and heterogeneity for modified-Whitaker plots can also be accomplished by establishing multiple plots.

Powell et al. (2005) and others (I\&M program, unpublished data) used similar field methods as reported here and found many of the same patterns with regard to species richness and cover estimates. Their use of "modular" plots (where point-intercept transects were established within Braun-Blanquet plots [similar to modifiedWhitaker plots; Braun-Blanquet 1965]) will provide a more rigorous comparison of those two methods. Regardless of the field method chosen, the use of plot or transect-based field surveys should be incorporated with remote sensing data, which is becoming an important tool for monitoring vegetation change (Frohn 1998).

Great attention should be paid in the planning process for vegetation monitoring to ensure that enough plots are surveyed to adequately capture the diversity of vegetation structure and composition represented in the district. An evaluation of our results clearly indicates that five line-intercept transects and modified-Whittaker plots was insufficient to capture this spatial diversity (Figs. 3.4, 3.5) and is inadequate for a rigorous long-term monitoring program. We suggest that monitoring be particularly focused on areas on and around Wasson Peak where impacts of global climate change are likely to be greatest. In addition to establishing long-term monitoring sites for the I\&M program, we encourage the I\&M network to continue the work by Funicelli et al. (2001) by reading those saguaro plots at least every 10 years. 


\section{Chapter 4: Amphibians and Reptiles}

Aaron D. Flesch, Don E. Swann, and Brian F. Powell

\section{Previous Research}

The Tucson Mountains are well known to herpetologists, and several species lists exist for Saguaro National Park (e.g., Doll et al. 1986, Lowe and Holm 1991, Swann 2004), yet little information is available on distribution and abundance of amphibians and reptiles (hereafter "herpetofauna") in the Tucson Mountain District. Lowe and Holm (1991) ranked abundance (e.g. rare, uncommon, and common) of herpetofauna known to occur in Tucson Mountain District, but abundance categories were not based on field observations. Therefore, our effort represents the first attempt to quantify relative abundance and species richness of herpetofauna in the Tucson Mountain District and to provide a welldocumented species list.

\section{Methods}

We surveyed herpetofauna in 2001 and 2002 using four field methods. These included intensive plot-based surveys and more flexible extensive non-plot based surveys (Table 4.1), as well as pitfall trapping and road surveys. We used multiple methods to describe species richness and relative abundance because temporal and spatial variation in detectability is high, both within and among species. We selected intensive plot-based survey locations at random and constrained the surveys by time and area (Crump and Scott 1994). Extensive, non-plotbased survey locations were selected randomly and non-randomly and allowed variation in time and area to better detect rare and elusive species. For road surveys and extensive surveys we used both diurnal and nocturnal surveys to detect species with restricted activity periods (Ivanyi et al. 2000). Although techniques were designed to detect both amphibians and reptiles, fewer amphibians were detected as they have more restrictive activity periods.

\section{Sampling Designs}

We selected random and non-random survey areas. Randomization allowed inference to the entire district and facilitated comparisons among parks. Non-random selection allowed inclusion of areas, such as seeps or areas with unique geology that have relatively low landscape coverage but may have high species richness and abundance or include rare species not previously recorded. For road surveys, we constrained effort to paved and unpaved public roads within the district and along the district boundary.

\section{Intensive Surveys}

\section{Field Methods}

In 2001, we used plot-based visual encounter surveys constrained by time and area to standardize effort (Crump and Scott 1994). Surveys were confined to 1 -ha $(100 \times 100 \mathrm{~m})$ subplots and searched for one hour (see Chapter 1 for discussion of location of focal-point transects). If dangerous topography prevented a survey in one of these subplots, we surveyed an adjacent subplot.

Table 4.1. Characteristics of three major active survey methods used during surveys for herpetofauna, Saguaro NP, Tucson Mountain District, 2001 and 2002.

\begin{tabular}{|c|c|c|c|}
\hline \multirow[b]{2}{*}{ Characteristic } & \multicolumn{3}{|c|}{ Survey type } \\
\hline & Intensive, plot-based & Extensive - Random & Extensive - Non-random \\
\hline Random location & Yes & Partially & No \\
\hline Area constrained & Yes & No & No \\
\hline Configuration & Plot-based visual encounter & Non-plot-based visual encounter & Non-plot-based visual encounter \\
\hline Area (ha) & three 1-ha plots per transect & Variable & Variable \\
\hline Time constrained & Yes, 1 hour & No & No \\
\hline Time of day & Morning & Morning & Morning, afternoon, and evening \\
\hline Advantages & $\begin{array}{l}\text { Facilitates comparison with other areas, } \\
\text { scope of inference to entire district, more } \\
\text { complete richness and abundance data }\end{array}$ & $\begin{array}{l}\text { Larger scope of inference and potential } \\
\text { to detect less common species }\end{array}$ & $\begin{array}{l}\text { Maximum flexibility facilitating } \\
\text { detection of rare species with } \\
\text { restricted distributions }\end{array}$ \\
\hline Disadvantages & $\begin{array}{l}\text { Inefficient for developing complete } \\
\text { species list }\end{array}$ & $\begin{array}{l}\text { Inefficient for developing complete } \\
\text { species list }\end{array}$ & $\begin{array}{l}\text { Scope of inference applies only to } \\
\text { those areas surveyed }\end{array}$ \\
\hline
\end{tabular}


We surveyed three subplots per focal-point transect (FPT) in spring (11 - 18 April) and two subplots per FPT during the summer monsoon season (16 - 24 July). Only the two end subplots (1 and 10) were surveyed in summer because there was not sufficient time during peak activity periods to search all three. We selected survey times that coincided with periods of peak diurnal reptile activity because activity levels vary with temperature. On cooler spring days we began our surveys between 0740 and 1405 whereas on hotter, summer days we began between 0618 and 0851 . To account for within-day variation in detectability and to reduce observer bias, each subplot was surveyed twice per day by a different observer. We did not conduct nocturnal/ crepuscular intensive surveys.

We searched subplots visually and aurally and worked systematically across each subplot. We used a Garmin E-map GPS to ensure we stayed within subplot boundaries during surveys. We also looked under rocks and litter and used a mirror to illuminate cracks and crevices. For each animal detected, we recorded species, sex and age/size class (if known), and microhabitat (ground, vegetation, rock, edifice, burrow, or water). We marked subplot corners with rubbercapped stakes and recorded UTM coordinates with a Trimble GPS. We recorded temperature, wind speed $(\mathrm{km} / \mathrm{h})$, percent relative humidity, and percent cloud cover using hand-held Kestrel 3000 weather meters (Nielson-Kellerman Inc., Boothwyn, PA) before and after surveys. We also described vegetation and soils.
Effort

We completed 42 one-hour surveys at 15 subplots located along 5 FPTs (Table 4.2; Fig. 4.2). We surveyed all 5 FPTs in spring and only 3 FPTs in summer. In 2002 we discontinued intensive surveys, because of the relatively low number of species detected, and instead focused on other methods.

\section{$\underline{\text { Analysis }}$}

We calculated abundance by summing detections for each species for the two or three subplots per FPT. Because we surveyed subplots twice per day to account for within-day variation in detectability, we used the maximum number of individuals detected on either survey for each visit because it reflected abundance when detectability was highest (Rosen and Lowe 1995). We estimated relative abundance (no/ha/hr) for each species (and all species combined) by averaging the maximum number of individuals detected on repeated visits to each FPT, then averaging among all FPTs. We present estimates by season (spring vs. summer) and for both seasons combined.

\section{Extensive Surveys}

Non-plot-based extensive surveys facilitated sampling in areas with low landscape coverage where we expected high species richness, abundance, or species not previously detected. Typically, we selected areas for extensive surveys in canyons or riparian areas but also included ridgelines, cliffs, rock piles, bajadas, or other features. We based extensive surveys

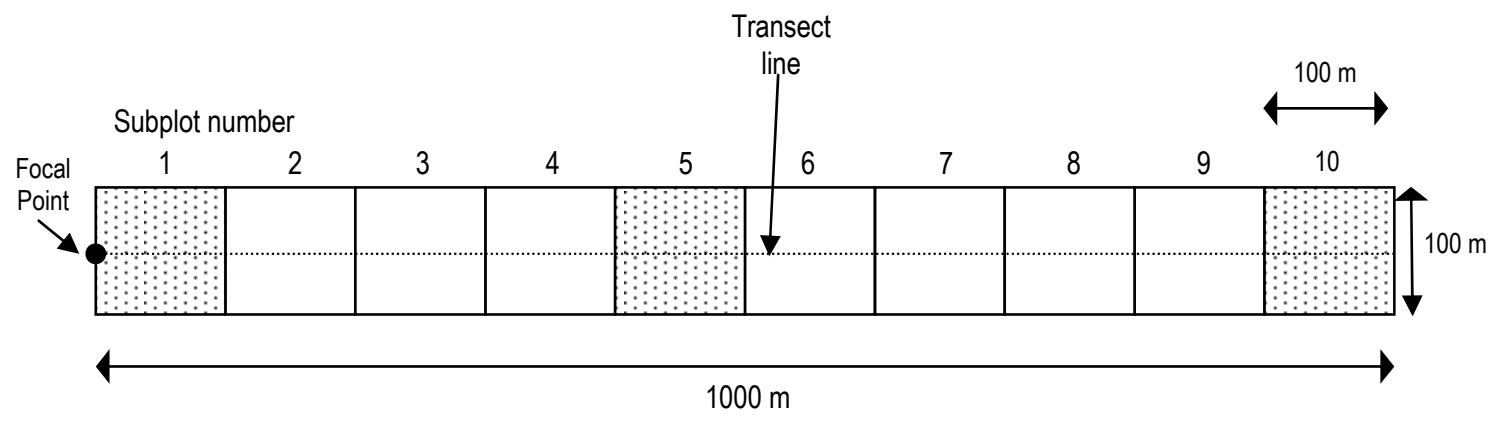

Figure 4.1. Typical plot layout of herpetofauna subplots along a 1-km focal-point transect $(n=5)$, Saguaro NP, Tucson Mountain District. We surveyed three $100 \times 100 \mathrm{~m}$ subplots (dotted boxes) in spring and two subplots (1 and 10) in summer. 

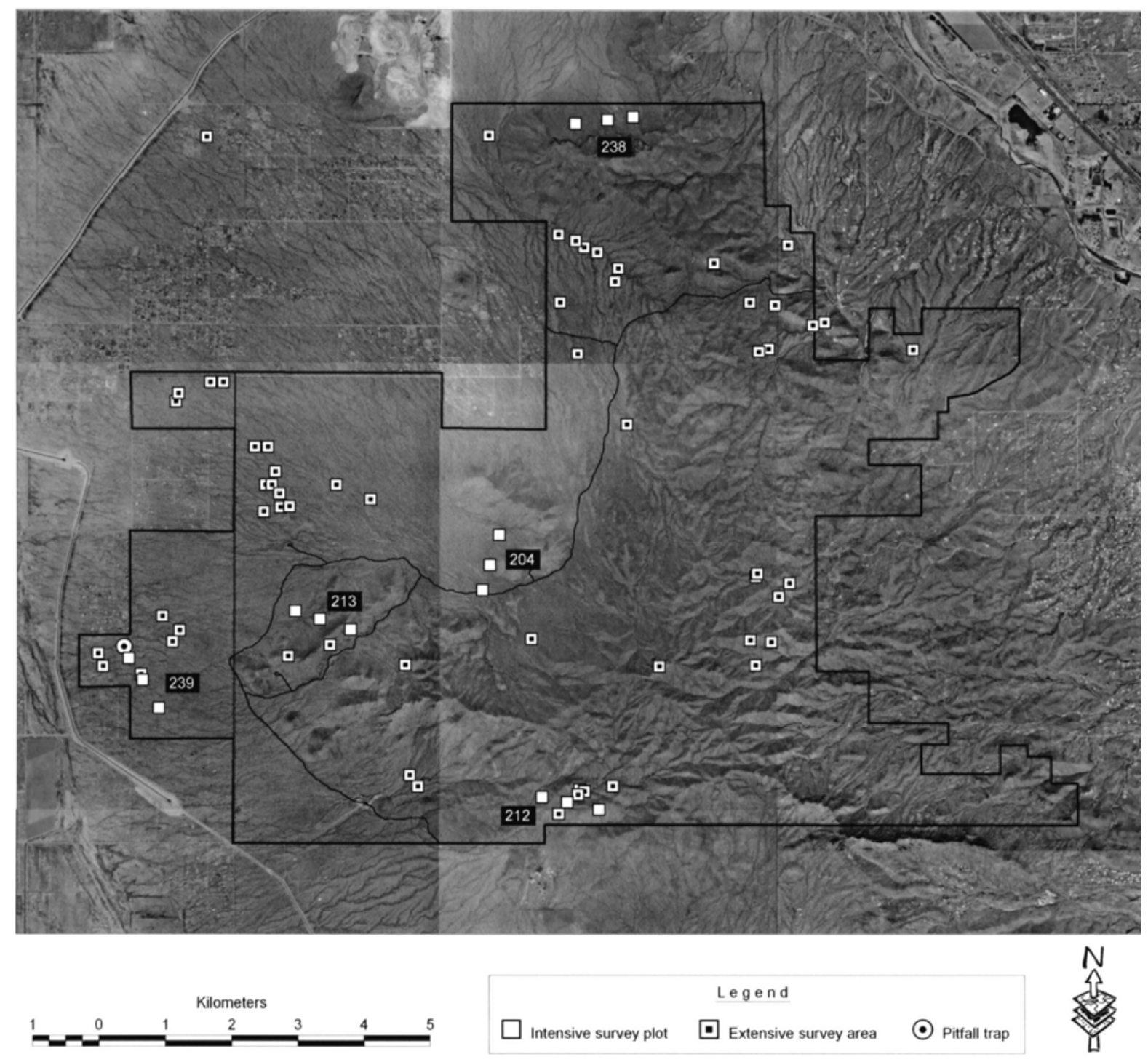

Figure 4.2. Study site locations for herpetofauna, Saguaro NP, Tucson Mountain District, 2001 and 2002.

on visual encounters (Crump and Scott 1994) and in contrast to intensive surveys, they were not constrained by area or time. We focused extensive surveys during mornings and also included evenings and nights when detectability of snakes and amphibians is highest (Ivanyi et al. 2000).

\section{Field Methods}

We located extensive surveys randomly and nonrandomly. Random surveys were located within approximately 1 to $2 \mathrm{~km}$ of FPTs used during intensive surveys and were conducted on one occasion. Non-random surveys were selected using topographic maps and prior knowledge and have been referred to as "special areas" in previous reports (Powell et al. 2002, 2003). We relied upon visual detection of herpetofauna during extensive surveys and often looked under objects and illuminated cracks to detect hidden individuals. We began morning surveys before $1000 \mathrm{hrs}$ and afternoon surveys after $1630 \mathrm{hrs}$ to avoid the hottest times of day. We also surveyed 
in late evenings and nights especially after the onset of the summer monsoon. We surveyed in spring (11-14 April) and summer (2 July - 25 September) of 2001 and 2002. Survey duration averaged $3.1 \pm 0.2( \pm \mathrm{SE})$ hrs and ranged from 1.3 to $6.2 \mathrm{hrs}$. One, two, or three observers searched areas simultaneously and recorded data separately. We recorded data using similar methods as intensive surveys and noted UTM coordinates and elevation at start and end points of each survey. We also classified survey areas by topographic formation (Lowe 1992) and considered two formations found in the Tucson Mountain District, bajada and rocky mountain, as well as the transition zone between them (within $\approx 1 \mathrm{~km}$ of either formation).

\section{Effort}

We surveyed 55 areas in 2001 and 2002, 90\% of which were surveyed in 2001 (Table 4.2). Total survey effort was $224.7 \mathrm{hrs}, 89 \%$ of which was in non-random extensive areas. Survey effort for extensive surveys was roughly 3 times greater than for other methods.

\section{$\underline{\text { Analysis }}$}

We calculated relative abundance as number of individuals detected for each species or all species combined per 10 hrs of effort. For surveys completed by $>1$ observer per survey area, we summed survey time and detection data for all surveyors when calculating effort and relative abundance for the area. To describe patterns of relative abundance and species richness across the district, we post-stratified survey areas by topographic formation and used one- or two-way ANOVA and linear contrasts to test for variation among formations. To describe patterns of relative abundance across elevation we used multiple linear regression. Because patterns of relative abundance often varied with temperature, relative humidity, and time of day we adjusted for their influence when necessary and report least square means which are adjusted for other important model parameters. To adjust for temporal variation in relative abundance we considered three time periods: day, late evening or night, or surveys that spanned portions of both periods. We considered $20 \mathrm{~min}$ before local sunset time as the cut-point between day and late evening surveys. Although we surveyed some areas multiple times within and between years, survey routes often varied. We therefore considered each survey as an independent sample despite some spatial overlap.

\section{Road Surveys}

Driving roads is a common method for surveying for herpetofauna and is recommended for augmenting species richness information in conjunction with other methods (Shaffer and Juterbock 1994). Road surveys involve driving slowly along a road, typically after sunset, and watching for animals.

\section{Field Methods}

We drove Golden Gate, Hohokam, Kinney, Picture Rocks, and Sandario roads and focused primarily on Kinney, Hohokam, and Golden Gate roads for safety reasons because of the high volume of traffic on the other roads. Because some bajada species, especially leaf-nosed snakes (genus Phyllorhynchus), would mostly likely be seen on Sandario Road, this may have caused us to miss them. We recorded weather information at beginning and end points of each survey as described in other methods. We recorded each

Table 4.2. Herpetofauna survey effort by method and year, Saguaro NP, Tucson Mountain District, 2001 and 2002.

\begin{tabular}{|c|c|c|c|c|c|}
\hline \multirow[b]{2}{*}{ Survey method } & \multirow[b]{2}{*}{ Elevation range $(\mathrm{m})$} & \multicolumn{2}{|c|}{2001} & \multicolumn{2}{|c|}{2002} \\
\hline & & $\begin{array}{l}\text { No. of samples } \\
\text { (subsamples) }^{\text {a }}\end{array}$ & $\begin{array}{c}\text { Survey } \\
\text { hours }\end{array}$ & $\begin{array}{l}\text { No. of samples } \\
\text { (subsamples) }^{\text {a }}\end{array}$ & $\begin{array}{c}\text { Survey } \\
\text { hours }\end{array}$ \\
\hline Intensive survey & $680-1108$ & $5(15)$ & 42.0 & 0 & 0.0 \\
\hline Extensive survey - random & $670-1067$ & $5(11)$ & 25.5 & 0 & 0.0 \\
\hline Extensive survey - non-random & $671-1219$ & 44 & 174.7 & 8 & 24.5 \\
\hline Road cruising & $670-768$ & 1 & 34.2 & 1 & 4.9 \\
\hline Pitfall array & 700 & 1 & 76.0 & 1 & 280.0 \\
\hline
\end{tabular}


individual detected by species and whether it was found alive or dead. We surveyed between 12 April and 24 August and began surveys during evenings or nights and ended surveys during nights.

\section{Effort}

We conducted 21 road surveys totaling $39.1 \mathrm{hrs}$ of effort (Table 4.2).

\section{Analysis}

Because survey routes varied in length and included a number of different segments surveyed in various orders, we pooled results from all routes and road segments. Mileage for each route was not recorded so we scaled estimates of relative abundance by time. We calculated relative abundance as the number of individuals detected for each species (or all species combined) per hour of survey effort.

\section{Pitfall Trapping}

Pitfall trapping is a live-trap, passive sampling technique useful for detecting species that are difficult to observe due to rarity, limited activity, or inconspicuous behavior (Corn 1994).

\section{Field Methods}

We constructed 1 pitfall trap array with three 19-L buckets spaced $8 \mathrm{~m}$ apart at angles of approximately 120 degrees from a central bucket. We dug shallow trenches connecting the central buckets to each outside bucket and placed drift fences (7.6-m long, 0.5-m tall aluminum-flashing supported by rebar) in each trench. We buried buckets so that their edges were at ground level and placed cover boards $(50 \times 50-\mathrm{cm}$ pieces of plywood) over them to keep animals cool during the day (Corn 1994).

To capture large snakes and other animals capable of escaping trap buckets, we placed one wire-mesh funnel-trap (tubes with inwardlydirected cones at each end) at midpoints along each side of drift fences ( $n=6$ traps) (Corn 1994). Animals entering funnels fell to the bottom of tubes and were unable to escape. We typically opened traps around sunset and checked and closed traps either around midnight or the following morning. We recorded species, sex, and age class (if known) for each animal captured.
Effort

The trap array was located on the bajada, west of Sandario Road and south of Manville Road (UTM 477739 m E, 3571005 m N) at 700-m elevation (Fig. 4.2). We operated traps for 9 nights totaling $76 \mathrm{hrs}$ from 2 July to 22 September 2001 and for 16 nights totaling 280 hrs from 2 August to 6 October 2002. Mean start time was $1809 \pm 0.34 \mathrm{hrs}$. We closed traps around midnight on eight occasions and after sunrise on 17 occasions.

\section{Analysis}

We report number of animals captured per $100 \mathrm{hrs}$ of trap array operation by species and taxonomic group.

\section{Vouchers}

We collected both voucher specimens and analog voucher photographs. All voucher specimens were prepared with formalin, tagged, placed in alcohol, and deposited in the University of Arizona's herpetology collection. Specimen tags included collector's name, species, date, and location of each specimen. To prioritize species for voucher collection, we first searched Saguaro National Park's specimens, university collections, and the NPS Inventory and Monitoring database NPSpecies to create a list of species that had already been collected in the district. Voucher specimens are important to verify species identifications and can be useful if species are reclassified and split into multiple species; all the specimens we collected at the district had been killed on park roads by cars.

We also obtained voucher photographs for each species we were able to capture. We obtained a close-up photograph of each animal "in hand" and, if possible, another photograph of the animal in natural surroundings. We recorded the same information for each voucher photo as above. In addition to documenting most species, these photos should be useful for interpretive purposes at the park.

\section{Incidental Observations}

We noted sightings of rare or important species by sex and age class (if known) and recorded time of observations and UTM coordinates for all detections. These incidental detections 
were often recorded before or after more formal surveys and were used in determining species richness and distribution. To complete the species list, we relied on incidental observations, voucher specimens, and voucher photographs collected by Saguaro National Park staff (Don Swann) during the inventory period.

\section{Species Identifications}

The most challenging reptiles to identify in the district are whiptail lizards (Cnemidophorus spp.). Many parthenogenetic (non-sexuallyreproducing) whiptail species may have arisen as hybrids from the same diploid, sexuallyreproducing parent species (Degenhardt et al. 1996) and several undescribed "parthenospecies" may exist in the desert southwest. Systematics of genus Cnemidophorus (Aspidoscelis according to some sources) remains challenging (Wright 1993) and some individuals we identified as western $(C$. tigris) or Sonoran spotted (C. sonorae) whiptails may be undescribed "species". On the district we saw "classic" Sonoran whiptails (adults with six longitudinal dorsal stripes, light spots in dark and occasionally light dorsal areas; dorsal stripes more yellow anteriorly; overall color was brown dorsally and unmarked white-cream ventrally; tail was more brownish-orange than bluish as seen in Gila spotted whiptails; Degenhardt et al. 1996, Phil Rosen pers. obs.) and a variation of this classic appearance (possibly older individuals) that superficially resembled Gila spotted whiptails (C. flagellicaudus). In this document we report all of these individuals as Sonoran whiptails.

\section{Results}

We detected 34 species of herpetofauna, four amphibian and 30 reptile species (Appendix B). Reptile species included one tortoise, 14 lizard, and 15 snake species. The greatest number of species (29) was detected during extensive surveys. Road cruising and pitfall trapping resulted in detection of one additional species (Couch's spadefoot toad) and incidental observations resulted in detection of four additional species (Great Plains toad, Sonoran whipsnake, western lyre snake, and Sonoran coral snake) not detected using other methods. All 14 species detected during intensive surveys were observed using other methods.

We detected 1,397 individuals during intensive, extensive, road cruising, pitfall trapping efforts, and 305 incidental detections during the study. Most individuals $(1,037)$ were detected during extensive surveys and the fewest (20) were detected during pitfall trapping (Table 4.3). The number of individuals detected per unit time was greatest for intensive surveys ( 6.3 individuals/ $\mathrm{hr}$ ) and roughly $27 \%$ lower for extensive surveys (4.6 individuals/hr). Efficiency was lowest for pitfall trapping with only 0.1 individuals detected per hour ( 0.8 individuals per trap night).

\section{Intensive Surveys}

We detected 264 animals and 14 species along five FPTs (Table 4.4). Lizards were most common and comprised $64.3 \%(n=9$ of 14$)$ of species and $96.2 \%(n=254$ of 264$)$ of individuals. We recorded no amphibians during intensive surveys. Relative abundance averaged $7.7 \pm 2.6$ individuals $/ \mathrm{ha} / \mathrm{hr}$ (range $=1.5-16.3$ ) and was similar between seasons.

Western whiptail, zebra-tailed lizard, and side-blotched lizard were most common ( $\geq 37$ detections), whereas Gila monster, coachwhip, western patch-nosed snake, and gopher snake were rarest (1 detection each). Western diamondbacked rattlesnake was the most common snake and was detected in both spring and summer. Relative abundance appeared to vary between seasons for some of the most common species (Table 4.4). Relative abundance of ornate tree lizards, for example, was 1.8 times greater in spring whereas relative abundance of sideblotched lizards was 5 times greater in summer.

Ornate tree lizards were the only species found on all FPTs whereas zebra-tailed lizard occurred on $80 \%$ ( $n=4$ of 5 ) of FPTs. All snake species were found on only one FPT each. Clark's spiny lizards occurred on three FPTs whereas desert spiny lizard occurred on two and occurrence of these species overlapped along one FPT. 
Table 4.3. Number of animals and species detected per hour by method and year, Saguaro NP, Tucson Mountain District, 2001 and 2002.

\begin{tabular}{|c|c|c|c|c|c|c|c|c|}
\hline \multirow[b]{2}{*}{ Survey type } & \multicolumn{4}{|c|}{2001} & \multicolumn{4}{|c|}{2002} \\
\hline & $\begin{array}{l}\text { Animals } \\
\text { detected }\end{array}$ & $\begin{array}{c}\text { Animals } \\
\text { per } \\
\text { hour }\end{array}$ & $\begin{array}{l}\text { Species } \\
\text { detected }\end{array}$ & $\begin{array}{c}\text { Species } \\
\text { per } \\
\text { hour } \\
\end{array}$ & $\begin{array}{l}\text { Animals } \\
\text { detected }\end{array}$ & $\begin{array}{c}\text { Animals } \\
\text { per } \\
\text { hour }\end{array}$ & $\begin{array}{l}\text { Species } \\
\text { detected }\end{array}$ & $\begin{array}{c}\text { Species } \\
\text { per } \\
\text { hour }\end{array}$ \\
\hline Intensive survey & 264 & 6.3 & 14 & 0.33 & & & & \\
\hline Extensive survey & 909 & 4.5 & 30 & 0.15 & 128 & 5.2 & 15 & 0.61 \\
\hline Road cruising & 72 & 2.1 & 15 & 0.44 & 4 & 0.8 & 3 & 0.61 \\
\hline Pitfall array & 4 & 0.1 & 4 & 0.05 & 16 & 0.1 & 8 & 0.03 \\
\hline
\end{tabular}

Table 4.4. Relative abundance (mean and SE; no./ha/hr) of herpetofauna detected during intensive surveys along random focal-point transects $(n=5)$ in spring (11-17 April) and summer (16-24 July) 2001, Saguaro NP, Tucson Mountain District.

\begin{tabular}{|c|c|c|c|c|c|c|}
\hline \multirow[b]{2}{*}{ Species } & \multicolumn{2}{|c|}{ Spring $(n=5)$} & \multicolumn{2}{|c|}{ Summer $(n=3)$} & \multicolumn{2}{|c|}{ All seasons } \\
\hline & mean & SE & mean & SE & mean & SE \\
\hline desert iguana & 0.07 & 0.07 & 0.33 & 0.33 & 0.20 & 0.20 \\
\hline zebra-tailed lizard & 1.87 & 0.65 & 2.17 & 1.17 & 2.20 & 0.79 \\
\hline desert spiny lizard & 0.13 & 0.08 & & & 0.13 & 0.08 \\
\hline Clark's spiny lizard & 0.33 & 0.15 & 0.17 & 0.17 & 0.37 & 0.15 \\
\hline side-blotched lizard & 0.60 & 0.31 & 3.00 & 1.89 & 1.93 & 1.23 \\
\hline ornate tree lizard & 1.20 & 0.13 & 0.67 & 0.17 & 1.20 & 0.13 \\
\hline regal horned lizard & & & 0.17 & 0.17 & 0.10 & 0.10 \\
\hline western whiptail & 2.27 & 1.94 & 3.33 & 1.58 & 3.00 & 1.85 \\
\hline Gila monster & 0.07 & 0.07 & & & 0.07 & 0.07 \\
\hline coachwhip & 0.07 & 0.07 & & & 0.07 & 0.07 \\
\hline western patch-nosed snake & 0.07 & 0.20 & & & 0.07 & 0.07 \\
\hline gopher snake & 0.07 & 0.07 & & & 0.07 & 0.07 \\
\hline western diamond-backed rattlesnake & 0.13 & 0.13 & 0.17 & 0.17 & 0.13 & 0.13 \\
\hline tiger rattlesnake & & & 0.17 & 0.17 & 0.10 & 0.10 \\
\hline all individuals & 6.67 & 2.59 & 8.67 & 3.81 & 7.67 & 2.62 \\
\hline
\end{tabular}

\section{Extensive Surveys}

We detected 1,037 animals of 29 species during 55 surveys in 2001 and 2002 (Table 4.5). We recorded only 2 amphibian species during extensive surveys, Sonoran desert toad and red-spotted toad. Reptile species included one tortoise, 14 lizards, and 12 snakes. Eighty seven percent $(n=909$ of 1,037$)$ of individuals detected were lizards. The most common species were the same as for intensive surveys: zebra-tailed lizard, western whiptail, and side-blotched lizard, and the western diamond-backed rattlesnake was the most common snake. Relative abundance of the zebra-tailed lizard was roughly three times higher than that of the next most common species (western whiptail). Blind snake, glossy snake, sidewinder, and Mohave rattlesnake were least abundant (1 detection each).

Most surveys were during the day (45.5\%) with fewer during the late evening or night (32.7\%) or spanning both periods $(21.8 \%)$. Relative abundance varied among time periods for lizards and snakes $\left(F_{2,52} \geq 3.61, P \leq 0.034\right.$, ANOVA) with more lizards detected during the day and more snakes detected during the night than during other periods. Further, species richness varied among time periods $\left(F_{2,52}=3.12\right.$, $P=0.053$, ANOVA) and averaged $36 \%$ greater for surveys during both day and night. We therefore adjusted for the influence of survey time in all comparisons.

Relative abundance of amphibians increased by $2.9 \pm 0.7$ individuals $/ 10 \mathrm{hrs}$ with 
each $10 \%$ increase in mean relative humidity after adjusting for survey time $\left(t_{51}=4.07, P=0.0001\right.$, test of slope from multiple linear regression) and amphibians were only detected during extensive surveys in July when mean relative humidity was 1.8 times greater than during other months $\left(t_{51}\right.$ $=3.34, P=0.0016$, linear contrast). There was no evidence that relative abundance of snakes varied with temperature or relative humidity $\left(t_{51}\right.$ $\leq 1.08, P \geq 0.29$ ) and some evidence that relative abundance of lizards increased with relative humidity (estimate $=1.1, \mathrm{SE}=0.6, t_{51}=1.71, P=$ 0.093), after adjusting for survey time.

Relative abundance averaged $61.0 \pm 8.8$ individuals $/ 10 \mathrm{hrs}$ (range $=0-415)$ and varied among topographic formations $\left(F_{4,46}=3.76, P\right.$ $=0.030,2$-way ANOVA). Relative abundance was more than two times higher on the bajada (least squared mean $\pm \mathrm{SE}=91.0 \pm 15.2$ ) than in the mountains $(40.4 \pm 14.2)$ or at the edge of the mountains $(41.1 \pm 13.9)\left(t_{50}=2.74, P=0.0085\right)$ and attributable mainly to increased relative abundance of lizards which was 2.8 times greater on the bajada. Relative abundance of snakes varied among topographic formations $\left(F_{4,46}=\right.$ $3.53, P=0.037,2$-way ANOVA) and was 3.7 times greater on the bajada $(7.7 \pm 1.5)$ than in the mountains $(2.2 \pm 1.4)$ and moderate at the edge (5.1 \pm 1.4$)$. Species richness was similar among topographic formations except for snakes, which averaged 2.5 times higher on the bajada $(1.7 \pm$ $0.2)$ than in the mountains $(0.6 \pm 0.2)\left(F_{4,46}=\right.$ $4.08, P=0.023,2$-way ANOVA).

Patterns of species occurrence and relative abundance often varied among topographic formations and across elevation. Relative abundance of desert iguana, Sonoran spotted and western whiptail, desert and Clark's spiny

Table 4.5. Relative abundance (mean $\pm \mathrm{SE}$; no./10 hrs) of amphibians and reptiles detected during extensive surveys ( $n=55$ ), by topographic formation, Saguaro NP, Tucson Mountain District, 2001 and 2002.

\begin{tabular}{|c|c|c|c|c|c|c|c|c|}
\hline \multirow[b]{2}{*}{ Species } & \multicolumn{2}{|c|}{ Bajada $(n=17)$} & \multicolumn{2}{|c|}{ Edge $(n=21)$} & \multicolumn{2}{|c|}{ Mountain $(n=17)$} & \multicolumn{2}{|c|}{ All surveys $(n=55)$} \\
\hline & Mean & $\mathrm{SE}$ & Mean & SE & Mean & $\mathrm{SE}$ & Mean & SE \\
\hline Sonoran desert toad & 0.08 & 0.08 & 0.34 & 0.34 & 0.06 & 0.06 & 0.17 & 0.13 \\
\hline red-spotted toad & 0.49 & 0.49 & 0.68 & 0.68 & 4.44 & 3.20 & 1.78 & 1.04 \\
\hline desert tortoise & & & 0.67 & 0.31 & 0.06 & 0.06 & 0.27 & 0.13 \\
\hline western banded gecko & 0.57 & 0.32 & 0.44 & 0.35 & 0.44 & 0.33 & 0.48 & 0.19 \\
\hline desert iguana & 0.80 & 0.39 & & & & & 0.25 & 0.13 \\
\hline Sonoran collared lizard & & & & & 0.51 & 0.40 & 0.16 & 0.13 \\
\hline long-nosed leopard lizard & 0.11 & 0.11 & & & & & 0.03 & 0.03 \\
\hline lesser earless lizard & 0.08 & 0.08 & 0.14 & 0.14 & 2.74 & 1.89 & 0.93 & 0.60 \\
\hline zebra-tailed lizard & 14.88 & 5.32 & 25.86 & 7.90 & 11.03 & 3.76 & 17.88 & 3.67 \\
\hline desert spiny lizard & 3.09 & 1.08 & 0.14 & 0.14 & 0.21 & 0.21 & 1.07 & 0.38 \\
\hline Clark's spiny lizard & 0.26 & 0.26 & 2.01 & 0.70 & 4.96 & 2.17 & 2.38 & 0.76 \\
\hline side-blotched lizard & 7.46 & 2.89 & 4.49 & 1.08 & 1.92 & 0.80 & 4.61 & 1.04 \\
\hline ornate tree lizard & 0.83 & 0.36 & 6.52 & 3.07 & 2.58 & 1.87 & 3.54 & 1.33 \\
\hline regal horned lizard & & & 0.44 & 0.25 & & & 0.17 & 0.10 \\
\hline Sonoran spotted whiptail & & & 0.19 & 0.19 & 1.48 & 0.67 & 0.53 & 0.23 \\
\hline western whiptail & 13.15 & 5.42 & 6.59 & 1.90 & 0.74 & 0.35 & 6.81 & 1.91 \\
\hline Gila monster & 0.61 & 0.33 & & & 0.55 & 0.49 & 0.36 & 0.18 \\
\hline western blind snake & 0.07 & 0.07 & & & & & 0.02 & 0.02 \\
\hline coachwhip & 0.22 & 0.13 & 0.54 & 0.25 & & & 0.28 & 0.11 \\
\hline western patch-nosed snake & & & 0.19 & 0.09 & & & 0.07 & 0.04 \\
\hline gopher snake & 0.21 & 0.14 & & & & & 0.06 & 0.05 \\
\hline glossy snake & 0.12 & 0.12 & & & & & 0.04 & 0.04 \\
\hline long-nosed snake & 0.95 & 0.44 & & & & & 0.29 & 0.15 \\
\hline night snake & 0.23 & 0.17 & & & & & 0.07 & 0.05 \\
\hline western diamond-backed rattlesnake & 2.28 & 0.72 & 1.53 & 0.72 & 1.00 & 0.43 & 1.60 & 0.38 \\
\hline sidewinder & 0.15 & 0.15 & & & & & 0.05 & 0.05 \\
\hline black-tailed rattlesnake & & & 0.10 & 0.10 & 0.12 & 0.12 & 0.08 & 0.05 \\
\hline tiger rattlesnake & & & 0.12 & 0.12 & 0.06 & 0.06 & 0.07 & 0.05 \\
\hline Mohave rattlesnake & 0.03 & 0.03 & & & & & 0.01 & 0.01 \\
\hline all individuals (no/10 hr) & 80.34 & 23.97 & 60.36 & 10.50 & 42.55 & 7.55 & 61.03 & 8.80 \\
\hline species richness & 22 & & 19 & & 17 & & 30 & \\
\hline
\end{tabular}


lizard, side-blotched lizard, and long-nosed snake varied among topographic formations ( $P$ $\leq 0.044$, ANOVA) (Table 4.5). Sonoran spotted whiptail and Clark's spiny lizard were most common in the mountains, and western whiptail and desert spiny lizard were most common on the bajada. Nine species were detected only on the bajada whereas one was detected only in the mountains. Relative abundance increased with elevation for four species (red-spotted toad, lesser earless lizard, Clark's spiny lizard, and Sonoran spotted whiptail) and decreased with elevation for another four species (desert iguana, desert spiny lizard, side-blotched lizard, and western whiptail) $(P \leq 0.049$, test of slope from simple linear regression).

When comparing areas selected at random $(n=11)$ to those selected non-randomly $(n=$ 44), species richness in non-random survey areas (least square mean $=4.9 \pm 0.3$ species) was 3.5 times greater than in random areas $\left(F_{3,51}=20.4\right.$, $P<0.0001)$ after adjusting for the influence of survey time. We detected 11 species in random areas, all of which were detected in nonrandom areas, and six of which were detected during intensive surveys. Relative abundance was over six times greater in nonrandom areas for all species groups combined $\left(F_{4,50}=9.11, P=0.004\right)$ after adjusting for the influence of survey time and relative humidity.

\section{Road Surveys}

We detected 76 animals representing 15 species. We recorded three amphibian species represented by 20 individuals $(26.3 \%$ of all individuals) while driving roads, proportionally more than for other survey methods (Table 4.6). Reptiles included seven lizard and five snake species; 44.7\% $(n=$ 34 of 76) of individuals were lizards and $28.9 \%$ ( $n=22$ of 76) were snakes, proportionally more snakes than for other survey methods. Relative abundance averaged $1.9 \pm 0.2$ individuals $/ \mathrm{hr}$ (range $=0.3-5.0$ ).

Relative abundance did not vary between seasons during road surveys $\left(t_{19}=0.067, P=\right.$ $0.95, t$-test), yet all amphibians were detected during summer. Western diamond-backed rattlesnake, zebra-tailed lizard, and red-spotted toad were the most common species detected
(14 detections each). Western patch-nosed snake, black-tailed rattlesnake, and side-blotched lizard were the least abundant species with one detection each.

\section{Pitfall Array}

We trapped 20 individuals of eight species during 25 nights of effort in 2001 and 2002. Species composition reflected that generally found on the bajada. Zebra-tailed lizard and desert spiny lizard were most common whereas Couch's spadefoot toad, western blind snake, and long-nosed snake were least common (Table 4.7). Pitfall trapping was the least efficient method in terms of number of species and total individuals detected per unit time, but because effort was mainly passive, comparisons with other methods are difficult.

\section{Incidental Observations}

We recorded 305 incidental observations of 28 species between 4 April 2001 and 1 October 2002 (Appendix B). Four species (Great Plains toad, Sonoran whipsnake, western lyre snake, and Sonoran coral snake) were only detected through this method, each by a single individual.

\section{Vouchers}

We collected eight voucher specimens in 2001 and 2002 and obtained records of nine other vouchers collected between 1968 and 2000 (Appendices $\mathrm{E}$ and F). All vouchers obtained in 2001 and 2002 were already dead when collected and are accessioned in the University of Arizona Herpetology Collection (UAZ). A voucher specimen was also located for the variable sandsnake (Chilomeniscus cinctus), a species not documented during this study. Sonoran mud turtle (Kinosternon sonoriense) was documented by a photograph at King's Canyon seep in 1997, but was not detected by us.

We obtained 51 voucher photos of 29 species during 2001 and 2002 (Appendix E). All voucher photos are stored digitally and in $35 \mathrm{~mm}$ color slide format in the I\&M office in Tucson.

\section{Inventory Completeness}

Based on extensive previous collecting in the Tucson Mountains, we believe that we detected most of the species that occur in the district. We 
Table 4.6. Relative abundance (no./hr) of amphibians and reptiles detected during road surveys in Saguaro NP, Tucson Mountain District, 2001 and 2002.

\begin{tabular}{|c|c|c|c|}
\hline Taxon & Species & Mean & SE \\
\hline \multirow[t]{3}{*}{ Amphibian } & Couch's spadefoot toad & 0.05 & 0.04 \\
\hline & Sonoran desert toad & 0.15 & 0.09 \\
\hline & red-spotted toad & 0.24 & 0.15 \\
\hline \multirow[t]{12}{*}{ Reptile } & western banded gecko & 0.10 & 0.08 \\
\hline & zebra-tailed lizard & 0.26 & 0.14 \\
\hline & desert spiny lizard & 0.04 & 0.03 \\
\hline & side-blotched lizard & 0.01 & 0.01 \\
\hline & regal horned lizard & 0.10 & 0.04 \\
\hline & western whiptail & 0.03 & 0.03 \\
\hline & Gila monster & 0.15 & 0.08 \\
\hline & western patch-nosed snake & 0.04 & 0.04 \\
\hline & long-nosed snake & 0.09 & 0.05 \\
\hline & western diamond-backed rattlesnake & 0.39 & 0.12 \\
\hline & black-tailed rattlesnake & 0.01 & 0.01 \\
\hline & tiger rattlesnake & 0.12 & 0.08 \\
\hline
\end{tabular}

Table 4.7. Relative abundance (no./100 hrs) of animals trapped in pitfall trap array $(n=1)$ in Saguaro NP, Tucson Mountain District, 2001 and 2002.

\begin{tabular}{|c|c|c|c|c|}
\hline Taxon & Species & $\begin{array}{c}\text { Total } \\
\text { captures }\end{array}$ & 2001 & 2002 \\
\hline Amphibian & Couch's spadefoot toad & 1 & & 0.4 \\
\hline \multirow[t]{7}{*}{ Reptile } & western banded gecko & 3 & 1.3 & \\
\hline & zebra-tailed lizard & 4 & 1.3 & 1.1 \\
\hline & desert spiny lizard & 4 & 1.3 & 1.1 \\
\hline & side-blotched lizard & 3 & 1.3 & 0.7 \\
\hline & western whiptail & 3 & & 1.1 \\
\hline & western blind snake & 1 & & 0.4 \\
\hline & long-nosed snake & 1 & & 0.4 \\
\hline
\end{tabular}

detected 34 of the 37 species ever documented for the Tucson Mountain District. Of the species not detected by us, one species, the common kingsnake, is certainly present because it has been observed several times on roadkill surveys by park staff during the past decade. This snake may have been missed because it is not very common, especially during drought years. We also missed the variable sandsnake, which is known to be relatively abundant in the district. This small, highly sedentary reptile is primarily found by road-driving in May and early June, and might have escaped detection in a sampling effort focused on April and July. This sampling regimen might also help to account for the absence of the saddled leaf-nosed snake in our observations (but see below). We do not believe that there is adequate aquatic habitat in the district to support a population of Sonoran mud turtle; the individual photo-documented in King's Canyon in 1997 could have escaped from the nearby Arizona-Sonora Desert Museum (ASDM) or may have been an emigrant from the Avra Valley where small populations may occur (Phil Rosen, pers. comm.).

Several species that we did not find have never been documented, but may occur in the district. Of these, existing data (Stebbins 2003) and personal observations by local herpetologists (e.g., Cecil Schwalbe) indicate that two species of snakes that spend most of their time underground,could occur at the district:

- western groundsnake (Sonora semiannulata) occurs in desert grassland and mesquite bottoms mid-valley, but is poorly known regionally and thus could possibly occur in the district; and 
- $\quad$ southwestern black-headed snake (Tantilla hobartsmithi) which occurs along the Santa Cruz River and may be found in major canyons in the district.

Two non-native species seem likely, but may depend on the presence of humans:

- spiny-tailed iguana (Ctenosaura hemilopha) have escaped from the grounds of the ASDM just outside the district, and some individuals may move into the district at King's Canyon, and

- Mediterranean gecko (Hemidactylus turcicus) occur in and near human-made structures and thus occur near the district. Mediterranean gecko likely occurs occasionally in the district already (Phil Rosen, pers. comm.).

The Tucson Mountains are fascinating in terms of reptile and amphibian biogeography, which makes it difficult to assess the completeness of our inventory. The mountains lie within the Sonoran Desert, but on the edge of several other major biogeographic provinces, including the Rocky Mountain region to the north and east; the Chihuahuan Desert to the east, and the Madrean "sky island" region to the south (Shreve 1951, Brown 1994). In addition, the Santa Cruz River, historically the site of a major desert riparian area, stream, cienega, agricultural landscapes, and grassland bottoms, runs along the east side of the Tucson Mountains. As a result, the district is near the edge of the geographic distribution of a large number of amphibians and reptile species. Some representatives of each of the four major regions are present, while others occur nearby but appear to not be present in the district. For example, sidewinder and desert iguana occur at the district, but not further east into the Tucson Basin.

A large number of other species have been found just west and/or north of the district, but were not documented in our inventory or in other previous surveys. These species may be found in the northwest part of the district, in or near creosotebush-dominated flats and lower bajadas (distribution information from Phil Rosen, pers. comm.):
- long-tailed brush lizard (Urosaurus graciosus), which still occurs at the north point of the Tucson Mountains near the Santa Cruz River;

- desert horned lizard (Phrynosoma platyrhinos), which occupied flats and lower bajada and may also be locally extirpated;

- western shovel-nosed snake (Chionactis occipitalis), which occupied the valleycenter desertscrub flats but may now be extirpated;

- $\quad$ spotted leaf-nosed snake (Phyllorhynchus decurtatus), which may have reached its eastern range limit near Sandario Road on lower to middle bajadas; and

- $\quad$ saddled leaf-nosed snake (Phyllorhynchus browni) was abundant on Silverbell Road at least through the late 1960's (Steve Goldberg, personal comm. to Phil Rosen, 1996), but was virtually absent along both sides of the river during the 1990s (Rosen, unpublished data).

Both leaf-nosed snakes could occur on the sandy-loam bajadas on the west side of the district. Leaf-nosed snakes are especially active at night (often late at night) from late May through July, and they could have been at a low abundance during the drought that was ongoing at the time of our surveys. The common chuckwalla (Sauromalus obesus), a large and conspicuous species associated with desert rockpiles (Rosen 2003), is found on the west side of Avra Valley and is not likely to be in the district.

The Tucson Mountain District also contains species typically associated with the Chihuahuan rather than the Sonoran Desert, including lesser earless lizard, but the district does not have others, including:

- greater earless lizard (Cophosaurus texanus), which is common only a few miles away in the desert grassland environs of the Tortolita and Santa Catalina Mountains.

Similarly, species present at lower elevations in the Madrean "sky islands" occur 
at the district, including the Clark's spiny lizard and the Sonoran whipsnake, both of which are associated with rocky slopes in the Arizona Uplands. However, several species not found in the district include:

- Madrean alligator lizard (Elgaria kingii), which occur at low elevations of Rincon Mountain District of Saguaro NP,

- $\quad$ ring-necked snake (Diadophis punctatus), mostly a temperate-zone species associated with forest and grassland that occurs in the Tortolita, Rincon, and Catalina mountains; and

- western box turtle (Terrapene ornata), a grassland species that had riparian populations in the Sonoran Desert along Rillito and Sabino creeks and the Santa Cruz River, including within a few $\mathrm{km}$ of the district boundary (Don Swann, pers. $o b s$.).

All these species are usually associated with grassland, woodland, and forest, and were known or likely to have been present on the Santa Cruz River in its wetland and riparian areas prior to the river's degradation during the $20^{\text {th }}$ century. When these species occurred along the river, occasional individuals may have entered the district, but these species probably would not have had viable populations within its boundaries.
A large number of species of reptiles and amphibians found in the Rincon Mountain District have not been documented in the TMD. Most of these are unlikely to occur because they are outside of their geographical or elevational range limits. Also, a number do not occur because suitable aquatic habitat is lacking. Historically, riparian species such as the lowland leopard frog (Rana yavapaiensis), Sonoran green toad (Bufo retiformis), Woodhouse's toad (Bufo woodhousii), Great Plains narrowmouthed toad (Gastrophryne olivacea), Mexican spadefoot (Spea multiplicata), Sonoran mud turtle (Kinosternon sonoriense), Mexican garter snake (Thamnophis eques), checkered garter snake (T. marcianus), black-necked garter snake (T. cyrtopsis), canyon spotted whiptail (Cnemidophorus burti) and the southern prairie lizard (Sceloporus undulatus consobrinus) occurred along the Santa Cruz River near the district (Rosen and Mauz 2001). A few of these species still occur and could be rare or occasional in the district, such as the narrow-mouthed or Mexican spadefoot toads, both of which could appear on the middle bajada in the Avra Valley area of the district. There is a single museum record of the canyon treefrog (Hyla arenicolor) from the Santa Cruz River east of the district, and this species could be present in the district, even though the river is very poor habitat for this

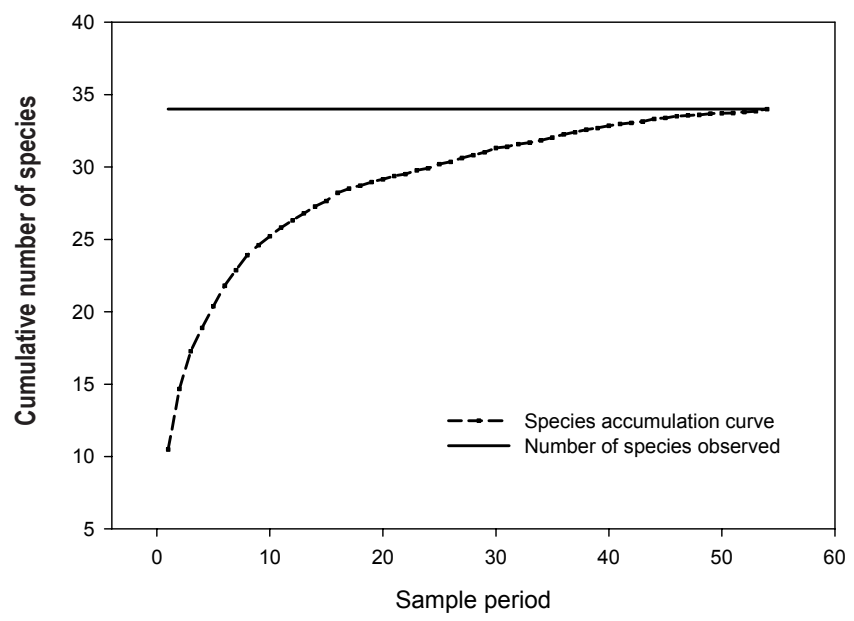

Figure 4.3. Species accumulation curve for herpetofauna surveys, all methods combined, Saguaro NP, Tucson Mountain District, 2001 and 2002. Each sampling period represents batches of 33 individuals, the mean number of individuals observed in an 8-hour field day. 
frog, and the district probably has at best limited marginal habitat. The non-native American bullfrog (Rana catesbeiana) and checkered garter snake are currently in the Santa Cruz River, and migrants of both could reach the district occasionally, though they would not find suitable habitat there.

A look at the species accumulation curves shows they are nearly asymptotic for all survey methods (Fig. 4.3). When selection of sampling periods was not randomized, however, no new species were detected during intensive surveys in the last $25 \%$ of sampling, whereas for extensive surveys, species richness increased by $16.7 \%$ ( 5 species) during the last $25 \%$ of sampling (Fig. 4.4).

\section{Discussion}

\section{Abundance and distribution}

The Tucson Mountain District of Saguaro National Park has a relatively well-studied herpetofauna compared to other areas, due mainly to its location in close proximity of Tucson. However, our study is the first to quantify relative abundance and distribution of amphibians and reptiles and to evaluate patterns of these parameters in space and time. Further, this inventory represents the first comprehensive effort to document species presence throughout the district and is a baseline for evaluating future changes in the herpetological community there.

Many of the patterns that we saw in distribution and abundance of herpetofauna confirm patterns observed in previous studies. The far greater number of diurnal lizards detected on both intensive and extensive surveys compared to snakes and amphibians is typical of species inventories in the southwestern United States (e.g., Turner et al. 2003, Swann 1999, Swann et al. 2000, Swann and Schwalbe 2001). Most snakes are nocturnal and spend a great deal of time underground, while toads are active almost exclusively at night during the summer rainy season, which was clearly evidenced by the large increase in the number of toads we detected with rising humidity. Western whiptails and zebra-tailed lizards, the most frequently encountered species on our surveys, are very common in desert environments in the Tucson area. The major shifts in abundance of two other common lizards, side-blotched and tree lizards, is also typical, with tree lizards more typically active in spring, and side-blotched lizards more active in late summer (Goode et al. 2004).

With some exceptions, we found that abundance and species richness of both lizards and snakes was higher on the bajada than in the

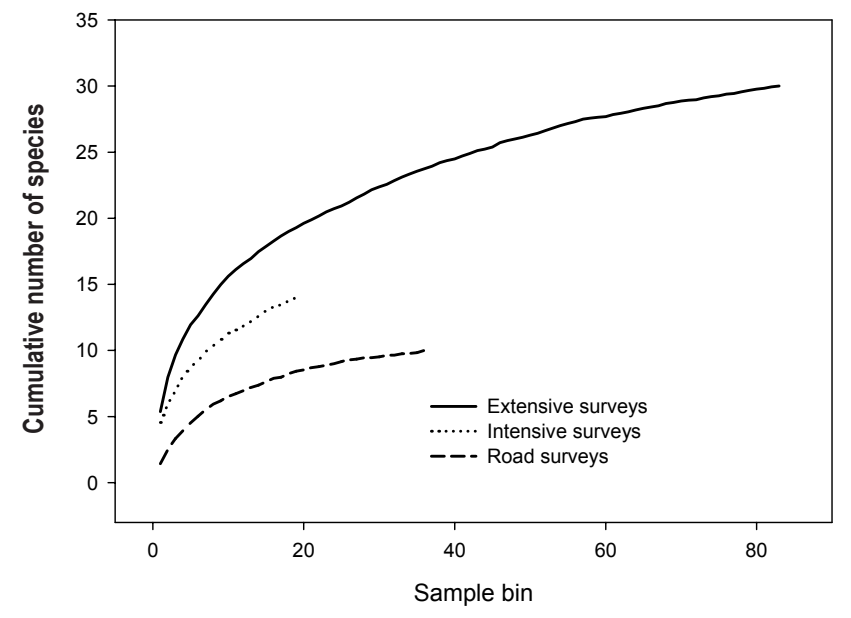

Figure 4.4. Species accumulation curve for herpetofauna surveys, by survey type, Saguaro NP, Tucson Mountain District, 2001 and 2002. Each sampling bin for extensive and intensive surveys represents batches of 11 individuals, and the sampling bin for road transects represents two individuals. 
mountains or the transition zone between them (Table 4.5). This relationship has been observed by herpetologists in the field but has not been well documented, and the reasons are not well understood. It seems possible that loose desert soils are better suited for digging and therefore allow for creation of underground structure, primarily by mammals, which provides protection for both reptiles and their prey. It is also possible that sandy desert soils support a greater density of plant foods and therefore a greater abundance of prey.

\section{Study design}

Our major goal for the herpetological inventory was to meet the multiple requirements of using a study design that was repeatable and allowed inference to the whole district, while also detecting the maximum number of species and being efficient in terms of field effort. In general we achieved these goals, but clearly some methods were more effective than others. Extensive surveys detected more species (30) than other methods, in part because more time was spent using this method and areas were surveyed in both day and night. However, this method did not detect as many individuals per unit effort as other methods and failed to detect six species known to occur in the district. In contrast, intensive surveys detected only 14 species but resulted in the greatest number of individuals observed per unit effort.

It is probable that differences in both abundance and richness results for the two methods are due to intensive surveys being conducted during the day, whereas many extensive surveys were conducted in the late afternoon and at night. Thus, intensive surveys focused on lizards, which are abundant and diurnal, while extensive surveys focused on both lizards and snakes, which tend to be more nocturnal and less abundant. In addition, intensive surveys were conducted in areas that were randomly located (and only very steep areas were excluded), and extensive surveys covered all areas of the district and were not randomly selected. For future surveys, an alternative design might be to combine the best of both intensive and extensive surveys; to establish both day and night sampling periods, and to establish plots based on a stratified design that either uses larger blocks (as in extensive surveys) or includes as strata features that are specific for herpetofauna, such as washes with high concentrations of caliche caves, wet areas and seeps, and low-lying areas that flood during summer rains.

For both pitfall trapping and road surveys, we would have detected more species with greater survey effort. However, pitfall trapping is probably not a good method for most of the district due to extremely hard soils and significant archaeological resources, which makes building trap arrays prohibitive. In addition, high daytime temperatures limit the number of traps that can be maintained. Road surveys can be extremely effective in detecting amphibians, but any method for sampling amphibians in the Sonoran Desert relies critically on timing: being present during summer evenings when rain is falling. Because summer rains are rare and unpredictable, adequate sampling for amphibians is nearly always difficult to achieve, especially for inventories such as ours that are of short duration. Because of this, it is important that park staff go out during rain events, because there is potential for detecting species that may occur in the district but are very rare. Road surveys also remain one of the most effective methods for detecting rare snakes and for collecting voucher specimens from road kill.

\section{Management Issues}

Our survey did not detect any species that were federally threatened or endangered. The Sonoran Desert population of the desert tortoise is currently being petitioned for federal listing, and the park has both a past inventory (Wirt and Robichaux 2001) and current monitoring plans for this species. The Tucson shovel-nosed snake, a candidate for federal listing, was not encountered during our inventory but may occur in the district.

In general, we suspect that the district has a relatively healthy herpetofauna. A possible exception is loss of valley-bottom species on the west side of the district that were never documented, and the unexplained absence of the saddled leaf-nosed snake and its early decline 
along the Santa Cruz River. There is little evidence that the district had greater surface water historically, and so aquatic species were probably never established. Similarly, there is little evidence that exotic species (reptiles, amphibians, mammals, or birds) are having an impact on reptiles and amphibians. If spinytailed iguanas and Mediterranean geckos were capable of establishing themselves in the district they probably would have already done so.

Currently, the greatest threats to herpetofauna include illegal collecting, mortality due to vehicles (roadkill) in bajada areas of high species richness, urban threats such as introduced diseases, and potential loss of species due to loss of habitat outside the district. Reptile poaching clearly occurs in the district, and law enforcement rangers are working closely with other agencies to combat this problem (Robert Stinson, Tucson Mountain District Ranger, pers. comm.). Roadkill is a well-documented issue; park staff estimate that literally thousands of reptiles and amphibians are killed in the district by cars each year (Kline and Swann 1998). Exotic diseases, such as upper respiratory tract disease may affect desert tortoises (Jones et al. 2005), and monitoring their health, here as well as throughout the species' range, remains important. Each of these issues has the potential to impact rare species such as sidewinders and long-lived species like desert tortoises and could reduce species richness over time.

Habitat loss and fragmentation outside the district are probably the major problems for species that occur in the district, but are at the edge of their range. The Central Arizona Project canal and major roads such as Sandario and Picture Rocks Roads are major barriers for movement of individuals between the district and other areas. If species are lost from the district in the next few decades, we predict that it will be species on the west side of the Tucson Mountains such as sidewinders and desert iguanas. It seems possible that, for the same reason, a few species that occurred in the past have already been lost. In a presentation to the Symposium on Research in Saguaro National Monument in 1991, the eminent herpetologist Charles H. Lowe bemoaned the development of Avra Valley and the fact that it was not protected by the National Park Service:

"Saguaro National Monument (SNM) could have included a representative portion of the historically and biologically significant Avra Valley within its boundaries with relative ease 50 60 years ago, perhaps even $30-40$ years ago. The then essentially pristine and little known area of Avra Valley that lies directly below the western boundary fence of SNM has since become variously occupied, and is now largely destroyed...But such thinking today is with the clarity of hindsight in a much more knowledgeable world. The problem in the early 1930s was ecological. Ecology was then a young and little-known science, and a fully coherent concept of the ecosystem much less the Sonoran Desert, was not at hand. The problem later in the 1960 s was political; it was too late." 


\section{Chapter 5: Birds}

Brian F. Powell

\section{Previous Research}

Prior to our work, there had been no comprehensive and well-documented bird inventory for the Tucson Mountain District of Saguaro National Park. Monson and Smith (1985) compiled a checklist, but there is no documentation for the list, though it was probably based on limited observations in the district. The list includes abundance categories and this information was likely based on Gale Monson's extensive knowledge of the distribution and relative abundance of birds in similar areas in the region. Yensen (1973) studied bird communities at four sites on the west side of the Tucson Mountains. The Arizona Game and Fish Department surveyed for breeding birds in one Breeding Bird Atlas block (Avra Valley) on the west side of the district (Short 1996). Those results are reported in Corman and WiseGuervais (2005). There was a Breeding Bird Survey route approximately $25 \mathrm{~km}$ northwest of the district in the Avra Valley which was surveyed from 1992 to 2002 (Sauer et al. 2005). The Tucson Bird Count has conducted counts along the eastern edge of the district (TBC 2005). Mannan and Bibles (1989) studied the impact of non-native species on native cavity-nesting species. Single species studies have included the purple martin (Stutchbury 1991) and elf owl (Bob Steidl, unpubl. data). Park personnel survey periodically for the cactus ferruginous pygmy-owl and park staff file annual reports on monitoring and relevant management activities related to this species to the U.S. Fish and Wildlife Service (Saguaro NP, unpubl. reports).

\section{Methods}

We surveyed for birds at the Tucson Mountain District from 2001 to 2002 using three field methods: variable circular-plot (VCP) counts for diurnal breeding birds, nocturnal surveys for owls, and incidental observations for all birds. We concentrated our survey effort during the breeding season because bird distribution is relatively uniform in that season due to territoriality among most landbird species (Bibby et al. 2002), and this uniformity increased our precision in estimating relative abundance and also enabled us to document breeding activity. Our survey period included peak spring migration times for most species, which added many migratory species to our list.

\section{Spatial Sampling Designs}

We established random study sites as described in Chapter 1. We established the locations of all other surveys (i.e., reconnaissance VCP and nocturnal surveys) subjectively in areas that we believed would have the highest species richness or as a matter of convenience (Fig. 5.1).

\section{Variable Circular-plot Surveys}

\section{Field Methods}

We used the variable circular-plot (VCP) method to survey for diurnally active birds during the breeding season (Reynolds et al. 1980, Buckland et al. 2001). Conceptually, these surveys are similar to traditional "point counts" (Ralph et. al 1995) during which an observer spends a standardized length of time at one location (i.e., station) and records all birds seen or heard and the distance to each bird or group of birds.

Each station within a transect was located a minimum of $250 \mathrm{~m}$ apart to maintain independence among observations. On each successive visit to a transect (except reconnaissance transects) we alternated the order in which we surveyed stations to minimize bias by observer, time of day, and direction of travel. We did not survey when wind exceeded $15 \mathrm{~km} / \mathrm{h}$ or when precipitation exceeded an intermittent drizzle. We attempted to begin surveys approximately 30 minutes before sunrise and conclude surveys no later than three hours after sunrise.

We used two variations of the standard VCP surveys. These methods differed only in number of visits (repeat-visit transects that were either random or non-random transects and reconnaissance VCP surveys that were all random) (Table 5.1). We revisited most survey stations multiple times to get better estimates of 

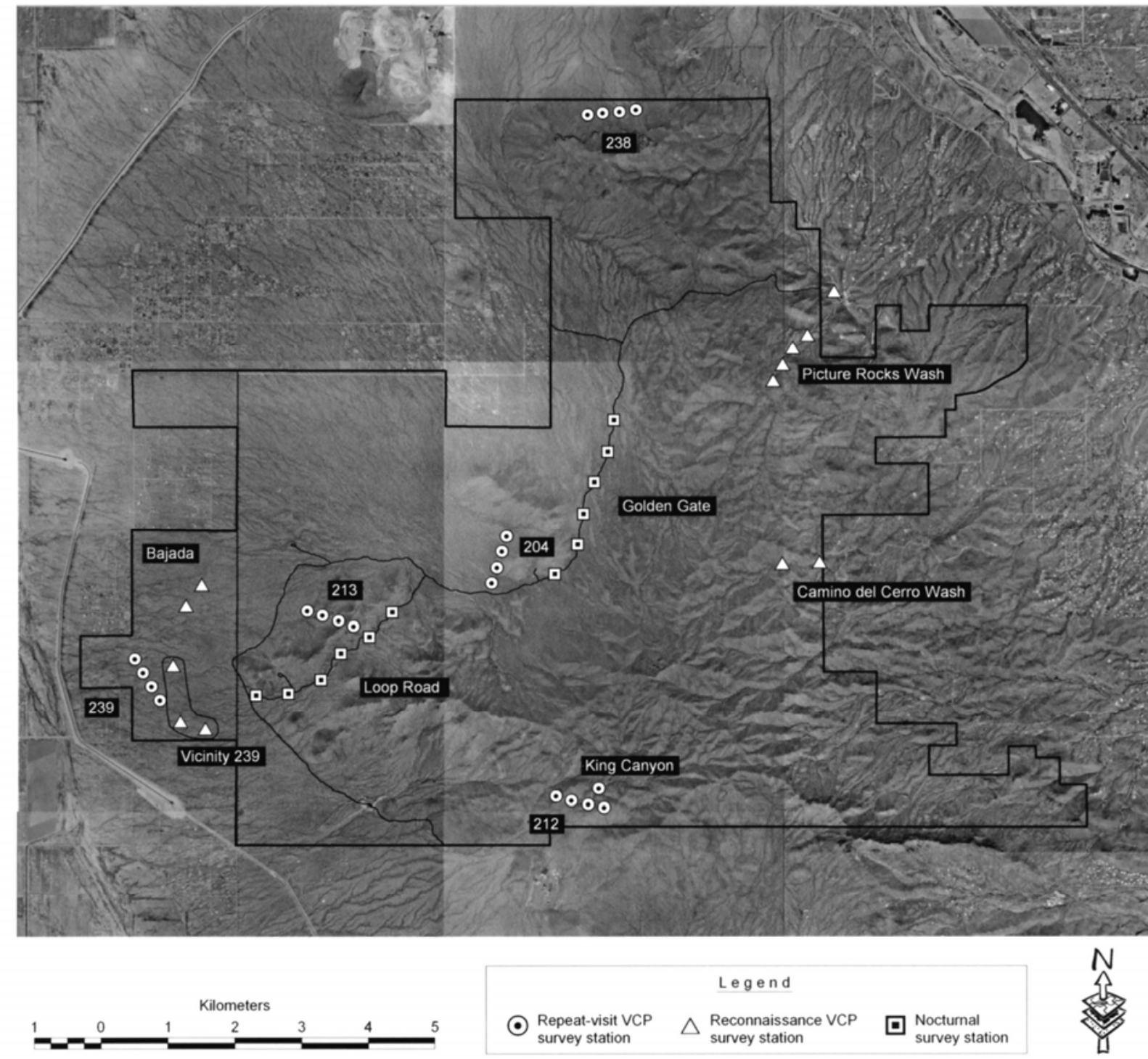

\section{Legend}

Repeat-visit VCP
survey station $\triangle \begin{aligned} & \text { Reconnaissance VCP } \\ & \text { survey station }\end{aligned}$

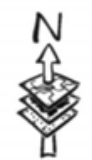

Figure 5.1. Location of VCP and nocturnal survey stations for birds, Saguaro NP, Tucson Mountain District, 2001 and 2002.

the species present at each site and their relative abundances. Although most of the survey effort was focused on repeat-visit transects, this left large areas of the district unsurveyed. Therefore, to get better spatial coverage of the district we established four reconnaissance transects (Fig. 5.1).

We recorded a number of environmental variables at the beginning of each transect: wind speed (Beaufort scale), presence and severity of rain (qualitative assessment), air temperature $\left({ }^{\circ} \mathrm{F}\right)$, relative humidity $(\%)$, and cloud cover
(\%). After arriving at a station, we waited one minute before beginning the count to allow birds to resume their normal activities. We identified to species all birds seen or heard during an eightminute "active" period (for reconnaissance VCP surveys we spent five minutes at each station to cover as much area as possible). For each detection we recorded the distance (in meters) the bird was from the observer (measured with laser range finder when possible), time of detection (measured in one-minute intervals beginning at the start of the active period), and the sex 
Table 5.1. Summary of bird survey effort by UA inventory personnel, Saguaro NP, Tucson Mountain District, 2001 and 2002. Sample size was used in calculating relative abundance for each transect and each year.

\begin{tabular}{|c|c|c|c|c|c|c|}
\hline \multirow[b]{3}{*}{ Survey type } & \multirow[b]{3}{*}{ Transect name } & \multirow[b]{3}{*}{$\begin{array}{c}\text { Number of } \\
\text { stations in transect }\end{array}$} & \multicolumn{4}{|c|}{ Years } \\
\hline & & & \multicolumn{2}{|c|}{2001} & \multicolumn{2}{|c|}{2002} \\
\hline & & & Visits & $n$ & Visits & $n$ \\
\hline \multirow[t]{5}{*}{ Repeat-visit VCP } & 204 & 4 & 5 & 20 & & \\
\hline & 212 & $5^{\mathrm{a}}$ & 4 & 20 & & \\
\hline & 213 & 4 & 4 & 16 & & \\
\hline & 238 & 4 & 4 & 16 & & \\
\hline & 239 & 4 & 4 & 16 & & \\
\hline \multirow[t]{4}{*}{ Reconnaissance VCP } & Bajada & 2 & & & 1 & 2 \\
\hline & Camino De Cerro Wash & 3 & & & 1 & 3 \\
\hline & Picture Rocks Wash & 5 & & & 1 & 5 \\
\hline & Vicinity Random 239 & 3 & & & 1 & 3 \\
\hline \multirow[t]{2}{*}{ Nocturnal } & Golden Gate & 6 & 3 & 18 & 2 & 12 \\
\hline & Loop Road & 6 & 3 & 18 & 1 & 6 \\
\hline
\end{tabular}

${ }^{a}$ Includes one station in King's Canyon that was non-randomly selected.

and/or age class (adult or juvenile), if known. We did not measure distances to birds that were flying overhead nor did we use techniques to attract birds (e.g., "pishing"). We made an effort to avoid double-counting individuals. If we observed a species during the "passive" count period (between the eight-minute counts) which had not been recorded previously at a station on that visit, we recorded its distance to the nearest station.

\section{Effort}

We surveyed at five random transects in 2001 (Table 5.1). Each transect had four stations (except number 238 which had one additional non-random transect in King's Canyon) and we surveyed at each transect four times. We completed reconnaissance VCP surveys for four transects in 2002. The number of stations along reconnaissance transects varied from two to five.

\section{Analysis}

We calculated relative abundance of each species along each transect as the number of detections at all stations and visits (including zero values) and divided by effort (total number of visits multiplied by total number of stations). We reduced our full collection of observations for each repeat-visit VCP station to a subset of data that was more appropriate for estimating relative abundance. We used only those detections that occurred $\leq 75 \mathrm{~m}$ from count stations because detectability is influenced by conspicuousness of birds (i.e., loud, large, or colorful species are more detectable than others) and environmental conditions (dense vegetation can reduce likelihood of some detections). Truncating detections may reduce the influence of these factors (Verner and Ritter 1983; for a review of factors influencing detectability see Anderson 2001, Pollock et al. 2002). We also excluded observations of birds that were flying over the station, birds observed outside of the eightminute count period, and unknown species. Some observations met more than one of these criteria for exclusion from analysis. We report the relative abundance by repeat-visit transect and year. Because relative abundance is the closest index to true population size that we employ (see Chapter 1 for more detailed discussion), we use it to note the "abundance" of species.

\section{Nocturnal Surveys}

\section{Field Methods}

To survey for owls we broadcast commercially available vocalizations (Colver et al. 1999), using a compact disc player and broadcaster (Bibby et al. 2002), and recorded other nocturnal species (nighthawks and poorwills) when observed. We established two transects (Fig. 5.1) and spaced stations with transects a minimum of $500 \mathrm{~m}$ 
apart. We attempted to reduce sampling biases by varying direction of travel along transects and by not surveying during periods of excessive rain or wind. We began surveys approximately 45 minutes after sunset. We began surveys at each station with a three-minute "passive" listening period during which time we broadcast no calls. We then broadcast vocalizations for a series of two-minute "active" periods. We broadcast vocalizations of species that we suspected might be present, based on habitat and range information: elf, western screech, burrowing, and barn owls. We excluded the great horned owl from the broadcast sequence because of its aggressive behavior toward other owls. Also, we did not survey for cactus ferruginous pygmy owls because that would have required use of specific protocols and because park staff survey annually for them.

We broadcast recordings of owls in sequence of species size, from smallest to largest size species, so that smaller species would not be inhibited by the "presence" of larger predators or competitors (Fuller and Mosher 1987). During active periods, we broadcast owl vocalizations for 30 seconds followed by a 30 -second listening period. This pattern was repeated two times for each species. During the count period we used a flashlight to scan nearby vegetation and structures for visual detections. If we observed a bird during the three-minute passive period, we recorded the minute of the passive period in which the bird was first observed, the type of detection (aural, visual, or both), and the distance to the bird. If a bird was observed during any of the two-minute active periods, we recorded in which interval(s) it was detected and the type of detection (aural, visual, or both). As with VCP surveys we attempted to avoid double-counting individuals recorded at previous stations. We also attempted to use a different observer for each visit, alternate direction of travel along transects, and not survey during inclement weather.

\section{Effort}

We surveyed two transects in the district. Each transect had six stations that we surveyed at least four times each (Table 5.1).
Analysis

We calculated relative abundance as per VCP surveys.

\section{Community-type Identification}

We sought to identify bird/vegetation communities within the district and to compare characteristics among them. To group transects, we used Ward's hierarchical cluster analysis using data from point-intercept transects. Cluster analysis is a multivariate technique that groups like entities (in our case transects) that share similar values. We used the total number of point intercepts by the most common plant species in all four height categories for this analysis.

\section{Incidental and Breeding Observations}

\section{Field Methods}

When we were not conducting formal surveys and we encountered a rare species, a species in an unusual location, or an individual engaged in breeding behavior, we recorded UTM coordinates, time of detection, and (if known) the sex and age class of the bird. We recorded all breeding observations using the standardized classification system developed by the North American Ornithological Atlas Committee (NAOAC 1990), which characterizes breeding behavior into one of nine categories: nest building, occupied nest, used nest, adult carrying nesting material, adult carrying food or fecal sac, adult feeding young, adult performing distraction display, or fledged young. We made breeding observations during standardized surveys and incidental observations.

\section{Analysis}

We report frequency counts of incidental and breeding observations.

\section{Results}

We made 2,142 observations representing 73 species in 2001 and 2002 (Appendix C). We found five species that had not been recorded for the district: great-tailed grackle, northern rough-winged swallow, cliff swallow, broadtailed hummingbird, and blue grosbeak. None of the species were particular surprising and 
Table 5.2. Total number of observations (sum) and relative abundance (mean \pm SE), by transect, of birds recorded during repeat-visit VCP surveys, Saguaro NP, Tucson Mountain District, 2001 and 2002. Total number of observations includes those observations excluded from relative abundance estimates.

\begin{tabular}{|c|c|c|c|c|c|c|c|c|c|c|c|c|c|c|c|}
\hline & \multicolumn{3}{|c|}{239} & \multicolumn{3}{|c|}{238} & \multicolumn{3}{|c|}{213} & \multicolumn{3}{|c|}{212} & \multicolumn{3}{|c|}{204} \\
\hline Species & Sum & Mean & SE & Sum & Mean & SE & Sum & Mean & SE & Sun & Mean & SE & Sum & Mean & $\mathrm{SE}$ \\
\hline Gambel's quail & 33 & 0.13 & 0.085 & 5 & & & 20 & 0.25 & 0.144 & 17 & 0.2 & 0.117 & 32 & 0.25 & 0.099 \\
\hline turkey vulture & & & & 5 & & & & & & 3 & & & 1 & & \\
\hline Harris's hawk & 8 & 0.06 & 0.063 & & & & & & & & & & & & \\
\hline red-tailed hawk & & & & & & & 1 & & & & & & 4 & & \\
\hline golden eagle & & & & 3 & & & & & & & & & & & \\
\hline American kestrel & & & & & & & 3 & & & & & & 2 & & \\
\hline prairie falcon & & & & 10 & & & & & & & & & & & \\
\hline white-winged dove & 28 & 0.25 & 0.112 & 20 & 0.19 & 0.101 & 29 & 0.44 & 0.157 & 40 & 0.55 & 0.24 & 49 & 0.35 & 0.109 \\
\hline mourning dove & 44 & 0.94 & 0.249 & 22 & 0.75 & 0.250 & 23 & 0.25 & 0.112 & 40 & 0.50 & 0.185 & 51 & 0.80 & 0.200 \\
\hline Inca dove & 1 & & & & & & & & & & & & & & \\
\hline common poorwill & & & & & & & & & & 1 & & & & & \\
\hline white-throated swift & & & & 36 & & & & & & & & & & & \\
\hline black-chinned hummingbird & & & & & & & & & & 1 & & & & & \\
\hline Costa's hummingbird & & & & 5 & 0.19 & 0.101 & & & & 4 & & & 1 & 0.05 & 0.050 \\
\hline Gila woodpecker & 53 & 0.69 & 0.285 & 40 & 0.50 & 0.183 & 69 & 1.75 & 0.348 & 42 & 0.25 & 0.143 & 84 & 1.55 & 0.246 \\
\hline ladder-backed woodpecker & & & & 2 & & & 3 & 0.06 & 0.063 & 2 & 0.1 & 0.069 & 2 & & \\
\hline gilded flicker & 1 & & & 7 & 0.19 & 0.136 & 10 & 0.31 & 0.151 & 7 & 0.1 & 0.069 & 10 & 0.05 & 0.050 \\
\hline gray flycatcher & 1 & & & & & & & & & & & & & & \\
\hline ash-throated flycatcher & 20 & 0.56 & 0.258 & 28 & 0.06 & 0.063 & 22 & 0.38 & 0.180 & 32 & 0.35 & 0.131 & 21 & 0.30 & 0.128 \\
\hline brown-crested flycatcher & 3 & 0.13 & 0.085 & & & & 3 & 0.13 & 0.085 & 7 & 0.2 & 0.117 & 8 & 0.25 & 0.123 \\
\hline western kingbird & & & & & & & & & & & & & 1 & 0.05 & 0.050 \\
\hline western scrub-jay & & & & 1 & & & & & & & & & & & \\
\hline common raven & 2 & & & 12 & & & 1 & & & & & & & & \\
\hline purple martin & 9 & & & & & & & & & & & & 14 & 0.05 & 0.050 \\
\hline cliff swallow & 1 & & & & & & & & & & & & & & \\
\hline verdin & 28 & 1.06 & 0.193 & 14 & 0.69 & 0.151 & 28 & 1.50 & 0.158 & 21 & 0.75 & 0.143 & 37 & 1.55 & 0.135 \\
\hline cactus wren & 34 & 1.44 & 0.203 & 27 & 0.88 & 0.202 & 25 & 1.13 & 0.221 & 22 & 0.60 & 0.152 & 41 & 1.10 & 0.176 \\
\hline rock wren & & & & 4 & & & & & & 3 & 0.1 & 0.069 & 1 & & \\
\hline canyon wren & & & & 24 & 0.13 & 0.085 & 3 & 0.06 & 0.063 & 13 & 0.2 & 0.092 & & & \\
\hline blue-gray gnatcatcher & & & & & & & & & & 1 & & & & & \\
\hline black-tailed gnatcatcher & 10 & 0.50 & 0.158 & 12 & 0.69 & 0.176 & 12 & 0.50 & 0.158 & 10 & 0.40 & 0.169 & 18 & 0.60 & 0.152 \\
\hline $\begin{array}{l}\text { northern mockingbird } \\
\text { Bendire's thrasher }\end{array}$ & 1 & & & 2 & & & & & & 4 & & & & & \\
\hline curve-billed thrasher & 34 & 0.88 & 0.221 & 15 & 0.06 & 0.063 & 16 & 0.56 & 0.182 & 3 & & & 20 & 0.45 & 0.114 \\
\hline phainopepla & 1 & & & & & & 2 & & & & & & & & \\
\hline orange-crowned warbler & & & & & & & & & & & & & 2 & 0.10 & 0.100 \\
\hline Lucy's warbler & 1 & & & & & & & & & & & & & & \\
\hline black-throated gray warbler & & & & & & & & & & 1 & & & & & \\
\hline green-tailed towhee & & & & 1 & & & & & & 2 & 0.05 & 0.050 & & & \\
\hline canyon towhee & 4 & 0.25 & 0.112 & 12 & 0.50 & 0.158 & 5 & 0.13 & 0.085 & 14 & 0.30 & 0.147 & 18 & 0.35 & 0.131 \\
\hline rufous-winged sparrow & 11 & 0.31 & 0.120 & & & & & & & & & & 3 & 0.10 & 0.069 \\
\hline rufous-crowned sparrow & & & & & & & & & & 1 & 0.05 & 0.050 & 5 & 0.05 & 0.050 \\
\hline chipping sparrow & & & & & & & 2 & & & & & & & & \\
\hline Brewer's sparrow & 16 & 0.31 & 0.176 & & & & & & & 2 & 0.05 & 0.050 & 3 & 0.10 & 0.069 \\
\hline black-throated sparrow & 1 & 0.06 & 0.063 & 37 & 1.63 & 0.473 & 13 & 0.56 & 0.203 & 28 & 0.80 & 0.186 & 12 & 0.35 & 0.109 \\
\hline white-crowned sparrow & & & & & & & & & & 2 & 0.10 & 0.100 & 1 & & \\
\hline northern cardinal & 1 & 0.06 & 0.063 & & & & & & & 3 & 0.15 & 0.082 & 3 & 0.10 & 0.069 \\
\hline pyrrhuloxia & 4 & 0.06 & 0.063 & 1 & & & 28 & 0.69 & 0.198 & 11 & 0.10 & 0.100 & 16 & 0.35 & 0.109 \\
\hline black-headed grosbeak & & & & & & & & & & & & & 1 & 0.05 & 0.050 \\
\hline lazuli bunting & & & & & & & & & & 1 & 0.05 & 0.050 & & & \\
\hline varied bunting & & & & & & & & & & 3 & & & & & \\
\hline great-tailed grackle & 3 & & & & & & & & & & & & & & \\
\hline brown-headed cowbird & 9 & 0.06 & 0.063 & 21 & 0.38 & 0.221 & 11 & 0.25 & 0.112 & 11 & 0.25 & 0.143 & 17 & 0.15 & 0.109 \\
\hline Bullock's oriole & & & & 1 & & & 2 & & & 1 & & & & & \\
\hline Scott's oriole & & & & 6 & & & 2 & & & 2 & & & 1 & & \\
\hline house finch & 10 & 0.25 & 0.144 & 8 & 0.13 & 0.085 & 17 & 0.25 & 0.112 & 25 & 0.30 & 0.147 & 9 & 0.20 & 0.156 \\
\hline lesser goldfinch & & & & 1 & & & 2 & & & 4 & 0.05 & 0.050 & & & \\
\hline
\end{tabular}


Table 5.3. Mean relative abundance of birds from reconnaissance VCP surveys, Saguaro NP, Tucson Mountain District, 2002.

\begin{tabular}{|c|c|c|c|c|c|c|c|c|c|c|c|c|}
\hline \multirow[b]{2}{*}{ Species } & \multicolumn{3}{|c|}{$\begin{array}{l}\text { Bajada } \\
(n=2)\end{array}$} & \multicolumn{3}{|c|}{$\begin{array}{c}\text { Camino del } \\
\text { Cerro }(n=3) \\
\end{array}$} & \multicolumn{3}{|c|}{$\begin{array}{c}\text { Picture Rocks } \\
(n=5)\end{array}$} & \multicolumn{3}{|c|}{$\begin{array}{c}\text { Vicinity } 239 \\
(n=3)\end{array}$} \\
\hline & Sum & Mean & SE & Sum & Mean & SE & Sum & Mean & SE & Sum & Mean & SE \\
\hline Gambel's quail & 3 & 1.50 & 0.500 & & & & 1 & 0.20 & 0.200 & & & \\
\hline white-winged dove & 1 & 0.50 & 0.500 & 1 & 0.33 & 0.333 & 4 & 0.80 & 0.200 & & & \\
\hline mourning dove & & & & 1 & 0.33 & 0.333 & & & & & & \\
\hline Anna's hummingbird & & & & 1 & 0.33 & 0.333 & & & & & & \\
\hline Gila woodpecker & 2 & 1.00 & 1.000 & 3 & 1.00 & 0.000 & 3 & 0.60 & 0.245 & 2 & 0.67 & 0.333 \\
\hline gilded flicker & & & & & & & & & & 1 & 0.33 & 0.333 \\
\hline ash-throated flycatcher & 1 & 0.50 & 0.500 & 1 & 0.33 & 0.333 & 1 & 0.20 & 0.200 & & & \\
\hline brown-crested flycatcher & & & & & & & & & & 4 & 1.33 & 0.667 \\
\hline verdin & 3 & 1.50 & 0.500 & 1 & 0.33 & 0.333 & 5 & 1.00 & 0.548 & 1 & 0.33 & 0.333 \\
\hline cactus wren & 4 & 2.00 & 1.000 & 1 & 0.33 & 0.333 & 3 & 0.60 & 0.245 & 4 & 1.33 & 0.333 \\
\hline blue-gray gnatcatcher & & & & & & & 1 & 0.20 & 0.200 & 1 & 0.33 & 0.333 \\
\hline black-tailed gnatcatcher & & & & & & & 2 & 0.40 & 0.245 & & & \\
\hline curve-billed thrasher & 2 & 1.00 & 1.000 & 2 & 0.67 & 0.333 & 2 & 0.40 & 0.245 & 3 & 1.00 & 0.000 \\
\hline Wilson's warbler & & & & 2 & 0.67 & 0.667 & & & & & & \\
\hline green-tailed towhee & & & & & & & 1 & 0.20 & 0.200 & & & \\
\hline canyon towhee & & & & 2 & 0.67 & 0.667 & 1 & 0.20 & 0.200 & & & \\
\hline black-throated sparrow & & & & 1 & 0.33 & 0.333 & 2 & 0.40 & 0.400 & & & \\
\hline pyrrhuloxia & 1 & 0.50 & 0.500 & 2 & 0.67 & 0.333 & 2 & 0.40 & 0.400 & 1 & 0.33 & 0.333 \\
\hline blue grosbeak & & & & & & & 1 & 0.20 & 0.200 & & & \\
\hline brown-headed cowbird & & & & 2 & 0.67 & 0.667 & 1 & 0.20 & 0.200 & & & \\
\hline Scott's oriole & & & & 1 & 0.33 & 0.333 & & & & & & \\
\hline house finch & 1 & 0.50 & 0.500 & & & & 4 & 0.80 & 0.583 & 1 & 0.33 & 0.333 \\
\hline
\end{tabular}

were likely overlooked by previous researchers. All of the species that we observed with species conservation designations were fairly common in the district: elf owl, Gila woodpecker, gilded flicker, Costa's hummingbird, purple martin, Lucy's warbler, and rufous-winged sparrow. The most interesting observation was of an active nest of a prairie falcon, which was located only about $20 \mathrm{~m}$ away from an active golden eagle nest.

\section{VCP Surveys}

We recorded 63 species during surveys at repeat-visit ( $n=58$ species; Table 5.2) and reconnaissance ( $n=31$ species) VCP surveys (Table 5.3, Appendix C). We found 13 species at all five repeat-visit VCP transects, and most of these species were the most abundant species at each transect (Table 5.2). Two of the three most abundant species on all transects were the verdin and cactus wren. Other widespread and abundant species included the white-winged and mourning doves, Gila woodpecker, ash-throated flycatcher, and black-throated sparrow. Many species were not as abundant but had very consistent relative abundance estimates among transects: blacktailed gnatcatcher, canyon towhee, brown-headed cowbird, and house finch. The phyrroloxia and curve-billed thrasher were two widespread species that had very different inter-transect abundance estimates (Table 5.2).

Despite some inter-transect differences in species composition and relative abundance estimates, we found no logical grouping of transects based on either the plant or the bird data from cluster analysis. This is most likely because many of the most common bird and plant species were found in all transects (see above). Similarly, we found no vegetation characteristics that predicted differences in observed species richness among transects using stepwise multiple linear regression.

We observed 31 species during reconnaissance VCP surveys, including six species that we did not observe on repeat-visit surveys: greater roadrunner, lesser nighthawk, Anna's hummingbird, northern rough-winged 
swallow, Wilson's warbler, and blue grosbeak (Table 5.3). Although sample sizes were too small to make meaningful comparisons among transects, there were similar patterns of abundance for some of the most widespread species such as verdin, cactus wren, and Gila woodpecker.

\section{Nocturnal Surveys}

We found three species of owls, the lesser nighthawk, and the common poorwill on both nocturnal transects (Table 5.4). Relative abundance estimates were similar between transects for all species except the western screech-owl, which was most abundant on the Golden Gate Loop transect. The elf owl was the most common species on both transects.

\section{Incidental and Breeding Observations}

We made incidental observations of 47 species including six species that had not been observed during other survey methods (Appendix C). We made 37 breeding behavior observations of 17 species (Table 5.5).

\section{Inventory Completeness}

The inventory of birds at the district is likely close to completion. Our effort, however, was insufficient to document even $90 \%$ of the species that have been recorded for the district; the species accumulation curve (Fig. 5.2) showed little sign of leveling off despite over 2,000 observations of birds. Given the low species richness of birds in the district (Appendix C), this

Table 5.4. Mean relative abundance of birds, by transect, from nocturnal surveys, Saguaro NP, Tucson Mountain District, 2001 and 2002.

\begin{tabular}{lcccccccc}
\hline & \multicolumn{3}{c}{ Golden Gate Loop } & & \multicolumn{3}{c}{ Loop Road } \\
\cline { 2 - 4 } \cline { 7 - 8 } Species & Sum & Mean & SE & & Sum & Mean & SE \\
\hline western screech-owl & 14 & 0.47 & 0.11 & & 4 & 0.17 & 0.08 \\
great horned owl & 2 & 0.07 & 0.05 & & 2 & 0.08 & 0.06 \\
elf owl & 34 & 1.13 & 0.22 & & 24 & 1.00 & 0.22 \\
lesser nighthawk & 7 & 0.23 & 0.17 & & 8 & 0.33 & 0.14 \\
\hline common poorwill & 16 & 0.53 & 0.13 & & 10 & 0.42 & 0.15 \\
\hline
\end{tabular}

Table 5.5. Number of observations for each breeding behavior for birds, Saguaro NP, Tucson Mountain District, 2001 and 2002. Breeding behaviors follow standards set by NAOAC (1990).

\begin{tabular}{|c|c|c|c|c|c|c|c|c|c|c|}
\hline \multirow[b]{2}{*}{ Species } & \multicolumn{4}{|c|}{ Nest } & \multicolumn{2}{|c|}{ Adults carrying } & \multirow[b]{2}{*}{$\begin{array}{c}\text { Distraction } \\
\text { displays }\end{array}$} & \multirow{2}{*}{$\begin{array}{c}\text { Feeding } \\
\text { recently } \\
\text { fledged } \\
\text { young }\end{array}$} & \multirow{2}{*}{$\begin{array}{l}\text { Recently } \\
\text { fledged } \\
\text { young }\end{array}$} & \multirow[b]{2}{*}{ Totals } \\
\hline & $\begin{array}{c}\text { Build- } \\
\text { ing }\end{array}$ & $\begin{array}{l}\text { With } \\
\text { eggs }\end{array}$ & $\begin{array}{l}\text { With } \\
\text { young }\end{array}$ & $\begin{array}{l}\text { Occu- } \\
\text { pied }\end{array}$ & Food & $\begin{array}{l}\text { Nesting } \\
\text { material }\end{array}$ & & & & \\
\hline prairie falcon & & & & 1 & & & & 1 & & 2 \\
\hline golden eagle & & & & 1 & & & & & & 1 \\
\hline white-winged dove & & 3 & & & & & & & & 3 \\
\hline mourning dove & & 1 & & & & & & & & 1 \\
\hline Costa's hummingbird & & & 1 & & & & 2 & & & 3 \\
\hline Gila woodpecker & & & 2 & 4 & & & & & & 6 \\
\hline gilded flicker & & & & & 1 & & & & & 1 \\
\hline ash-throated flycatcher & & & 1 & 1 & & & & & & 2 \\
\hline common raven & & & & 1 & & & & & & 1 \\
\hline verdin & & & & 2 & & & & & 1 & 3 \\
\hline cactus wren & & & & 1 & & & & & & 1 \\
\hline canyon wren & & & 1 & & & & & & & 1 \\
\hline black-tailed gnatcatcher & & & & & & 1 & & & & 1 \\
\hline curve-billed thrasher & & 1 & & & 2 & & & & & 3 \\
\hline black-throated sparrow & & & & & & & & 1 & 5 & 6 \\
\hline pyrrhuloxia & & & & & 1 & & & & & 1 \\
\hline varied bunting & & & & & & & 1 & & & 1 \\
\hline Totals & & 5 & 5 & 11 & 4 & 1 & 3 & 2 & 6 & 37 \\
\hline
\end{tabular}




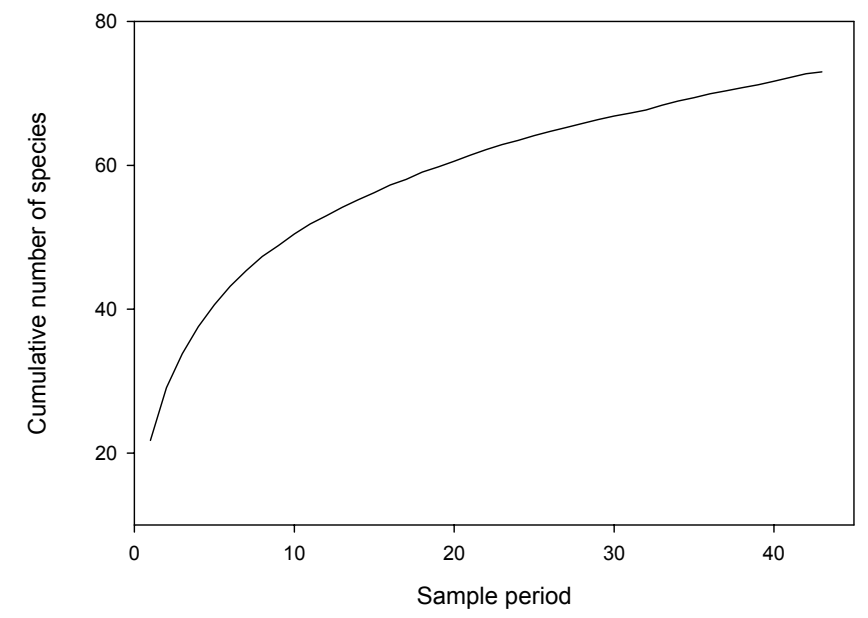

Figure 5.2. Species accumulation curve for birds, all survey methods, Saguaro NP, Tucson Mountain District, 2001 and 2002. Each sample period is a randomized combination of approximately 50 observations $(N=2,142)$.

result was surprising, but is probably explained by the relatively high percentage of passage migrant species compared to the number of resident or breeding species. Although our effort was not sufficient to document at least $90 \%$ of the species thought to occur in the district, we believe that we accounted for almost all of the species that are thought to be resident or breeding species. By combining our effort with others (summarized in Appendix C), the species list for the district is likely $90 \%$ complete.

\section{Discussion}

The species richness at the district is unremarkable when compared to other areas of the region. Species typical of the Sonoran desert uplands, such as the white-winged dove, Gila woodpecker, verdin, cactus wren, and curvebilled thrasher were widespread and abundant throughout the district. The district also hosts some migratory and overwintering species common in the spring including: green-tailed towhee, ruby-crowned kinglet, and blue-gray gnatcatcher.

The low number of species in the district is not surprising; Sonoran desert scrub does not have high species richness (Tomoff 1974). The low number of species in the district is also not surprising given the lack of mesic riparian vegetation (e.g., Fremont cottonwood, Arizona sycamore, and netleaf hackberry), which has the highest species richness in the region (Strong and Bock 1990). Even areas with dense assemblages of xeric riparian vegetation (e.g., mesquite and palo verde) in southern Arizona have a high number of species, especially spring passage migrants (Hardy et al. 2004). The Tucson Mountain District has no mesic and few areas of well-developed xeric riparian vegetation, so it was not surprising that we found only a few migratory species and very few individuals of xeric riparian-obligate birds (e.g., Lucy's warbler and varied bunting). Nevertheless, many of the species that are common to the Sonoran Desert uplands are species of management concern because their global distribution is largely restricted to the desert southwest and adjacent Mexico (Latta et al. 1999). Increased conversion of these areas to housing and other forms of development may severely impact these bird communities, making refugia such as the Tucson Mountain District all the more important.

The district's bird community has surprisingly few individuals of non-native 
or human-adapted species (e.g., great-tailed grackle, European starling, house sparrow; Table 5.2). These species are usually abundant in and around development (Mills et al. 1989, Germaine et al. 1998) and we observed them in areas of the district that were adjacent to housing development, particularly on the west side of the district. An increase in these human-adapted species is likely with increasing development in the Picture Rocks area. All three non-native species (rock pigeon, European starling, and house sparrow) will likely reach their highest densities in lands directly adjacent to the district, but only the starling is likely to have impacts further in the from the boundary; they are known to travel great distances between nest sites (primarily saguaro cavities) and foraging areas, particularly around lawns and horse facilities. Mannan and Bibles (1989) assessed the potential for competition for nesting sites between native and non-native cavity-nesting species and concluded that there was little cause for concern in both districts of the park. They cited an abundance of available cavities and few sightings of direct competition between native and nonnative species.

An increase in housing and other development adjacent to the district may facilitate the spread of non-native plants and animals, which can impact the native bird community. Non-native plants that alter fire regimes (e.g., buffelgrass) may ultimately impact the bird community because of changes to the plant community that result from fire. These losses include many of the cacti, such as saguaros, that are important food and nesting sites for many birds. Non-native pets are also a concern, particularly free-roaming feral cats, which kill and harass birds (Clarke and Pacin 2002). Unlike the significant changes that have taken place to the bird community on the Rincon Mountain District (Powell et al. 2006), we do not believe there have been recent species extirpations in the Tucson Mountain District, though there are no historical data with which to compare. A few species of note included a single observation of Bendire's thrasher despite a concerted effort to find it. This species has likely undergone population declines in the vicinity of Tucson (Tom Huels, pers. comm.). We also expected to find a few Bell's vireo and perhaps Abert's towhee in some of the xeroriparian washes but could not locate them. They remain on the district's list because of observations by Yensen (1973) and Monson and Smith (1985). 


\section{Chapter 6: Mammals}

Don E. Swann and Brian F. Powell

\section{Previous and Ongoing Research}

Prior to our effort, Saguaro National Park had never had a comprehensive survey of its mammals. There have been several studies on mammals, but mostly in the Rincon Mountain District (summarized in Swann and Powell 2006b). Notable exceptions in Tucson Mountain District include an inventory of bats by Sidner and Davis (1994), part of a PhD study of rodents by Yensen (1973), part of a PhD study by M'Closkey (1980), and a long-term monitoring plot for rodents, established by Robert Parmenter, that was first trapped in 1991 and adopted by park biologists in 2004 (Parmenter, unpubl. data). In addition, there have been surveys for species of management interest, including mule deer and kit foxes associated with the Central Arizona Project (CAP) in the 1980s (deVos et al. 1983), and subsequent monitoring of water catchments intended to mitigate the effects of the CAP (Kline et al. 1998). Other relevant work includes recent monitoring of bats associated with mines (Dalton and Wolf 2002, Wolf and Dalton 2003) and surveys for mountain lions and bobcats (Hackl et al. 2006, Haynes et al. 2007). Finally, TMD was the site for a series of studies of collared peccary during the 1960s and 1970s by wildlife students from the University of Arizona (e.g., Schweinsburg 1971).

Saguaro National Park has also been collecting observations of wildlife for several decades. Most of these sightings, while not $100 \%$ reliable, have been entered into a database and mapped in a GIS and are available in an appendix to this report (available at the park and I\&M office in Tucson). In Saguaro's administrative records at the Western Archaeological and Conservation Center there is a limited amount of information on mammals from the Tucson Mountain Park in the 1930s, when NPS assisted Pima County in management of the park, and in the 1960s, after TMD was established.

\section{Methods}

We surveyed for mammals using four field methods: (1) trapping for rodents and ground squirrels (primarily nocturnal; herein referred to collectively as small mammals), (2) infraredtriggered photography for medium and large mammals, (3) netting for bats, and (4) incidental observations for all mammals (Figs. 6.1, 6.2) We established a pitfall array for reptiles and amphibians (see Chapter 4) but captured very few mammals. The infrared-triggered photography survey was a collaborative effort and most of the field survey effort was carried out by park biologists. Two previous reports use a subset of the data presented here. Dee et al. (2002) compared species richness based on infraredtriggered photography and mitochondrial DNA extracted from animal scat. Hackl et al. (2006) used photography and DNA analysis based on scat to assess status of mountain lions and bobcats in the district.

\section{Small Mammals}

\section{Field Methods}

We trapped small mammals using Sherman live traps (large, folding aluminum, or steel, 3 x 3.5 x 9"; H. B. Sherman, Inc., Tallahassee, FL) set in grids (Figs. 6.3, 6.4). We opened and baited traps (one tablespoon: 16 parts dried oatmeal to one part peanut butter) in the evening, then checked and closed traps the following morning. We placed a small amount of polyester batting in each trap to prevent trap deaths due to cold nighttime temperatures. We marked each captured animal with a permanent marker to facilitate recognition; these "batch marks" appeared to last for the duration of the sampling period. For each animal we recorded species, sex, age class (adult, subadult, or juvenile), reproductive condition, weight, and measurements for right hindfoot, tail, ear, head, and body. For males we recorded reproductive condition as either scrotal or non-reproductive; for females we recorded reproductive condition as one or more of the following: non-reproducing, open pubis, closed pubis, enlarged nipples, small or non-present nipples, lactating, post-lactating, or non-lactating. 


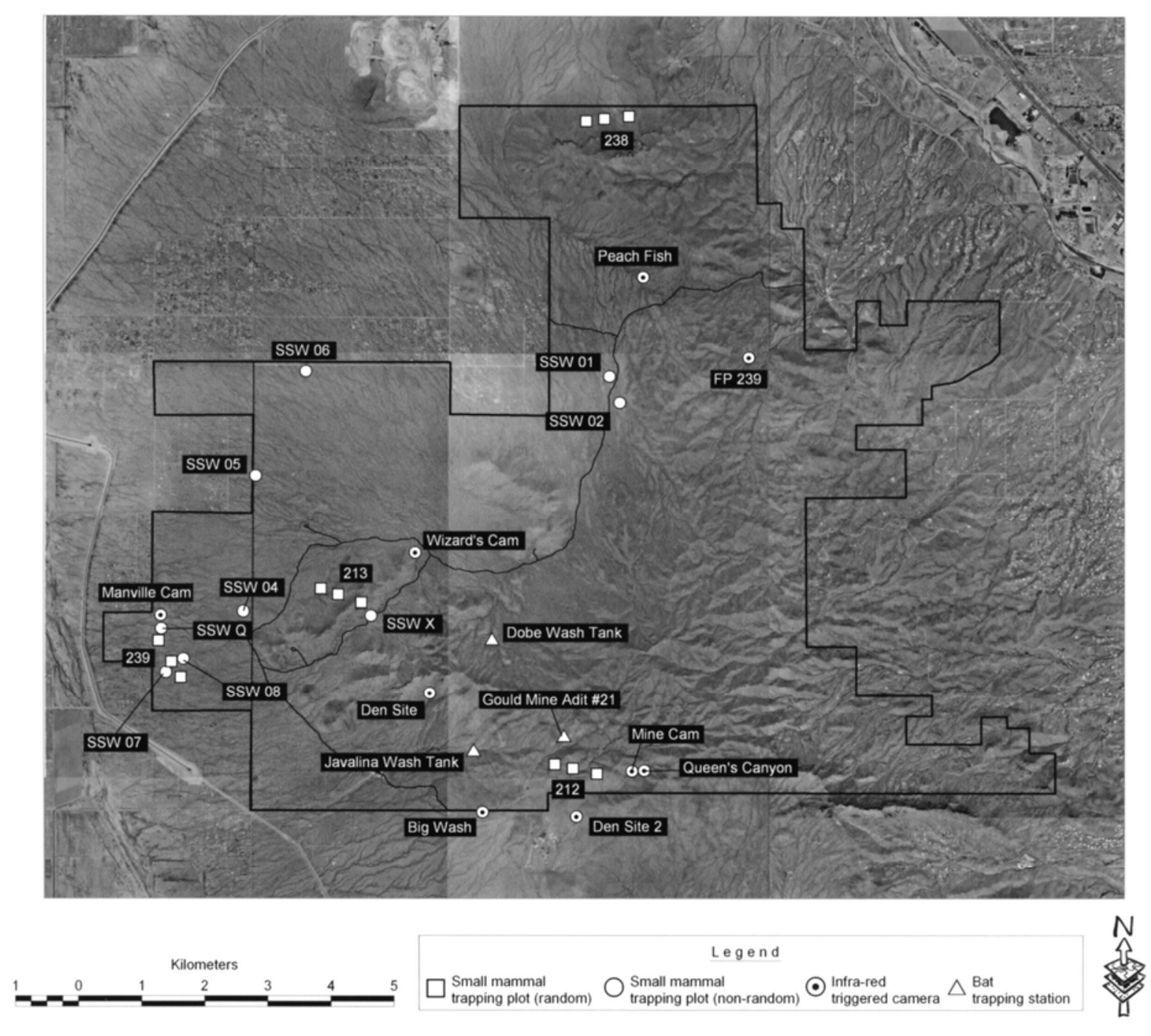

Figure 6.1. Location of random and non-random small-mammal trapping sites, bat trapping stations, and Trailmaster cameras (infrared-triggered cameras), Saguaro NP, Tucson Mountain District, 2001.

We were confident in most species identifications in the field, with the exception of one individual in the genus Peromyscus (see Results), and some individuals of rock pocket mice and desert pocket mice; both species were confirmed, but can be very difficult to conclusively distinguish in the field.

\section{Spatial Sampling Design}

The majority of our trapping effort was at focalpoint transects set throughout the district (see Chapter 1; Fig. 6.1). We trapped at a subset of four random transects $(212,213,238$, and 239) that were surveyed for other taxonomic groups.
Transect 239 was in a bajada area of low slope and sandy soils, while the other sites were in areas of relatively higher slopes with rocks present. We visited transects 213 and 239 twice in 2001, with each visit one month apart, and visited the other sites only once (Appendix I). We also trapped (one visit only) at non-random sites in areas that we believed would have high species richness: near Kinney Road, and near Sandario Road (Fig. 6.1).

At each random site we established three grids (Fig. 6.3) with either a $3 \times 7$ or a $5 \times 5$ trap configuration (Fig. 6.4; Appendix I). Traps set in a $3 \times 7$ configuration had $16.7 \mathrm{~m}$ spacing among 

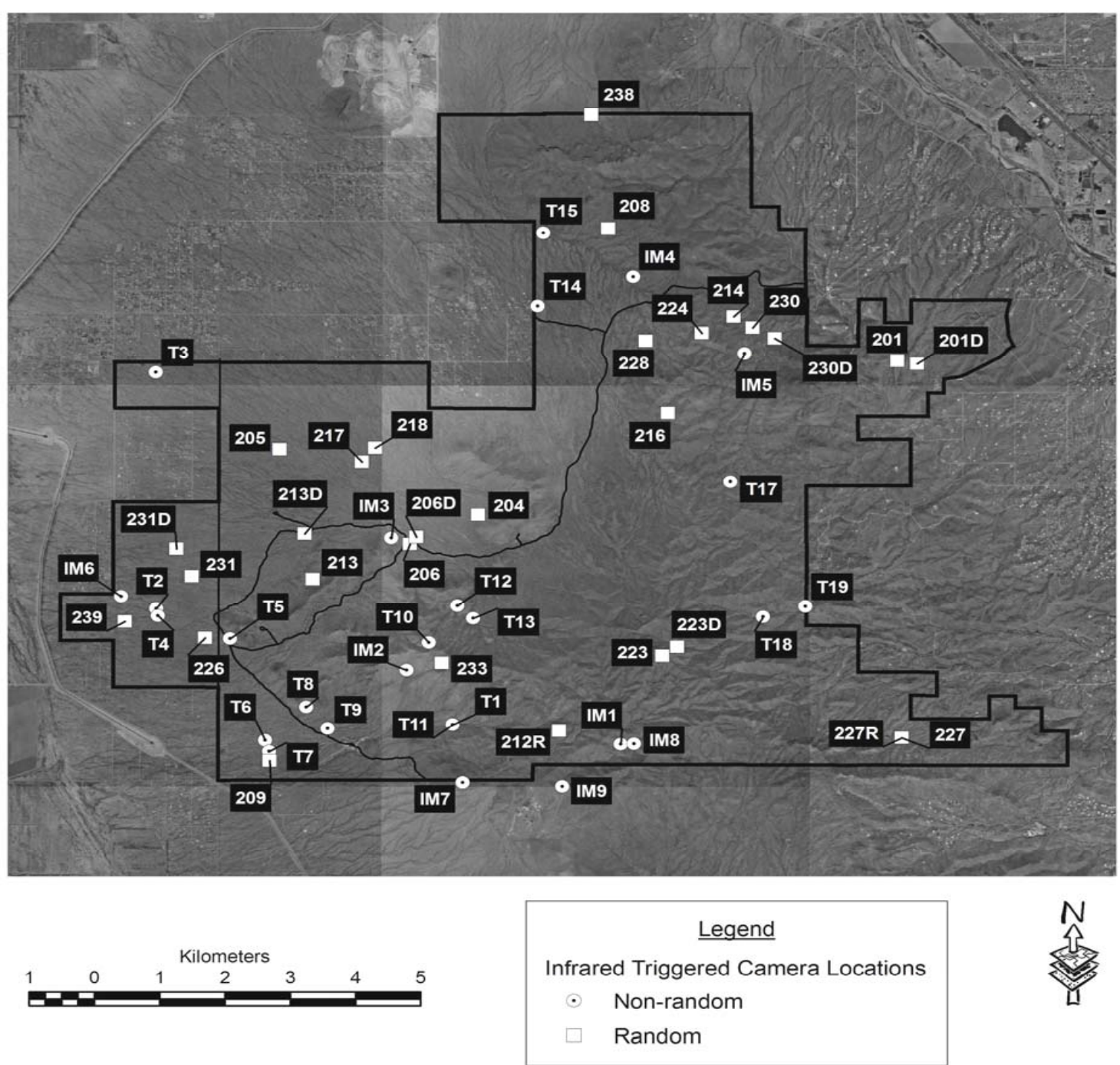

Figure 6.2. Location of infrared-triggered camera units, Saguaro NP, 2002-2005. Includes symbols for 2001 and 2002 (from Fig. 6.1), non-random points; 2002-2005, random points, and 2002-2005, non-random points.

them and traps in a $5 \times 5$ configuration had 12.5 $\mathrm{m}$ spacing among them. Occasionally we also placed traps "preferentially", meaning that traps were not set in grids with even spacing, but rather in locations that the field crews felt contained areas with high species richness. Typically these "preferential" sites were near the random grids; the crew set out 5 to 70 additional traps after setting up the random grids (Appendix I). At non-random sites the layout of traps was variable, but typically they were in a $5 \times 5$ or a $2 \times 10$ configuration. The $2 \times 10$ configuration was usually along both edges of a wash, because we believed that these areas would have more animals.

We always trapped at multiple plots on the same night to maximize efficiency. At focal points we always trapped all the grids along the transect on the same nights and typically trapped other, nearby non-random areas. In some nonrandom areas (e.g., Kinney Road) we trapped on multiple grids. In this report we summarize results by "plot group", which is the collection of trapping grids that represents an area (see Appendix I). 


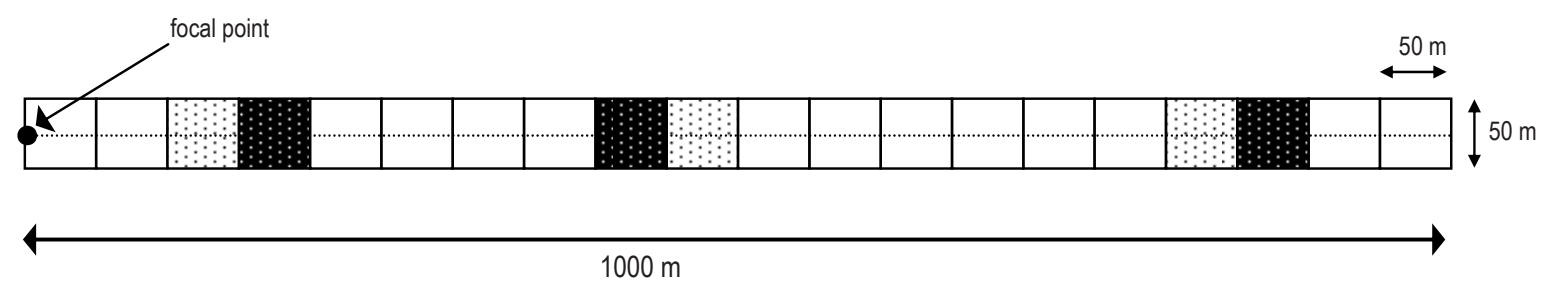

Figure 6.3. Layout of small-mammal trapping grids along focal-point transects, Saguaro NP, Tucson Mountain District, 2001. See Fig. 6.4 for more details.

A

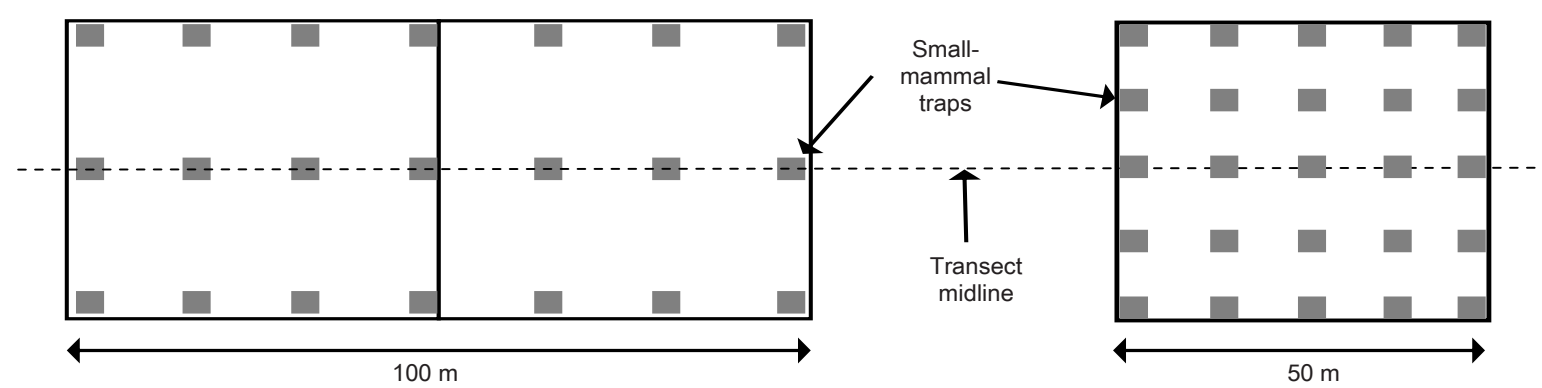

Figure 6.4. Detailed layout of small-mammal trapping grids at Saguaro NP, Tucson Mountain District, 2001 and 2002. We used $3 \times 7$ trap grids in 50×100 m plots (A) from mid-April through mid-June and $5 \times 5$ trap grids in $50 \times 50 \mathrm{~m}$ plots (B) from mid-June through October.

$\underline{\text { Effort }}$

We trapped for a total of 1,431 trap-nights (Table 6.1), all in 2001. In total, we had 521.5 trap nights at non-random sites, and 909.5 trap nights at random sites.

\section{Temporal Sampling Design}

The total number of nights that we trapped each grid was variable, but was typically two or three nights per visit (see Appendix I for complete list). Occasionally we trapped for as many as four nights or as few as one night. Because our goal was to maximize the number of individuals and species trapped, we varied the number of nights trapped based on the trapping results in the first few nights of trapping; if we were catching few animals, we moved to a different location.

\section{Analysis}

We expressed effort as the number of trap nights (number of traps multiplied by number of nights they were open) after accounting for sprung traps (misfired or occupied; Beauvais and Buskirk 1999). Sprung traps reduce trap effort because they are no longer "available" to capture animals; we account for this by multiplying the number of sprung traps by 0.5 (lacking specific information, we estimate sprung traps were available for half of the night; Nelson and Clark 1973). We calculated relative abundance for species by dividing the number of captures by the number of trap nights times 100. For this report we calculated relative abundance by plot group, type of plot (random or non-random), and visit. It is important to note that relative abundance 
Table 6.1. Summary of small mammal trapping effort, Saguaro NP, Tucson Mountain District, 2001 and 2002. See Appendix I for additional trapping event information.

\begin{tabular}{|c|c|c|c|c|c|c|c|c|}
\hline Plot group & $\begin{array}{l}\text { Site } \\
\text { characteristics }\end{array}$ & Plot type & Visit & $\begin{array}{l}\text { Number of } \\
\text { traps set }\end{array}$ & $\begin{array}{l}\text { Sprung but } \\
\text { empty traps }\end{array}$ & $\begin{array}{l}\text { Number } \\
\text { of animals } \\
\text { captured }\end{array}$ & $\begin{array}{l}\text { Number } \\
\text { of animals } \\
\text { recaptured }\end{array}$ & $\begin{array}{l}\text { Number of } \\
\text { trap nights }\end{array}$ \\
\hline \multirow[t]{2}{*}{212} & Rocky slope & Non-random & 1 & 40 & 0 & 2 & 0 & 39.0 \\
\hline & & Random & 1 & 126 & 0 & 8 & 0 & 122.0 \\
\hline \multirow[t]{3}{*}{213} & Rocky slope & Non-random & 1 & 40 & 0 & 4 & 0 & 38.0 \\
\hline & & Random & 1 & 189 & 8 & 22 & 7 & 170.5 \\
\hline & & & 2 & 150 & 8 & 19 & 2 & 135.5 \\
\hline 238 & Rocky slope & Random & 1 & 225 & 9 & 5 & 1 & 217.5 \\
\hline \multirow[t]{3}{*}{239} & Bajada & Non-random & 1 & 64 & 5 & 22 & 4 & 48.5 \\
\hline & & Random & 1 & 189 & 1 & 51 & 10 & 158.0 \\
\hline & & & 2 & 150 & 6 & 64 & 18 & 106.0 \\
\hline Kinney Road & Rocky slope & Non-random & 1 & 231 & 5 & 7 & 2 & 224.0 \\
\hline Sendario Road & Rocky slope & Non-random & 1 & 175 & 0 & 5 & 1 & 172.0 \\
\hline \multirow[t]{2}{*}{ Total } & & Random & & & & & & 909.5 \\
\hline & & Non-random & & & & & & 521.5 \\
\hline
\end{tabular}

assumes an equal probability of detections among species. Although beyond the scope of this report to quantify those differences, it is important to recognize that individuals of each species react differently to the metal traps. Therefore, aside from species-richness estimates, the most meaningful comparisons are intra-specific differences, both within and among sites.

\section{Bats}

We surveyed for bats using two field methods: netting and roost-site investigation. For netting, we concentrated our survey effort in areas that were most likely to have bats, mostly riparian areas with surface water present. We did not survey for bats near focal points because of the low probability of success in these areas.

\section{Roosts}

We visited three roosts at TMD (Gould Mine, Wild Horse Mine, and Yuma Mine) that were known to have bats based on historic records, or were likely to have bats based on habitat characteristics. At roosts, we observed bats with the aid of infrared-filtered light and night-vision equipment or red-filtered light. When bats were present, we worked quickly to identify them to species, but if there were no bats we used bright light, then searched for, and collected, skeletal material. If there was skeletal material, we collected it for later identification.

\section{Mist Netting}

Because most insectivorous bats congregate at water sites, we selected two sites (Dobe Wash Tank and Javelina Wash Tank) known to have reliable surface water (Fig. 6.1). We set mist nets directly over water, and varied the number of net hours among sites and visits depending on field conditions. We used monofilament nylon nets of three net sizes (5-m, 9-m, or 12$\mathrm{m})$ depending on the site and set nets singly or stacked, depending on conditions. For each bat captured, we recorded time of capture, species, and sex. When appropriate, we also recorded reproductive condition, forearm length, mass, body condition, tooth wear, presence of parasites, and other measurements. We determined whether individuals were adult, subadult (by closure of epiphyses), or juvenile (by appearance). We estimated age by tooth wear. For females, we recorded reproductive condition as pregnant (palpation for fetal bones), currently lactating (mammary gland with milk), previous evidence of lactation (misshapen or scarred nipples), or nulliparity (non-use of nipples). We determined reproductive condition for males by degree of swelling of testes or the presence of black epididymides and used this information to determine if the male was not reproductive, semireproductive, or reproductive. We marked all captured bats with a temporary, non-lethal marker 
to prevent counting the same individual more than once in the same evening. We used sonar detectors (Anabat and/or QMC Mini) at all sites to aid in determining bat presence/absence and relative activity as compared to the visual or mistnet results. We listened passively for the call of pallid bats, the only species in the area that can be definitively identified by its directive call.

\section{Effort and Analysis}

We visited each roost once in 2001 except for Gould Mine, which we visited twice, once in 2001 and once in 2002. We netted bats at two sites for a total of 2 nights (41.7 net-hours) in 2001 (Appendix J). We report the number of species and individuals caught at each site.

Percent netting success was calculated as the number of animals caught divided by effort (total length of net coverage multiplied by amount of time nets were open times 100).

\section{Large and Medium Mammals}

\section{Spatial Sampling Design}

We used infrared-triggered cameras to detect medium and large mammals at a combination of random and non-random sites (Fig. 6.1) during May 2001 through June 2002, and in a separate effort from March 2002 through March 2005 (Fig. 6.2). During the early effort in 2001 and 2002 we used cameras at 9 non-random sites; because we did not record the dates that these photos were taken, in the Results section we report these results separately.

In the later effort, from March 2002 to March 2005, we located non-random sites primarily at known water sources and game trails, but also targeted large holes in the ground, wash corridors, and other areas in an effort to detect as many species as possible. Location of random sites was based on the random coordinates chosen as focal points for the plant and animal inventories (see Introduction chapter), though many of these focal points were not surveyed for the other taxonomic groups. To avoid interference with other inventory activities at sites where there was other inventory work, and to maintain consistency among all focal points, we offset all camera locations from the focal point by using the same coordinates but with the NAD
27 map datum instead of NAD 83; this moved the focal points approximately $200 \mathrm{~m}$ from the original location. At each random location one unit was located at the random point; at selected sites we also placed a camera unit at a random point located at the nearest measured point in a mapped drainage (Dee et al. 2005).

\section{Temporal design}

After setting up a camera unit, we generally returned to it one week later to check that it was functioning properly and to make repairs and change film, if necessary. We then left the camera in place for approximately two weeks. However, the length of time varied, especially in remote areas that required hiking to reach, and we left in place a subset of cameras at both random and non-random locations for extended periods of several months.

\section{Field methods}

We primarily used the Trailmaster camera system (model 1500, Goodson and Associates, Inc., Lenaxa, KS; Kucera and Barrett 1993). The system consists of a transmitter that emits an infrared beam, a receiver that detects the beam, and a camera that is connected to the receiver with a cable (Fig. 6.5). The receiver triggers the camera to take a picture when an animal breaks the beam. We also used passive infraredtriggered systems, which are triggered by the combined heat and movement of an animal, including the DeerCam (model DC-100) and digital Cuddeback (both from Non-typical, Inc., Park Falls, WI) and the CamTrakker (CamTrak South,Watkinsville, Ga.). Because they function similarly, we do not further differentiate among the different camera systems used.

We initially baited each focal point camera using a fish-based canned catfood and a commercial trapping lure that attracted predators. Generally, we baited with catfood the first week, then the trapping lure the second week. We occasionally baited non-random camera locations. For visitor safety reasons, we did not locate baited stations within $100 \mathrm{~m}$ of a park trail.

\section{Effort}

In addition to the 9 non-random sites during the 2001 and 2002 effort, we placed cameras at 18 non-random and 29 random sites throughout the 


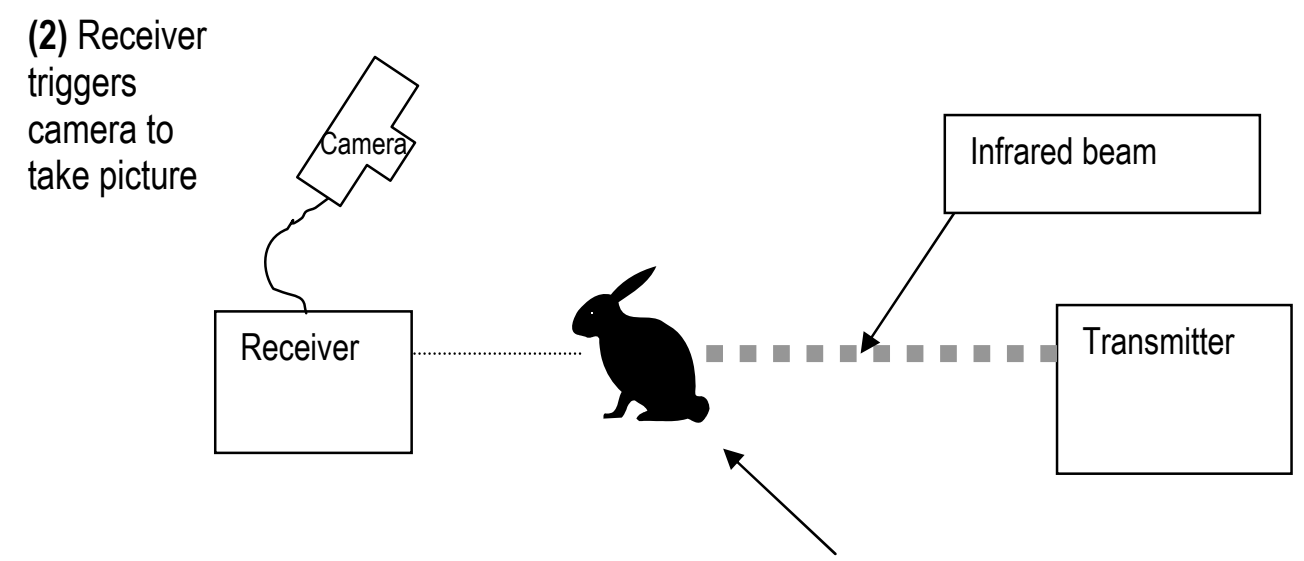

(1) Animal blocks infrared beam from getting to receiver

Figure 6.5. Typical configuration for an active infrared-triggered camera system. Image based on Swann et al. (2004).

district (Fig. 6.2). Considering both types of camera locations (i.e., random and non-random), we placed the majority of cameras in bajada areas (characterized as areas with relatively low slopes $\left.\left[<10^{\circ}\right]\right)$ compared to high slopes $\left(\geq 10^{\circ}\right.$; Table 6.2). The total number of camera-nights at all sites was approximately 1753, including 1450 in bajada areas and 303 in rocky areas (Table 6.2).

\section{Analysis}

We analyzed all photos and identified the animals present. A few species pairs (black-tailed and antelope jackrabbits, hooded and striped skunks, and kit and gray foxes) are difficult to distinguish under poor light conditions or if only part of the animal is visible; for these we made the best possible attempt to distinguish them, and sometimes identified the individual to genus only. We entered these and other data (species, number of individuals, film number, location, date, time if available, bait, etc.) into an Access database. We excluded from analysis all nonmammals (birds, reptiles, and blanks) as well as unknowns that could not be identified to genus, humans, horses with riders, and nocturnal rodents (mostly woodrats). For each camera location we summarized the number of photographs and number of individuals photographed for each species. To create species distribution maps, we converted UTM coordinates to NAD 83 datum and imported them into ArcView (these maps are available only at the park and I\&M office in Tucson).

Comparing species abundance and presence among locations using infraredtriggered photography is problematic. As with all methods, animals may not be detected because they are absent, or because they were present and not detected. In addition, rates of detection undoubtedly vary greatly among species. Determining relative abundance can also be difficult. Infrared-triggered camera units often do not operate continuously between the time they are set and when they are next checked because the film may be shot out or because the unit may fail due to technical problems or field errors. To estimate relative abundance based on effort, we used dates on photographs to determine as closely as possible how many nights a camera unit was operating for each roll of film, then summed the number of operational days at each location. Where dates were not available for a roll of film, 
Table 6.2. Summary of infrared-triggered camera effort, Saguaro NP, Tucson Mountain District, 2002-2005. This table does not include camera use during 2001 and 2002 because we could not calculate effort for this period (see text); data from 2001 and 2002 are reported separately in the Results. Low slope $<10^{\circ}$, high slope $\geq 10^{\circ}$.

\begin{tabular}{|c|c|c|}
\hline Type of camera & Site characteristics & Number of estimated camera-nights \\
\hline \multirow[t]{2}{*}{ Non-random } & Bajada & 296 \\
\hline & Rocky slopes & 91 \\
\hline \multirow[t]{2}{*}{ Random } & Bajada & 1154 \\
\hline & Rocky slopes & 212 \\
\hline Total & & 1753 \\
\hline
\end{tabular}

Table 6.3. Relative abundance of small mammals trapped at Saguaro NP, Tucson Mountain District, 2001 and 2002 at random (R) and non-random (NR) trapping grids. Numbers 1 and 2 in table heading indicate visit number. See Table 6.1 and Appendix I for details of effort (e.g., trap nights), dates of trapping, and grid configuration information.

\begin{tabular}{|c|c|c|c|c|c|c|c|c|c|c|c|}
\hline \multirow[b]{4}{*}{ Species } & \multicolumn{11}{|c|}{ Plot group } \\
\hline & \multicolumn{2}{|c|}{212} & \multicolumn{3}{|c|}{213} & 238 & \multicolumn{3}{|c|}{239} & \multirow{3}{*}{$\begin{array}{c}\begin{array}{c}\text { Kinney } \\
\text { Road }\end{array} \\
\text { NR } \\
1\end{array}$} & \multirow{3}{*}{$\begin{array}{c}\begin{array}{c}\text { Sandario } \\
\text { Road }\end{array} \\
\text { NR } \\
1 \\
\end{array}$} \\
\hline & \multirow{2}{*}{$\begin{array}{l}R \\
1 \\
\end{array}$} & \multirow{2}{*}{$\begin{array}{c}\mathrm{NR} \\
1 \\
\end{array}$} & \multicolumn{2}{|c|}{$\mathrm{R}$} & \multirow{2}{*}{$\begin{array}{c}\text { NR } \\
1 \\
\end{array}$} & \multirow{2}{*}{$\begin{array}{c}\mathrm{R} \\
1\end{array}$} & \multicolumn{2}{|c|}{$\mathrm{R}$} & \multirow{2}{*}{$\begin{array}{c}\text { NR } \\
1 \\
\end{array}$} & & \\
\hline & & & 1 & 2 & & & 1 & 2 & & & \\
\hline Harris' antelope squirrel & & & & & & & & 0.9 & & & \\
\hline pocket mouse species & & 2.6 & 3.5 & 0.7 & 5.3 & 0.5 & 1.3 & 7.5 & 8.2 & 1.3 & 0.6 \\
\hline Arizona pocket mouse & & & 2.3 & 2.2 & & & 3.8 & 14.2 & 2.1 & & 0.6 \\
\hline Sonoran Desert pocket mouse & & & & & & & 1.3 & 26.4 & 18.6 & & \\
\hline rock pocket mouse & 3.3 & & 0.6 & 2.2 & & & 7.6 & & 8.2 & 1.3 & 1.7 \\
\hline Bailey's pocket mouse & 0.8 & & 3.5 & 8.1 & 5.3 & 0.5 & 1.3 & 1.9 & 2.1 & 0.4 & \\
\hline Merriam's kangaroo rat & & & & & & & 13.3 & 7.5 & 6.2 & & \\
\hline unknown white-footed mouse & & 2.6 & 1.2 & & & 1.4 & & & & & \\
\hline cactus mouse & & & 1.8 & 0.7 & & & & & & & \\
\hline unknown woodrat & & & & & & & & 0.9 & & & \\
\hline western white-throated woodrat & 2.5 & & & & & & 3.8 & 0.9 & & & \\
\hline All species & 6.6 & 5.2 & 12.9 & 14.0 & 10.5 & 2.3 & 32.3 & 60.4 & 45.4 & 3.1 & 2.9 \\
\hline Species richness & 3 & 2 & 4 & 4 & 1 & 2 & 6 & 6 & 5 & 2 & 2 \\
\hline Species richness by plot group & & & & 4 & & 2 & & 7 & & 2 & 2 \\
\hline
\end{tabular}

we substituted the mean number of days it took to fill a roll of film (11.76 days). Because no photograph dates were recorded during the 2001 and 2002 effort, we did not include data from this period in the analysis. Relative abundance was presented as the number of photographs per operational day times 100 .

\section{Results}

\section{Species Richness}

We confirmed a total of 32 species of mammals in Saguaro National Park's Tucson Mountain District (Appendix D). This includes two species confirmed through specimens only, 15 species confirmed through photographs only, eight species confirmed through a combination of both specimens and photos, and seven species captured for which a voucher specimen or a reliable report previously existed. This total includes only species for which we have photographs or voucher specimens; two additional species (brush mouse and coati) may have been observed but could not be confirmed during our study.

We confirmed nine species of mammals not previously confirmed for TMD, although these species were already believed to be present (e.g., Doll et al. 1989). We did not observe any species 
Table 6.4. Results of roost site detections and netting for bats, Saguaro NP, Tucson Mountain District, 2001 and 2002. See Appendix J for additional information.

\begin{tabular}{|c|c|c|c|}
\hline Type of investigation & Study site & Species & Number observed/captured \\
\hline \multirow[t]{3}{*}{ Roost } & Gould Mine & California leaf-nosed bat & 2 \\
\hline & & cave myotis & 5 \\
\hline & Yuma Mine & California leaf-nosed bat & $18+$ \\
\hline \multirow[t]{4}{*}{ Netting } & Dobe Wash Tank & cave myotis & 7 \\
\hline & & western pipistrelle & 3 \\
\hline & Javelina Wash Tank & cave myotis & 1 \\
\hline & & western pipistrelle & 1 \\
\hline
\end{tabular}

listed by the U.S. Fish and Wildlife Service as endangered or threatened. We documented two non-native animals (feral cat and domestic dog); domestic dogs are a potential management issue, but we found no evidence that either species has established feral populations in the district.

Based on a review of our inventory and other studies in the district, there have been a total of 40 species of mammals confirmed or reliably documented in the Tucson Mountain District of Saguaro National Park since it was established in 1961. We could not confirm four species that have been previously confirmed for TMD and four others that have been reliably documented. The previously confirmed species include two bats, Townsend's big-eared bat and big brown bat (Sidner and Davis 1994) that probably still occur at the district, and two rodents, Arizona cotton rat (collected at TMD in 1993 [SNP specimen records], and deer mouse (a single specimen from 1970 near the northern TMD boundary). Reliably documented species include southern grasshopper mouse, which has been trapped by Robert Parmenter (unpublished data; SNP files) as well as by Yensen (1973); a house mouse recorded by Yensen (1973) for which no specimen was collected, and two species that appear to be extirpated from TMD: bighorn sheep (Coss 1969) and North American porcupine (SNP records, 1975). Coatis have also been observed at TMD (SNP observation database), but we are not certain if these are reliable observations.

\section{Small Mammals}

We trapped 254 individual rodents (including 45 recaptures) and documented eight species (Table 6.3) through our trapping effort, including one of the three species of diurnal squirrels also documented by infrared-triggered photography. There were no species found to be new for the district; we could not confirm the identity of a brush mouse identified as such in the field but not brought in for expert identification. As noted previously, we did not capture four species previously documented for TMD.

Small mammal species richness was eight on random plots and six on non-random plots (Table 6.2), though sampling effort was also greater on random plots. The single bajada site that we trapped, plot 239, had the most species captured (7) and the highest relative abundance of any site for six of these species.

\section{$\underline{\text { Bats }}$}

We confirmed only three species of bats during 2001 and 2002: California leaf-nosed bat, cave myotis, and western pipistrelle (Table 6.4). The most widespread species was the cave myotis, which we found at one mine site (on both visits) and at both tanks at which we placed nets. We found California leaf-nosed bat at both mine sites and it numbered at least 18 individuals at the Yuma mine site. In total, we observed greater than 25 bats at roost sites and trapped 12 bats at water sources (Table 6.4). The percent netting success was $57.1 \%$ at Dobe Wash and $8.3 \%$ at Javelina Wash.

\section{Medium and Large Mammals}

\section{1 and 2002}

We took 181 photographs of 197 individual mammals representing 12 species (not including nocturnal rodents and people) during the early photography effort 2001 and 2002 (Table 6.5). The largest number of photographs was of the gray fox (127 photos). 
2002-2005

In 1,753 estimated camera-nights during 20022005 , we took 1,525 photographs that captured at least one mammal that could be identified to genus, and a total of 1,701 individual mammals (Table 6.5). We photographed 21 species, including one non-native species, the domestic dog. The largest number of photographs was of the gray fox (455 photos), followed by collared peccary (307 photos), coyote ( 238 photos), and desert cottontail (169 photos). Cameras at non-random sites captured an average of 0.99 photographs per camera-night compared with 0.84 at random sites. Species richness was similar at random (18) and non-random sites (17), although effort was greater at random sites.

Relative abundance of a number of species, including coyote, mule deer, black-tailed jackrabbit, and desert cottontail was higher in bajada areas than in rocky areas of higher slope, as was overall relative abundance (Table 6.5). Species richness was 18 in bajada areas and 14 in rocky areas, though effort was greater on the bajada.

\section{Inventory Completeness}

We confirmed a total of 32 species of mammals in the district, and failed to confirm eight species previously documented for the Tucson Mountains. Of these eight, two species (bighorn sheep and American porcupine) are certainly extirpated from the district. We believe that two species of bats and at least one rodent (southern grasshopper mouse) documented in the past are still present and would be confirmed with additional survey effort. Due to lack of habitat at the district, three rodents detected in the past (deer mouse, house mouse, and Arizona cotton rat) are probably rare or transient at TMD, as are raccoons and coatis. Based on historic records,

Table 6.5. Number of photographs of mammal species, from infrared-triggered photography, Saguaro NP, Tucson Mountain District, 2001-2005. Relative abundance (RA) is number of photographs of that species per estimated number of working camera-nights. Does not include individuals that could be identified to genus, but not species (e.g., some photos of deer, skunks, rabbits, and squirrels).

\begin{tabular}{|c|c|c|c|c|c|c|}
\hline \multirow[b]{2}{*}{ Species } & \multicolumn{2}{|c|}{$2001-2002$} & \multicolumn{2}{|c|}{ 2002-2005 Bajada } & \multicolumn{2}{|c|}{ 2002-2005 Rocks } \\
\hline & No. Photos & RA & No. Photos & $\mathrm{RA}$ & No. Photos & $\mathrm{RA}$ \\
\hline$\overline{\text { ringtail }}$ & 4 & - & 4 & .3 & 7 & 2.3 \\
\hline common raccoon & 0 & - & 1 & 0.1 & 0 & 0 \\
\hline American badger & 2 & & 7 & 0.5 & 0 & 0 \\
\hline striped skunk & 1 & - & 1 & 0.1 & 1 & 0.3 \\
\hline hooded skunk & 7 & - & 44 & 3.0 & 11 & 3.6 \\
\hline white-backed hog-nosed skunk & 3 & - & 3 & 0.2 & 0 & 0 \\
\hline western spotted skunk & 3 & - & 0 & 0 & 1 & 0.3 \\
\hline unknown skunk & 0 & - & 0 & 0 & 6 & 2.0 \\
\hline coyote & 7 & - & 225 & 15.5 & 13 & 4.3 \\
\hline domestic dog & 0 & - & 2 & 0.1 & 1 & 0.3 \\
\hline common gray fox & 127 & - & 356 & 24.6 & 99 & 32.7 \\
\hline kit fox & 0 & & 2 & 0.1 & 0 & 0 \\
\hline mountain lion & 0 & - & 5 & 0.3 & 2 & 0.7 \\
\hline bobcat & 2 & - & 24 & 1.7 & 10 & 3.3 \\
\hline round-tailed ground squirrel & 0 & - & 2 & 0.1 & 0 & 0 \\
\hline rock squirrel & 1 & - & 23 & 1.6 & 6 & 2.0 \\
\hline Harris' antelope squirrel & 0 & - & 17 & 1.2 & 0 & 0 \\
\hline antelope jackrabbit & 0 & - & 22 & 1.5 & 0 & 0 \\
\hline black-tailed jackrabbit & 4 & - & 87 & 6.0 & 7 & 2.3 \\
\hline unknown jackrabbit & 0 & & 8 & 0.6 & 0 & 0 \\
\hline desert cottontail & 0 & - & 168 & 11.6 & 1 & 0.3 \\
\hline collared peccary & 20 & - & 278 & 19.2 & 29 & 9.6 \\
\hline mule deer & 0 & - & 50 & 3.5 & 2 & 0.7 \\
\hline Totals & 181 & - & 1329 & 91.7 & 196 & 64.7 \\
\hline Species richness & 12 & & 21 & & 14 & \\
\hline
\end{tabular}


if we assume that six species of rodents and bats went undetected, our inventory confirmed $84 \%$ of mammals known for the district. The species accumulation curve for small mammal trapping (Fig. 6.6) suggests that we may have trapped additional species with greater effort, and we certainly would have detected more bats with greater effort. The species accumulation curve for infrared-triggered cameras (Fig. 6.7) suggests that our inventory for medium and large mammals was fairly complete.
The nine "new" species reported during this study were probably not previously confirmed simply due to lack of previous inventory effort. Indeed, some of these species (especially Harris antelope squirrel) are quite common at the district. However, we were pleased to detect American badgers and kit foxes, two species that do not appear to be common at TMD and may be declining due to habitat loss outside the district.

We believe that more bats would be detected with a more intensive survey effort.

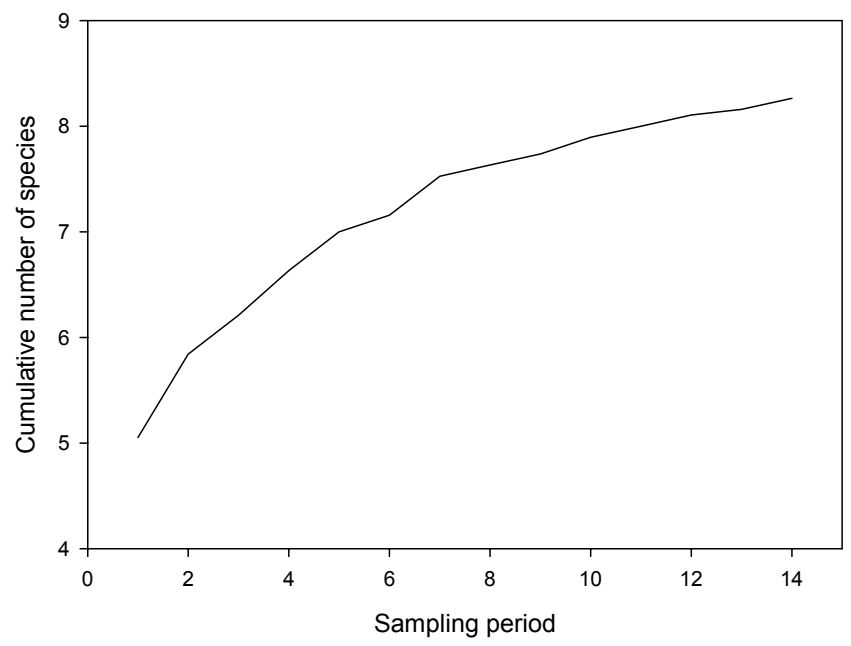

Figure 6.6. Species accumulation curve for small-mammal trapping, Saguaro NP, Tucson Mountain District, 2001. Each sampling period represents a random ordering of 10 observations.

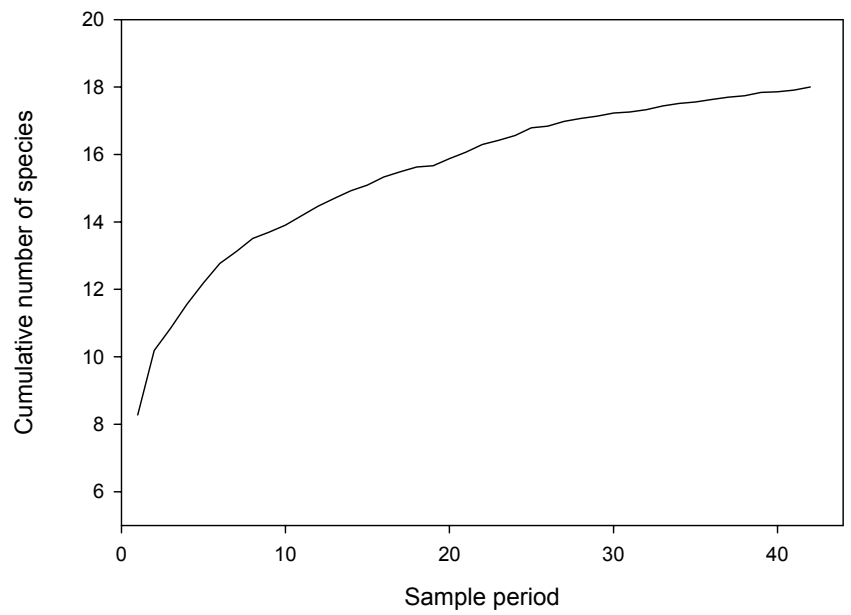

Figure 6.7. Species accumulation curve for infrared-triggered photography, Saguaro NP, Tucson Mountain District, 2002-2005. Each sampling period represents a random ordering of 10 observations. 
Because bats congregate at water sources, detecting bats at TMD is more difficult than in many other parks in the region because there are no large water sources where mist-netting can be conducted, and water in general is scarce. Dr. Ronnie Sidner, who collected data for this effort and is a regional expert on the distribution and ecology of bats (see Sidner and Davis 1994), believes that an additional 10 species could be found in the district with additional survey effort (Table 6.6). We encourage the park to promote additional studies of bats at TMD, particularly as newer audio technologies develop.

Additional species of rodents near the edge of their geographic range could also be present at TMD (Table 6.6), but the lack of grassland and riparian habitats make this unlikely for most of the species listed. The two species most likely to be found in the future are probably Botta's pocket gopher and banner-tailed kangaroo rat. We have recently observed burrowing activity that could be that of pocket gophers (Don Swann, Erin Zylstra, pers. obs.).

\section{Discussion}

Despite its close proximity to Tucson, the Tucson Mountain District has had only a few mammal studies. Our study represents the first comprehensive inventory of the district and the first to quantify relative abundance and distribution of species; we intend that it will provide a good baseline for evaluating future changes in the mammal community at the district, and will also lead to additional research on mammals of concern.

\section{Biogeography}

As noted in other chapters, the Tucson Mountain District stands in unique geographic contrast to the Rincon Mountain District (RMD) of the park. The Rincon Mountains have great topographical diversity, rising from the desert floor to more than 8600' (2621 m) in elevation, and contain elements of several major biogeographic provinces. By contrast, the Tucson Mountains are a desert range, with a peak elevation of $4687^{\prime}$ (1429 m). Not surprisingly we confirmed 59 species of mammals in the RMD, and 32 at TMD. However, the Tucson Mountains do contain elements of the Lower Colorado subdivision of the Sonoran Desert not found at RMD, which increases diversity of desert mammals.

The mammal community of the Tucson Mountains is dominated by "classic" desert species, including Merriam's kangaroo rats, round-tailed ground squirrels, Sonoran Desert

Table 6.6. List of possible bat and rodent species for Saguaro NP, Tucson Mountain District. Bat list developed by Ronnie Sidner based on her knowledge of the distribution and habitat requirements of bats; rodent list from Hoffmeister (1986) based on specimens collected within approximately 10 miles of TMD.

\begin{tabular}{|c|c|c|}
\hline Family & Scientific name & Common name \\
\hline \multirow[t]{2}{*}{ Phyllostomidae } & Choeronycteris mexicana & Mexican long-tongued bat \\
\hline & Leptonycteris curasoae yerbabuenae & southern long-nosed bat \\
\hline \multirow[t]{4}{*}{ Vespertilionidae } & Myotis californicus & California myotis \\
\hline & Myotis ciliolabrum & western small-footed myotis \\
\hline & Lasiurus xanthinus & western yellow bat \\
\hline & Antrozous pallidus & pallid bat \\
\hline \multirow[t]{4}{*}{ Molossidae } & Tadarida brasiliensis & Brazilian free-tailed bat \\
\hline & Nyctinomops femorosaccus & pocketed free-tailed bat \\
\hline & Nyctinomops macrotis & big free-tailed bat \\
\hline & Eumops perotis californicus & western bonneted bat \\
\hline \multirow[t]{3}{*}{ Heteromyidea } & Dipodomys spectabilis & banner-tailed kangaroo rat \\
\hline & Dipodomys ordii & Ord's kangaroo rat \\
\hline & Perognatus flavus & Silky pocket mouse \\
\hline \multirow[t]{4}{*}{ Muridae } & Reithrodontomys fulvescens & fulvous harvest mouse \\
\hline & Reithrodontomys megalotis & western harvest mouse \\
\hline & Peromyscus merriami & mesquite mouse \\
\hline & Peromuscus leucopus & white-footed mouse \\
\hline Geomyidae & Thomomys bottae & Botta's pocket gopher \\
\hline
\end{tabular}


pocket mice, cave myotis, and mule deer. A number of other species, particularly bats and grassland rodents, occur nearby, but are just beyond the western and southern edges of their range. For example, red bats, yellow-nosed cotton rats, fulvous harvest mice, and a number of other species occur in the Santa Catalina and Rincon mountains, but probably not in the Tucson Mountains (Hoffmeister 1986). It is possible that with more intensive effort these species might be found in the Tucson Mountains, but it is more probable that they do not occur in the district due to the lack of riparian and grassland habitats.

\section{Habitat Associations}

We chose to stratify by habitat type in this inventory based on slope rather than elevation, because elevation differences are not significant at Tucson Mountain District, yet changes in substrate characteristics throughout the district are striking. Changes in slope from low to high correspond with changes in geology. In the valley bottoms, soils are loose and fine; at the base of the mountains soils are coarse, and larger boulders are present; and the mountains themselves are extremely rocky. As seen in other chapters of this report, the vegetation and herpetofauna also vary with changes in slope (see also Yang and Lowe 1956). It is noteworthy that abundance and diversity of both small and large mammals were greater in the bajada than in rocky areas. This may correspond with greater availability of food, including grass seeds and the rodents that eat these seeds. A number of species, such as kit fox, badger, Merriam's kangaroo rats, round-tailed ground squirrels, and others, occur almost exclusively in areas with friable soil. In contrast, ringtails and rock pocket mouse are rarely found far from rock outcrops. Unlike the Rincon Mountains, TMD has no perennial water sources and no mesic riparian vegetation. The xeric riparian washes, however, are likely corridors and places of increased cover suitable for larger mammals.

\section{Changes in the Mammal Community}

In the RMD we found evidence of important changes in the mammal community since the establishment of the park in 1933 (Swann and
Powell 2006b). If these patterns are evident in the Tucson Mountain District, they do not appear to be as pronounced. However, as in the Rincon Mountains, lack of historic data preclude a full understanding of the situation. Like the Rincon Mountains, the Tucson Mountains have lost bighorn sheep, which were detected on game surveys in the 1930s (Saguaro NP historical data). It is not known when this species was extirpated from the TMD, but the last recorded sighting was in 1957 (Coss 1969). It seems possible that other large mammals that have disappeared from southern Arizona during the past century, including Mexican gray wolves, were once present in the Tucson Mountains as well, but the habitat for these forest animals was limited at best.

In southern Arizona, North American porcupines occupy a variety of habitats, including desert and semidesert grassland (Hoffmeister 1986). Little is known about porcupines at TMD, but "several" skeletons of this species were observed near the Wasson Peak Trail in 1975 by a park ranger (SNP, historical data). Porcupines appear to be declining for unknown reasons in southern Arizona, possibly due to habitat changes, although Harley Shaw (pers. comm.) has suggested that it is due to the large increase in the population of mountain lions. We found no evidence that porcupines occur at TMD and consider them extirpated.

Unlike the Rincon Mountains, gross habitat changes at TMD in recent decades do not appear to be significant. Grazing in the park, currently excluded, was never heavy at TMD and appears to have ended in 1934 when the county park was established (Borell 1936, Saguaro National Park, 1987). The Sonoran Desert typically is not fire-adapted so there is little history of fire suppression at TMD. There is a long history of mining in the district, but few of these mines were large. Predator control of coyotes probably occurred during the mid $20^{\text {th }}$ century in the Tucson Mountains, but we have been unable to document this.

The major current issue at TMD is habitat loss outside the boundary of the district, as well as urban impacts inside the district associated with roads. Species that may be most negatively 
affected by habitat changes, and indeed may face extirpation from TMD, include American badgers, kit foxes, and other low desert species for which there is only a limited amount of habitat in the district. In addition, it seems that mountain lions, which require large amounts of land, could be losing their ability to move easily in and out of the Tucson Mountains. All three of these species appear to be rare at TMD. Kit foxes occurred in high and low densities along the edges of TMD in the early 1980s (deVos et al. 1983) and were captured readily (6 in 167 trap-nights) for a study just north of TMD (at Twin Peaks) in 1988 (Harper and Messing 1987). It seems likely that this species is declining as habitat outside the district decreases. Mountain lions still occur in low numbers at TMD (Hackl et al. 2006, Haynes and Swann, in prep.). It is unknown if badgers were ever common at TMD, but they share similar habitat as kit foxes and are probably impacted by loss of this habitat outside the district. In contrast, urban development probably favors species that adapt well to humans, such as coyotes and bobcats.

\section{Management Implications}

Like many natural areas (Newmark 1995, Powell et al. 2006a), the Tucson Mountain District of Saguaro National Park has seen some loss of mammal species since it was established as a park (originally, as a county park) in the 1930s. Our study indicates that these losses may be continuing at the district, with the diminishing habitat outside the district being the primary concern for medium and large mammals at the present time. It seems probable that significant management efforts would be needed to prevent the future extirpation of species like American badger and mountain lion. The major issue for $\mathrm{TMD}$, in contrast to RMD, is that the district is relatively small and is on the verge of becoming completely isolated by barriers to movement by mammals.

While some species have declined or disappeared during the park's history, others have increased. The park deserves credit for instituting land management practices that have improved habitat for many species. NPS policies, including cessation of cattle grazing, banning of hunting and trapping, elimination of off-road vehicles, and restriction of road-building have all helped to improve conditions for mammals at the district. On the other hand, the lack of high-profile encounters between humans and mountain lions at the park, so far, have probably been at least partly a matter of good luck. Park managers are currently working on plans for lion management that include responding to humanlion encounters.

Areas for future research should focus on mammals for which little data are available, such as kit fox, American badgers, mule deer, and bats. Additional inventory work should focus on bats and rodents, and an effort should be made to determine the status of pocket gophers on the district.

The major ecological changes that are occurring throughout the west are certainly impacting mammal populations at Saguaro National Park. In the future, habitat loss outside of district boundaries will probably continue to reduce the great mammal diversity that Saguaro National Park has but, at the same time, knowledge of this loss should only make the preservation of parklands more critical in the years to come. 


\section{Chapter 7: Literature Cited}

Allen, C. D., and D. D. Breshears. 1998. Droughtinduced shift of a forest-woodland ecotone: rapid landscape response to climate variation. Proceedings of the National Academy of Sciences of the United States of America 95:14839-14842.

American Ornithologists' Union (AOU). 1998. Checklist of North American birds, seventh edition. American Ornithologists' Union and Allen Press Inc., Lawrence, KS.

American Ornithologists' Union (AOU). 2003. Forty-second supplement to the American Ornithologists' Union checklist of North American birds. Auk 117:847-858.

Anable, M. E., M. P. McClaran, and G. B. Ruyle. 1992. Spread of introduced Lehmann's lovegrass Eragrostis lehmanniana Nees. in southern Arizona, USA. Biological Conservation 61:181188.

Anderson, D. R. 2001. The need to get the basics right in wildlife field studies. Wildlife Society Bulletin 29:1294-1297.

Baker, R. J., L. C. Bradley, R. D. Bradley, J. W. Dragoo, M. D. Engstrom, R. S. Hoffmann, C. A. Jones, F. Reid, D. W. Rice, and C. Jones. 2003. Revised checklist of North American mammals north of Mexico, 2003. Occasional Papers of the Museum of Texas Tech University 229:1-23.

Beauvais, G. P., and S. W. Buskirk. 1999. Modifying estimates of sampling effort to account for sprung traps. Wildlife Society Bulletin 27:3943.

Bertelsen, C. D. 1998. Vegetation of Tucson Mountain District expansion lands at Saguaro National Park. Unpublished report to Saguaro National Park, Tucson.

Bibby, C. J., N. D. Burgess, and D. A. Hill. 2002. Bird census techniques. Academic Press, London, England.

Bock, C. E., J. H. Bock, K. L. Jepson, and J. C. Ortega. 1986. Ecological effects of planting African lovegrasses in Arizona. National Geographic Research 2:456-463.

Bonham, C. D. 1989. Measurements for terrestrial vegetation. John Wiley and Sons Inc., New York, NY.

Borell, A. E. 1936. Technical comment - wildlife, Tucson Mountain Park, Arizona. Memorandum to Mr. Collins. Saguaro National Park files, Tucson.
Braun-Blanquet, J. 1965. Plant sociology: the study of plant communities. Hafner Inc., London, England.

Briggs, M. K., L. Harris, J. Howe, and W. Halvorson. 1996. Using long-term monitoring to understand how adjacent land development affects natural areas: an example from Saguaro National Park, Arizona (USA). Natural Areas Journal 16:354361.

Brown, D. E., and C. H. Lowe. 1980. Biotic communities of the southwest. U.S. Forest Service General Report RM-78, Rocky Mountain Forest and Range Experiment Station, Fort Collins, Colorado.

Brown, D. E. 1994. Biotic communities: southwestern United States and northwestern Mexico. University of Utah Press, Salt Lake City, UT.

Buckland, S. T., D. R. Anderson, K. P. Burnham, J. L. Laake, D. L. Borchers, and L. Thomas. 2001. Introduction to distance sampling: Estimating abundance of biological populations. Oxford University Press, London, England.

Burgess, T. L., J. E. Bowers, and R. M. Turner. 1991. Exotic plants at the Desert Laboratory, Tucson, Arizona. Madrono 38:96-114.

Clarke, A. L., and T. Pacin. 2002. Domestic cat "colonies" in natural areas: a growing exotic species threat. Natural Areas Journal 22:154159.

Colver, K. J., D. Stokes, and L. Stokes. 1999. Stokes field guide to bird songs. Time Warner, New York, NY.

Corman, T. E., and C. Wise-Gervais, editors. 2005. Arizona breeding bird atlas. University of New Mexico Press, Albuquerque, NM.

Corn, S. P. 1994. Straight-line drift fences and pitfall traps. Pp. 109-117. In W. R. Heyer, M. A. Donnelly, R. W. McDiarmid, L. C. Hayek, and M. S. Foster, editors. Measuring and monitoring biodiversity: standard methods for amphibians. Smithsonian Institution Press, Washington, D.C.

Coss, H. 1969. Untitled report on the history and potential for reintroduction of desert bighorn sheep in Saguaro National Park. Saguaro National Park files, Tucson.

Crump, M. L., and N. J. Scott. 1994. Visual encounter surveys. Pp. 84-92. In W. R. Heyer, M. A. Donnelly, R. W. McDiarmid, L. C. Hayek, and M. S. Foster, editors. Measuring 
and monitoring biodiversity: Standard methods for amphibians. Smithsonian Institution Press, Washington, D.C.

Dalton, D., and S. Wolf. 2002. Design of a bataccessible gate for the cave bat, Myotis velifer, at Wildhorse Mine, Saguaro National Park. Unpublished report to Saguaro National Park (Project No. SAGU-N-048.002), Tucson.

D'Antonio, C. M., and P. M. Vitousek. 1992. Biological invasions by exotic grasses, the grass fire cycle, and global change. Annual Review of Ecology and Systematics 23:63-87.

Davis, K., and W. L. Halvorson. 2000. A study plan to inventory vascular plants and vertebrates: Sonoran Desert Network. National Park Service, Southern Arizona Office, Phoenix.

Dee, A. J., D. E. Swann, and M. Culver. 2005. Evaluating genetic analysis of scat as a technique for monitoring species richness in national parks. Unpublished report to Western National Parks Association and Saguaro National Park, Tucson.

Degenhardt, W. G., C. W. Painter, and A. H. Price. 1996. Amphibians and reptiles of New Mexico. University of New Mexico Press, Albuquerque, NM.

DeVos, J. C., C. R. Miller, S. L. Walchuk, W. D. Ough, and D. E. Taylor. 1983. Final report for the biological resource inventory: Tucson Division - Phase B Central Arizona Project Aqueduct. Unpublished report, US Bureau of Reclamation, Arizona Projects Office, Phoenix.

Dimmitt, M. A. 2000. Biomes and communities of the Sonoran Desert region. In S. J. Phillips and P. W. Comus, editors. A natural history of the Sonoran Desert. Arizona-Sonora Desert Museum Press, Tucson.

Doll, M. H., R. V. Ellis, R. L. Hayes, R. Sidner, H. McCrystal, R. Davis, and R. L. Hall. 1989. A checklist of the herpetofauna and mammals of Saguaro National Monument. Southwest Parks and Monuments Association, Tucson.

Elzinga, C. L., D. W. Salzer, J. W. Willoughby, and J. P. Gibbs. 2001. Monitoring plant and animal populations. Blackwell Science, Malden, MA.

Flesch, A. D. 2001. Distribution, relative abundance, and microhabitat associations of small mammals in Saguaro National Park, southeast Arizona. Unpublished report to the University of Arizona Inventory and Monitoring Program, Tucson.

Frohn, R. C. 1998. Remote sensing for landscape ecology: new metric indicators for monitoring, modeling and assessment of ecosystems. Lewis Publishers, Boca Raton, FL.
Fuller, M. R., and J. A. Mosher. 1987. Raptor survey techniques. Pp. 37-66. In B. A. GeronPendleton, B. A. Millsap, K. W. Cline, and D. M. Bird, editors. Raptor management techniques manual. National Wildlife Federation, Washington, D.C.

Funicelli, C. S., P. J. Anning, and D. S. Turner. 2001. Long-term vegetation monitoring at Saguaro National Park: A decade of change. Technical Report No. 70. USGS Sonoran Desert Research Station, University of Arizona, Tucson.

Germaine, S. S., S. S. Rosenstock, R. E. Schweinsburg, and W. S. Richardson. 1998. Relationships among breeding birds, habitat, and residential development in greater Tucson, Arizona. Ecological Applications 8:680-691.

Goldberg, D. E., and R. M. Turner. 1986. Vegetation change and plot demography in permanent plots in the Sonoran Desert. Ecology 67:695-712.

Goode, M. J., D. E. Swann, and C. R. Schwalbe. 2004. Effects of destructive collecting practices on reptiles: A field experiment. Journal of Wildlife Management 68:427-432.

Hackl, C. Z., L. Haynes, M. Culver, and D. E. Swann. 2006. Conservation and management of jaguars, mountain lions, and other felids in four southern Arizona parks. Final report to Desert Southwest Cooperative Ecosystems Study Unit, University of Arizona, Tucson.

Halvorson, W. L., and P. P. Guertin. 2003. USGS Weeds in the West project: status of introduced plants in southern Arizona parks. USGS, Sonoran Desert Research Station, University of Arizona, Tucson.

Hardy, P. C., D. J. Griffin, A. J. Kuenzi, and M. L. Morrison. 2004. Occurrence and habitat use of passage neotropical migrants in the Sonoran Desert. Western North American Naturalist 64:59-71.

Harper, S. D., and H. J. Messing. 1987. Kit fox monitoring study on Tucson Aqueduct, Phase B, July 1986-1987. Unpublished report, U.S. Department of the Interior, Bureau of Reclamation, Arizona Projects Office, Environmental Division, Phoenix.

Hayek, L. C., and M. A. Buzas. 1997. Surveying natural populations. Columbia University Press, New York, NY.

Haynes, L., D. E. Swann, and B. Williams. 2007. Bobcats on the urban fringe - research in Saguaro National Park, Tucson Mountain District. Final report to Friends of Saguaro National Park, Tucson. 
Haynes, L., and D. E. Swann. In preparation. Status of mountain lions in the Tucson Mountain District of Saguaro National Park. Unpublished final report to Saguaro National Park, Tucson.

Heritage Data Management System (HDMS). 2004. Arizona Game and Fish Department. Accessed 5 March from: http://www.azgfd.gov/w_c/edits/ hdms_species_lists.shtml.

Hoffmeister, D. F. 1986. Mammals of Arizona. University of Arizona Press and Arizona Game and Fish Department, Tucson.

Holden, M. 2005. Sonoran upland vegetation monitoring in Saguaro National Park, 1999_ 2005. Draft in-park report.

Integrated Taxonomic Information System (ITIS). 2005. Accessed 20 March 2005 from: http://www.itis.gov

Ivanyi, C., J. Perry, T. R. Van Devender, and H. Lawler. 2000. Reptile and amphibian accounts. Pp. 533-585. In S. J. Phillips and P. W. Comus, editors. A natural history of the Sonoran Desert. Arizona-Sonora Desert Museum Press, Tucson.

Jones, C. A., C. R. Schwalbe, D. E. Swann, D. P. Prival, and W. W. Shaw. 2005. Mycoplasma agassizii in desert tortoises. Final report to the Arizona Game and Fish Department Heritage Grant Project \#U03005, Phoenix.

Kennedy, K. A., and P. A. Addison. 1987. Some considerations for the use of visual estimates of plant cover in biomonitoring. Journal of Ecology 75:151-157.

Kline, N. C. 1998. Results of wildlife monitoring at two wildlife catchments in the Tucson Mountain District of Saguaro National Park. Unpublished report to the Bureau of Reclamation, Lower Colorado Region, Phoenix.

Kline, N. C., and D. E. Swann. 1998. Quantifying wildlife mortality on roads in Saguaro National Park. Pp. 23-31. In G. L. Evink, P. Garrett, D. Zeigler, and J. Berry, editors. Proceedings of conference on transportation and wildlife ecology, Fort Meyers, FL, February 10-12, 1998.

Kline, N. C., D. E. Swann, and T. Hubbard. 1998. Results of wildlife monitoring at two water catchments in the Tucson Mountain District of Saguaro National Park from 1989-1993. Final report to Department of Reclamation, Tucson.

Kucera, T. E., and R. H. Barrett. 1993. The Trailmaster camera system for detecting wildlife. Wildlife Society Bulletin 21:505-508.

Latta, M. J., C. J. Beardmore, and T. E. Corman. 1999. Arizona Partners in Flight conservation plan. Technical Report 142. Nongame and
Endangered Wildlife Program, Arizona Game and Fish Department, Phoenix, AZ.

Lowe, C. H. 1992. On the biogeography of the herpetofauna of Saguaro National Monument. Pp. 91-104. In Proceedings of the symposium on research in Saguaro National Monument. Cooperative Park Studies Unit, University of Arizona, Tucson.

Lowe, C. H., and P. A. Holm. 1991. The amphibians and reptiles at Saguaro National Monument, Arizona. Technical Report No. 37. Cooperative National Park Resources Studies Unit, University of Arizona, Tucson.

McAuliffe, J. R. 1993. Case study of research, monitoring, and management programs associated with the saguaro cactus (Carnegia gigantea) at Saguaro National Monument, Arizona. Technical report NPS/WRUA/NRTR93/01. National Park Service, Cooperative National Park Resources Studies Unit, University of Arizona, Tucson.

M'Closkey, R. T. 1980. Spatial patterns in sizes of seeds collected by four species of heteromyid rodents. Ecology 61:486-489.

McLaughlin, S. P., and J. E. Bowers. 1999. Diversity and affinities of the flora of the Sonoran Floristic Province. Pages 12-35. In R. H. Robichaux, editor. Ecology of Sonoran Desert plants and plant communities. The University of Arizona Press, Tucson.

Mannan, R. W., and B. Bibles. 1989. Impacts of exotic cavity-nesting birds on native cavitynesting birds in Saguaro National Monument. Unpublished report to Saguaro National Park, Tucson.

Mau-Crimmins, T., A. Hubbard, D. Angell, C. Filipone, and N. Kline. 2005. Sonoran Desert Network vital signs monitoring plan. Technical report NPS/IMR/SODN-003. National Park Service. Denver, CO.

May, L. A. 1970. Vegetation type map of Tucson Mountain District of Saguaro National Monument. Unpublished report to the National Park Service. File located at Saguaro National Park, Tucson.

Mills, G. S., J. B. Dunning, Jr., and J. M. Bates. 1989. Effects of urbanization of breeding bird community structure in southwestern desert habitats. Condor 91:416-428.

Monson, G., and S. Smith. 1985. Bird checklist for Saguaro National Monument. Southwest Parks and Monuments Association, Tucson. 
Mott, D. N. 1997. Saguaro National Park, Arizona Water Resources Report. Unpublished report by the National Park Service, Fort Collins, CO.

Naeem, S., L. J. Thompson, T. H. Jones, J. H. Lawton, S. P. Lawler, and R. M. Woodfin. 1996. Changing community composition and elevated $\mathrm{CO}_{2}$. Pp. 93-100. In C. Korner, and F. A. Bazzaz, editors. Carbon dioxide, populations, and communities. Academic Press, San Diego, CA.

National Park Service (NPS). 1992a. NPS-75: Natural resources inventory and monitoring guidelines. U.S. Dept. of Interior, Washington, D.C.

National Park Service (NPS). 1992b. Update to the natural/cultural resources management plan. Saguaro National Monument, Tucson.

National Park Service (NPS). 2005. NPS visitation database reports. Accessed 9 January 2005 from:. http://www.nature.nps.gov/stats/

Nelson, L., and F. W. Clark. 1973. Correction for sprung traps in catch/effort calculations of trapping results. Journal of Mammology 54:295-298.

Newmark, W. D. 1995. Extinction of mammal populations in western North-American national parks. Conservation Biology 9:512-526.

North American Ornithological Atlas Committee (NAOAC). 1990. Handbook for atlasing North American breeding birds. C. Smith, editor. Accessed 13 July 2001 from: http://bsc-eoc.org/norac/atlascont.htm

Pima Association of Governments (PAG). 2005. Population estimates 1980-2004. Accessed 22 Aug 2005 from: http://www.pagnet.org/ RegionalData/Population/tabid/104/Default.aspx.

Pollock, K. H., J. D. Nichols, T. R. Simons, G. L. Farnsworth, L. L. Bailey, and J. R. Sauer. 2002. Large scale wildlife monitoring studies: statistical methods for design and analysis. Environmetrics 13:105-119.

Powell, B. F., E. W. Albrecht, W. L. Halvorson, and K. Docherty. 2003. Biological inventory report for the Sonoran Desert Network: 2002. Annual Report No. 2. Sonoran Desert Network Inventory Program. USGS, Sonoran Desert Research Station and School of Natural Resources, University of Arizona, Tucson.

Powell, B. F., E. W. Albrecht, W. L. Halvorson, C. A. Schmidt, P. Anning, and K. Docherty. 2005. Vascular plant and vertebrate inventory of Tumacácori National Historical Park. USGS Open File Report 2005-1142. U.S. Geological
Survey, Southwest Biological Sciences Center, Sonoran Desert Research Station, University of Arizona, Tucson. http://pubs.usgs.gov/ of $/ 2005 / 1142$.

Powell, B. F., E. W. Albrecht, C. A. Schmidt, W. L. Halvorson, P. Anning, and K. Docherty. 2006a. Vascular plant and vertebrate inventory of Casa Grande Ruins National Monument. USGS Open File Report 2005-1185. U.S. Geological Survey, Southwest Biological Sciences Center, Sonoran Desert Research Station, University of Arizona, Tucson. http://pubs.usgs.gov/of/2005/1185.

Powell, B. F., K. Docherty, and W. L. Halvorson. 2002. Biological inventory report for the Sonoran Desert Network: 2000 and 2001 field seasons. Annual Report No. 1. Sonoran Desert Network Inventory Program. USGS, Sonoran Desert Research Station and School of Natural Resources, University of Arizona, Tucson.

Powell, B. F., W. L. Halvorson, and C. A. Schmidt. 2006b. Vascular plant and vertebrate inventory of Saguaro National Park, Rincon Mountain District. USGS Open File Report 2006-1075. U.S. Geological Survey, Southwest Biological Sciences Center, Sonoran Desert Research Station, University of Arizona, Tucson. http:// pubs.usgs.gov/of/2006/1075.

Ralph, C. J., J. R. Sauer, and S. Droege, technical editors. 1995. Monitoring bird populations by point counts. General Technical Report PSW-GTR-149. USDA Forest Service, Pacific Southwest Research Station, Albany, CA.

Rappole, J. H. 1995. The ecology of migrant birds: a neotropical perspective. Smithsonian Institution Press, Washington, D.C.

Reynolds, R. T., J. M. Scott, and R. A. Nussbaum. 1980. A variable circular-plot method for estimating bird numbers. Condor 82:309-313.

Rondeau, R., T. R. Van Devender, C. D. Bertelsen, P. Jenkins, R. K. Wilson, and M. A. Dimmitt. 1996. Annotated flora and vegetation of the Tucson Mountains, Pima County, Arizona. Desert Plants 12:1-47.

Rosen, P. C. 2003. Distribution and ecology of amphibians and reptiles at Ironwood National Monument. I. Desert iguana, and chuckwalla, and desert tortoise. Unpublished report to Bureau of Land Management, Tucson Field Office, Tucson.

Rosen, P. C., and C. H. Lowe. 1995. Lizard monitoring protocol for the ecological monitoring program in Organ Pipe Cactus National Monument, Arizona. Special Report 
11, Section 4. Cooperative Park Study Unit, University of Arizona, Tucson.

Rosen, P. C., and K. Mauz. 2001. Biological values of the West Branch of the Santa Cruz River, with an outline for a potential reserve; including a preliminary flora. Document for the Sonoran Desert Conservation Plan, Pima County Board of Supervisors, Tucson.

Saguaro National Park. 1987. Rehabilitation of manmade water sources to mitigate impacts of CAP construction on wildlife activities. Unpublished report, probably by Robert Hall. Located in files at Saguaro National Park, Tucson.

Sauer, J. R., J. E. Hines, and J. Fallon. 2005. The North American Breeding Bird Survey, Results and Analysis 1966 - 2004. Version 2005.2. USGS Patuxent Wildlife Research Center, Laurel, MD. Accessed 25 August 2005 from: http://www.mbr-pwrc.usgs.gov/bbs/bbs.htm

Scarborough, R. 2000. The geologic origin of the Sonoran Desert. In S. J. Phillips and P. W. Comus, editors. A Natural History of the Sonoran Desert. Arizona-Sonora Desert Museum Press, Tucson.

Schwalbe, C. R., T. C. Esque, M. J. Nijhuis, D. F. Haines, J. W. Clark, and P. J. Swantek. 1999. Effects of fire on Arizona Upland Desertscrub at Saguaro National Park. Pp. 107-109. In L. Benson and B. Gebow, editors. A century of parks in southern Arizona: second conference on research and resource management in southern Arizona national parks, extended abstracts. National Park Service, Southern Arizona Office and USGS Sonoran Desert Research Station, University of Arizona, Tucson.

Schweinsburg, R. E. 1971. Home range, movements, and herd integrity of the collared peccary. Journal of Wildlife Management 35:455-460.

Shaffer, H. B., and J. E. Juterbock. 1994. Night driving. Pp. 163-166. In W. R. Heyer, M. A. Donnelly, R. W. McDiarmid, L. C. Hayek, and M. S. Foster, editors. Measuring and monitoring biodiversity: standard methods for amphibians. Smithsonian Institution Press, Washington, D.C.

Shmida, A. 1984. Whittaker's plant diversity sampling method. Israel Journal of Botany 33:41-46.

Short, K. C. 1996. Results of the Arizona Breeding Bird Atlas effort in Saguaro National Park. Unpublished report to Saguaro National Park, Tucson.

Shreve, F. 1951. Vegetation of the Sonoran Desert. Carnegie Institution of Washington Publication no. 591. Washington, D.C.
Sidner, R., and R. Davis. 1994. Bats of Saguaro National Monument, 1992-1994. Unpublished report to Saguaro National Park, Tucson.

Sprouse, T., R. Emanuel, and B. Tellman. 2002. Final report: surface water quality monitoring overview and assessment for the Sonoran Desert Network, National Park Service. Unpublished report. Water Resources Research Center, University of Arizona, Tucson.

Stebbins, R. C. 2003. A field guide to western reptiles and amphibians. Third edition. Houghton Mifflin, New York, NY.

Steenbergh, W. F., and C. H. Lowe. 1977. Ecology of the saguaro: II Reproduction, germination, establishment, growth, and survival of the young plant. National Park Service Monograph Series No. 8, Washington, D.C.

Stohlgren, T. J., M. B. Falkner, and L. D. Schell. 1995a. A modified-Whittaker nested vegetation sampling method. Vegetatio 117:113-121.

Stohlgren, T. J., J. F. Quinn, M. Ruggiero, and G. S. Waggoner. 1995b. Status of biotic inventories in U.S. national parks. Biological Conservation 71:97-106.

Strong, T. R., and C. E. Bock. 1990. Bird species distribution in riparian habitats in southeastern Arizona. Condor 92:866-885.

Stutchbury, B. J. 1991. Coloniality and breeding biology of purple martins (Progne subis hesperia) in saguaro cactus. Condor 93:666675.

Swann, D. E. 1999. Evaluating approaches for monitoring terrestrial vertebrates in U.S. national parks: an example from Tonto National Monument. MS Thesis, School of Natural Resources, University of Arizona, Tucson.

Swann. D. E. 2004. A checklist of herpetofauna and mammals of Saguaro National Park, Arizona. Western National Parks Association, Tucson.

Swann, D. E., M. J. Goode, and C. R. Schwalbe. 2000. Inventory and recommendations for longterm monitoring of reptiles and amphibians at Fort Bowie National Historic Site, Arizona. Report to the National Park Service, Southern Arizona Office, Phoenix.

Swann, D. E., C. C. Hass, D. C. Dalton, and S. A. Wolf. 2004. Infrared-triggered cameras for detecting wildlife: an evaluation and review. Wildlife Society Bulletin 32:1-9.

Swann, D. E., and B. F. Powell. 2006. Mammals. Pages 67-87. In B. F. Powell, W. L. Halvorson, and C. A. Schmidt, editors. Vascular plant and vertebrate inventory of Saguaro National Park, Rincon Mountain District. Final report to the 
National Park Service, Sonoran Desert Inventory and Monitoring Program, Tucson.

Swann, D. E., and C. R. Schwalbe. 2001. Inventory and recommendations for long-term monitoring of reptiles and amphibians at Coronado National Memorial, Arizona. Unpublished report to National Park Service, Southern Arizona Office, Phoenix, AZ.

Tomoff, C. S. 1974. Avian species diversity in desert scrub. Ecology 55:396-403.

Tucson Bird Count (TBC). 2005. Accessed 4 August 2005 from: http://www.tucsonbirds.org/index. html.

Turner, D. S., and C. S. Funicelli. 2000. Ten-year resurvey of epidermal browning and population structure of saguaro cactus (Carnegiea gigantea) in Saguaro National Park. Technical Report No. 69. USGS, Sonoran Desert Research Station, University of Arizona, Tucson.

Turner, D. S., P. A. Holm, E. B. Wirt, and C. R. Schwalbe. 2003. Amphibians and reptiles of the Whetstone Mountains, Arizona. The Southwestern Naturalist 48:347-355.

United States Department of Agriculture (USDA). 2005. The PLANTS Database, Version 3.5. National Plant Data Center, Natural Resources Conservation Service, Baton Rouge, LA. Accessed 10 March 2003 from: http://plants.usda.gov

Van Devender, R. 1992. Floristic Survey of a proposed Protected Natural Area within Saguaro National Monument, Tucson Mountain Unit: final report. Unpublished report to Saguaro National Park, Tucson.
Verner, J., and L. V. Ritter. 1983. A comparison of transects and point counts in oak-pine woodlands of California. Condor 87:47-68.

Wadleigh, R. 1969. Plant species list for the Tucson Mountain District of Saguaro National Monument. Unpublished report to Saguaro National Park. Copies available at the park and I\&M office in Tucson.

Western Regional Climate Center (WRCC). 2005. Arizona climate summaries for the University of Arizona. Accessed 15 February 2005 from: http://www.wrcc.dri.edu/summary/climsmaz. html.

Wirt, E. B, and R. H. Robichaux. 2001. Survey and monitoring of the desert tortoise Gopherus agassizii at Saguaro National Park. Unpublished report to Saguaro National Park, Tucson.

Wolf, S., and D. Dalton. 2003. Winter bat survey. Tucson Mountain District, Saguaro National Park. Unpublished report to Saguaro National Park, Tucson.

Wright, J. W., and L. J. Vitt. 1993. Biology of the whiptail lizards (genus Cnemidophorus). Oklahoma Museum of Natural History, Norman, OK.

Yang, T. W., and C. H. Lowe. 1956. Correlation of major vegetation climates with soil characteristics in the Sonoran Desert. Science 123:542.

Yensen, A. E. 1973. An analysis of a Sonoran Desert species diversity gradient. PhD. Dissertation, University of Arizona, Tucson. 
Appendix A. List of plant species that were observed (O) or collected $(X)$ at Saguaro NP, Tucson Mountain District. Species list derives from: species seen or collected by UA Inventory effort (UA), specimens from 1909-1994 located in the University of Arizona Herbarium (UAH), Van Devender (VnD; 1992), Rondeau et al. (Rea; 1996), Halvorson and Guertin (H\&G; 2003), Saguaro National Park long-term monitoring plots 1998-2004 (SNP; In prep). Species in bold-faced type are non-native according to USDA (2004).

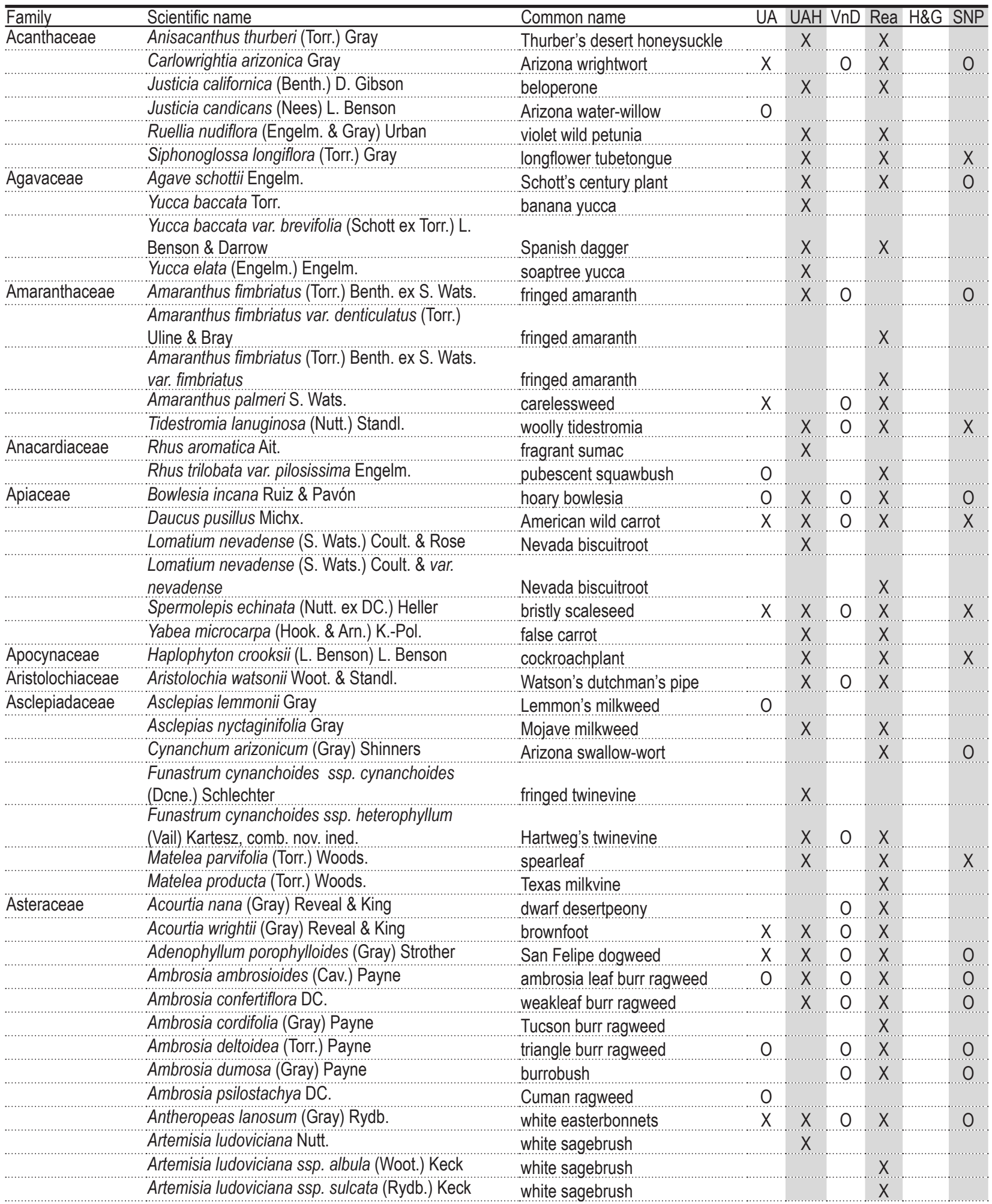




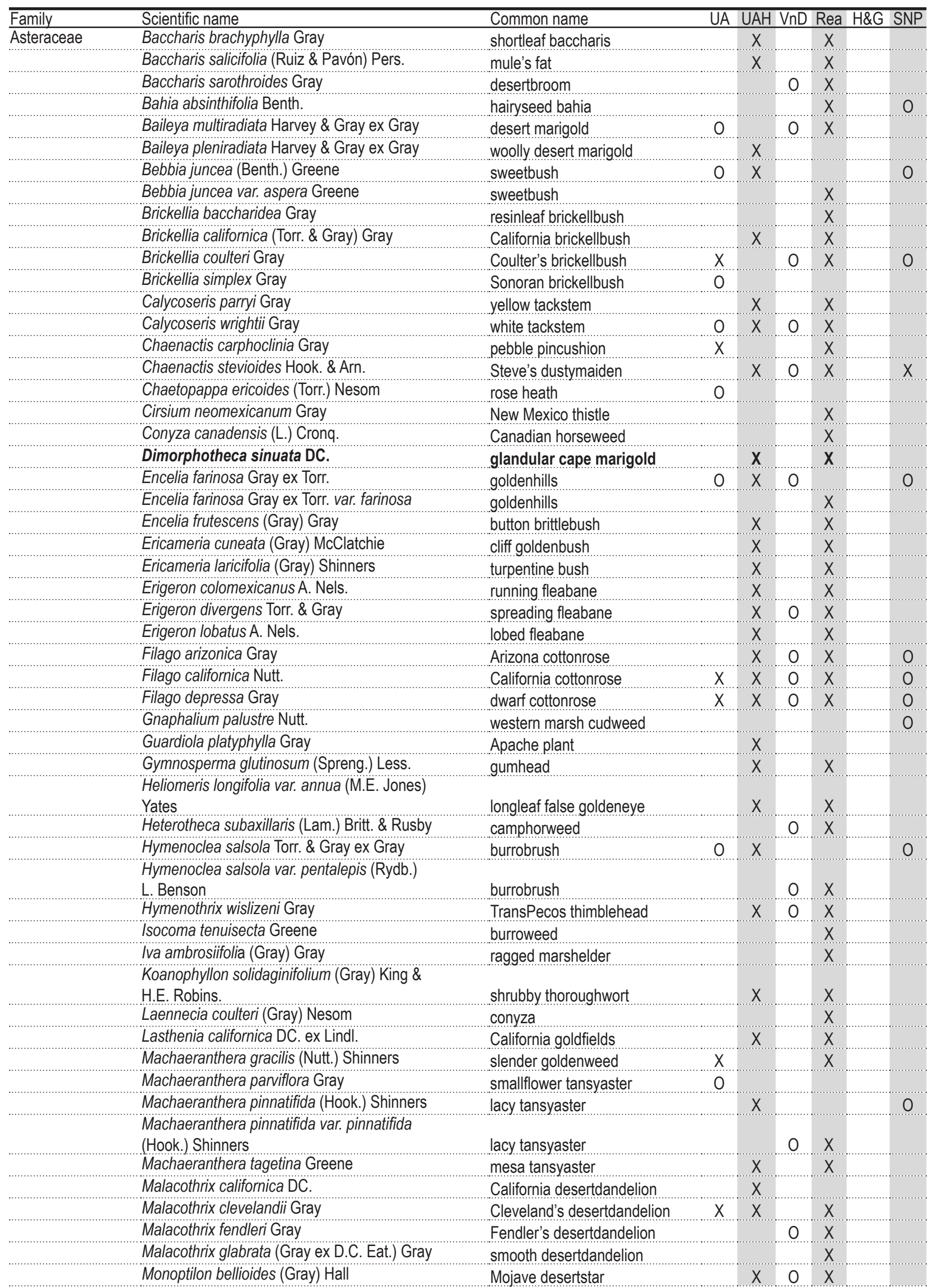




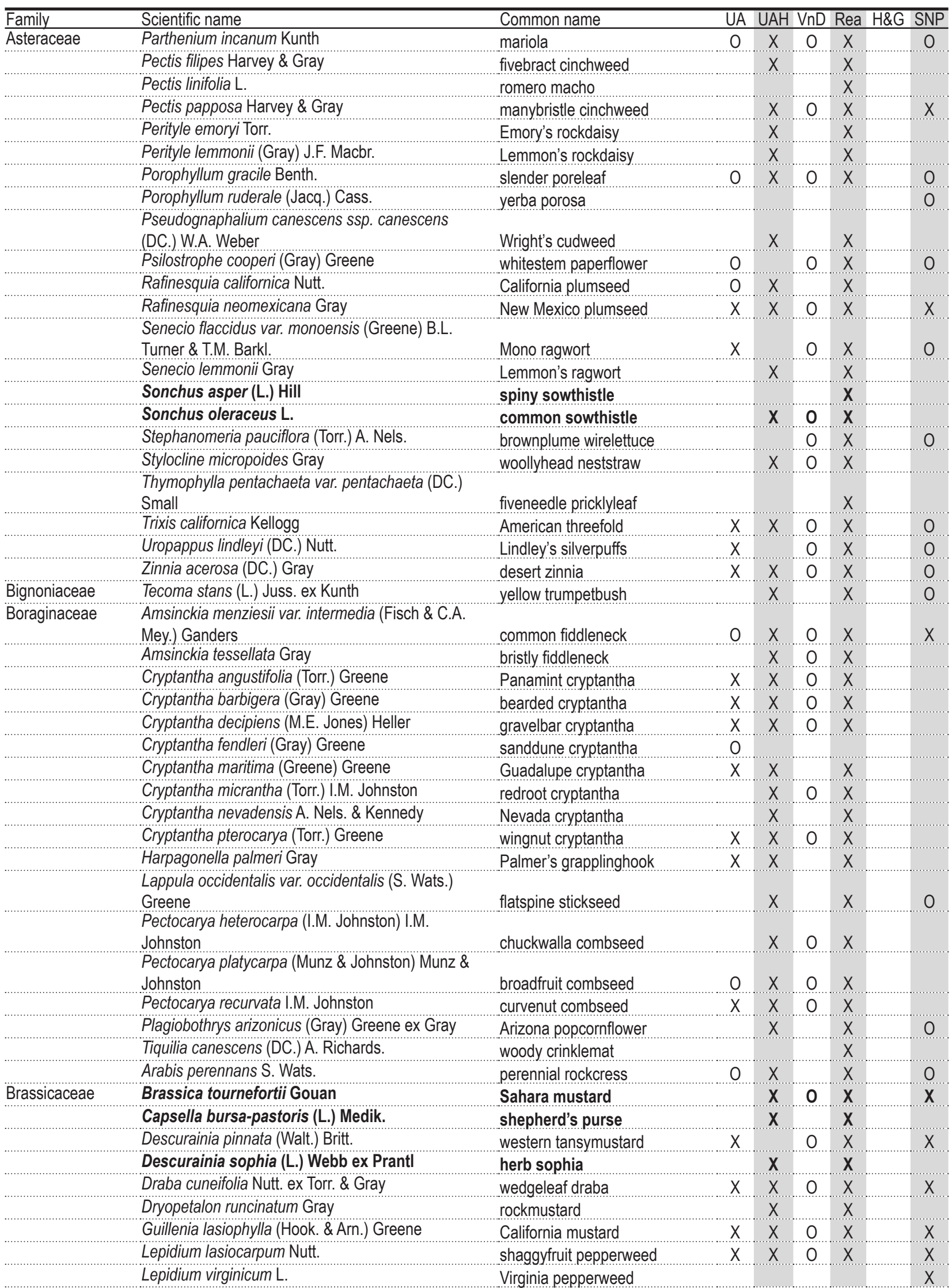




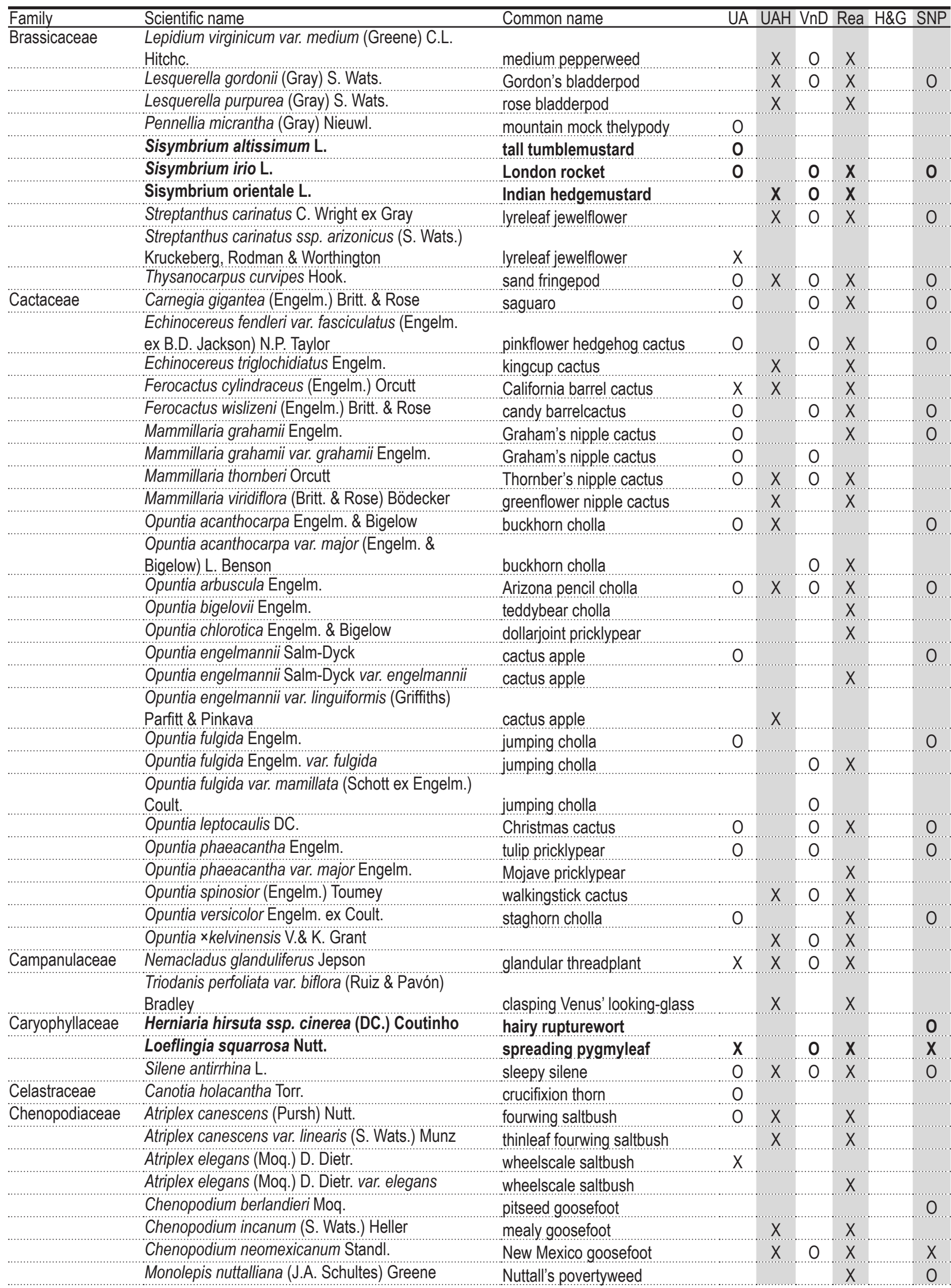




\begin{tabular}{|c|c|c|c|c|c|c|c|}
\hline Family & Scientific name & Common name & $\mathrm{UA}$ & $\mathrm{JAH}$ & $\mathrm{VnD}$ & Rea & $\mathrm{H} \& \mathrm{G}$ SNP \\
\hline \multirow{2}{*}{ Chenopodiaceae } & Salsola kali L. & Russian thistle & $\mathrm{x}$ & & & & \\
\hline & Salsola tragus $\mathrm{L}$. & prickly Russian thistle & & & & $\mathrm{x}$ & \\
\hline \multirow[t]{7}{*}{ Convolvulaceae } & Evolvulus alsinoides (L.) L. & slender dwarf morning-glory & & $\mathrm{X}$ & 0 & $x$ & $\mathrm{x}$ \\
\hline & Evolvulus arizonicus Gray & wild dwarf morning-glory & & & & & 0 \\
\hline & Evolvulus nuttallianus J.A. Schultes & shaggy dwarf morning-glory & & $\mathrm{x}$ & & $\mathrm{X}$ & \\
\hline & Ipomoea barbatisepala Gray & canyon morning-glory & & $\mathrm{x}$ & & $\mathrm{X}$ & \\
\hline & Ipomoea coccinea L. & redstar & & $\mathrm{x}$ & & & \\
\hline & Ipomoea costellata Torr. & crestrib morning-glory & & $\mathrm{x}$ & & $\mathrm{x}$ & \\
\hline & Ipomoea cristulata Hallier $\mathrm{f}$. & Transpecos morning-glory & & $\mathrm{x}$ & & $\mathrm{x}$ & \\
\hline \multirow[t]{3}{*}{ Crassulaceae } & Crassula connata (Ruiz \& Pavón) Berger & sand pygmyweed & 0 & $\mathrm{x}$ & & & \\
\hline & Crassula connata var. connata (Ruiz \& Pavón) & & & & & & \\
\hline & Berger & sand pygmyweed & & $\mathrm{X}$ & 0 & $\mathrm{x}$ & $\mathrm{x}$ \\
\hline Crossosomataceae & Crossosoma bigelovii S. Wats. & ragged rockflower & & $\mathrm{x}$ & & $\mathrm{X}$ & \\
\hline \multirow[t]{5}{*}{ Cucurbitaceae } & Apodanthera undulata Gray & melon loco & & $\mathrm{x}$ & & $\mathrm{x}$ & \\
\hline & $\begin{array}{l}\text { Citrullus lanatus (Thunb.) Matsumura \& Nakai } \\
\text { var. lanatus }\end{array}$ & watermelon & & & & $\mathrm{x}$ & \\
\hline & Cucurbita digitata Gray & fingerleaf gourd & & $\mathrm{x}$ & 0 & $\mathrm{x}$ & \\
\hline & Echinopepon wrightii (Gray) S. Wats. & wild balsam apple & & $\mathrm{x}$ & & $\mathrm{x}$ & \\
\hline & Tumamoca macdougalii Rose & Tumamoc globeberry & & & & $\mathrm{x}$ & \\
\hline Cyperaceae & Cyperus esculentus $\mathrm{L}$. & chufa flatsedge & & $\mathrm{X}$ & & $\mathrm{x}$ & \\
\hline \multirow[t]{4}{*}{ Ephedraceae } & Ephedra aspera Engelm. ex S. Wats. & rough jointfir & & & & $x$ & \\
\hline & Ephedra nevadensis S. Wats. & Nevada jointfir & & $\mathrm{x}$ & & & 0 \\
\hline & Ephedra trifurca Torr. ex S. Wats. & longleaf jointfir & 0 & $x$ & & $\mathrm{x}$ & \\
\hline & Ephedra viridis Coville & Mormon tea & 0 & & & & \\
\hline \multirow[t]{22}{*}{ Euphorbiaceae } & Acalypha neomexicana Muell.-Arg. & New Mexico copperleaf & & $\mathrm{x}$ & & $\mathrm{x}$ & \\
\hline & Argythamnia lanceolata (Benth.) Muell.-Arg. & narrowleaf silverbush & $\mathrm{x}$ & $x$ & & $x$ & 0 \\
\hline & Argythamnia neomexicana Muell.-Arg. & New Mexico silverbush & $x$ & $x$ & & $x$ & $x$ \\
\hline & Bernardia incana Morton & hoary myrtlecroton & & $\mathrm{x}$ & & $\mathrm{x}$ & \\
\hline & Chamaesyce abramsiana (L.C. Wheeler) Koutnik & Abrams' sandmat & & $x$ & 0 & $x$ & \\
\hline & Chamaesyce arizonica (Engelm.) Arthur & Arizona sandmat & & $\mathrm{x}$ & & $\mathrm{x}$ & \\
\hline & Chamaesyce capitellata (Engelm.) Millsp. & head sandmat & 0 & $\mathrm{x}$ & & $\mathrm{x}$ & $\mathrm{x}$ \\
\hline & Chamaesyce florida (Engelm.) Millsp. & Chiricahua Mountain sandmat & & $\mathrm{x}$ & 0 & $x$ & 0 \\
\hline & Chamaesyce gracillima (S. Wats.) Millsp. & Mexican sandmat & & $x$ & 0 & $x$ & $x$ \\
\hline & Chamaesyce hyssopifolia (L.) Small & hyssopleaf sandmat & & $\mathrm{x}$ & 0 & $\mathrm{x}$ & 0 \\
\hline & Chamaesyce melanadenia (Torr.) Millsp. & squaw sandmat & & $\mathrm{x}$ & & $\mathrm{x}$ & \\
\hline & Chamaesyce micromera (Boiss. ex Engelm.) & & & & & & \\
\hline & Woot. \& Standl. & Sonoran sandmat & & $\mathrm{X}$ & 0 & $\mathrm{x}$ & \\
\hline & Chamaesyce pediculifera (Engelm.) Rose \& Standl. & Carrizo Mountain sandmat & & & & $\mathrm{x}$ & \\
\hline & Chamaesyce polycarpa (Benth.) Millsp. ex Parish & smallseed sandmat & $x$ & $\mathrm{X}$ & 0 & $\mathrm{x}$ & 0 \\
\hline & Chamaesyce setiloba (Engelm. ex Torr.) Millsp. ex & & & & & & \\
\hline & Parish & Yuma sandmat & & $\mathrm{x}$ & 0 & $\mathrm{x}$ & $\mathrm{X}$ \\
\hline & Euphorbia eriantha Benth. & beetle spurge & & $\mathrm{x}$ & & & $\mathrm{x}$ \\
\hline & Euphorbia heterophylla L. & Mexican fireplant & & $x$ & & $\mathrm{x}$ & \\
\hline & Jatropha cardiophylla (Torr.) Muell.-Arg. & sangre de cristo & 0 & & 0 & $x$ & 0 \\
\hline & Tragia nepetifolia Cav. & catnip noseburn & & $\mathrm{x}$ & & $\mathrm{x}$ & \\
\hline & Tragia ramosa Torr. & branched noseburn & & $\mathrm{X}$ & & & \\
\hline \multirow[t]{9}{*}{ Fabaceae } & Acacia constricta Benth. & whitethorn acacia & 0 & & 0 & $\mathrm{x}$ & 0 \\
\hline & Acacia greggii Gray & catclaw acacia & 0 & & 0 & $\mathrm{x}$ & 0 \\
\hline & Astragalus arizonicus Gray & Arizona milkvetch & & $\mathrm{x}$ & & $\mathrm{X}$ & \\
\hline & Astragalus didymocarpus Hook. \& Arn. & dwarf white milkvetch & 0 & $\mathrm{x}$ & 0 & & \\
\hline & $\begin{array}{l}\text { Astragalus didymocarpus var. dispermus (Gray) } \\
\text { Jepson }\end{array}$ & dwarf white milkvetch & & & & $\mathrm{X}$ & \\
\hline & Astragalus lentiginosus Dougl. ex Hook. & freckled milkvetch & $\mathrm{x}$ & $\mathrm{X}$ & & & \\
\hline & Astragalus Ientiginosus var. australis Barneby & freckled milkvetch & & & 0 & $\mathrm{x}$ & \\
\hline & Astragalus nothoxys Gray & sheep milkvetch & & & & & 0 \\
\hline & Astragalus nuttallianus DC. & smallflowered milkvetch & 0 & $\mathrm{x}$ & & & 0 \\
\hline
\end{tabular}




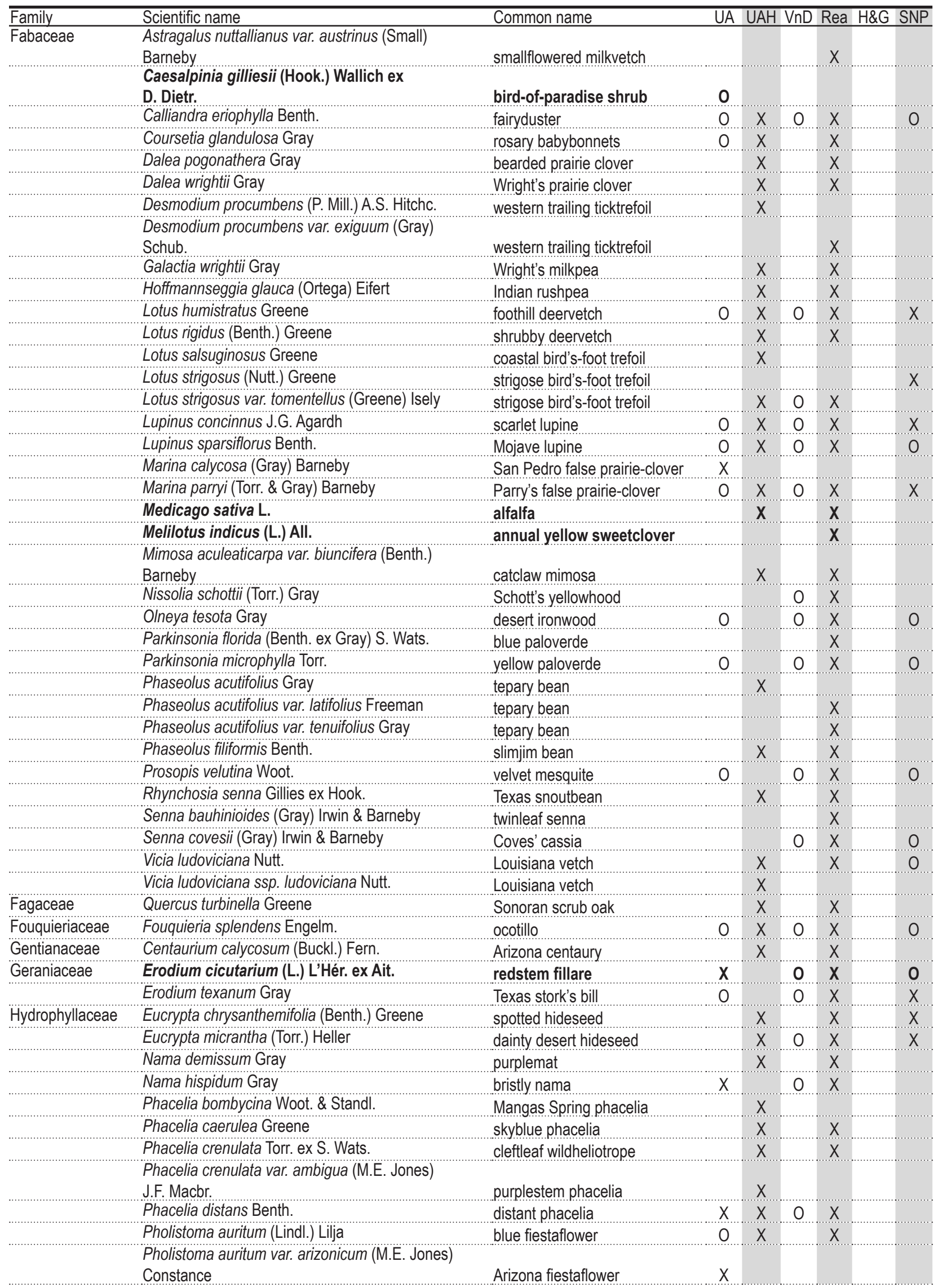




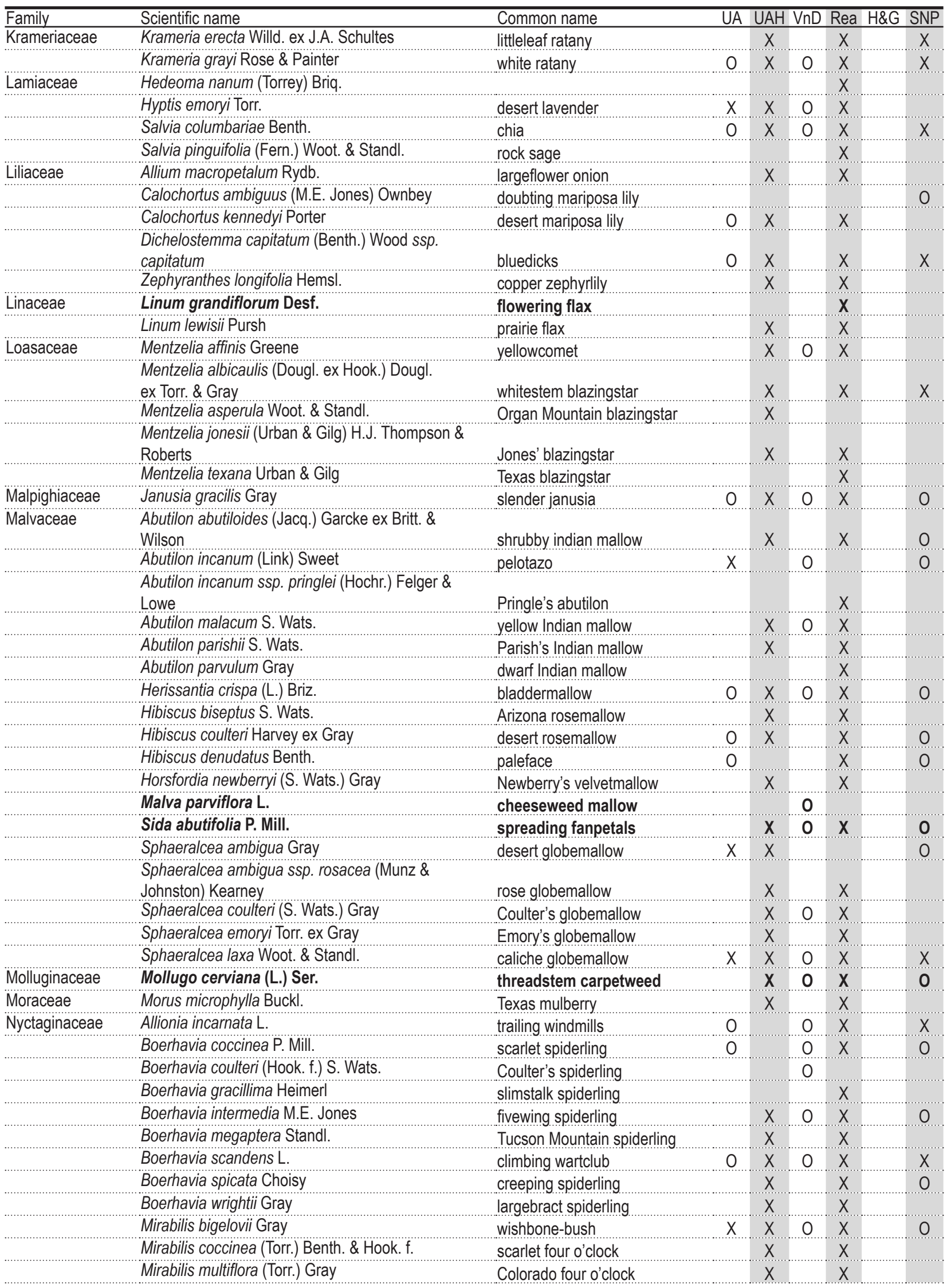




\begin{tabular}{|c|c|c|c|c|c|c|c|c|}
\hline Family & Scientific name & Common name & $\mathrm{UA}$ & $\mathrm{UAH}$ & $\mathrm{VnD}$ & Rea & $H \& G$ & SNP \\
\hline \multirow[t]{2}{*}{ Oleaceae } & Forestiera shrevei Standl. & desert olive & 0 & $x$ & & $x$ & & \\
\hline & Menodora scabra Gray & rough menodora & 0 & & 0 & $x$ & & 0 \\
\hline \multirow[t]{5}{*}{ Onagraceae } & Camissonia californica (Nutt. ex Torr. \& Gray) Raven & California suncup & & $x$ & & $x$ & & 0 \\
\hline & Camissonia chamaenerioides (Gray) Raven & longcapsule suncup & $X$ & $x$ & $\mathrm{O}$ & $X$ & & $\mathrm{X}$ \\
\hline & Camissonia claviformis (Torr. \& Frém.) Raven & browneyes & & & & $x$ & & \\
\hline & Gaura mollis James & velvetweed & & $X$ & & $x$ & & \\
\hline & Oenothera primiveris Gray & desert evening-primrose & 0 & & & $X$ & & $\mathrm{X}$ \\
\hline \multirow[t]{2}{*}{ Orobanchaceae } & Orobanche cooperi (Gray) Heller & desert broomrape & & $\mathrm{X}$ & & & & \\
\hline & Orobanche cooperi (Gray) Heller ssp. cooperi & desert broomrape & & & & $X$ & & \\
\hline \multirow[t]{2}{*}{ Oxalidaceae } & Oxalis albicans ssp. pilosa (Nutt.) Eiten & radishroot woodsorrel & & & 0 & & & \\
\hline & Oxalis alpina (Rose) Rose ex R. Knuth & alpine woodsorrel & & & 0 & & & \\
\hline \multirow[t]{2}{*}{ Papaveraceae } & Eschscholzia californica ssp. mexicana (Greene) & & & & & & & \\
\hline & C. Clark & California poppy & 0 & $\mathrm{X}$ & 0 & $x$ & & 0 \\
\hline Passifloraceae & Passiflora mexicana Juss. & Mexican passionflower & 0 & & & & & \\
\hline \multirow[t]{2}{*}{ Pedaliaceae } & Proboscidea althaeifolia (Benth.) Dcne. & desert unicorn-plant & & $x$ & 0 & $X$ & & \\
\hline & Proboscidea parviflora (Woot.) Woot. \& Standl.' & doubleclaw & & & 0 & $X$ & & \\
\hline \multirow[t]{2}{*}{ Plantaginaceae } & Plantago ovata Forsk. & desert Indianwheat & & $\mathrm{X}$ & 0 & $x$ & & $\mathrm{X}$ \\
\hline & Plantago patagonica Jacq. & woolly plantain & $X$ & $\mathrm{X}$ & 0 & $x$ & & $X$ \\
\hline Plumbaginaceae & Plumbago scandens $\mathrm{L} . \quad \ldots$ & doctorbush & & $\mathrm{X}$ & & $X$ & & \\
\hline \multirow[t]{37}{*}{ Poaceae } & Achnatherum speciosum (Trin. \& Rupr.) Barkworth & desert needlegrass & & $x$ & & $x$ & & \\
\hline & Alopecurus carolinianus Walt. & Carolina foxtail & 0 & & & & & \\
\hline & Aristida adscensionis $L$. & sixweeks threeawn & $\mathrm{X}$ & $X$ & 0 & $x$ & & 0 \\
\hline & Aristida californica var. glabrata Vasey & Santa Rita threeawn & $x$ & & & & & \\
\hline & Aristida purpurea Nutt. & purple threeawn & & $X$ & 0 & & & 0 \\
\hline & Aristida purpurea var. nealleyi (Vasey) Allred & blue threeawn & $X$ & $x$ & & $X$ & & \\
\hline & Aristida purpurea var. parishii (A.S. Hitchc.) Allred & Parish's threeawn & & $\mathrm{X}$ & & $x$ & & \\
\hline & Aristida purpurea var. purpurea Nutt. & purple threeawn & & $\mathrm{X}$ & & $x$ & & \\
\hline & Aristida ternipes Cav. & spidergrass & 0 & $x$ & 0 & $x$ & & 0 \\
\hline & Aristida ternipes var. gentilis (Henr.) Allred & spidergrass & & $x$ & & $x$ & & \\
\hline & Arundo donax $L$. & giant reed & & & & $x$ & & \\
\hline & Avena fatua $\mathrm{L}$. & wild oat & & $\mathbf{X}$ & 0 & $x$ & & \\
\hline & Bothriochloa barbinodis (Lag.) Herter & cane bluestem & & $x$ & & $\mathrm{X}$ & & 0 \\
\hline & Bouteloua aristidoides (Kunth) Griseb. & needle grama & $X$ & $x$ & $\mathrm{O}$ & $x$ & & 0 \\
\hline & Bouteloua barbata Lag. & sixweeks grama & & $x$ & 0 & $x$ & & 0 \\
\hline & $\begin{array}{l}\text { Bouteloua chondrosioides (Kunth) Benth. ex } \\
\text { S. Wats. }\end{array}$ & sprucetop grama & 0 & & & $\mathrm{x}$ & & \\
\hline & Bouteloua curtipendula (Michx.) Torr. & sideoats grama & 0 & $X$ & 0 & $\mathrm{X}$ & & 0 \\
\hline & Bouteloua eriopoda (Torr.) Torr. & black grama & & $x$ & & $\mathrm{X}$ & & 0 \\
\hline & Bouteloua hirsuta Lag. & hairy grama & & $x$ & & $\mathrm{X}$ & & \\
\hline & Bouteloua repens (Kunth) Scribn. \& Merr. & slender grama & & $x$ & 0 & $x$ & & 0 \\
\hline & Bouteloua rothrockii Vasey & Rothrock's grama & & & 0 & $x$ & & 0 \\
\hline & Bouteloua trifida Thurb. & red grama & $X$ & & & $X$ & & \\
\hline & Bromus arizonicus (Shear) Stebbins & Arizona brome & & $X$ & & & & \\
\hline & Bromus carinatus Hook. \& Arn. & California brome & $\mathrm{O}$ & $x$ & 0 & $X$ & & \\
\hline & Bromus catharticus Vahl & rescuegrass & & & 0 & & & \\
\hline & Bromus madritensis $\mathrm{L}$. & compact brome & & & 0 & & & \\
\hline & Bromus rubens $\mathrm{L}$. & red brome & & & 0 & $X$ & $\mathbf{X}$ & 0 \\
\hline & Chloris virgata Sw. & feather fingergrass & & $X$ & & $X$ & & \\
\hline & $\begin{array}{l}\text { Cortaderia selloana (J.A. \& J.H. Schultes) } \\
\text { Aschers. \& Graebn. }\end{array}$ & Uruguayan pampas grass & 0 & & & & & \\
\hline & Cottea pappophoroides Kunth & cotta grass & & $X$ & & $X$ & & \\
\hline & Cynodon dactylon (L.) Pers. & Bermudagrass & & $\mathrm{X}$ & 0 & $x$ & $\mathbf{X}$ & \\
\hline & Dasyochloa pulchella (Kunth) Willd. ex Rydb. & low woollygrass & $X$ & & 0 & $x$ & & $\mathrm{X}$ \\
\hline & Digitaria californica (Benth.) Henr. & Arizona cottontop & 0 & $X$ & 0 & $X$ & & 0 \\
\hline & Digitaria insularis (L.) Mez ex Ekman & sourgrass & & & & $\mathrm{X}$ & & \\
\hline & Echinochloa colona (L.) Link & jungle rice & & $X$ & & $x$ & & \\
\hline & Elymus elymoides (Raf.) Swezey & squirreltail & & & & $x$ & & \\
\hline & Enneapogon desvauxii Desv. ex Beauv. & nineawn pappusgrass & & $x$ & & $X$ & & 0 \\
\hline
\end{tabular}




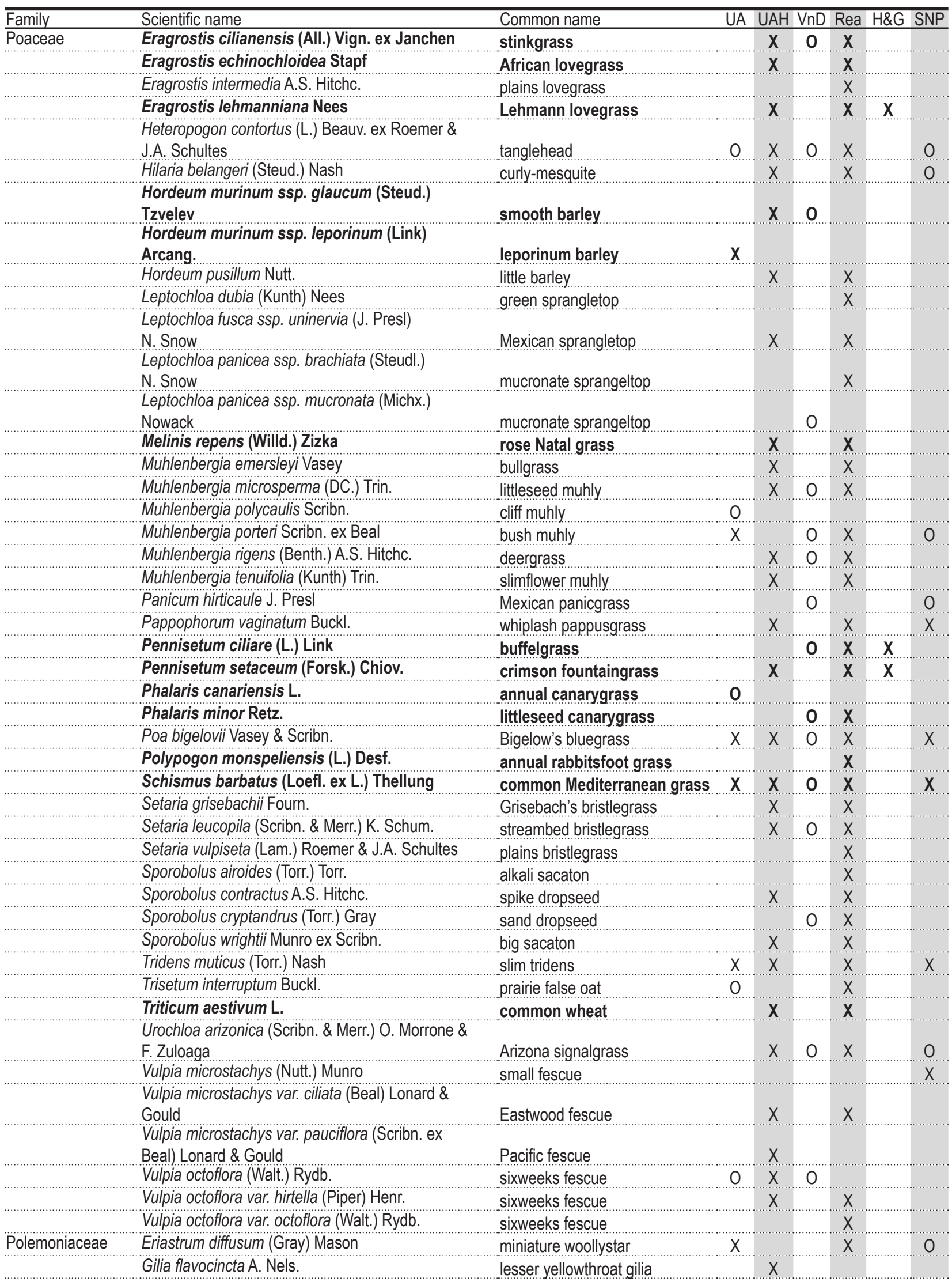




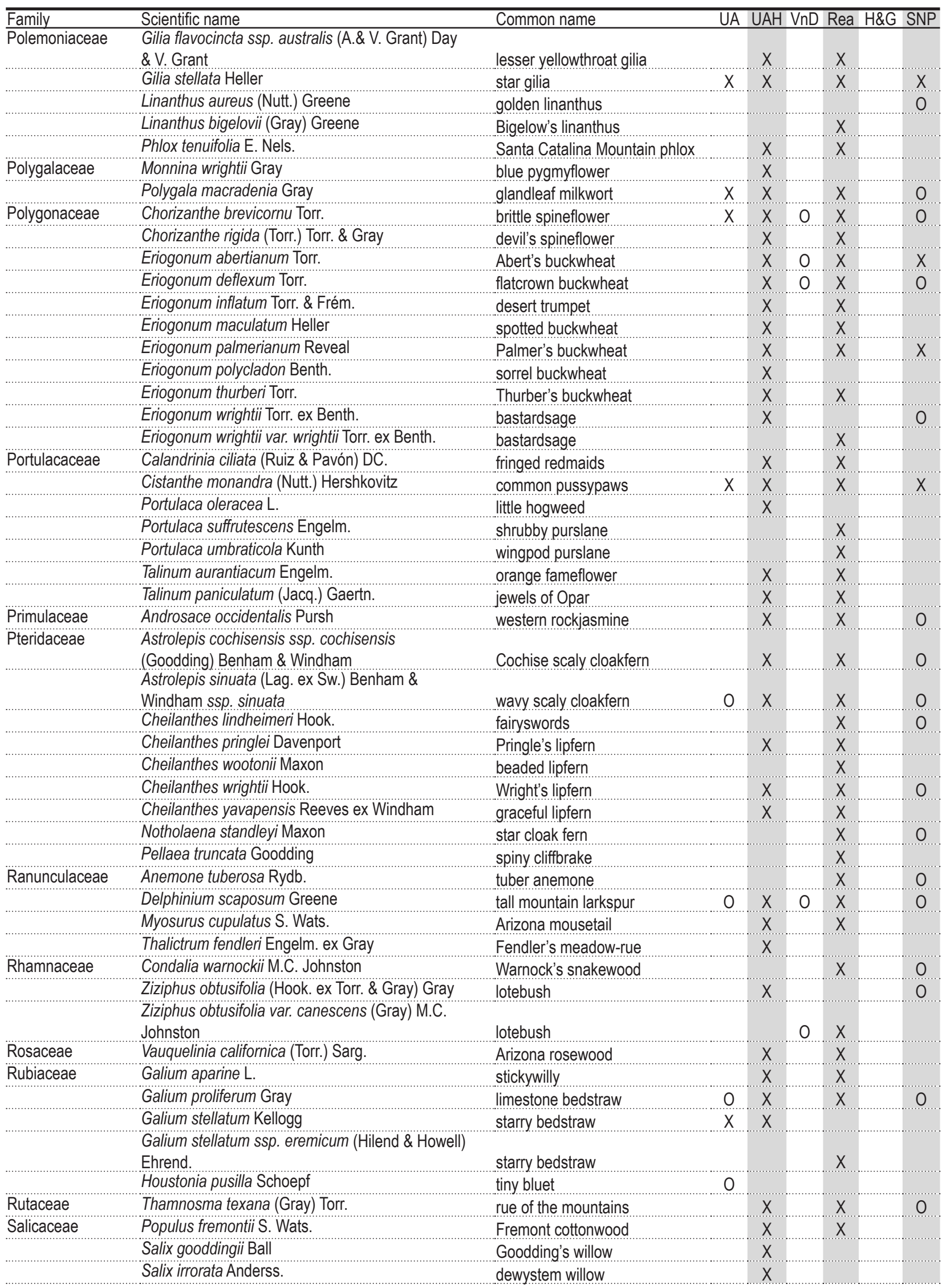




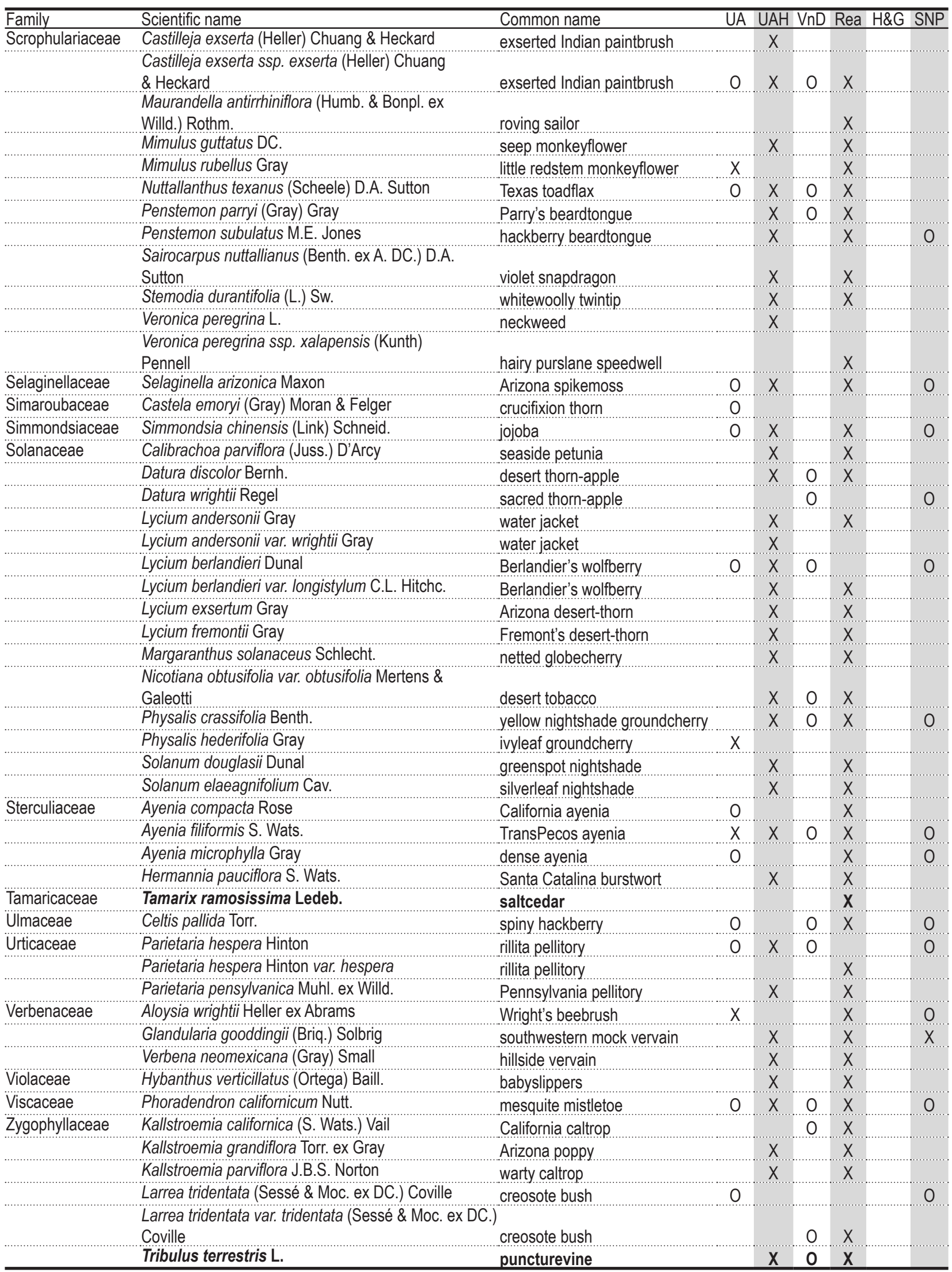


Appendix B. List of reptiles and amphibians found by University of Arizona Inventory personnel and field method(s) used to detect them, Saguaro NP, Tucson Mountain District, 2001 and 2002.

\begin{tabular}{|c|c|c|c|c|c|c|c|}
\hline Family & Scientific name & Common name & Intensive & Extensive & $\begin{array}{c}\text { Road } \\
\text { surveys }\end{array}$ & Pitfall & Incidental \\
\hline \multicolumn{8}{|l|}{ Anura } \\
\hline Pelobatidae & Scaphiopus couchii & Couch's spadefoot toad & & & & & \\
\hline \multirow{3}{*}{ Bufonidae } & Bufo alvarius & Sonoran desert toad & & $X$ & $x$ & & $X$ \\
\hline & Bufo punctatus & red-spotted toad & & $x$ & $X$ & & $X$ \\
\hline & Bufo cognatus & Great Plains toad & & & & & $x$ \\
\hline \multicolumn{8}{|l|}{ Testudines } \\
\hline Testudinidae & Gopherus agassizii & desert tortoise ${ }^{\mathrm{a}}$ & & $x$ & & & $x$ \\
\hline \multicolumn{8}{|l|}{ Squamata } \\
\hline Gekkonidae & Coleonyx variegatus & western banded gecko & \multirow{5}{*}{$x$} & $\mathrm{X}$ & \multirow[t]{5}{*}{$x$} & $\mathrm{X}$ & $\mathrm{X}$ \\
\hline Iguanidae & Dipsosaurus dorsalis & desert iguana & & $x$ & & & $x$ \\
\hline \multirow[t]{2}{*}{ Crotaphytidae } & Crotaphytus nebrius & Sonoran collared lizard & & $x$ & & & \\
\hline & Gambelia wislizenii & long-nosed leopard lizard & & $x$ & & & $\mathrm{X}$ \\
\hline \multirow{7}{*}{ Phrynosomatidae } & Holbrookia maculata & lesser earless lizard & & $x$ & & & $x$ \\
\hline & Callisaurus draconoides & zebra-tailed lizard & \multirow{2}{*}{$\begin{array}{l}x \\
X\end{array}$} & $X$ & \multirow{3}{*}{$\begin{array}{l}X \\
X\end{array}$} & $X$ & $\mathrm{X}$ \\
\hline & Sceloporus magister & desert spiny lizard & & $\mathrm{X}$ & & $\mathrm{x}$ & $\mathrm{X}$ \\
\hline & Sceloporus clarkii & Clark's spiny lizard & $x$ & $x$ & & & $x$ \\
\hline & Uta stansburiana & side-blotched lizard & $x$ & $\mathrm{X}$ & $X$ & $\mathrm{X}$ & $\mathrm{X}$ \\
\hline & Urosaurus ornatus & ornate tree lizard & $x$ & $x$ & & & $x$ \\
\hline & Phrynosoma solare & regal horned lizard & $x$ & $x$ & $X$ & & $x$ \\
\hline \multirow[t]{2}{*}{ Teiidae } & Cnemidophorus sonorae & Sonoran spotted whiptail & \multirow{4}{*}{$\frac{X}{X}$} & $x$ & \multirow{4}{*}{$\frac{X}{X}$} & & $x$ \\
\hline & Cnemidophorus tigris & western whiptail & & $\mathrm{X}$ & & $X$ & \multirow{3}{*}{$\frac{X}{X}$} \\
\hline Helodermatidae & Heloderma suspectum & Gila monster & & $x$ & & & \\
\hline Leptotyphlopidae & Leptotyphlops humilis & western blind snake & & $x$ & & $X$ & \\
\hline \multirow[t]{8}{*}{ Colubridae } & Masticophis flagellum & coachwhip & \multirow[t]{3}{*}{$x$} & $x$ & \multirow{5}{*}{$X$} & & $x$ \\
\hline & Masticophis bilineatus & Sonoran whipsnake & & & & & \multirow[t]{2}{*}{$x$} \\
\hline & Salvadora hexalepis & $\begin{array}{l}\text { western patch-nosed } \\
\text { snake }\end{array}$ & & $X$ & & & \\
\hline & Pituophis catenifer & gopher snake & \multirow[t]{2}{*}{$x$} & $x$ & & & \multirow[t]{2}{*}{$x$} \\
\hline & Arizona elegans & glossy snake & & $x$ & & & \\
\hline & Rhinocheilus lecontei & long-nosed snake & & $x$ & $x$ & $X$ & $x$ \\
\hline & Trimorphodon biscutatus & western lyre snake & & & & & $x$ \\
\hline & Hypsiglena torquata & night snake & & $X$ & & & $x$ \\
\hline & Micruroides euryxanthus & Sonoran coral snake & & & & & $x$ \\
\hline \multirow[t]{5}{*}{ Viperidae } & Crotalus atrox & $\begin{array}{l}\text { western diamond-backed } \\
\text { rattlesnake }\end{array}$ & \multirow[t]{2}{*}{$x$} & $x$ & \multirow[t]{2}{*}{$x$} & & \multirow[t]{2}{*}{$x$} \\
\hline & Crotalus cerastes & Sidewinder & & $x$ & & & \\
\hline & Crotalus molossus & black-tailed rattlesnake & \multirow{3}{*}{$x$} & $x$ & \multirow{3}{*}{$\begin{array}{l}x \\
x\end{array}$} & & \\
\hline & Crotalus tigris & tiger rattlesnake & & $x$ & & & $X$ \\
\hline & Crotalus scutulatus & Mohave rattlesnake & & $x$ & & & $x$ \\
\hline Species richness & & & 14 & 30 & 15 & 8 & 28 \\
\hline
\end{tabular}

a "Species of Concern", U.S. Fish and Wildlife Service; "Wildlife of Special Concern", Arizona Game and Fish Department. Data from HDMS (2004). 
Appendix C. List of bird species observed at Saguaro NP, Tucson Mountain District by UA inventory personnel (2001 and 2002) or by other survey efforts or lists: Monson and Smith (M\&S; 1986), Yensen (YE; 1976), Short (SH; 1996), and Kline (KL; 1998). See text for descriptions of UA survey types. Underlined species are neotropical migrants (Rappole 1995) and species in bold-faced type are non-native.

\begin{tabular}{|c|c|c|c|c|c|c|c|c|c|c|c|c|c|c|c|c|}
\hline \multirow[b]{2}{*}{ Order } & \multirow[b]{2}{*}{ Family } & \multirow[b]{2}{*}{ Scientific name } & \multirow[b]{2}{*}{ Common name } & \multicolumn{3}{|c|}{$\begin{array}{c}\text { UA survey } \\
\text { method }\end{array}$} & \multicolumn{4}{|c|}{ Species lists } & \multicolumn{6}{|c|}{ Conservation designation ${ }^{\mathrm{a}}$} \\
\hline & & & & VCP & Noct & Incid & $M \& S$ & $\mathrm{YE}$ & $\mathrm{SH}$ & $\mathrm{KL}$ & ESA & BLM & USFS & WSCA & APF & USFWS \\
\hline Galliformes & Odontophoridae & Callipepla gambelii & Gambel's quail & 115 & & & $\mathrm{X}$ & $\mathrm{X}$ & $x$ & $x$ & & & & & & \\
\hline \multirow[t]{2}{*}{ Ciconilformes } & Cathartidae & Coragyps atratus & black vulture & \multirow{4}{*}{10} & & & $\mathrm{X}$ & \multirow{3}{*}{$x$} & & \multirow{4}{*}{$\mathrm{X}$} & & & & & & \\
\hline & & Cathartes aura & turkey vulture & & & & $\mathrm{x}$ & & $X$ & & & & & & & \\
\hline \multirow[t]{9}{*}{ Falconiformes } & Accipitridae & Circus cyaneus & northern harrier & & & & $x$ & & & & & & & & & \\
\hline & & Accipiter striatus & sharp-shinned hawk & & & & $\mathrm{X}$ & $X$ & & & & & S & & & \\
\hline & & Accipiter cooperii & Cooper's hawk & \multirow{3}{*}{9} & & & $x$ & \multirow{3}{*}{$x$} & \multirow{3}{*}{$x$} & \multirow{3}{*}{$\frac{X}{X}$} & & & & & & \\
\hline & & Parabuteo unicinctus & Harris's hawk & & & 2 & $x$ & & & & & & & & & \\
\hline & & Buteo albonotatus & zone-tailed hawk & & & 1 & $x$ & & & & & & & & & \\
\hline & & Buteo jamaicensis & red-tailed hawk & 6 & & 1 & $x$ & \multirow[t]{2}{*}{$x$} & $x$ & \multirow[t]{3}{*}{$X$} & & & & & & \\
\hline & & Aquila chrysaetos & golden eagle & 3 & & 7 & $x$ & & $x$ & & & & & & & \\
\hline & Falconidae & Falco sparverius & American kestrel & 5 & & 1 & $x$ & $x$ & $\mathrm{x}$ & & & & & & & \\
\hline & & Falco mexicanus & prairie falcon & 10 & & 1 & $x$ & & & & & & & & & \\
\hline Charadriformes & Charadriidae & Charadrius vociferus & killdeer & & & & $x$ & & & & & & & & & \\
\hline \multirow[t]{5}{*}{ Columbiformes } & Columbidae & Columba livia & rock pigeon & & & & $x$ & & & & & & & & & \\
\hline & & Zenaida asiatica & white-winged dove & 331 & & 3 & $x$ & $X$ & $x$ & & & & & & & \\
\hline & & Zenaida macroura & mourning dove & 205 & & 4 & $\mathrm{X}$ & $X$ & & & & & & & & \\
\hline & & Columbina inca & Inca dove & 1 & & & $x$ & & & & & & & & & \\
\hline & & Columbina passerina & common ground-dove & & & & $x$ & & & & & & & & & \\
\hline Cuculiformes & Cuculidae & Coccyzus americanus occidentalis & yellow-billed cuckoo ${ }^{\mathrm{b}}$ & & & & $x$ & & & & C & & S & WSC & $P$ & BCC \\
\hline & & Geococcyx californianus & greater roadrunner & 1 & & & $\mathrm{X}$ & $x$ & & $X$ & & & & & & \\
\hline Strigiformes & Tytonidae & Tyto alba & barn owl & & & & $x$ & & & $x$ & & & & & & \\
\hline & Strigidae & Megascops kennicottii & western screech-owl & & 18 & 2 & $x$ & & $x$ & & & & & & & \\
\hline & & Bubo virginianus & great horned owl & & 4 & 1 & $\mathrm{X}$ & $x$ & $x$ & $x$ & & & & & & \\
\hline & & Athene cunicularia hypugaea & burrowing owl & & & & $\mathrm{X}$ & & & & SC & $S$ & & & & \\
\hline & & Micrathene whitneyi & elf owl & & 58 & 2 & $x$ & & $X$ & & & & & & & $\mathrm{BCC}$ \\
\hline Caprimulgiformes & Caprimulgidae & Chordeiles acutipennis & lesser nighthawk & 1 & 15 & 3 & $x$ & $x$ & & & & & & & & \\
\hline & & Phalaenoptilus nuttallii & common poorwill & 1 & 26 & & $x$ & & & & & & & & & \\
\hline Apodiformes & Apodidae & Chaetura vauxi & Vaux's swift & & & & $x$ & & & & & & & & & \\
\hline & & Aeronautes saxatalis & white-throated swift & 37 & & 1 & $x$ & & $\mathrm{X}$ & & & & & & & \\
\hline & Trochilidae & Archilochus alexandri & black-chinned hummingbird & 1 & & & $x$ & & & & & & & & & \\
\hline & & Calypte anna & Anna's hummingbird & 1 & & & $x$ & & & & & & & & & \\
\hline & & Calypte costae & Costa's hummingbird & 10 & & 3 & $x$ & $X$ & & & & & & & $P$ & \\
\hline & & Stellula calliope & calliope hummingbird & & & & $x$ & & & & & & & & & \\
\hline & & Selasphorus platycercus & broad-tailed hummingbird & & & 1 & & & & & & & & & & \\
\hline Piciformes & Picidae & Melanerpes uropygialis & Gila woodpecker & 308 & & 2 & $x$ & $x$ & $x$ & & & & & & & $\mathrm{BCC}$ \\
\hline & & Sphyrapicus varius & yellow-bellied sapsucker & & & & $x$ & & & & & & & & & \\
\hline
\end{tabular}




\begin{tabular}{|c|c|c|c|c|c|c|c|c|c|c|c|c|c|c|}
\hline \multirow[b]{2}{*}{ Order } & \multirow[b]{2}{*}{ Family } & \multirow[b]{2}{*}{ Scientific name } & \multirow[b]{2}{*}{ Common name } & \multicolumn{2}{|c|}{$\begin{array}{l}\text { UA survey } \\
\text { method }\end{array}$} & \multicolumn{4}{|c|}{ Species lists } & \multicolumn{5}{|c|}{ Conservation designation ${ }^{a}$} \\
\hline & & & & VCP & Noct Incid & $M \& S$ & YE & $\mathrm{SH}$ & $\mathrm{KL}$ & ESA & BLM USFS & WSCA & APF & USFWS \\
\hline \multirow{3}{*}{ Piciformes } & Picidae & Picoides scalaris & ladder-backed woodpecker & 9 & & $X$ & $\mathrm{X}$ & & & & & & & \\
\hline & & Colaptes auratus & northern flicker & & & $x$ & $\mathrm{X}$ & & & & & & & \\
\hline & & Colaptes chrysoides & gilded flicker & 37 & 1 & & $\mathrm{X}$ & $\mathrm{x}$ & & & & & $P$ & BCC \\
\hline \multirow[t]{36}{*}{ Passeriformes } & Tyrannidae & Contopus cooperi & olive-sided flycatcher & & & $x$ & & & & SC & & & & \\
\hline & & Contopus sordidulus & western wood-pewee & & & $x$ & & & & & & & & \\
\hline & & Empidonax traillii & willow flycatcher & & & $\mathrm{x}$ & & & & & & WSC & & \\
\hline & & Empidonax hammondii & Hammond's flycatcher & & & $x$ & & & & & & & & \\
\hline & & Empidonax wrightii & gray flycatcher & 1 & & $x$ & & & & & & & & \\
\hline & & Empidonax oberholseri & dusky flycatcher & & & $x$ & & & & & & & & \\
\hline & & Empidonax occidentalis or difficilis & western flycatcher & & & $x$ & & $X$ & & & & & & \\
\hline & & Sayornis saya & Say's phoebe & & & $x$ & $\mathrm{X}$ & & & & & & & \\
\hline & & Myiarchus cinerascens & ash-throated flycatcher & 126 & 1 & $x$ & $X$ & $x$ & & & & & & \\
\hline & & Myiarchus tyrannulus & brown-crested flycatcher & 27 & 1 & $x$ & $\mathrm{X}$ & $\mathrm{X}$ & & & & & & \\
\hline & & Tyrannus verticalis & western kingbird & 1 & & $x$ & & & & & & & & \\
\hline & Laniidae & Lanius ludovicianus & loggerhead shrike & & & $x$ & $X$ & $X$ & & SC & $S$ & & & \\
\hline & Vireonidae & Vireo bellii & Bell's vireo & & & $x$ & $\mathrm{X}$ & & & & S & & & BCC \\
\hline & & Vireo vicinior & gray vireo & & & $\mathrm{X}$ & & & & & & & & \\
\hline & & Vireo gilvus & warbling vireo & & & $x$ & & & & & & & & \\
\hline & Corvidae & Cyanocitta stelleri & Steller's jay & & & $x$ & & & & & & & & \\
\hline & & Aphelocoma californica & western scrub-jay & 1 & 4 & $x$ & & & & & & & & \\
\hline & & Corvus corax & common raven & 15 & & $x$ & & $x$ & & & & & & \\
\hline & Hirundinidae & Progne subis & purple martin & 33 & 10 & $x$ & $X$ & $x$ & & & & & $P$ & \\
\hline & & Tachycineta bicolor & tree swallow & & & $x$ & & & & & & & & \\
\hline & & Tachycineta thalassina & violet-green swallow & & & $x$ & & & & & & & & \\
\hline & & Stelgidopteryx serripennis & northern rough-winged swallow & 1 & & & & & & & & & & \\
\hline & & Petrochelidon pyrrhonota & cliff swallow & 1 & & & & & & & & & & \\
\hline & & Hirundo rustica & barn swallow & & & $x$ & & $\mathrm{X}$ & & & & & & \\
\hline & Remizidae & Auriparus flaviceps & verdin & 141 & 2 & $x$ & $\mathrm{X}$ & $\mathrm{X}$ & & & & & & \\
\hline & Troglodytidae & Campylorhynchus brunneicapillus & cactus wren & 161 & 2 & $x$ & 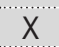 & $x$ & & & & & & \\
\hline & & Salpinctes obsoletus & rock wren & 8 & & $x$ & $X$ & & & & & & & \\
\hline & & Catherpes mexicanus & canyon wren & 41 & 3 & $x$ & & $\mathrm{X}$ & & & & & & \\
\hline & & Thryomanes bewickii & Bewick's wren & & & $x$ & $X$ & & & & & & & \\
\hline & & Troglodytes aedon & house wren & & & $x$ & & & & & & & & \\
\hline & Regulidae & Regulus calendula & ruby-crowned kinglet & & 1 & $x$ & $\mathrm{X}$ & & & & & & & \\
\hline & Sylviidae & Polioptila caerulea & blue-gray gnatcatcher & 3 & 2 & $x$ & & & & & & & & \\
\hline & & Polioptila melanura & black-tailed gnatcatcher & 64 & 3 & $x$ & $X$ & $x$ & & & & & & \\
\hline & Turdidae & Sialia mexicana & western bluebird & & & $x$ & & & & & & & & \\
\hline & & Sialia currucoides & mountain bluebird & & & $x$ & & & & & & & & \\
\hline & & Myadestes townsendi & Townsend's solitaire & & & $x$ & & & & & & & & \\
\hline
\end{tabular}




\begin{tabular}{|c|c|c|c|c|c|c|c|c|c|c|c|c|c|c|c|}
\hline \multirow[b]{2}{*}{ Order } & \multirow[b]{2}{*}{ Family } & \multirow[b]{2}{*}{ Scientific name } & \multirow[b]{2}{*}{ Common name } & \multicolumn{2}{|c|}{$\begin{array}{c}\text { UA survey } \\
\text { method }\end{array}$} & \multicolumn{4}{|c|}{ Species lists } & \multicolumn{6}{|c|}{ Conservation designation ${ }^{a}$} \\
\hline & & & & VCP & Noct Incid & M\&S & YE & $\mathrm{SH}$ & $\mathrm{KL}$ & ESA & BLM & USFS & WSCA & APF & USFWS \\
\hline \multirow[t]{39}{*}{ Passeriformes } & Turdidae & Catharus guttatus & hermit thrush & & 1 & $X$ & & & & & & & & & \\
\hline & & Turdus migratorius & American robin & & & $x$ & $x$ & & & & & & & & \\
\hline & Mimidae & Mimus polyglottos & northern mockingbird & 6 & 1 & $x$ & $X$ & $x$ & & & & & & & \\
\hline & & Oreoscoptes montanus & sage thrasher & & & $\mathrm{X}$ & & & & & & & & & \\
\hline & & Toxostoma bendirei & Bendire's thrasher & 1 & 2 & $x$ & & & & & & & & & \\
\hline & & Toxostoma curvirostre & curve-billed thrasher & 98 & 3 & $x$ & $x$ & $x$ & & & & & & & \\
\hline & & Toxostoma crissale & crissal thrasher & & & $x$ & & & & & & & & & BCC \\
\hline & Sturnidae & Sturnus vulgaris & European starling & & & $x$ & $x$ & & & & & & & & \\
\hline & Bombycillidae & Bombycilla cedrorum & cedar waxwing & & & $x$ & & & & & & & & & \\
\hline & Ptilogonatidae & Phainopepla nitens & phainopepla & 3 & 2 & $\mathrm{x}$ & $X$ & & & & & & & & \\
\hline & Parulidae & Vermivora celata & orange-crowned warbler & 2 & 3 & $x$ & & & & & & & & & \\
\hline & & Vermivora ruficapilla & Nashville warbler & & & $x$ & & & & & & & & & \\
\hline & & Vermivora virginiae & Virginia's warbler & & & $x$ & & & & & & & & & \\
\hline & & Vermivora luciae & Lucy's warbler & 1 & & $x$ & $X$ & & & & & & & $P$ & \\
\hline & & Dendroica coronata & yellow-rumped warbler & & & $x$ & $x$ & & & & & & & & \\
\hline & & Dendroica nigrescens & black-throated gray warbler & 1 & 1 & $x$ & $x$ & $x$ & & & & & & & \\
\hline & & Dendroica townsendi & Townsend's warbler & & & $x$ & & & & & & & & & \\
\hline & & Dendroica occidentalis & hermit warbler & & & $x$ & & & & & & & & & \\
\hline & & Oporornis tolmiei & MacGillivray's warbler & & 1 & $x$ & & & & & & & & & \\
\hline & & Wilsonia pusilla & Wilson's warbler & 2 & 1 & $x$ & $x$ & & & & & & & & \\
\hline & Thraupidae & Piranga ludoviciana & western tanager & & 1 & $x$ & & $x$ & & & & & & & \\
\hline & Emberizidae & Pipilo chlorurus & green-tailed towhee & 4 & 3 & $x$ & & & & & & & & & \\
\hline & & Pipilo maculatus & spotted towhee & & & $x$ & & & & & & & & & \\
\hline & & Pipilo fuscus & canyon towhee & 57 & & $x$ & $x$ & $x$ & & & & & & & \\
\hline & & Aimophila carpalis & rufous-winged sparrow & 15 & 8 & $x$ & $x$ & $x$ & & & & & & $P$ & BCC \\
\hline & & Aimophila cassinii & Cassin's sparrow & & & $x$ & & & & & & & & & \\
\hline & & Aimophila ruficeps & rufous-crowned sparrow & 6 & & $x$ & & $X$ & & & & & & & \\
\hline & & Spizella passerina & chipping sparrow & 2 & 3 & $x$ & & & & & & & & & \\
\hline & & Spizella breweri & Brewer's sparrow & 21 & 7 & $x$ & $x$ & & & & & & & & \\
\hline & & Spizella atrogularis & black-chinned sparrow & & & $x$ & & & & & & & & & \\
\hline & & Pooecetes gramineus & vesper sparrow & & & $x$ & & & & & & & & & \\
\hline & & Chondestes grammacus & lark sparrow & & & $x$ & $x$ & & & & & & & & \\
\hline & & Melospiza lincolnii & Lincoln's sparrow & & & $x$ & & & & & & & & & \\
\hline & & Amphispiza bilineata & black-throated sparrow & 95 & 1 & $x$ & $X$ & & & & & & & & \\
\hline & & Amphispiza belli & sage sparrow & & & $x$ & $x$ & & & & & & & & \\
\hline & & Calamospiza melanocorys & lark bunting & & & $x$ & & & & & & & & & \\
\hline & & Melospiza melodia & song sparrow & & & & $X$ & & & & & & & & \\
\hline & & Zonotrichia albicollis & white-throated sparrow & & & $x$ & & & & & & & & & \\
\hline & & Zonotrichia leucophrys & white-crowned sparrow & 3 & & $x$ & $x$ & & & & & & & & \\
\hline
\end{tabular}




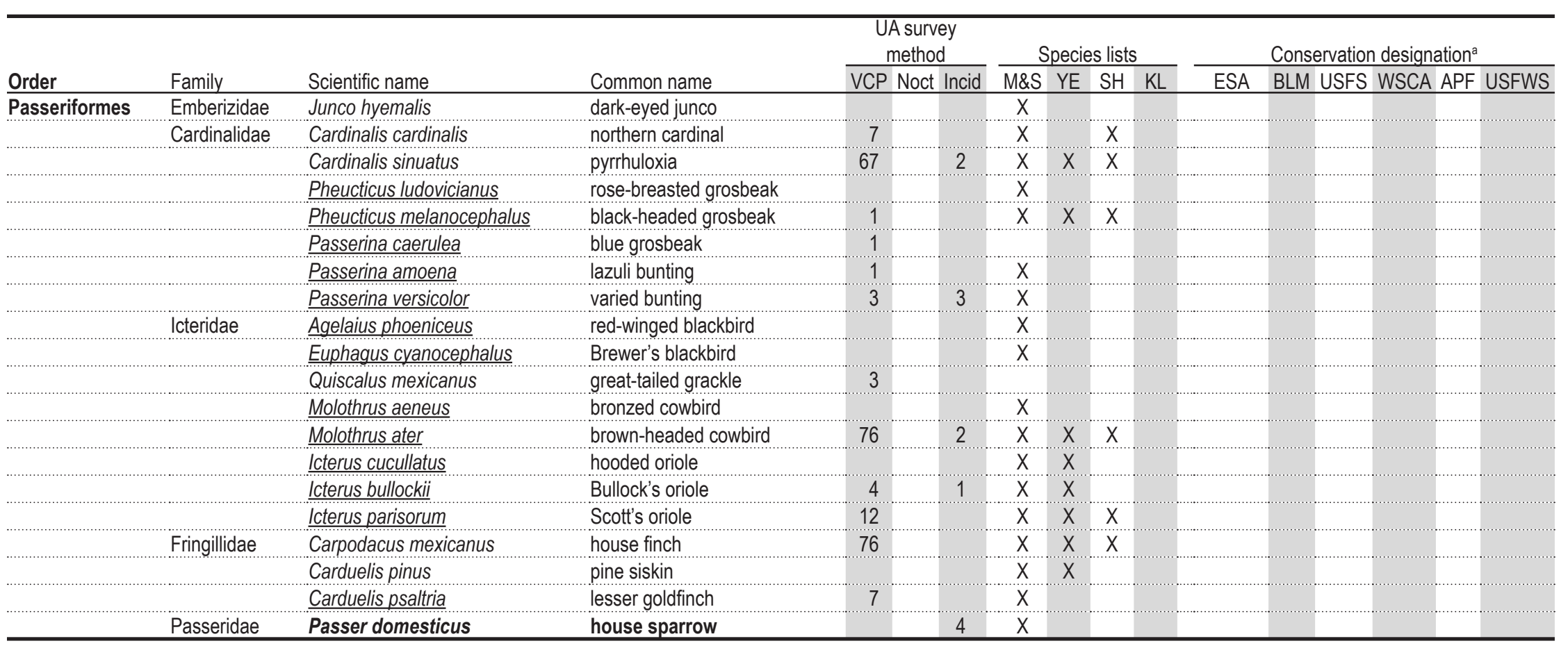

a ESA = Endangered Species Act; U.S. Fish and Wildlife Service; "SC" = "Species of Concern"; "C" = Candidate for listing. USFS = U.S.D.A. Forest Service, "Sensitive species" (HDMS 2004). WSCA = Arizona Game and Fish Department "Wildlife of Special Concern" (HDMS 2004). APF = Arizona Partners in Flight, "Priority species"; (Latta et al. 1999). U.S. Fish and Wildlife Service, "Species of conservation concern" (HDMS 2004).

'Unlikely to occur except as rare passage migrant. 
Appendix D. List of mammals observed at Saguaro NP, Tucson Mountain District by University of Arizona (UA) and Saguaro National Park (SNP) Inventory personnel by survey type, 2001-2005 and other efforts. Numbers of observations are not scaled by search effort and should not be used for comparison among species or survey types. See Appendix E for additional information on specimen (Spec.) and photographic (Photo) vouchers. Historical data from: Historical specimen records (HSR; Appendix F), Sidner and Davis (S\&D; 1994), Yensen (YEN;1973), Parmenter (PAR; unpubl. data), and Kline et al (Kea; 1999). Species in bold-faced type are non-native.

\begin{tabular}{|c|c|c|c|c|c|c|c|c|c|c|c|c|c|}
\hline \multirow[b]{2}{*}{$\begin{array}{l}\text { Order } \\
\text { Family }\end{array}$} & \multirow[b]{2}{*}{ Scientific name } & \multirow[b]{2}{*}{ Common name } & \multicolumn{4}{|c|}{$\begin{array}{c}\text { Number of observation by UA/SNP } \\
\text { survey method }\end{array}$} & \multicolumn{2}{|c|}{$\begin{array}{c}\text { Vouchers from this } \\
\text { effort }\end{array}$} & \multicolumn{5}{|c|}{$\begin{array}{l}\text { Historical Data/ } \\
\text { Species Lists }\end{array}$} \\
\hline & & & $\begin{array}{c}\text { Small } \\
\text { mammal }\end{array}$ & $\begin{array}{c}\text { Bat } \\
\text { netting }\end{array}$ & Trailmaster & Incidental & Photograph & Specimen & HSR & S\&D & YEN & PAR & Kea \\
\hline $\begin{array}{l}\text { Chiroptera } \\
\text { Phyllostomidae }\end{array}$ & Macrotus californicus & California leaf-nosed bat & & 2 & & & & 1 & & $x$ & & & \\
\hline \multirow[t]{4}{*}{ Vespertilionidae } & Myotis velifer ${ }^{a b}$ & cave myotis & & 11 & & & & 4 & & $x$ & & & \\
\hline & Pipistrellus hesperus & western pipistrelle & & 4 & & & & & & $X$ & & & \\
\hline & Eptesicus fuscus & big brown bat & & & & & & & & $\mathrm{X}$ & & & \\
\hline & Corynorhinus townsendii pallescens ${ }^{a}$ & Townsend's big-eared bat & & & & & & & 1 & $X$ & & & \\
\hline \multirow[t]{3}{*}{ Procyonidae } & Procyon lotor & northern raccoon & & & 1 & & 1 & & & & & & $x$ \\
\hline & Nasua narica & white-nosed coati & & & & & & & $\mathrm{obs}^{\mathrm{c}}$ & & & & \\
\hline & Bassariscus astutus & ringtail & & & 15 & & 1 & & & & & & $\mathrm{X}$ \\
\hline Mustelidae & Taxidea taxus & American badger & & & 9 & & 1 & 1 & & & & & \\
\hline \multirow[t]{4}{*}{ Mephitidae } & Spilogale gracilis & western spotted skunk & & & 4 & & 1 & & & & & & \\
\hline & Mephitis mephitis & striped skunk & & & 3 & & 1 & & & & & & $x$ \\
\hline & Mephitis macroura & hooded skunk & & & 62 & & 1 & & & & & & \\
\hline & Conepatus mesoleucus & white-backed hog-nosed skunk & & & 6 & & 1 & & & & & & \\
\hline \multirow[t]{4}{*}{ Canidae } & Canis familiaris & feral dog & & & 3 & & 1 & 1 & & & & & \\
\hline & Canis latrans & coyote & & & 245 & 1 & 1 & 1 & & & & & $X$ \\
\hline & Urocyon cinereoargenteus & common gray fox & & & 582 & 2 & 1 & & & & & & $x$ \\
\hline & Vulpes macrotus & kit fox & & & 2 & & 1 & & & & & & $x$ \\
\hline \multirow[t]{3}{*}{ Felidae } & Felis catus & feral cat & & & & & & 1 & & & & & \\
\hline & Puma concolor azteca & mountain lion & & & 7 & & 1 & & & & & & $X$ \\
\hline & Lynx rufus & bobcat & & & 36 & & 1 & & & & & & $x$ \\
\hline \multirow[t]{3}{*}{$\begin{array}{l}\text { Rodentia } \\
\text { Sciuridae }\end{array}$} & Spermophilus variegatus & rock squirrel & & & 30 & 1 & 1 & 1 & & & & & $x$ \\
\hline & Spermophilus tereticaudus & round-tailed ground squirrel & & & 2 & & 1 & & & & & & \\
\hline & Ammospermophilus harrisii & Harris' antelope squirrel & 1 & & 17 & 2 & 1 & & & & & $\mathrm{X}$ & \\
\hline \multirow[t]{5}{*}{ Heteromyidae } & Perognathus amplus taylori & Arizona pocket mouse & 30 & & & & & & 2 & & $\mathrm{X}$ & $\mathrm{X}$ & \\
\hline & Chaetodipus penicillatus & Sonoran Desert pocket mouse & 39 & & & & & 3 & 6 & & $x$ & $X$ & \\
\hline & Chaetodipus intermedius intermedius ${ }^{a}$ & rock pocket mouse & 30 & & & & & & & & $x$ & & \\
\hline & Chaetodipus baileyi & Bailey's pocket mouse & 27 & & & & & & 3 & & $\mathrm{x}$ & $\mathrm{X}$ & \\
\hline & Dipodomys merriami & Merriam's kangaroo rat & 32 & & & & & & & & $x$ & $x$ & \\
\hline \multirow[t]{2}{*}{ Muridae } & Peromyscus eremicus eremicus ${ }^{a}$ & cactus mouse & 4 & & & & & & 3 & & & $\mathrm{X}$ & \\
\hline & Peromyscus boylii & brush mouse & $1^{d}$ & & & & & & & & & & \\
\hline
\end{tabular}




\begin{tabular}{|c|c|c|c|c|c|c|c|c|c|c|c|c|c|}
\hline \multirow[b]{2}{*}{$\begin{array}{l}\text { Order } \\
\text { Family }\end{array}$} & \multirow[b]{2}{*}{ Scientific name } & \multirow[b]{2}{*}{ Common name } & \multicolumn{4}{|c|}{$\begin{array}{c}\text { Number of observation by UA/SNP } \\
\text { survey method }\end{array}$} & \multicolumn{2}{|c|}{$\begin{array}{c}\text { Vouchers from this } \\
\text { effort }\end{array}$} & \multicolumn{5}{|c|}{$\begin{array}{l}\text { Historical Data/ } \\
\text { Species Lists }\end{array}$} \\
\hline & & & $\begin{array}{c}\text { Small } \\
\text { mammal }\end{array}$ & $\begin{array}{c}\text { Bat } \\
\text { netting }\end{array}$ & Trailmaster & Incidental & Photograph & Specimen & HSR & S\&D & YEN & PAR & Kea \\
\hline \multirow[t]{5}{*}{$\begin{array}{l}\text { Rodentia } \\
\text { Muridae }\end{array}$} & Peromyscus maniculatus & deer mouse & & & & & & & 1 & & & & \\
\hline & Mus musculus & house mouse & & & & & & & & & $\mathrm{X}$ & & \\
\hline & Onychomys torridus & southern grasshopper mouse & & & & & & & 2 & & $x$ & $\mathrm{X}$ & \\
\hline & Neotoma albigula & western white-throated woodrat & 10 & & & & & & 3 & & $x$ & $\mathrm{X}$ & \\
\hline & Sigmodon arizonae arizonae & Arizona cotton rat & & & & & & & 1 & & & & \\
\hline \multirow[t]{3}{*}{$\begin{array}{c}\text { Lagomorpha } \\
\text { Leporidae }\end{array}$} & Lepus alleni & antelope jackrabbit & & & 22 & & 1 & & & & & & \\
\hline & Lepus californicus & black-tailed jackrabbit & & & 98 & 1 & 1 & & & & & & $\mathrm{x}$ \\
\hline & Sylvilagus audubonii & desert cottontail & & & 169 & 1 & 1 & 1 & & & & $x$ & $\mathrm{X}$ \\
\hline $\begin{array}{l}\text { Artiodactyla } \\
\text { Tayassuidae }\end{array}$ & Pecari tajacu & collared peccary & & & 327 & 5 & 1 & 2 & & & & & $x$ \\
\hline Cervidae & Odocoileus hemionus & mule deer & & & 52 & 3 & 1 & & & & & & $\mathrm{X}$ \\
\hline
\end{tabular}

a U.S. Fish and Wildlife Service "Species of Concern."

"Bureau of Land Management (BLM) "Sensitive species"

${ }^{\circ}$ Coati has been observed by staff only and could be misidentified; see text.

${ }^{\mathrm{d}}$ Brush mouse not confirmed and could be misidentified; see text. 
Appendix E. Vertebrate specimen and photograph vouchers collected by University of Arizona or park personnel, Saguaro National Park, Tucson Mountain District, 1997-2002. All voucher specimens are located in the University of Arizona (AZ) collections. All photographic vouchers are located in the I\&M office in Tucson.

\begin{tabular}{|c|c|c|c|c|c|c|}
\hline \multirow{2}{*}{$\begin{array}{l}\text { Voucher type } \\
\text { Specimen }\end{array}$} & \multirow{2}{*}{$\begin{array}{l}\text { Taxon } \\
\text { Reptile }\end{array}$} & \multirow{2}{*}{$\begin{array}{l}\text { Common Name } \\
\text { zebra-tailed lizard }\end{array}$} & \multirow{2}{*}{$\begin{array}{l}\text { Collector(s) } \\
\text { James E. Borgmeyer }\end{array}$} & \multicolumn{3}{|c|}{ Collection date AZ collection \# Specimen type } \\
\hline & & & & $04 / 11 / 01$ & 52697 & \\
\hline & & regal horned lizard & Kevin E. Bonine & $07 / 29 / 02$ & 54441 & \\
\hline & & western whiptail (tiger whiptail) & Chris K. Kirkpatrick & $04 / 24 / 01$ & 53647 & \\
\hline & & coachwhip & Larry L. Norris & $03 / 31 / 01$ & 53642 & \\
\hline & & western patch-nosed snake & James E. Borgmeyer & $04 / 14 / 01$ & 52699 & \\
\hline & & glossy snake & Dave B. Prival & $10 / 25 / 01$ & 53668 & \\
\hline & & long-nosed snake & James E. Borgmeyer & $04 / 17 / 01$ & 52700 & \\
\hline & & variable sandsnake & Brian F. Powell & $11 / 03 / 01$ & 52450 & \\
\hline & & & Pam Swantek (Anning) & $05 / 13 / 97$ & & \\
\hline & & Sonoran coral snake & Mark Holden & & & \\
\hline & & western diamond-backed rattlesnake & George Bradley & $10 / 04 / 01$ & 53676 & \\
\hline & Mammal & California leaf-nosed bat & Ronnie Sidner & $03 / 28 / 01$ & 26751 & Partial Cranium \\
\hline & & cave myotis & Ronnie Sidner & $05 / 15 / 01$ & 26839 & Skin and Skull \\
\hline & & & Ronnie Sidner & $01 / 28 / 02$ & 26753 & Skull \\
\hline & & & Ronnie Sidner & $01 / 28 / 02$ & 26754 & Skull \\
\hline & & & Ronnie Sidner & $03 / 28 / 01$ & 26752 & Skull \\
\hline & & American badger & Jason A. Schmidt & $09 / 30 / 01$ & 26768 & Skull \\
\hline & & feral dog & Jason A. Schmidt & $04 / 13 / 01$ & 26780 & Skull \\
\hline & & coyote & Jason A. Schmidt & $08 / 25 / 01$ & 27027 & Skull \\
\hline & & feral cat & Neil D. Perry & $09 / 26 / 01$ & 26767 & Skull \\
\hline & & rock squirrel & Jason A. Schmidt & $08 / 23 / 01$ & & Skin and Skull \\
\hline & & Sonoran Desert pocket mouse & Jason A. Schmidt & $10 / 02 / 01$ & 26903 & Skull \\
\hline & & & Jason A. Schmidt & $10 / 01 / 01$ & 26930 & Skull \\
\hline & & & Jason A. Schmidt & $10 / 02 / 01$ & 26932 & Skull \\
\hline & & desert cottontail & Neil D. Perry & $06 / 06 / 01$ & 26748 & Skull and Skin \\
\hline & & collared peccary & Jason A. Schmidt & $08 / 25 / 01$ & & Skull \\
\hline & & & Neil D. Perry & $04 / 12 / 01$ & 26775 & Skull \\
\hline Photograph & Amphibiar & Couch's spadefoot & Dave B. Prival & $07 / 05 / 01$ & & \\
\hline & & Sonoran desert toad & Dave B. Prival & $06 / 29 / 01$ & & \\
\hline & & red-spotted toad & Dave B. Prival & $07 / 02 / 01$ & & \\
\hline & & Great Plains toad & Dave B. Prival & $07 / 31 / 01$ & & \\
\hline & Reptile & desert tortoise & Dave B. Prival & $04 / 14 / 01$ & & \\
\hline & & western banded gecko & Dave B. Prival & $07 / 15 / 01$ & & \\
\hline & & desert iguana & Dave B. Prival & $07 / 17 / 01$ & & \\
\hline & & eastern collared lizard & Dave B. Prival & $04 / 14 / 01$ & & \\
\hline & & long-nosed leopard lizard & Dave B. Prival & $09 / 08 / 01$ & & \\
\hline & & lesser earless lizard & Dave B. Prival & $07 / 16 / 01$ & & \\
\hline & & zebra-tailed lizard & Dave B. Prival & $04 / 12 / 01$ & & \\
\hline & & Clark's spiny lizard & Dave B. Prival & $04 / 14 / 01$ & & \\
\hline & & common side-blotched lizard & Dave B. Prival & $04 / 12 / 01$ & & \\
\hline & & ornate tree lizard & Dave B. Prival & $04 / 11 / 01$ & & \\
\hline & & regal horned lizard & Dave B. Prival & $04 / 14 / 01$ & & \\
\hline & & Gila monster & Dave B. Prival & $04 / 13 / 01$ & & \\
\hline & & western blind snake & Dave B. Prival & $09 / 11 / 01$ & & \\
\hline & & coachwhip & Dave B. Prival & $07 / 05 / 01$ & & \\
\hline & & western patch-nosed snake & Dave B. Prival & $04 / 13 / 01$ & & \\
\hline & & gopher snake & Dave B. Prival & $07 / 03 / 01$ & & \\
\hline & & glossy snake & Dave B. Prival & $09 / 25 / 01$ & & \\
\hline & & long-nosed snake & Dave B. Prival & $04 / 14 / 01$ & & \\
\hline & & western lyre snake & Dale S. Turner & $07 / 11 / 02$ & & \\
\hline & & night snake & Dave B. Prival & $07 / 15 / 01$ & & \\
\hline & & western diamond-backed rattlesnake & Dave B. Prival & $06 / 29 / 01$ & & \\
\hline & & sidewinder & Dave B. Prival & $07 / 13 / 01$ & & \\
\hline
\end{tabular}




\begin{tabular}{|c|c|c|c|}
\hline Voucher type Taxon & Common Name & Collector(s) & Collection date AZ collection \# Specimen type \\
\hline \multirow{3}{*}{ Photograph } & black-tailed rattlesnake & Mike D. Wall & $04 / 17 / 01$ \\
\hline & tiger rattlesnake & Dave B. Prival & $06 / 29 / 01$ \\
\hline & Mojave rattlesnake & Dave B. Prival & $07 / 16 / 01$ \\
\hline \multirow[t]{4}{*}{ Bird } & Gambel's quail & Neil D. Perry & $08 / 27 / 01$ \\
\hline & mourning dove & Neil D. Perry & $08 / 27 / 01$ \\
\hline & greater roadrunner & Neil D. Perry & $08 / 27 / 01$ \\
\hline & western screech-owl & Ronnie Sidner & $05 / 11 / 01$ \\
\hline \multirow[t]{13}{*}{ Mammal } & cave myotis & Ronnie Sidner & $05 / 11 / 01$ \\
\hline & western pipistrelle & Ronnie Sidner & $05 / 11 / 01$ \\
\hline & ringtail & Neil D. Perry & $04 / 27 / 02$ \\
\hline & American badger & Neil D. Perry & $04 / 27 / 01$ \\
\hline & western spotted skunk & Neil D. Perry & $10 / 03 / 01$ \\
\hline & striped skunk & Neil D. Perry & $10 / 29 / 01$ \\
\hline & hooded skunk & Neil D. Perry & 09/19/01 \\
\hline & white-backed hog-nosed skunk & Neil D. Perry & 10/17/01 \\
\hline & common gray fox & Neil D. Perry & $08 / 22 / 01$ \\
\hline & bobcat & Neil D. Perry & $04 / 27 / 02$ \\
\hline & rock squirrel & Neil D. Perry & 09/19/01 \\
\hline & black-tailed jackrabbit & Neil D. Perry & 09/19/01 \\
\hline & collared peccary & Neil D. Perry & $10 / 01 / 01$ \\
\hline
\end{tabular}

Appendix F. List of existing voucher specimens collected prior to our inventory effort. See Table 1.1 for list of collections queried for these data.

\begin{tabular}{|c|c|c|c|c|c|}
\hline Taxon & Common name & Collection $^{\mathrm{a}}$ & Collection number & Collection date & Collector \\
\hline \multirow[t]{2}{*}{ Amphibian } & Couch's spadefoot & UA & 25626 & $00 / 00 / 68$ & \\
\hline & Sonoran desert toad & UA & 25623 & $00 / 00 / 68$ & \\
\hline \multirow[t]{7}{*}{ Reptile } & desert spiny lizard & TTU & 6,38 & $08 / 06 / 69$ & P. Tatano \\
\hline & regal horned lizard & NHMLAC & 107276 & & \\
\hline & Gila monster & NPS & 597 & $05 / 26 / 66$ & E. Pingry \\
\hline & gopher snake & UA & 31761 & $00 / 00 / 69$ & \\
\hline & western diamond-backed rattlesnak & EUCB & 206949,206950 & $09 / 01 / 87$ & H. W. Greene \\
\hline & sidewinder & NPS & 573 & $08 / 04 / 66$ & B. A. Lund \\
\hline & tiger rattlesnake & UM & 134070,134071 & $06 / 13 / 70$ & R. W. Van Devender \\
\hline \multirow[t]{10}{*}{ Mammal } & cave myotis & NPS & $5297,5686,5687$ & $05 / 02 / 91,07 / 01 / 94,03 / 16 / 93$ & Sidner \\
\hline & Townsend's big eared bat & UA & 1077 & $10 / 6 / 51 \quad-\quad-1-1$ & J.B. Elder \\
\hline & Arizona pocket mouse & UA & 16751,22650 & $09 / 17 / 66,06 / 15 / 71$ & J. L. Patton, C. B. Robbins \\
\hline & Sonoran Desert pocket mouse & UA & $\begin{array}{l}22655,4026-30,5710, \\
25704\end{array}$ & $06 / 13 / 71,10 / 6 / 51$ & $\begin{array}{l}\text { C. B. Robbins, W. G. } \\
\text { Swank, J. B. Elder }\end{array}$ \\
\hline & Bailey's pocket mouse & UA & $25948,26297,26411$ & $11 / 04 / 83,11 / 03 / 83$ & E. E. Johnson, J. Hazam \\
\hline & deer mouse & UA & 19605 & $12 / 27 / 71$ & L. Jacobs \\
\hline & cactus mouse & UA & $25945,1196,5320$ & $11 / 04 / 83,11 / 23 / 51$ & E. E. Johnson, J. B. Elder \\
\hline & Arizona cotton rat & NPS & & 1993 & N. Kline \\
\hline & southern grasshopper mouse & UA & 5321,18960 & $11 / 23 / 51,3 / 2 / 70$ & J. B. Elder, J.C. Geest \\
\hline & western white-throated woodrat & UA & $1260-61,25953$ & $11 / 6 / 51,11 / 4 / 83$ & $\begin{array}{l}\text { W. G. Swank, E. E. } \\
\text { Johnson }\end{array}$ \\
\hline
\end{tabular}

a NHMLAC = Natural History Museum of Los Angeles County; NPS = National Park Service, Western Archaeological Conservation Center ; TTU = Texas Tech University; UA = University of Arizona Collections; UCB = Museum of Vertebrate Zoology, University of California; UM = University of Michigan. 
Appendix G. Percent composition (Comp.) and cover from point-intercept transects, by height category, Saguaro NP, Tucson Mountain District, 2001. See text for description of calculations of percent composition ("Comp.") and cover.

\begin{tabular}{|c|c|c|c|c|c|c|c|c|c|}
\hline \multirow[b]{2}{*}{ Transect } & \multirow[b]{2}{*}{ Species } & \multicolumn{2}{|c|}{$0-.5 \mathrm{~m}$} & \multicolumn{2}{|c|}{$.5-2 m$} & \multicolumn{2}{|c|}{$2-4 m$} & \multicolumn{2}{|c|}{$>4 m$} \\
\hline & & $\begin{array}{c}\% \\
\text { Comp. }\end{array}$ & $\begin{array}{c}\% \\
\text { Cover }\end{array}$ & $\begin{array}{c}\% \\
\text { Comp. }\end{array}$ & $\begin{array}{c}\% \\
\text { Cover }\end{array}$ & $\begin{array}{c}\% \\
\text { Comp. }\end{array}$ & $\begin{array}{c}\% \\
\text { Cover }\end{array}$ & $\begin{array}{c}\% \\
\text { Comp. }\end{array}$ & $\begin{array}{c}\% \\
\text { Cover }\end{array}$ \\
\hline 204 & Jacobinia candicans & 0.2 & 0.1 & & & & & & \\
\hline & Asclepias lemmonii & 0.2 & 0.1 & & & & & & \\
\hline & Ambrosia ambrosioides & 0.3 & 0.2 & 0.3 & 0.1 & & & & \\
\hline & Ambrosia deltoidea & 17.0 & 10.4 & 3.7 & 1.3 & & & & \\
\hline & Aster leucelene & 0.2 & 0.1 & & & & & & \\
\hline & Brickellia coulteri & 0.7 & 0.4 & & & & & & \\
\hline & Dyssodia porophylloides & 0.8 & 0.5 & & & & & & \\
\hline & Encelia farinosa & 1.1 & 0.7 & 0.6 & 0.2 & & & & \\
\hline & Hymenoclea salsola & 8.5 & 5.2 & 8.0 & 2.8 & 1.4 & 0.1 & & \\
\hline & Machaeranthera gracilis & 0.2 & 0.1 & & & & & & \\
\hline & Machaeranthera parviflora & 0.2 & 0.1 & 0.3 & 0.1 & & & & \\
\hline & Psilostrophe cooperi & 0.2 & 0.1 & & & & & & \\
\hline & Uropappus linearifolius & 0.2 & 0.1 & & & & & & \\
\hline & Zinnia acerosa & 0.5 & 0.3 & & & & & & \\
\hline & Pennellia micrantha & 0.5 & 0.3 & 1.7 & 0.6 & 2.7 & 0.2 & & \\
\hline & Opuntia acanthocarpa & 3.9 & 2.4 & 4.6 & 1.6 & & & & \\
\hline & Opuntia leptocaulis & 1.3 & 0.8 & 0.6 & 0.2 & & & & \\
\hline & Opuntia phaeacantha & 7.5 & 4.6 & 9.8 & 3.4 & & & & \\
\hline & Opuntia versicolor & 0.3 & 0.2 & 0.6 & 0.2 & & & & \\
\hline & Atriplex canescens & 0.2 & 0.1 & & & & & & \\
\hline & Euphorbia capitellata & 0.2 & 0.1 & & & & & & \\
\hline & Euphorbia sp. & 0.2 & 0.1 & & & & & & \\
\hline & Jatropha cardiophylla & 0.8 & 0.5 & 1.7 & 0.6 & & & & \\
\hline & Acacia constricta & 3.6 & 2.2 & 13.5 & 4.7 & & & & \\
\hline & Acacia greggii & 0.5 & 0.3 & 0.6 & 0.2 & & & & \\
\hline & Caesalpinia gilliesii & 0.2 & 0.1 & & & 4.1 & 0.3 & & \\
\hline & Calliandra eriophylla & 10.1 & 6.2 & 1.1 & 0.4 & & & & \\
\hline & Dead olneya tesota & & & 0.9 & 0.3 & 2.7 & 0.2 & & \\
\hline & Olneya tesota & 1.5 & 0.9 & 5.7 & 2.0 & 23.3 & 1.7 & & \\
\hline & Parkinsonia microphylla & 2.9 & 1.8 & 17.0 & 5.9 & 35.6 & 2.6 & & \\
\hline & Prosopis velutina & 0.3 & 0.2 & 3.4 & 1.2 & 5.5 & 0.4 & & \\
\hline & Fouquieria splendens & & & 0.9 & 0.3 & 4.1 & 0.3 & & \\
\hline & Krameria grayi & 1.6 & 1.0 & 0.3 & 0.1 & & & & \\
\hline & Krameria sp. & 0.8 & 0.5 & & & & & & \\
\hline & Dichelostemma pulchellum & 0.5 & 0.3 & & & & & & \\
\hline & Janusia gracilis & 10.8 & 6.6 & 9.8 & 3.4 & 1.4 & 0.1 & & \\
\hline & Abutilon incanum & 0.5 & 0.3 & 0.6 & 0.2 & & & & \\
\hline & Hibiscus coulteri & & & 0.6 & 0.2 & & & & \\
\hline & Sphaeralcea laxa & 0.2 & 0.1 & & & & & & \\
\hline & Commicarpus scandens & 1.3 & 0.8 & 0.3 & 0.1 & & & & \\
\hline & Forestiera shrevei & & & 0.3 & 0.1 & & & & \\
\hline & Menodora scabra & 0.5 & 0.3 & & & & & & \\
\hline & Passiflora mexicana & 0.5 & 0.3 & 2.3 & 0.8 & 6.8 & 0.5 & & \\
\hline & Alopecurus carolinianus & 0.2 & 0.1 & & & & & & \\
\hline & Aristida ternipes & 0.2 & 0.1 & & & & & & \\
\hline & Bouteloua chondrosioides & 2.8 & 1.7 & & & & & & \\
\hline & Cortaderia selloana & 0.5 & 0.3 & 0.6 & 0.2 & & & & \\
\hline & Digitaria californica & 1.3 & 0.8 & 0.3 & 0.1 & & & & \\
\hline & Heteropogon contortus & 0.2 & 0.1 & 0.3 & 0.1 & & & & \\
\hline & Muhlenbergia polycaulis & 0.3 & 0.2 & & & & & & \\
\hline & Muhlenbergia porteri & 1.6 & 1.0 & & & & & & \\
\hline
\end{tabular}




\begin{tabular}{|c|c|c|c|c|c|c|c|c|c|}
\hline \multirow[b]{2}{*}{ Transect } & \multirow[b]{2}{*}{ Species } & \multicolumn{2}{|c|}{$0-.5 \mathrm{~m}$} & \multicolumn{2}{|c|}{$.5-2 m$} & \multicolumn{2}{|c|}{$2-4 m$} & \multicolumn{2}{|c|}{$>4 \mathrm{~m}$} \\
\hline & & $\begin{array}{c}\% \\
\text { Comp. }\end{array}$ & $\begin{array}{c}\% \\
\text { Cover }\end{array}$ & $\begin{array}{c}\% \\
\text { Comp. }\end{array}$ & $\begin{array}{c}\% \\
\text { Cover }\end{array}$ & $\begin{array}{c}\% \\
\text { Comp. }\end{array}$ & $\begin{array}{c}\% \\
\text { Cover }\end{array}$ & $\begin{array}{c}\% \\
\text { Comp. }\end{array}$ & $\begin{array}{c}\% \\
\text { Cover }\end{array}$ \\
\hline \multirow[t]{8}{*}{204} & Phalaris canariensis & 0.3 & 0.2 & 0.9 & 0.3 & 1.4 & 0.1 & & \\
\hline & Hedyotis crassifolia & 0.3 & 0.2 & & & & & & \\
\hline & Selaginella arizonica & 6.2 & 3.8 & & & & & & \\
\hline & Castela emoryi & 0.2 & 0.1 & & & & & & \\
\hline & Lycium berlandieri & 0.7 & 0.4 & 1.1 & 0.4 & & & & \\
\hline & Celtis pallida & 1.8 & 1.1 & 3.7 & 1.3 & 5.5 & 0.4 & & \\
\hline & Phoradendron californicum & 0.5 & 0.3 & 1.4 & 0.5 & 5.5 & 0.4 & & \\
\hline & Larrea tridentata & 1.3 & 0.8 & 2.3 & 0.8 & & & & \\
\hline \multirow[t]{37}{*}{212} & Carlowrightia arizonica & 1.7 & 1.0 & & & & & & \\
\hline & Jacobinia candicans & & & 1.0 & 0.3 & & & & \\
\hline & Ambrosia deltoidea & 1.1 & 0.7 & & & & & & \\
\hline & Baileya multiradiata & 0.6 & 0.3 & & & & & & \\
\hline & Bebbia juncea & & & 1.0 & 0.3 & & & & \\
\hline & Encelia farinosa & 3.9 & 2.3 & 3.8 & 1.3 & & & & \\
\hline & Trixis californica & 2.2 & 1.3 & & & & & & \\
\hline & Carnegia gigantea & 0.6 & 0.3 & & & & & & \\
\hline & Opuntia acanthocarpa & 2.2 & 1.3 & 3.8 & 1.3 & & & & \\
\hline & Opuntia arbuscula & 2.2 & 1.3 & 1.0 & 0.3 & & & & \\
\hline & Opuntia phaeacantha & 5.1 & 3.0 & 3.8 & 1.3 & & & & \\
\hline & Ditaxis sp. & 0.6 & 0.3 & & & & & & \\
\hline & Jatropha cardiophylla & 2.2 & 1.3 & 3.8 & 1.3 & & & & \\
\hline & Acacia constricta & 1.7 & 1.0 & 5.8 & 2.0 & & & & \\
\hline & Acacia greggii & 3.4 & 2.0 & 6.7 & 2.3 & 7.7 & 0.3 & & \\
\hline & Calliandra eriophylla & 1.7 & 1.0 & & & & & & \\
\hline & Coursetia microphylla & & & 5.8 & 2.0 & 7.7 & 0.3 & & \\
\hline & Dead Parkinsonia microphylla & 0.6 & 0.3 & & & & & & \\
\hline & Dead Parkinsonia microphylla & & & 1.0 & 0.3 & & & & \\
\hline & Parkinsonia microphylla & 3.9 & 2.3 & 25.0 & 8.7 & 69.2 & 3.0 & & \\
\hline & Dead Fouquieria splendens & 0.6 & 0.3 & 1.0 & 0.3 & & & & \\
\hline & Fouquieria splendens & 1.1 & 0.7 & 5.8 & 2.0 & 15.4 & 0.7 & & \\
\hline & Janusia gracilis & 12.4 & 7.3 & 8.7 & 3.0 & & & & \\
\hline & Abutilon incanum & 3.9 & 2.3 & 1.9 & 0.7 & & & & \\
\hline & Hibiscus denudatus & 4.5 & 2.7 & & & & & & \\
\hline & Allionia incarnata & 0.6 & 0.3 & & & & & & \\
\hline & Aristida ternipes & 0.6 & 0.3 & & & & & & \\
\hline & Heteropogon contortus & 0.6 & 0.3 & & & & & & \\
\hline & Muhlenbergia porteri & 1.7 & 1.0 & & & & & & \\
\hline & Poa sp. & 0.6 & 0.3 & & & & & & \\
\hline & Tridens muticus & 0.6 & 0.3 & & & & & & \\
\hline & Notholaena sinuata & 2.8 & 1.7 & & & & & & \\
\hline & Selaginella arizonica & 26.4 & 15.7 & & & & & & \\
\hline & Simmondsia chinensis & 5.1 & 3.0 & 8.7 & 3.0 & & & & \\
\hline & Lycium sp. & 2.2 & 1.3 & 8.7 & 3.0 & & & & \\
\hline & Celtis pallida & & & 1.0 & 0.3 & & & & \\
\hline & Larrea tridentata & 0.6 & 0.3 & 1.9 & 0.7 & & & & \\
\hline \multirow[t]{9}{*}{213} & Ambrosia ambrosioides & 1.0 & 0.3 & & & & & & \\
\hline & Ambrosia deltoidea & 51.0 & 16.7 & 1.5 & 0.3 & & & & \\
\hline & Brickellia simplex & & & 1.5 & 0.3 & & \multirow{7}{*}{0.3} & & \\
\hline & Encelia farinosa & 2.0 & 0.7 & & & & & & \\
\hline & Hymenoclea salsola & 5.1 & 1.7 & 3.1 & 0.7 & & & & \\
\hline & Opuntia acanthocarpa & 1.0 & 0.3 & 1.5 & 0.3 & & & & \\
\hline & Opuntia arbuscula & 1.0 & 0.3 & 3.1 & 0.7 & & & & \\
\hline & Opuntia phaeacantha & 3.1 & 1.0 & 7.7 & 1.7 & 4.0 & & & \\
\hline & Canotia holacantha & 1.0 & 0.3 & 3.1 & 0.7 & & & & \\
\hline
\end{tabular}




\begin{tabular}{|c|c|c|c|c|c|c|c|c|c|}
\hline \multirow[b]{2}{*}{ Transect } & \multirow[b]{2}{*}{ Species } & \multicolumn{2}{|c|}{$0-.5 \mathrm{~m}$} & \multicolumn{2}{|c|}{$.5-2 m$} & \multicolumn{2}{|c|}{$2-4 m$} & \multicolumn{2}{|c|}{$>4 m$} \\
\hline & & $\begin{array}{c}\% \\
\text { Comp }\end{array}$ & $\begin{array}{c}\% \\
\text { Cover }\end{array}$ & $\begin{array}{c}\% \\
\text { Comp }\end{array}$ & $\begin{array}{c}\% \\
\text { Cover }\end{array}$ & $\begin{array}{c}\% \\
\text { Comp }\end{array}$ & $\begin{array}{c}\% \\
\text { Cover }\end{array}$ & $\begin{array}{c}\% \\
\text { Comp }\end{array}$ & $\begin{array}{c}\% \\
\text { Cover }\end{array}$ \\
\hline \multirow[t]{13}{*}{213} & Jatropha cardiophylla & 2.0 & 0.7 & 4.6 & 1.0 & & & & \\
\hline & Acacia constricta & 3.1 & 1.0 & 10.8 & 2.3 & 4.0 & 0.3 & & \\
\hline & Calliandra eriophylla & 5.1 & 1.7 & 1.5 & 0.3 & & & & \\
\hline & Olneya tesota & 4.1 & 1.3 & 12.3 & 2.7 & 28.0 & 2.3 & & \\
\hline & Parkinsonia microphylla & 4.1 & 1.3 & 24.6 & 5.3 & 64.0 & 5.3 & 100.0 & 1.3 \\
\hline & Fouquieria splendens & 1.0 & 0.3 & 4.6 & 1.0 & & & & \\
\hline & Krameria grayi & 5.1 & 1.7 & 3.1 & 0.7 & & & & \\
\hline & Krameria sp. & 1.0 & 0.3 & 1.5 & 0.3 & & & & \\
\hline & Janusia gracilis & 3.1 & 1.0 & 6.2 & 1.3 & & & & \\
\hline & Abutilon incanum & 1.0 & 0.3 & 1.5 & 0.3 & & & & \\
\hline & Selaginella arizonica & 3.1 & 1.0 & & & & & & \\
\hline & Lycium sp. & 2.0 & 0.7 & 1.5 & 0.3 & & & & \\
\hline & Larrea tridentata & & & 3.1 & 0.7 & & & & \\
\hline \multirow[t]{27}{*}{238} & Ambrosia deltoidea & 11.5 & 8.0 & 2.5 & 1.0 & & & & \\
\hline & Brickellia coulteri & & & 1.7 & 0.7 & & & & \\
\hline & Encelia farinosa & 17.7 & 12.3 & 15.0 & 6.0 & & & & \\
\hline & Porophyllum gracile & 0.5 & 0.3 & 0.8 & 0.3 & & & & \\
\hline & Trixis californica & 1.0 & 0.7 & 1.7 & 0.7 & & & & \\
\hline & Arabis eremophila & 0.5 & 0.3 & & & & & & \\
\hline & Carnegia gigantea & & & & & 3.3 & 0.3 & & \\
\hline & Opuntia acanthocarpa & 0.5 & 0.3 & 0.8 & 0.3 & & & & \\
\hline & Opuntia arbuscula & 0.5 & 0.3 & & & & & & \\
\hline & Ephedra viridis & 1.0 & 0.7 & 1.7 & 0.7 & & & & \\
\hline & Calliandra eriophylla & 4.3 & 3.0 & & & & & & \\
\hline & Olneya tesota & 2.4 & 1.7 & 13.3 & 5.3 & 33.3 & 3.3 & & \\
\hline & Parkinsonia microphylla & 6.7 & 4.7 & 39.2 & 15.7 & 63.3 & 6.3 & & \\
\hline & Fouquieria splendens & 0.5 & 0.3 & 0.8 & 0.3 & & & & \\
\hline & Krameria grayi & 0.5 & 0.3 & & & & & & \\
\hline & Janusia gracilis & 4.3 & 3.0 & 3.3 & 1.3 & & & & \\
\hline & Herissantia crispa & 0.5 & 0.3 & & & & & & \\
\hline & Sphaeralcea ambigua & 0.5 & 0.3 & & & & & & \\
\hline & Aristida adscensionis & 3.8 & 2.7 & & & & & & \\
\hline & Aristida ternipes & 1.9 & 1.3 & & & & & & \\
\hline & Bouteloua chondrosioides & 0.5 & 0.3 & & & & & & \\
\hline & Trichachne californica & 1.4 & 1.0 & & & & & & \\
\hline & Trisetum interruptum & 0.5 & 0.3 & & & & & & \\
\hline & Selaginella arizonica & 23.4 & 16.3 & & & & & & \\
\hline & Lycium sp. & 4.3 & 3.0 & 10.8 & 4.3 & & & & \\
\hline & Celtis pallida & 0.5 & 0.3 & 0.8 & 0.3 & & & & \\
\hline & Larrea tridentata & 1.9 & 1.3 & 6.7 & 2.7 & & & & \\
\hline \multirow[t]{15}{*}{239} & Ambrosia deltoidea & 65.7 & 23.0 & 4.2 & 1.0 & & & & \\
\hline & Mammillaria microcarpa & 1.0 & 0.3 & & & & & & \\
\hline & Mammillaria thornberi & 1.0 & 0.3 & & & & & & \\
\hline & Opuntia acanthocarpa & 2.9 & 1.0 & 11.3 & 2.7 & & & & \\
\hline & Opuntia arbuscula & 4.8 & 1.7 & 1.4 & 0.3 & & & & \\
\hline & Opuntia fulgida & 1.9 & 0.7 & 7.0 & 1.7 & & & & \\
\hline & Opuntia phaeacantha & 2.9 & 1.0 & 14.1 & 3.3 & & & & \\
\hline & Jatropha cardiophylla & & & 1.4 & 0.3 & & & & \\
\hline & Acacia greggii & & & 1.4 & 0.3 & & & & \\
\hline & Dead Parkinsonia microphylla & 1.0 & 0.3 & 1.4 & 0.3 & & & & \\
\hline & Olneya tesota & 1.0 & 0.3 & 2.8 & 0.7 & & & & \\
\hline & Parkinsonia microphylla & 2.9 & 1.0 & 19.7 & 4.7 & 90.9 & 3.3 & & \\
\hline & Janusia gracilis & & & 1.4 & 0.3 & & & & \\
\hline & Muhlenbergia porteri & 3.8 & 1.3 & & & & & & \\
\hline & Larrea tridentata & 11.4 & 4.0 & 33.8 & 8.0 & & & & \\
\hline
\end{tabular}


Appendix $\mathrm{H}$. Presence of plant species at modified-Whitaker vegetation plots, by vegetation community and plot number, Saguaro NP, Tucson Mountain District, 2001.

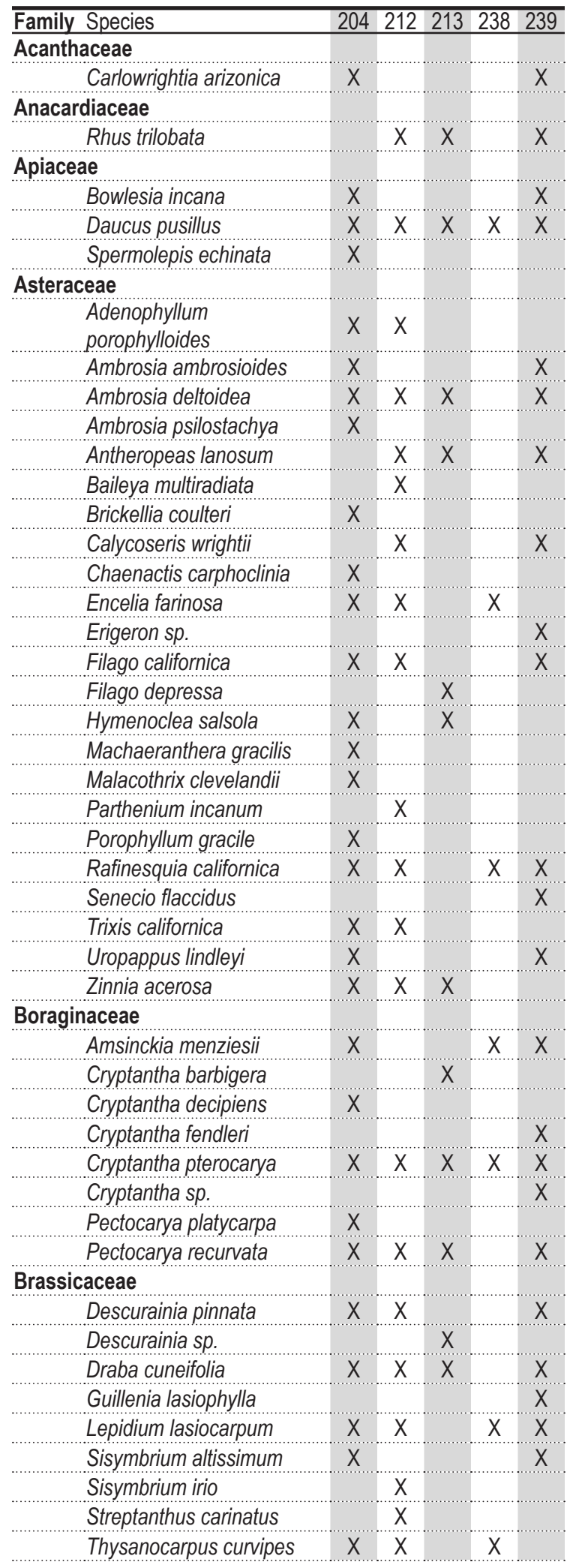

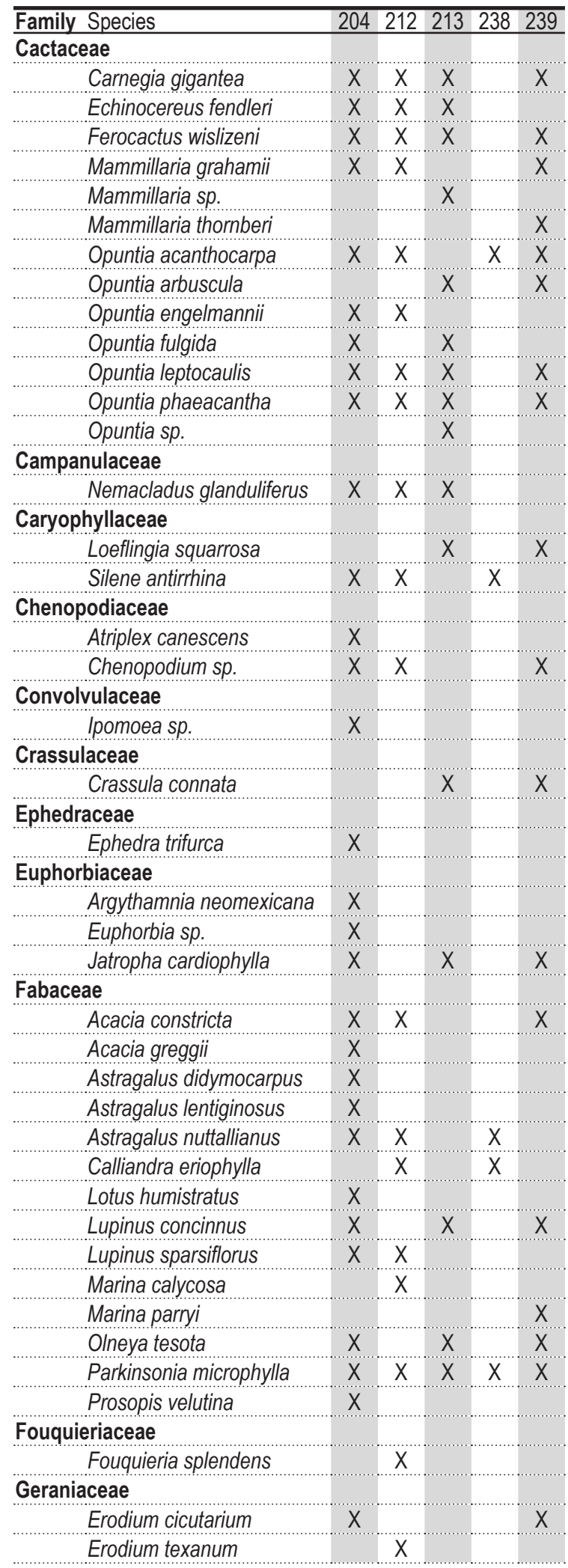




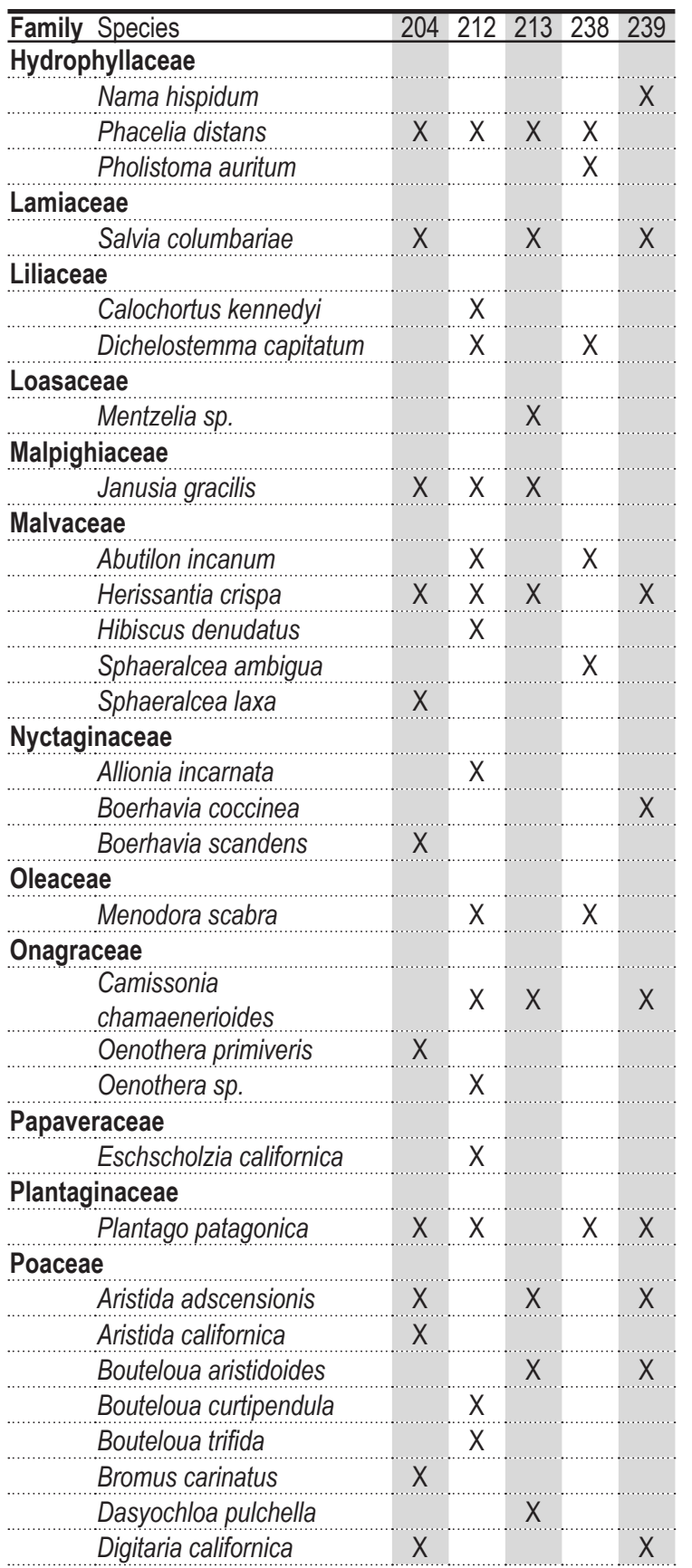

\begin{tabular}{|c|c|c|c|c|c|}
\hline Family Species & 204 & 212 & 213 & 238 & 239 \\
\hline \multicolumn{6}{|l|}{ Poaceae } \\
\hline Muhlenbergia porteri & \multirow{3}{*}{$\begin{array}{l}X \\
X\end{array}$} & $\mathrm{X}$ & $x$ & \multirow[b]{2}{*}{$X$} & $\mathrm{X}$ \\
\hline Poa bigelovii & & & $X$ & & \multirow[t]{2}{*}{$X$} \\
\hline Schismus arabicus & & $\mathrm{X}$ & $\mathrm{X}$ & & \\
\hline Schismus barbatus & \multirow[t]{2}{*}{$X$} & & & & \multirow[t]{2}{*}{$X$} \\
\hline Tridens muticus & & $\mathrm{X}$ & & & \\
\hline Vulpia octoflora & \multirow[t]{2}{*}{$X$} & $\mathrm{X}$ & \multirow[t]{2}{*}{$\mathrm{X}$} & $X$ & \multirow[t]{2}{*}{$X$} \\
\hline Polemoniaceae & & & & & \\
\hline Eriastrum diffusum & \multirow[t]{2}{*}{$X$} & $\mathrm{X}$ & \multirow[t]{2}{*}{$X$} & $\mathrm{X}$ & \multirow{3}{*}{$\begin{array}{l}X \\
X\end{array}$} \\
\hline Gilia sp. & & $\mathrm{X}$ & & $X$ & \\
\hline \multicolumn{5}{|l|}{ Polygalaceae } & \\
\hline Polygala macradenia & & $X$ & & & \\
\hline \multicolumn{6}{|l|}{ Polygonaceae } \\
\hline Chorizanthe brevicornu & & & & & $\mathrm{X}$ \\
\hline \multicolumn{6}{|l|}{ Portulacaceae } \\
\hline Cistanthe monandra & \multirow[t]{2}{*}{$X$} & & & & \\
\hline \multicolumn{5}{|l|}{ Pteridaceae } & \\
\hline Astrolepis sinuata & & $\mathrm{X}$ & & & \\
\hline \multicolumn{6}{|l|}{ Ranunculaceae } \\
\hline Delphinium scaposum & & $X$ & & & \\
\hline \multicolumn{6}{|l|}{ Rubiaceae } \\
\hline Galium proliferum & & $X$ & & & \\
\hline \multicolumn{6}{|l|}{ Scrophulariaceae } \\
\hline Castilleja exserta & & & & & $\mathrm{X}$ \\
\hline Mimulus rubellus & $x$ & & & & \\
\hline Nuttallanthus texanus & $X$ & & & & \\
\hline Selaginellaceae & & & & & \\
\hline Selaginella arizonica & & $X$ & & $X$ & \\
\hline Simmondsiaceae & & & & & \\
\hline Simmondsia chinensis & & $X$ & & & \\
\hline Solanaceae & & & & & \\
\hline Lycium berlandieri & $\mathrm{X}$ & $\mathrm{X}$ & $X$ & & \\
\hline Physalis hederifolia & $\mathrm{X}$ & & & & \\
\hline Sterculiaceae & & & & & \\
\hline Ayenia compacta & $\mathrm{X}$ & & & & \\
\hline Ayenia microphylla & & $X$ & & & \\
\hline Ulmaceae & & & & & \\
\hline Celtis pallida & $\mathrm{X}$ & & $\mathrm{X}$ & & $\mathrm{X}$ \\
\hline Parietaria hespera & $\mathrm{X}$ & & & & \\
\hline Viscaceae & & & & & \\
\hline Phoradendron californicum & $X$ & $\mathrm{X}$ & $\mathrm{X}$ & & $\mathrm{X}$ \\
\hline Zygophyllaceae & & & & & \\
\hline Larrea tridentata & $\mathrm{X}$ & X & & & $\mathrm{X}$ \\
\hline
\end{tabular}


Appendix I. Detail of small mammal trapping effort at Saguaro NP, Tucson Mountain District, 2001 and 2002. Data from this table are summarized in Table 6.3. In some cases plot group for random plots (those with numbers) included non-random transects set in areas near to the random grids.

\begin{tabular}{|c|c|c|c|c|c|c|c|c|c|}
\hline Focal point & Plot name & Grid & Visit number & Month & Year & Number of nights trapped & Number of traps set & $\begin{array}{c}\text { Grid } \\
\text { layout }\end{array}$ & $\begin{array}{c}\text { Trap } \\
\text { spacing }(\mathrm{m})\end{array}$ \\
\hline \multirow[t]{4}{*}{212} & 212 & $17 / 18$ & 1 & 4 & 2001 & $2=2$ & 42 & $3 \times 7$ & 16.7 \\
\hline & & $3 / 4$ & 1 & 4 & 2001 & 2 & 42 & $3 \times 7$ & 16.7 \\
\hline & & $9 / 10$ & 1 & 4 & 2001 & 2 & 42 & $3 \times 7$ & 16.7 \\
\hline & SSW 09 & 1 & 1 & 4 & 2001 & 2 & 40 & Preferential & \\
\hline \multirow[t]{7}{*}{213} & 213 & 17 & 1 & 5 & 2001 & 3 & 63 & $3 \times 7$ & 16.7 \\
\hline & & 3 & 1 & 5 & 2001 & 3 & 63 & $3 \times 7$ & 16.7 \\
\hline & & 9 & 1 & 5 & 2001 & 3 & 63 & $3 \times 7$ & 16.7 \\
\hline & & 17 & 2 & 9 & 2001 & 2 & 50 & $5 \times 5$ & 12.5 \\
\hline & & 3 & 2 & 9 & 2001 & 2 & 50 & $5 \times 5$ & 12.5 \\
\hline & & 9 & 2 & 9 & 2001 & 2 & 50 & $5 \times 5$ & 12.5 \\
\hline & SSWX & & 1 & 9 & 2001 & 2 & 40 & $10 \times 2$ & \\
\hline \multirow[t]{3}{*}{238} & 238 & 10 & 1 & 6 & 2001 & 3 & 75 & $5 \times 5$ & 12.5 \\
\hline & & 18 & 1 & 6 & 2001 & 3 & 75 & $5 \times 5$ & 12.5 \\
\hline & & 3 & 1 & 6 & 2001 & 3 & 75 & $5 \times 5$ & 12.5 \\
\hline \multirow[t]{9}{*}{239} & 239 & 17 & 1 & 4 & 2001 & 3 & 63 & $3 \times 7$ & 16.7 \\
\hline & & 3 & 1 & 4 & 2001 & 3 & 63 & $3 \times 7$ & 16.7 \\
\hline & & 9 & 1 & 4 & 2001 & 3 & 63 & $3 \times 7$ & 16.7 \\
\hline & & 17 & 2 & 10 & 2001 & 2 & 50 & $5 \times 5$ & 12.5 \\
\hline & & 3 & 2 & 10 & 2001 & 2 & 50 & $5 \times 5$ & 12.5 \\
\hline & & 9 & 2 & 10 & 2001 & 2 & 50 & $5 \times 5$ & 12.5 \\
\hline & SSW 07 & 1 & 1 & 4 & 2001 & 3 & 12 & Preferential & \\
\hline & SSW 08 & 1 & 1 & 4 & 2001 & 3 & 12 & Preferential & \\
\hline & SSWQ & 1 & 1 & 10 & 2001 & 2 & 40 & $10 \times 2$ & 15 \\
\hline \multirow[t]{3}{*}{ Kinney Road } & SSW 01 & 1 & 1 & 6 & 2001 & 2 & 56 & $7 \times 4$ & \\
\hline & SSW 02 & 1 & 1 & 6 & 2001 & 4 & 100 & $5 \times 5$ & 12.5 \\
\hline & SSW 03 & 1 & 1 & 6 & 2001 & 3 & 75 & $5 \times 5$ & 12.5 \\
\hline \multirow[t]{3}{*}{ Sendario } & SSW 04 & 1 & 1 & 6 & 2001 & 3 & 75 & $5 \times 5$ & 12.5 \\
\hline & SSW 05 & 1 & 1 & 6 & 2001 & 2 & 50 & $5 \times 5$ & 12.5 \\
\hline & SSW 06 & 1 & 1 & 6 & 2001 & 2 & 50 & $5 \times 5$ & 12.5 \\
\hline
\end{tabular}

Appendix J. Summary of field research for bats, Saguaro NP, Tucson Mountain District, 2001 and 2002. See text for explanation of net hours calculations.

\begin{tabular}{|c|c|c|c|c|c|c|c|}
\hline $\begin{array}{l}\text { Type of } \\
\text { investigation }\end{array}$ & Location & Year & $\begin{array}{c}\text { Month/ } \\
\text { day }\end{array}$ & $\begin{array}{c}\text { Visit } \\
\text { number }\end{array}$ & $\begin{array}{c}\begin{array}{c}\text { Total time } \\
\text { (hours) }\end{array} \\
\text { (hes }\end{array}$ & $\begin{array}{c}\text { Total net } \\
\text { length }(\mathrm{m})\end{array}$ & $\begin{array}{l}\text { Net } \\
\text { hours }\end{array}$ \\
\hline \multirow[t]{4}{*}{ Roost } & Gould Mine & 2001 & $03 / 28$ & 1 & & & \\
\hline & & 2002 & $07 / 23$ & 2 & & & \\
\hline & Wild Horse Mine & 2002 & $2 / 27$ & 1 & & & \\
\hline & Yuma Mine & 2002 & $1 / 28$ & 1 & & & \\
\hline \multirow[t]{2}{*}{ Netting } & Dobe Wash Tank & 2001 & $05 / 15$ & 1 & 3.5 & 5 & 17.5 \\
\hline & Javelina Wash Tank & 2001 & $05 / 11$ & 1 & 4.8 & 5 & 24.2 \\
\hline
\end{tabular}


This page left intentionally blank. 


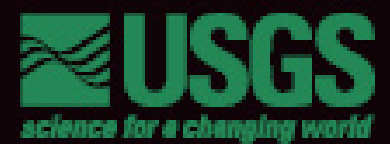

US. Geological Sunvey

Southwest Biological Science Center 2255 K. Genini Drive

Fagstaff, AZ 85001 